\title{
Endogenous growth with national innovation systems
}

Citation for published version (APA):

Perilla Jiménez, J. R. (2019). Endogenous growth with national innovation systems: The ultimate route to catching up in the world economy. [Doctoral Thesis, Maastricht University]. ProefschriftMaken. https://doi.org/10.26481/dis.20191218jp

Document status and date:

Published: 01/01/2019

DOI:

10.26481/dis.20191218jp

Document Version:

Publisher's PDF, also known as Version of record

\section{Please check the document version of this publication:}

- A submitted manuscript is the version of the article upon submission and before peer-review. There can be important differences between the submitted version and the official published version of record.

People interested in the research are advised to contact the author for the final version of the publication, or visit the DOI to the publisher's website.

- The final author version and the galley proof are versions of the publication after peer review.

- The final published version features the final layout of the paper including the volume, issue and page numbers.

Link to publication

\footnotetext{
General rights rights.

- You may freely distribute the URL identifying the publication in the public portal. please follow below link for the End User Agreement:

www.umlib.nl/taverne-license

Take down policy

If you believe that this document breaches copyright please contact us at:

repository@maastrichtuniversity.nl

providing details and we will investigate your claim.
}

Copyright and moral rights for the publications made accessible in the public portal are retained by the authors and/or other copyright owners and it is a condition of accessing publications that users recognise and abide by the legal requirements associated with these

- Users may download and print one copy of any publication from the public portal for the purpose of private study or research.

- You may not further distribute the material or use it for any profit-making activity or commercial gain

If the publication is distributed under the terms of Article $25 \mathrm{fa}$ of the Dutch Copyright Act, indicated by the "Taverne" license above, 


\section{Endogenous Growth with National Innovation Systems: The Ultimate Route to Catching Up in the World Economy}

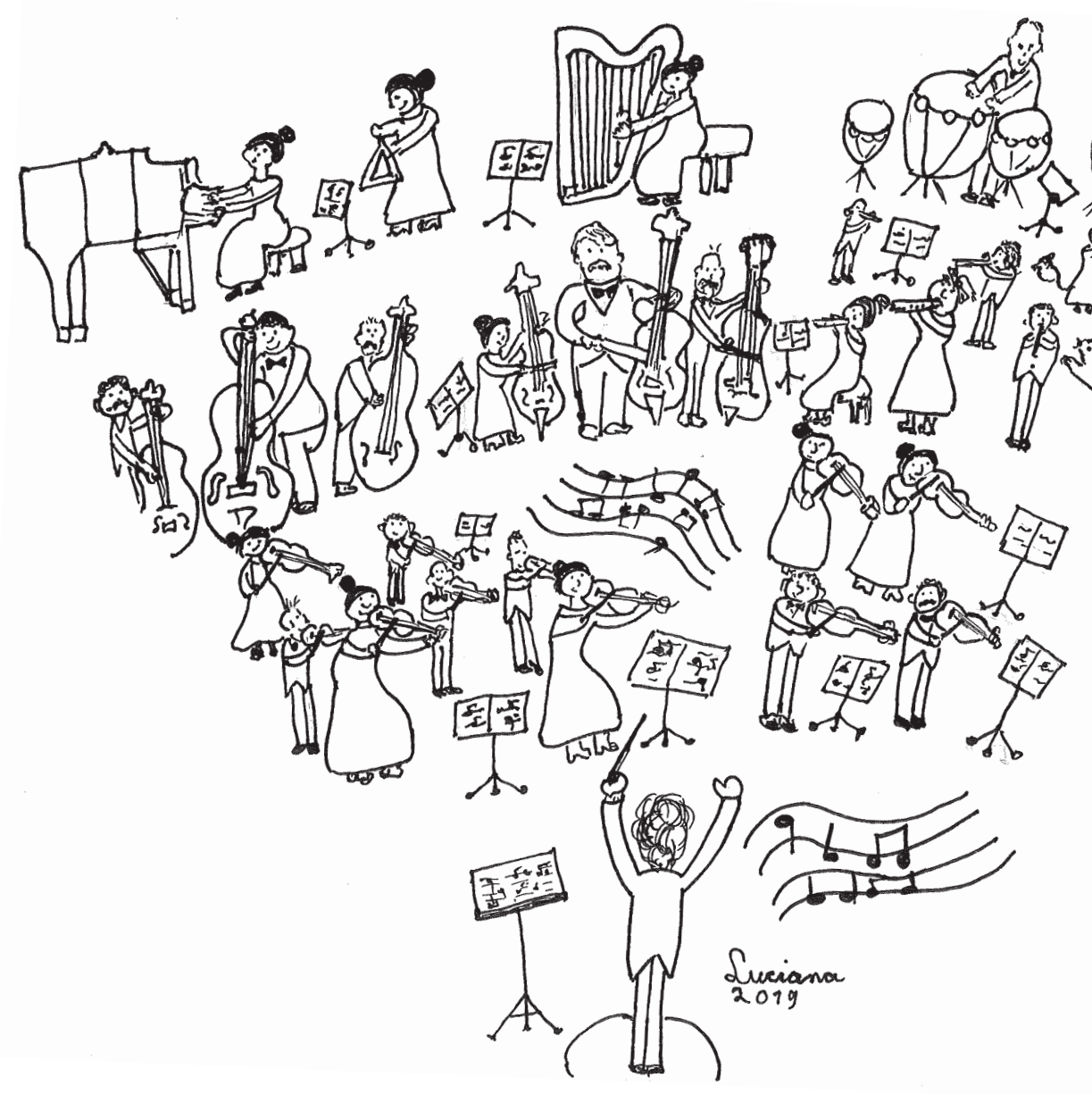

Juan Ricardo Perilla Jiménez 


\title{
Endogenous Growth with National Innovation Systems: The Ultimate Route to Catching Up in the World Economy.
}

\section{ACADEMISCH PROEFSCHRIFT}

\author{
ter verkrijging van de graad van doctor \\ aan de Universiteit Maastricht \\ op gezag van de Rector Magnificus \\ prof. dr. Rianne M. Letschert \\ volgens het besluit van het College van Decanen, \\ in het openbaar te verdedigen \\ op Woensdag 18 December 2019, om 11:45 uur
}

door

Juan Ricardo Perilla Jiménez 


\section{Promotor:}

Prof. dr. Bart Verspagen

\section{Co-Promotor:}

Dr. Thomas Ziesemer

\section{Assessment Committee:}

Prof. dr. Joan Muysken, (Chair)

Dr. Adriaan van Zon

Prof. dr. Carolina Castaldi, (Utrecht University)

Prof. dr. Jan Fagerberg (Centre for Technology, Innovation and Culture (TIK), University of Oslo, Norway) 
To my beloved Mother Maria Emma

my wife Liliana

my daughter Luciana 


\section{Contents}

\section{List of Figures}

\section{List of Tables}

\section{Acknowledgment}

1 Introduction 1

2 Overview of the Problem 9

2.1 Introduction. . . . . . . . . . . . . . . . 9

2.2 Backward Countries' Relative Levels of Income . . . . . . . . . 10

2.3 Backward Countries' Adjusted Growth Rates . . . . . . . . . . . 16

2.4 An Extrapolation Formula . . . . . . . . . . . . . . . . . . . 19

2.5 Conventional Convergence Revisited . . . . . . . . . . . 23

2.6 Cross-Country Differences in Technology . . . . . . . . . . . . 27

2.6.1 Variance Decomposition . . . . . . . . . . . . . . . 28

2.6.2 Addressing Concerns on the Measurement of Productivity 30

2.6.3 Efficiency and Technical Changes . . . . . . . . . . . . 37

2.7 Concluding Remarks . . . . . . . . . . . . . . . . 40

3 The Theory of Technology and Growth 51

3.1 Introduction . . . . . . . . . . . . . . . . 51

3.2 The Economics of Technology . . . . . . . . . . . . . . 54

3.3 Technology and Growth Theory . . . . . . . . . . . . . 58

3.4 Advantage of Backwardness Revisited . . . . . . . . . . . . 69

3.5 Policy Implications . . . . . . . . . . . . . . . . . . . 72

3.5 .1 Sponsorship . . . . . . . . . . . . . . . 74

3.5 .2 Leadership . . . . . . . . . . . . . . . . . . . . . 75

3.5 .3 Coordination . . . . . . . . . . . . . . . 77

3.6 Concluding Remarks . . . . . . . . . . . . . . . . . . 79

4 A Formal Model of Growth and Catching up 81

4.1 Introduction . . . . . . . . . . . . . . . . . 81

4.2 Related Literature . . . . . . . . . . . . . . . . . . . . . 83

4.3 The Model Setup . . . . . . . . . . . . . . . . . . . 87 
4.3.1 The problem of the representative agent . . . . . . . . 88

4.3.2 The role of government . . . . . . . . . . . . . . 92

4.4 The Sponsorship Mechanism . . . . . . . . . . . . . . . . 94

4.5 Solving the optimization problem . . . . . . . . . . . . . 96

4.5.1 Equilibria without transfers $(\tilde{z}=1) \ldots 100$

4.5.2 Equilibria with positive transfers $(\tilde{z}>1) \ldots . . . . .104$

4.5.3 Equilibria with confiscatory taxation $(\tilde{z}<1)$. . . . . 106

4.5.4 A numerical application . . . . . . . . . . . . . . 108

4.5.5 The change of transfers into subsidies . . . . . . . . . 110

4.6 Concluding Remarks . . . . . . . . . . . . . . . . 114

5 Econometrics of Adoption and Innovation 121

5.1 Introduction. . . . . . . . . . . . . . . . . 121

5.2 Theoretical Framework . . . . . . . . . . . . . . . . 123

5.3 The Data . . . . . . . . . . . . . . . . . . . . 127

5.4 Analytical Framework . . . . . . . . . . . . . . . . 135

5.5 Results . . . . . . . . . . . . . . . . . . . 138

5.6 Concluding Remarks . . . . . . . . . . . . . . . 163

6 Conclusion. $\quad 171$

6.1 Contributions. . . . . . . . . . . . . . . 171

6.2 Limitations. . . . . . . . . . . . . . . . . . . . . . . . . . . . . . . . . . . . . . . . . . . . . .

6.3 Future Research. . . . . . . . . . . . . . . . 177

$\begin{array}{lr}\text { Bibliography } & 179\end{array}$ 


\section{List of Figures}

2.1 Cross country levels of income per capita (relative to the frontier). 13

2.2 Relative income per capita FRCs, CUCs, STCs, and LGCs classifications. . . . . . . . . . . . . . . . . 15

2.3 10-year average growth rates FRCs, CUCs, STCs and LGCs. . . 17

2.4 Distance to the frontier FRCs, CUCs, STCs, LGCs . . . . . . . 21

2.5 Analysis of conventional $\beta$-convergence CUCs, STCs and LGCs vis-à-vis FRCs. . . . . . . . . . . . . . . . . . . . . . . . 24

2.6 Density kernel: dispersion of productivity growth rates with respect to the FRCs' mean. . . . . . . . . . . . . . . . 30

2.7 Percentage shortfall of CUCs, STCs and LGCs with respect to the FRCs. . . . . . . . . . . . . . . . . . . . 33

2.8 Development accounting decomposition of the determinants of countries' percentage shortfall. . . . . . . . . . . . . 35

2.9 Data Envelopment Analysis (Diagram) . . . . . . . . . . 38

4.1 Phase diagram under scenario $\tilde{z}=1 \ldots \ldots$. . . . . . . . 102

4.2 The sponsorship mechanism scenario with $\tilde{z}>1$. . . . . . 105

4.3 The sponsorship mechanism scenario with $\tilde{z}<1$. . . . . . 107

5.1 Productivity vis $-\grave{a}-v i s$ foreign $\mathrm{R} \& \mathrm{D}$, innovation and their interaction in FRCs, CUCs, STCs and LGCs. . . . . . . . . 136

5.2 Innovation vis-à-vis government coordination in FRCS, CUCs, STCs and LGCs. . . . . . . . . . . . . . . . . . 137

5.3 Multipliers analysis: Impulse-Response Functions CUCs over a horizon of 70 -years. . . . . . . . . . . . . . . . . . 149

5.4 Average and median impulse-response functions for the CUCs over a horizon of 70 -years. . . . . . . . . . . . . . . . 152

5.5 Overall median impulse-response functions for FRCs, CUCs, STCs and LGCs. . . . . . . . . . . . . . . . . . . . 159

5.6 Long-run multipliers: overall median response values of the longrun productivity effects for FRCs, CUCs, STCs and LGCs. . . . 160 



\section{List of Tables}

2.1 Estimates of $\beta$-convergence for the FRCs, CUCs, STCs and LGCs. 25

2.2 Multi-factorial productivity based on DEA decomposition. . . . . 39

2A.1 Country classifications on the base of income per capita relative to the FRCs average. . . . . . . . . . . . . . . . 42

2A.2 Country classifications on the base of income per capita relative to the FRCs average. . . . . . . . . . . . . . . . . 43

2A.3 Country classifications on the base of income per capita relative to the FRCs average. . . . . . . . . . . . . . . . . 44

2A.4 Country classifications on the base of income per capita relative to the FRCs average. . . . . . . . . . . . . . . . 45

2A.5 CUCs countries subgroups. . . . . . . . . . . . . 46

2A.6 STCs countries subgroups. . . . . . . . . . . . . . . . 47

2A.7 LGCs countries subgroups. . . . . . . . . . . . . . . . . 48

2A.8 Distribution Statistics for the relative levels of income. . . . . . . 49

2A.9 Distribution Statistics: basic points of difference relative to the frontier. . . . . . . . . . . . . . . 50

5.1 Unit Root Tests CUCs countries. . . . . . . . . . . . . . . . . 140

5.2 Cointegration tests CUCs countries. . . . . . . . . . . . . 141

5.3 Estimated cointegration vectors with Johansen normalization restrictions (CUCs). . . . . . . . . . . . . . . . . 143

5.4 Estimated cointegration vectors (CUCs) . . . . . . . . . 145

5.5 Mean group estimated cointegration vectors. . . . . . . . . . 155

5A.1 Classification of ISCO working activities. . . . . . . . . . . 165

5A.2 Local Innovation Data Availability. . . . . . . . . . . . . . 166

5A.3 Local Innovation Data Availability. . . . . . . . . . . . . . . 167

5B.1 Technology classifications for the manufacturing sector. . . . . 168

5B.2 Government Coordination Data Availability. . . . . . . . . . 170 



\section{Acknowledgment}

Writing this thesis has been a long lasting and very stimulating work, and certainly a life changing experience. Yet, it has not been a lonely endeavor by any means. There are many persons that have contributed to make it a reality one way or the other.

First in the list are my supervisors Prof. Dr. Bart Verspagen and Dr. Thomas Ziesemer: I have benefited immensely from your knowledge and sense of perfection, thanks so much for your continuous advice, your patience and motivation throughout the years of my $\mathrm{PhD}$ research. I was very fortunate to have as my mentors a renowned expert on the economics of innovation, and a top expert on every aspect of the economics of development, mathematical modeling and advanced econometrics. Not only I have learned so much from you, I am indebted also because you gave me lots of your time, reading my (probably too wordy) drafts, and giving me thoughtful comments and useful suggestions. Needless to say, I take the sole responsibility for all errors and weaknesses that may still remain in the document.

I am very grateful also to the members of my thesis committee: Prof. Dr. Carolina Castaldi, Prof. Dr. Jan Fagerberg, Dr. Adriaan van Zon and Prof. Dr. Joan Muysken. Dr. Adriaan and Prof. Dr. Muysken gave me insightful comments and suggestions which helped to improve the mathematical approach to modelling economic growth in an innovative economy. Your questions gave me an incentive to widen my approach from various perspectives, and helped me to clarify the formal structure of the model. Also, I have benefited immensely from the insightful comments, suggestions and reflections provoked by Prof. Dr. Jan Fagerberg on my approach to evolutionary theory and the innovation systems approach. I feel deeply honored of having received too many suggestions and prize words from such a renowned expert. Last but no least, I have benefited from the comments and suggestions Prof. Dr. Carolina Castaldi has provided me with on my bold attempt to distinguish between mainstream and non-mainstream categories, and the complex relationship between the innovation systems approach and other theoretical branches on this research front. I hope you will see your insightful contributions properly reflected in my work and also keep the responsibility for the remaining weaknesses in the document.

My gratitude goes also to my office, $\mathrm{PhD}$ and teaching mates, particularly, Adam, Merve, Marius, Elisa, Dominick, Norman, Sergio, Tom, Sam and Noi: you were always kind and helpful in numerous ways and I am grateful for the 
constant chance of warmth chats and stimulating discussions. My thanks are also for the staff and faculty at the School of Business and Economics, Maastricht University, Tom van Veen, Chief of the MILE (Macroeconomics, International and Labor Economics at the time), and Sylvia Beenen, Administrative Manager: you constantly supported me with lots of nice teaching opportunities and I am grateful because of that, but overall because of your kindness and sympathy; Fleur Roemers, Silvana de Sanctis, Marion Muitjens: you always kindly assisted me with administrative procedures and paper work. My special thanks go to Silvana, you used to say 'it was just part of your work to assist me' and yet, to me, you were constantly a way beyond your official duty, and I am grateful beyond words for all your help.

My PhD journey could not have even started without the early "wisdom sticks", the example and encouragement of my mother, Maria Emma: this thesis is for you Mamá, the woman who taught me how to battle to make dreams held true. And this thesis is also for you, Liliana: thanks so much for existing, for being my wife and my companion in the journey and for helping me to find balance in every single hard time I face. And this thesis is also for our beloved daughter Luciana: I hope I have managed to save you the need of hiding your head inside a bag the whole life. Also I am grateful for your contribution drawing the 'Orchestra' for the cover page of the thesis, which comes to remind us of the central role the director is to have if we are going to have a successful Concerto. And this is for my mother in law, Elizabeth, my brother in law, Danny, my sister in law, Patricia: there is nothing I can do to repay your kindness.

Finally, my dedication and deepest thanks go to my brother and sisters. Gabriel: I wish you all the best on your own $\mathrm{PhD}$ investigation to uncover the chemistry of happiness; and good luck also to Jacky's PhD study to find a new endemic spider which, who knows, might this time bear my name. Nohora, Maria, Gladys: thanks for standing by me during my PhD journey, and thanks for the great family we have, now too big to name everybody in any detail:) I really miss you all guys, and look forward to see and tightly hug you all soon...pretty soon.

Juan Ricardo Perilla Jiménez Maastricht University - SBE Maastricht, The Netherlands August, 2019 


\section{Chapter 1}

\section{Introduction}

The core objective of this thesis is to bridge two contesting intellectual traditions that currently shape the understanding about the best way less developed countries can catch-up with countries at the frontier in terms of income per capita. ${ }^{1}$ One of these traditions, the mainstream in our discussion, is associated with the issues of convergence spurred by the Solow model which were followed by numerous contributions of the endogenous growth literature and, currently, is split into two versions, so-called the Semi-endogenous and the Product-variety Schumpeterian models of growth. ${ }^{2}$ The other tradition relates to contributions on issues of innovation, economic growth and catching-up that are underlined by the theory of evolutionary economics and contributions of the literature on

\footnotetext{
${ }^{1}$ The issues of catching-up (and convergence) have been object of continuous controversy and debate, including conceptual reviews, new theoretical avenues and empirical evaluations, since the very beginning of the economics science-Pomeranz 2009 actually refers to it as a process of "Great Divergence" that started with the industrial revolution. The present day debates in this regard (e.g., Spence 2011, Stiglitz 2014, Lee and Malerba 2018.) — which are at the core of our discussion throughout this thesis - are a continuation of concerns highlighted in different contributions during the 1980s and 1990s (Lucas 1988, Romer 1986, 1993, Verspagen 1991, Fagerberg 1995, Pritchett 1997, among others) which, in turn, where influenced by ideas formulated by Abramovitz and Baumol, in separate contributions published in 1986. The latter authors (re)initiated a debate advanced earlier by Gerschenkron 1962, whose ideas followed the line of thought in contributions made in previous decades by Schumpeter 1934, 1950, and propositions advanced, still earlier, by Veblen 1915 . Veblen is credited to have laid the foundations about the importance of technology and political institutions in the development of industrialized economies. Yet, in their first stage, his ideas were pioneered by the German Historical School which, during the 19th century showed a major concern for such subjects as economic history, evolution, national policy and institutions, a focus that arose as a reaction to the alleged universality of British economic thinking, based on individual rationality, and the (misleading) implications of that approach for explaining the industrialization process of the less developed Germany at the time (Shionoya 2002). The intellectual genesis of these ideas, however, has been related back to the so-called HumeTucker debate, which was spurred by David Hume in 1742 - on the convergence side - and Tucker 1776 - on the divergence side (Semmel 1965, Elmslie 1995).

${ }^{2}$ Solow 1956, Arrow 1962, Shell 1966, Uzawa 1965, Phelps 1966, Romer 1986, 1993, Lucas 1988, Jones 1995, 2005, Ang and Madsen 2011, Aghion et al., 2013.
} 
National Innovation Systems-NIS. ${ }^{3}$ Throughout, the key distinctive feature between the mainstream and the evolutionary and NIS traditions is their distinct emphases on the importance of technology diffusion and (local) innovation to spur long run growth and development.

Consequently, our core research question is whether and how catching-up strategies hinge on the diffusion of technological knowledge or on domestic innovation activities. As we shall see, the apparently obvious answers to this question have involved a wide range of frequently controversial issues - between the mainstream and the other schools in our discussion, namely, the evolutionary and NIS frameworks - regarding the conceptual definitions of technology and innovation; and regarding also the proper role of innovation policy in a market economy and, therefore, the justifications for government intervention in the economy.

Certainly, on the theoretical front, most growth economists have come to terms that technology is the key subject of interest in studying the performance of the economy over the long run - even though the economic contributions of technology and the way they work still are far from safely understood. The distinction between the productivity impacts accrued to technology diffusion/adoption and its (local) uses - and also the development of (local) technology - has gained, on the other hand, increasing attention in the modern analysis that explores the determinants of long-run growth and development. ${ }^{4}$ Throughout, we differentiate these two sources of a country's technology by referring to them simply as "adoption" (of foreign technologies), and (local) "innovation."

In the empirical front, the evidence for the importance of technology in explaining differences in cross country development suggests that technology accounts for up to between $60 \%$ and $90 \%$ of the differences in economic growth across countries, and for more than $90 \%$ of the difference in levels of income between poor and rich countries. ${ }^{5}$ Not surprisingly, this preeminence has influenced a widespread belief among mainstream economist that the eventual convergence of growth rates and levels of income per capita is driven fundamentally by a process of technological catch-up across countries. ${ }^{6}$

\footnotetext{
${ }^{3}$ Our discussion of evolutionary economics relates to recent debates spurred by the ideas of Nelson and Winter 1982 and the numerous works that have followed from this publication (see Nelson et al., 2018 for a recent appraisal of the literature). Yet, it is worth noting that the literature on evolutionary economics has been traced back to classical economist, e.g., Malthus and Marshall (Nelson and Winter 1982, Dosi and Nelson 1994), and related also to the foundations of the German Historical School which were followed by contributions by Veblen and Schumpeter (Veblen 1898, Schumpeter 1934, 1950). Likewise, our discussion of the NIS literature follows from the ideas presented by, among others, Freeman 1987, Nelson 1993 and Lundvall 1992, 1993, 2007. But, again, it is worth noting that the NIS literature has developed from a thread that goes back to the systemic approach to economic analysis characteristic of Schumpeter (Fagerberg 2003) and even further back to propositions advanced by Friedrich List 1841 (Soete, Verspagen and ter Weel 2010).

${ }^{4}$ For example, Coe and Helpman 1995, Coe, Helpman and Hoffmaister 1995, Verspagen 1997, and Keller 2002, 2004.

${ }^{5}$ King and Levine 1994, Hall and Jones 1999, and Easterly and Levine 2001.

${ }^{6}$ For example, Barro 1991, Romer 1993, Mankiw, Phelps and Romer 1995, Pritchett 1997,
} 
In this context, mainstream growth economics emphasizes on adoption of foreign technology as the most expedite way for less developed countries that want to make the transition to the frontier. ${ }^{7}$ Some evidence in support of this hypothesis suggests that technology inflows account for more than $90 \%$ of productivity growth in countries off the frontier. ${ }^{8}$ Thus, despite some debate and controversy in the past over the question whether income and income growth differences across countries are better explained by differences in the accumulation of capital (physical and human) or by ideas gaps, ${ }^{9}$ the current understanding within the mainstream is that, at least potentially, less developed countries benefit overall from the adoption of the technology developed at the frontier. Therefore, this approach holds, the most governments can do to take advantage of the opportunities created by the free flow of ideas is to provide price incentives (taxes, subsidies, low wages) and set the right market institutions, including property rights and openness to trade. ${ }^{10}$

From the perspective of the evolutionary economics of innovation and technology change, which has developed as an alternative theoretical account in this regard, ${ }^{11}$ the major shortcoming of the mainstream analysis above is the presumption that the acquisition and mastery of foreign technology are "automatic". In contrast, as Nelson 2008 points out, what the experience of many countries show is that significant improvements in the economic activity of less developed countries have resulted overall from the assimilation rather than the, however important, acquisition of new ideas and technology developed elsewhere. ${ }^{12}$ From this account, assimilation and then (local) innovationunderstood in broad terms as the ability to develop new products and new ways of doing things in a localized context - is the crucial challenge for countries aiming to catch-up. ${ }^{13}$ As we shall largely discuss in this thesis, the economics of innovation is not alien to the mainstream. ${ }^{14}$ In fact, both mainstream and evolutionary traditions retrieved their core ideas from earlier writings by Schumpeter, ${ }^{15}$ but the scope of the analysis is sufficiently different to deserve comparison.

As we pointed out at the outset, another strand of the literature on the role of

Lucas 2000, Rodrik 2011, and Spence 2011. As we shall see later in this thesis, the mainstream analysis in these works - however based on similar contributions by Abramovitz 1986 and Gerschenkron 1962 - differs substantially from the emphasis on historical analysis, institutional factors and social capabilities highlighted by, among others, Fagerberg 1995.

${ }^{7}$ Romer 1993, 1994, Grossman and Helpman 2001, Benhabib and Spiegel 2005, Jones 2005, Snowdown and Vane 2005, Ch. 11.

${ }^{8}$ Keller 2002, 2004, though it is worth noting a sense of exaggeration in this figure. It refers to the comparison of estimates upon the relative productivity elasticity to foreign/domestic $\mathrm{R} \& \mathrm{D}$ in a small sample of nine rich countries. Counter-evidence is provided by Bernard and Jones 1996a.

${ }^{9}$ Mankiw et al., 1995, Romer 1993.

${ }^{10}$ Baumol 2002, Parente and Prescott 2002, Rodrick 2005, Spence 2011.

${ }^{11}$ Verspagen and Werker 2003.

${ }^{12}$ Pack and Nelson 1999, Nelson 2008.

${ }_{13}$ Nelson 2008, Fagerberg, Srholec and Verspagen 2010.

${ }^{14}$ See, for instance, Aghion, Akcigit and Howitt 2003; and Aghion and Howitt 2006.

${ }^{15}$ Schumpeter 1934, 1950. 
technology in explaining income and income growth differences across countries has been associated with the national innovation systems (NIS) framework. ${ }^{16}$ The NIS literature does not deny either the importance of technology diffusion. But, it puts more emphasis on the institutional environment needed to cope with all market and non-market interactions and interdependencies involved in the design of a country's science and technology strategy; and on the implementation of variegated policies toward the production and commercialization of innovations including, for instance, knowledge transfers, firm networking, public-private partnerships, the education system, the labor market, financial institutions and so on.

Which is perhaps the most salient difference between the mainstream and the NIS views on how innovation is realized is the market-failures view that characterizes the former approach versus the system failures view that characterizes the later. ${ }^{17}$ As pointed out in Soete et al. 2010 the market-failure-based policy rationale is not useful or appropriate when it comes to understand the nature of innovation and to formulate innovation policy as the interactive nature of innovation, combined with the non-market-based nature of the institutions that govern those interactions raise more concerns on the possibility of "systemic failures". 18

Given this background, the goal of pulling together the above mentioned different strands of the literature - namely the mainstream, and the evolutionary and NIS literatures - providing a unified framework of analysis seems warranted in order to better the academic understanding of the relationship between technology diffusion, innovation and economic growth. Noticeably, even though these are indeed different fields of the research, the evolutionary and NIS literatures are frequently acknowledged to be closely related concerning the role and conduct of innovation and innovation policy. ${ }^{19}$ It is when we examine the theoretical understandings and policy implications between mainstream economics and these two other strands of research that we find fundamental disagreements which blur our understanding; and thus our ability to derive sensible predictions or formulate policy prescriptions on the connections between innovation policy and economic growth whose consequences, in the end, only can be confirmed in the distant future.

Our aim here may be seen as a first step in a larger scale research project seeking to integrate different theoretical positions in a "new" stylized model of economic growth intended to remedy some weaknesses, as suggested by its critics, in the classical approach to the issues of technology, innovation and long-run growth. Such an endeavor requires, of course, a focus on the generalizable patterns that in each theoretical approach are deemed to govern the long-run dynamics of technology and income across countries, rather than on the exploitation of examples applying just to particular countries or periods of

\footnotetext{
${ }^{16}$ Nelson 1993, Freeman 1995, Nelson and Winter 2002, Lundvall 1992, 1993, 2007

${ }^{17}$ Soete, Verspagen and Ter Weel 2010, Steinmuller 2010, Lee and Malerba 2018.

18 Soete et. al., 2010.

${ }^{19}$ Nelson and Winter 2002, Fagerberg 2003, Nelson 2008, Dosi and Nelson 2010, Soete et al., 2010, Lee and Malerba 2018.
} 
time.

To address this core objective, this thesis is split into six chapters, the first of which is formed by this introduction. The second chapter presents an overview of the problem. Its focus is on the historical dynamics exhibited by relative levels of income per capita, long-run growth rates, and technology, across a large number of countries in the world. A sample of 133 countries is classified into those at the frontier and those that, over long periods of time show patterns consistent with catching-up, remain stagnant, or have otherwise lagged further behind. A simple extrapolation formula is proposed to calculate the years that each country would need to catch-up given its income level and historical growth performance.

While we investigate how consistent are the observed per capita income differences with the technology differences observed across countries in the world economy, we pay attention to a number of criticisms that have been raised concerning the use of productivity as a proxy for technology. These are critics on the assumption of constant factor shares, ${ }^{20}$ the need to account for differences in terms of trade in the comparison of productivity across countries, ${ }^{21}$ and the fact that most comparisons of productivity across countries do not account for the fact that technology changes over time. ${ }^{22}$

Although we reach similar conclusions as in previous literature: that differences in levels of income and growth rates are highly correlated with differences in productivity, we find that differences in the overall level of productivity have less leverage than has been attributed in other research. In other words, we find that differences in the overall level of productivity are insufficient to explain differences in income per capita across countries. This difference in our conclusion arises from a simple twist in the assessment of the observable evidence, namely the comparisons between successful and unsuccessful cases of catching-up. Thus, we justify our approach to focusing on the assessment of the economic contributions accrued to distinct sources of technology, particularly the distinction between foreign and local sources of technology.

In Chapter 3, we delve into a review of the theory of technology and economic growth. The aim of doing so is to provide a fair background about what the economics profession think is the prominent role of technology in the analysis of economic growth over the long-run. The chapter begins by clarifying the nature and interlinkages of the diverse notions of technology that are usually at play in the discussion of growth economics. Then, we focus on the concepts of technology and innovation, as well as the insights relating to the role of government and the institutions/policies needed to promote them that are underlined by the mainstream, the evolutionary economics and the NIS framework. Finally, consistent with our research question, we elaborate on the distinction between the economic impacts of adoption and innovation.

The conclusions reached in this chapter support our contention that when-

\footnotetext{
${ }^{20}$ Kongsamut et al., 2001, Gollin 2002, Caselli 2005

${ }^{21}$ Levine and Renelt 1991, De Long and Summers 1991, Eaton and Kortum 2001, Bosworth and Collins 2003, Kohli 2004, Kehoe and Ruhl 2008

${ }^{22}$ Nuxoll 1994, Nordhaus 1997, and Bosworth and Collins 2003
} 
ever the theoretical underpinnings are taken into account, the academic understanding of the determinants of backwardness in the world economy, catching-up prospects, and corresponding institutional/policy implications are largely ambiguous. Notably, we argue that though the policy implications underlined by the NIS framework have gained ample recognition in the policy context, they remain to be incorporated in the formal modelling structures that have become customary and shape the academic understanding of cross-country growth economics.

Chapter 4 endeavors to construct a model of this kind, namely, a formal model of economic growth where the long-run growth of income per capita depends on a broad notion of technology, including the interaction between foreign technology and local innovation. The analytical framework features elements of the mainstream, the evolutionary and NIS approaches, with a focus on government sponsorship or innovation promoting public financial mechanisms. The basic setup is a model of optimization consistent with the conventional mainstream approach, but where government interventions, underlined by the NIS framework, explicitly account for the financial support of business innovation activities, therefore enhancing long-run grow and the catching-up potential of the economy. ${ }^{23}$

The model in this chapter may be seen as an advance over previous models of endogenous growth. ${ }^{24}$ The major theoretical improvement that emerged from the endogenous growth literature was that it explicitly modelled technology as a partly private good-i.e., with at least some degree of market power (appropriability or excludability). ${ }^{25}$ In this framework, market incentives could explicitly be considered to influence the production of new technology, and government intervention plays a potential role to influence its production and foster long-run growth - though just implicitly, mainly through taxes, subsidies, and policies akin to the efficient market hypothesis (i.e, institutions and incentives to affect the ability and willingness of private agents to save, to invest and to acquire knowledge).

Instead, in our approach, we focus on the government financial sponsorship of private investments in innovation. We rely on a wide review of the literature documenting that this is widespread policy practice in the most advanced economies worldwide, and indeed used as a means to increase the production of innovation. Our claim is that having an explicit role for government intervention provides a more realistic analytical framework, and endows the researcher with sounder grounds to provide the policy-making with better insights on the issue of technology policy.

\footnotetext{
${ }^{23}$ see Barro 1990, and Ziesemer 1990, 1991, 1995a, for previous models where the long-run growth of income per capita depends on public goods or influenced by government policy.

${ }^{24}$ see Verspagen 1992, and Schneider and Ziesemer 1995, for reviews.

${ }^{25}$ See Snowdown and Vane, Ch. 11. Let us remember that the received theory of economic growth started with a public-good characterization of technology in a framework of perfect competition. In this context, the production of technology could not be influenced by either market incentives or government intervention; for example, entrepreneurs were deemed unable to capture as a private return even some of the economic benefits their technology investments created.
} 
Finally, Chapter 5 provides a test of the effects of adoption and innovation on the ability of backward countries to catch-up. The setup is focused on the longrun productivity effects accrued through the adoption of foreign technology and local innovation, and the effects of government coordination on local innovation. Unfortunately, as we explain in the chapter, data availability prevent us from a complete assessment including further aspects of the NIS framework than the issue of coordination (i.e., leadership and sponsorship). ${ }^{26}$

Consistent with our model we find some evidence that support the key theoretical claims in this thesis. In the first place, that the interaction of foreign technology with local innovation has strong and statistically significant long-run effects on the productivity performance of countries falling behind. Notably, this result contradicts earlier studies that find a long-run relationship between productivity in backward countries and foreign technology alone. ${ }^{27}$ In the second place, we find some evidence to support the view that government coordination is highly correlated with local innovation over the long-run. The effects of government coordination on local innovation are particularly meaningful for a group of countries that have been identified in country-case studies as key examples where government-directed innovation systems have been at work.

The econometric analysis, based on cointegration techniques, is motivated by the fact that the relationship between technology and economic growth we deal with is predominantly a long-run relationship. In fact, we provide statistical evidence whether such long-run association does exist or not between each of the adoption and innovation sources of technology and a country's productivity performance. Further, we elaborate on feasible explanations of why a sound structural cointegration relationship may fail to show up between the variables of interests in specific cases. Data limitations imply, however, that our econometrics is based on a small sample of 63 countries out of the 133 countries in Chapter 2.

In our econometric analysis, productivity is measured using the conventional multifactor productivity term (MFP); adoption (of foreign technology) is captured through a measure of the local stocks of foreign $\mathrm{R} \& \mathrm{D} ;^{28}$ innovation is captured through the share of the labor force involved in cognitive non-routine activities; ${ }^{29}$ and government coordination is based on a mild version of this indicator, in particular, we propose an index based on the simple average of four components: labor productivity, financial development, human capital and governance. Our approach to measuring each of these indicators is based on earlier insights in the literature and fully explained in the chapter.

Remarkably, our statistical approach supports two key claims in this thesis, namely that the interplay between local innovations and technology adoption

\footnotetext{
${ }^{26}$ As it is explained later, most aspects dealing with the NIS framework that will be discussed here are poorly measured, if at all.

${ }^{27}$ Coe and Helpman 1995, Coe, Helpman and Hoffmaister 1995, and Keller 2002, 2004.

${ }^{28}$ These stocks are constructed for each country, based on the import shares of the destination country with respect to countries at the frontier, and the latter countries' expenditures in R\&D. See, Coe and Helpman 1995 and Coe, Helpman and Hoffmaister 1995.

${ }^{29}$ We argue in Chapter 4 other indicators used in the literature and the reasons why they do not fit the goals in our approach.
} 
provides a meaningful explanation of the ability of backward countries to catchup, and that government coordination has a long-run impact on the innovation process. As we hypothesize in Chapter 5, the long-run associations of interest are generally more meaningful in the case of successful catching-up countries than in their counterparts, namely countries that have remained in stagnation, or that have lagged further behind over long periods of time.

The final chapter, Chapter 6, is devoted to recap over what we claim are the key contributions of this thesis, the limitations arising from our approach, and directions for future research. 


\section{Chapter 2}

\section{Overview of the Problem}

\subsection{Introduction.}

In this chapter, we introduce a methodology to split world economies into successful and unsuccessful cases of growth and catching up. For this purpose, we use data from the Penn World Tables. ${ }^{1}$ In particular, a sample of 133 countries is classified into those at the frontier and groups that over the long-term show patterns consistent with catching up, stagnation, or laggardness. This classification and the corresponding analysis involves the comparison, across-countries, of 10-year averages in levels of income per capita with respect to the average at the frontier (Section 2.2). Further, we provide also an analysis of the 10-year average growth rates adjusted by the average growth at the frontier (Section 2.3). Our analysis is conducted over the six decades of the period 1950-2010.

Based on the previous analysis, in Section 2.4 we propose a simple formula to calculate the number of years each country would need to catch-up given its current average level of income per capita and historical records of growth. Our simple mathematical formula shows that countries that have successfully managed to close the income gap are between 9 and 54 years short of the frontier. By contrast, countries classified in stagnation are between 38-191 years of getting at this target, and countries classified in laggardness are between 227-302 years of getting at the frontier. In Section 2.5, further analysis of $\beta$-convergence shows that there is evidence of unconditional convergence that holds for countries that classify among the successful catching-ups, but not for those countries that classify in stagnation or laggardness. Put otherwise, our analysis shows that there is convergence conditional on being a successful case of catching-up.

Then we investigate, in Section 2.6, how consistent are the observed income per capita differences with technology differences across countries. To this end, technology differences are related to differences in the productivity of the working force. We find that changes in overall productivity are insufficient to explain either stories of success or the lack of it across our country classifications. In-

\footnotetext{
${ }^{1}$ PWT V.8.
} 
stead, the decomposition of overall productivity into changes in efficiency and technical changes appears to have more leverage to explain the distinct stories of growth and catching-up across countries. In our approach, based on related literature, we associate efficiency to each country's own productivity contributions. In turn, we associate technical change to productivity changes associated to received technology (technology adoption). These productivity decompositions are based on nonparametric methods of data envelopment analysis (DEA) that are now firmly established in the literature. ${ }^{2}$

The final section in the chapter, Section 2.7, provides our concluding remarks.

\subsection{Backward Countries' Relative Levels of In- come}

One way to gain understanding on the catching-up dynamics of backward countries is by comparing those countries that over long periods of time have managed to catch up vis-⿳亠㐅冋-vis those that have not. Below, we provide a comparison in this regard.

For each country, the average income per capita is calculated as a 10-year average. For a cluster of countries with full data availability, there are six decades with information between the 1950s (the years between 1950-1959) and the 2000s (the years between 2000-2009). The six decades of the period 19502010 are 1950s, 1960s, 1970s, 1980s, 1990s, and 2000s. As many countries do not have observations going back far enough into the 1950s, we consider two further clusters of countries spanning the five decades period $1960 \mathrm{~s}-2000$ s and the four-decades period 1970 s-2000s, respectively. ${ }^{3}$

Overall, we have a sample of 133 countries: a cluster of 35 countries with data for the six decades spanning the period 1950s-2000s, a cluster of 46 countries with data for the five decades spanning the period 1960s-2000s, and a cluster of 28 countries with data spanning the four-decades period 1970s-2000s. These three cluster makes for a total sample of 109 countries to which the countries that make up the frontier (FRCs) are added. These are 24 high-income countries in the OECD classification standards that became members of the organization before $1990 .^{4}$

\footnotetext{
${ }^{2}$ See Kumar and Russell 2002, Coelli et al., 2005, and Los and Timmer 2005.

${ }^{3}$ We use PWT V.8. The sample includes 167 countries, of which 10 are excluded from the outset on the basis they had relative income per capita greater than $75 \%$ of the frontier at the outset (including Equatorial Guinea). This exclusion criterion is intended to eliminate the rich oil-producing countries and high-income countries whose income is greater than $75 \%$ of the average of the frontier. Other 24 countries are excluded on the basis that they have data only for less than 20 years - as explained further below. In the baseline calculations - unless stated otherwise - we use the rgdpna variable, which reports real GDP at constant 2005 national prices (in millions, 2005 US\$). Ten-year averages are calculated so long as a given country has information for at least 8 years. A detailed account of the country classification and relative levels of income is provided in Tables A.1-A.4 in the Appendix at the end of this chapter.

${ }^{4}$ There are, moreover, 24 countries with information over the two-decade period 1990s2000s. However, this latter group of (mostly Eastern European) countries will be dropped. We
} 
Admittedly, many of the countries that make up the FRCs have not been always at the frontier. In fact, Japan and almost all of Europe were catching up with the US during the 1950s, the 1960s and even the 1970s (one exception is Switzerland). Since the time when the Committee for European Economic Cooperation that later became the OECD was settled, Turkey has been far behind other European countries and so have been, although to a lesser extent, Greece, Spain and Portugal (See Table 2A.1). We do have good reasons, however, to think that our choice, setting the OECD average (per capita) income as the benchmark instead of the most customary US figure, is well justified: first, the OECD average income is higher that the corresponding figures in any other country classification throughout the six decades period in this study (Tables 2A.2-2A.4); and second, the OECD represents a richer number of countries that have developed under variegate principles and policy standards. ${ }^{5}$

We calculate, for each of the 109 countries falling off the frontier, a measure of the relative income (per capita). This is obtained as the ratio between the country's 10-year average income and the average income of countries at the frontier - the average of the 10 -year averages for FRCs countries. ${ }^{6}$

Consider, for instance, that in the 1950s the 10-year average income per capita in Colombia was US\$2671, and in South Korea (Korea now onwards) it was US\$1435, whereas the average at the FRCs was US\$8826. Half a century later, in the 2000s, the same figures were US\$6433, US\$23983, and US\$32860, respectively. Clearly, the two countries and the FRCs as a group experienced improvements in their levels of income per capita, though Colombia less so. Relative to the FRCs countries, the Colombian income per capita in the 1950s (around $30 \%$ of the FRCs figure) was almost double that of Korea (slightly above $16 \%$ of the FRCs figure). Fifty years later, the relative income per capita increased to around $73 \%$ for Korea, whereas for Colombia it decreased to under $20 \%$.

In Figure 2.1, the 109 countries behind the frontier are attached with a suffix to denote the first decade with available data, and then a comparison is set between the relative income per capita at the beginning and final decades (i.e., either of the 1950s, the 1960s, or the 1970s decades in the vertical axis, and the 2000s decade in the horizontal axis). A 45-degree diagonal is superimposed to help in assessing the difference between countries that managed to improve their income position and those that failed to do so. Though difficult to see precisely since the details are obscured by the large number of countries clustering to-

strongly believe these countries deserve a separate analysis as - at least partly — their success owes to the transition effect from communist regimes to Western capitalism and the support given for this process by the most advanced countries in the region. Moreover, the 1990s and the 2000s have been acknowledged as special decades, characterized by high commodity prices, low interest rates, and abundant flows of foreign capital (Summers 2014). An analysis of countries with data for these two decades in isolation would tend to confound cyclical events with the kind of long-run tendencies that are of interest in this thesis.

${ }^{5}$ See, for instance, Hall and Soskice 2003.

${ }^{6}$ See Table $2 \mathrm{~A} .1$ in the appendix at the end of this chapter for a list of the countries. Note that the OECD currently has 32 member countries. However, countries that became members of the organization after the 1990s are not included in the FRCs classification. 
gether at the bottommost of the figure, we find that of the 35 countries observed in the six decades (1950s-2000s), 12 managed to improve their levels of income per capita and got positioned under the diagonal; the remaining 23 failed to do so and got positioned above the diagonal. Likewise, of the 46 countries observed in five decades (1960s-2000s), 11 are under and 35 are above the diagonal; and for the 28 countries observed in four decades (1970s-2000s), 14 are under and 14 are above the diagonal.

There are, however, further differences to consider both within the groups of countries that managed to improve their income position, and within the groups that failed to do so. For instance, the relative income per capita of Brazil barely increased from $21.6 \%$ in the 1950 s to $22.6 \%$ in the 2000 s. By taking the ratio between the latter and the former figures it seems evident that no meaningful change occurred in the period of six decades in the relative position of Brazil vis-à-vis the countries at the frontier $(22.6 \% / 21.6 \% \cong 1.0)$. A similar pattern is observed for Dominican Republic (1.1), India (1.0), Panama (1.2), Sri Lanka (1.2), and Trinidad and Tobago (1.2). The relative stagnation of these six countries contrasts with the ability of other countries to narrow their income gaps by improving their position vis-⿳亠丷⿵冂-vis the countries at the frontier: Korea (4.5), Taiwan (4.2), Thailand (2.8), Cyprus (2.0), Egypt (1.6), and Israel (1.6).

We use an ad hoc 0.75-1.25 threshold to help bring distinction between these different patterns. Thus, countries for which the ratio of income per capita between the first and last decade is within the threshold are classified as stagnant (STCs); countries for which the ratio is above the upper bound are classified as catching-ups (CUCs); and countries for which the ratio is below the lower bound are classified as laggards (LGCs). Together, the 133 countries in the sample split into $24 \mathrm{FRCs}, 27 \mathrm{CUCs}, 24 \mathrm{STCs}$, and $58 \mathrm{LGCs}^{7}$

Along these classifications, in our analysis we pay further attention to the specific development circumstances of some groups of countries conventionally split by their levels of income: the low-income countries (LICs), the lowermiddle-income countries (LMICs), the upper-middle-income countries (UMICs), and the high-income-non-OECD countries (HInOECDs). And we control for the success of the South-East new industrialized countries (Nics), and the failure of the so-called fragile states (Frags). ${ }^{8}$ Thus, for instance, the CUCs classification

\footnotetext{
${ }^{7}$ See Tables 2A.1-2A.4 in the Appendix. Clearly, changes in this ad hoc threshold do lead to corresponding changes in country classification, though it is dubious that doing so within reasonable boundaries substantially alters the main conclusions. A larger threshold makes little sense, as it may lead to classifying more successful catching-up and laggard countries as stagnant instead. Conversely, a reduction in the threshold would lead to classifying more countries as being in the catching-up and laggard groups, and less in the stagnation group.

${ }^{8}$ These classifications are determined according to the World Bank classification standards. "Fragile states" refers to countries characterized by weak or ineffective central governmentsstates that are characterized by inability to maintain control over a country's territory, nonprovision of public services, widespread corruption and criminality, refugees and involuntary population movements, and extremely poor economic performance. The current classification is based on the 2014 version of the index published annually - since 2005-by the Fund for Peace and the magazine Foreign Policy. The countries in the graph are those considered to be under alert, high alert, or very high alert. See Tables A.5-A.7 in the Appendix to this chapter.
} 
does not include LICs, but does include 6 LMICs, 10 UMICs, 9 HInOECDs and 1 fragile country. ${ }^{9}$ And it includes of course the Nics (Taiwan, Hong-Kong, Korea and Singapore) as well as China and other well-known Southeast Asian cases of success (Thailand, Malaysia, and Indonesia).



Figure 2.1: Cross country levels of income per capita (relative to the frontier). The dashed line is a 45-degree line. A suffix on each country's name indicates the first decade with available data-e.g., Hong Kong60 indicates that the data for this country is available for the $1960 \mathrm{~s}$ (1960-1969) and 2000s (2000-2009). The figure depicts the performance of each country between the first and last decade. Note, for instance, that in the 1960s, Hong Kong's relative level of income was around $50 \%$ of the average at the frontier (vertical axis), and it increased to over $100 \%$ in the 2000 s (horizontal axis). In contrast, Argentina was around $70 \%$ of the average at the frontier in the 1950s, and shrunk to around $30 \%$ in the 2000 s.

Note also that the 27 countries in the CUCs classification include every one of the successful growth stories reported by the World Bank growth commission and the innovation policy guide issued by the same organization - except for Brazil. ${ }^{10}$ And include nearly all of the same countries as in a recent clas-

\footnotetext{
${ }^{9}$ It includes many well-known rich island states (Antigua and Barbuda, Malta, St. Vincent and Grenadines, St. Kitts and Nevis, Dominica, and Cyprus, among others.

${ }^{10}$ World Bank 2008, 2010. The work of this commission was to determine the lessons to be drawn from a select number of successful stories of sustained high growth-above $7 \%$ on a year-over-year basis - over an extended period of time.
} 
sification based on the Conference Board Database. ${ }^{11}$ However, the list here may not include every country usually dubbed an "emerging market" in other widespread classifications that are focused mainly on the analysis of shorter and more recent periods of time.

Indeed, our focus on the long-run implies that we prefer to analyze welldefined dynamic trends rather than short-run or one-time stochastic changes in a country's relative level of income per capita. We think that those long-run trends are a reflection of policy strategies that are unmistakably able to produce sustainable paths of economic growth. ${ }^{12}$ Of course, along those paths many short-run deviations are possible that not necessarily extend over the long-term. For example, the circumstances that during the past couple of decades have led to a profound productivity slowdown in many developed countries might have created an opportunity for the improvement in the relative performance of countries falling behind. ${ }^{13}$ But, it is yet hard to envisage - at the present time - whether a permanent change is underway in the trends of laggardness, stagnation and catching-up that we are discussing here. We just can't judge whether the relative improvement of today's backward countries may persist in the distant future based - for instance - on strong innovation policies in these countries, or it may get offset at some point by a new era of scientific innovation at the frontier.

Figure 2.2 shows that there are clear, though non-linear, tendencies in the evolution of relative levels of income per capita for each group (CUCs, STCs, and LGCs) and cluster (1950s-2000s, 1960s-2000s, and 1970s-2000s) of countries in our classification. In Figure 2.2a, the increasing trend in the relative levels of income per capita fits well the catching-up property argued for the CUCs group. Notably, this result does not stem from the exceptional performance of the NICs - which are depicted separately using thin dashed lines. And it does not stem either from the good performance of the HInOECDs countries - which are depicted separately using longdash-dotted lines. Indeed, after omitting the NICs and NInOECDs, a cluster of four countries emerges that shows a long-run tendency consisting with catching-up over the period 1950s-2000s (Thailand, Cyprus, Egypt, and Israel). Another cluster shows a similar tendency over the period 1960s-2000s (including China, Malta, Indonesia, and Malaysia). And another over the period 1970s-2000s (including Vietnam, Oman, and Macao). These clusters are depicted with thick dotted lines in the middle of Figure 2.2a.

In turn, Figure 2.2b fits well the relative stagnation attributed to the STCs group. And in Figure 2.2c, there is a clear decline in the relative levels of income

\footnotetext{
${ }^{11}$ Rodrik 2011.

${ }^{12}$ Sustainable growth and development achievements has been usually associated to the fundamental factors that are more likely to boost economic growth with persistent effects into the distant future (see Radelet 2016).

${ }^{13}$ The debate about the origins of the so-called current process of secular stagnation in the developed countries is still underway. Many authors point to circumstances associated to high commodity prices, low interest rates, and abundant flows of foreign capital that might have led, over time, to a slowdown in industrial countries during the pre-2007 crisis, see Summers 2014 and Teuling and Baldwin 2014.
} 
per capita that fits well the condition of laggardness attributed to the group of LGCs. Remarkably, the performance of the countries in these two groups does not stem from the weak development conditions that are specific to LICs and fragile states - which are depicted separately using dashed and dash-dotted thin lines, respectively. In other words, after omitting the LICs and fragile countries, the performance of the remaining countries in the STCs and LGCs classifications is consistent with the established conditions of stagnation or laggardness.

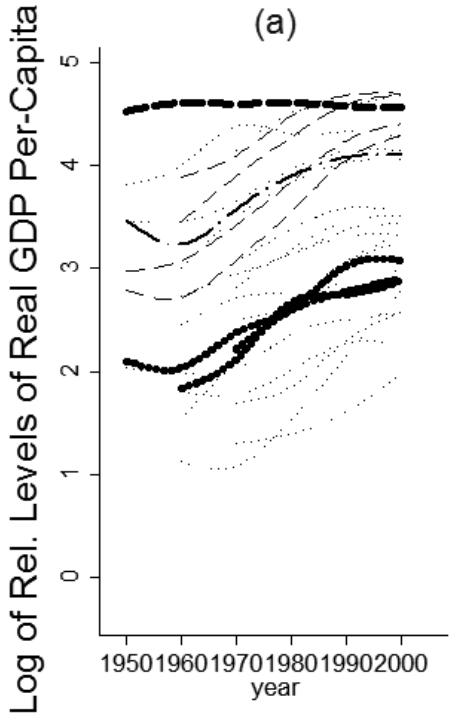

(b)

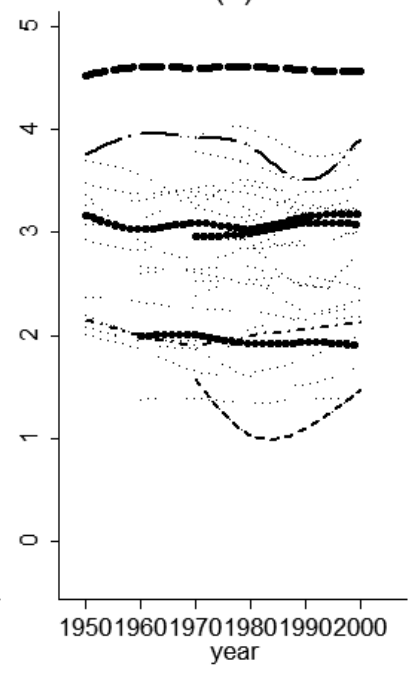

(c)



Figure 2.2: Relative income per capita FRCs, CUCs (a), STCs (b), and LGCs (c) (natural logs). Every line represents the (decade-per-decade) median of the distribution within a country classification. The thick dashed line on the top is the frontier (FRCs). For panels (a)-(c) there are three other thick-dotted black lines: the longest spans from 1950s-2000s, the medium sized spans from 1960s-2000s, and the shortest spans from 1970s-2000s. The thin dashed lines in (a) are the four Asian Nics. The longdash-dotted lines in (a) and (b) are HInOECDs. The dashed lines in panels (b) and (c) are LICs, and the dash-dotted thin lines are fragile countries. Figures are obtained using the scatter and mspline commands in Stata V 11.0.

Though not shown in the graph, in our analysis we have have paid attention too to the dispersion in levels of income per capita across the countries in each group and cluster. The dispersion is captured here using the absolute value of the coefficient of variation (the mean-normalized standard deviation) for each aggregation of countries. In general, we observe declining or at most only minor increases in this dispersion within each group and time-cluster of countries. 
Though volatility continues to be an important issue, mainly for LICs and fragile states, this reduction of the dispersion suggests a decline of within-group differences in relative levels of income. And notably, because the reduction occurs within each of the FRCs, CUCs, STCs, and LGCs groups, this seems to support the idea of convergence clubs emphasized in previous research. ${ }^{14}$

\subsection{Backward Countries' Adjusted Growth Rates}

Catching-up requires of backward countries to grow permanently at higher rates than the countries at the frontier so that their relative levels of income converge to the high income level. A simple way to assess this behavior is to calculate by how many percentage points the growth rate of each country exceeds (or falls short of) the average growth rate at the frontier. To this end, "adjusted growth rates" are calculated by subtracting the frontier's average growth rate from the growth rate of each other country and averaging the resulting quantities over each country classification.

For example, over the 60 years between 1950-2010 the average growth rate was $2.6 \%$ in the FRCs (the average of the growth rates across all FRCs countries). Correspondingly, it was $4.1 \%$ in the CUCs, $2.4 \%$ in the STCs, and $0.7 \%$ in the LGCs countries. By subtracting the average of the frontier $(2.6 \%)$ from each other country, the "adjusted growth rate" becomes $0 \%$ for the FRCs, $1.5 \%$ for the CUCs, $-0.2 \%$ for STCs and $-1.9 \%$ for the LGCs. Obviously, the "adjusted growth rate" of zero for the FRCs determines a cutoff below which countries are unable to catch-up. Further, the large negative adjusted growth rate of the LGCs, the nearly zero adjusted rate of the STCs and the positive adjusted rate of the CUCs, are all consistent with our classification in terms of the ability of each group of countries to catch-up.

Below we present a detailed analysis of the decade-per-decade average growth rates adjusted by subtracting the frontier's average growth rate from the 10-year average growth rate for every other country classification. That is, for every country classification, we calculate 10-year average growth rates. Then, from every country average that is obtained in this way, we subtract the corresponding average growth rate of frontier countries (which is determined by the average of the 10-year averages across FRCs countries).

As expected, in Figure 2.3a the CUCs countries are featured by positive adjusted growth rates (they evolve over the zero cutoff line determined by the FRCs). In other words, catching-up countries are featured because over time their growth rates exceeded the average growth rate at the frontier - as is shown by the thick solid lines evolving over the zero-cutoff for the periods $1950 \mathrm{~s}-2000 \mathrm{~s}$, 1960s-2000s and 1970s-2000s. As in the analysis of the previous section, this result does not hinge on the exceptional performance of the Nics countries, which are depicted apart using a dashed line and indeed show higher growth rates than the rest of the CUCs after the adjustment.

\footnotetext{
${ }^{14}$ The relevant calculations are provided in Table $2 \mathrm{~A} .8$ in the Appendix at the end of this chapter.
} 
(a)

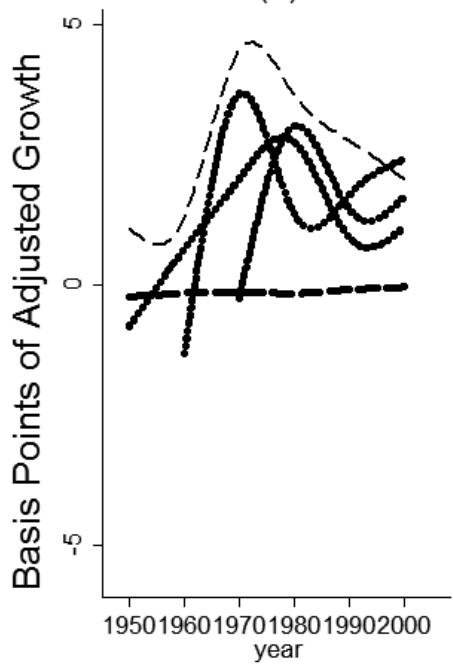

(b)

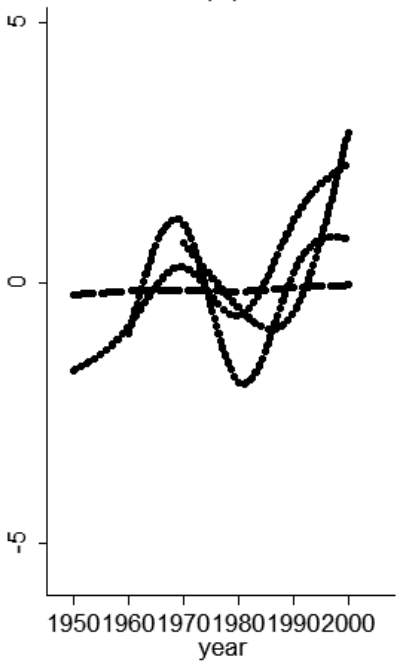

(c)

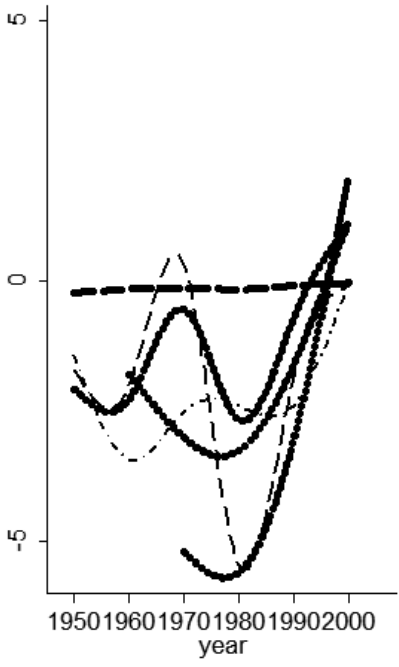

Figure 2.3: 10-year average growth rates FRCs, CUCs (a), STCs (b) and LGCs (c). Every line segment represents the (decade-per-decade) median of the distribution within a country classification. The thick dashed line falling short to zero is the frontier (FRCs). For panels (a)-(c) there are three other thick-dotted black lines: the longest spans from 1950s-2000s, the medium sized spans from 1960s-2000s, and the shortest spans from 1970s-2000s. The thin line in (a) represents the Nics. The thin dashed line in (c) represents the fragile states and the dash-dot thin line represents the LICs countries. Figures obtained using the scatter and mspline commands in Stata $V$ 11.0. 
For stagnant countries, clearly, there is a different situation. As shown in Figure 2.3b, the adjusted growth rates for this group oscillate over and below the zero-cutoff reflecting the well known weakness of many countries that fall in this group: alternating waves of rapid and slow or negative growth. Brazil, Argentina, and Mexico are examples of countries where periods of rapid economic growth were offset by subsequent periods of sluggishness, stagnation and recession. In the case of Brazil, for instance, during the 1950s, 1960s, and 1970s, the rates of economic growth (non adjusted) were on the rise $(3.7 \%, 4.0 \%$, and $6.1 \%$, respectively) and well above the average growth rates at the frontier $(3.2 \%, 4.2 \%$, and $2.9 \%$, respectively). However, during the $1980 \mathrm{~s}, 1990 \mathrm{~s}$, and $2000 \mathrm{~s}$, the growth rates in Brazil slowed down $(0.7 \%, 0.1 \%$, and $2.1 \%$, respectively) at a faster pace than in countries at the frontier $(2.1 \%, 2.0 \%$, and $1.2 \%$, respectively), which made the country unable to catch-up through the entire 1950s-2000s period.

In turn, for the LGCs countries in Figure 2.3c the adjusted growth rates evolve mostly below the zero-cutoff. Consistent with our country classifications, this accurately reflects the tendency of LGCs to fall further and further behind. And, notably, that behavior does not stem from the volatility that is customarily expected from fragile states - shown by the thin dashed line - and low income countries (LICs) - shown by the thick dash-dotted line. True, there have been some episodes of growth acceleration in many middle-income countries (both LMICs and UMICs) during the 1990s and the 2000s that pushed the LGCs over the zero-cutoff. But, as we have pointed out above, at present it is hard to envisage whether such accelerations are a new and permanent feature of these countries or just a temporal improvement explained by the productivity slowdown of the last decade in the countries at the frontier.

Back to Figure 2.3a, we observe reducing adjusted growth rates as the Nics countries get closer to the frontier. The median (adjusted) growth rate for these countries (the thin dashed line) increased from $1.3 \%$ in the $1960 \mathrm{~s}$ to $4.5 \%$ in the 1970 s. Subsequently, it decreased to $3.7 \%$ in the $1980 \mathrm{~s}, 2.8 \%$ in the $1990 \mathrm{~s}$, and $2.0 \%$ in the $2000 \mathrm{~s}$. And that reduction was explained mostly by the growth deceleration of the Nics. ${ }^{15}$ In other words, even though they have generally outgrown the average at the frontier, the experience of the Nics suggests a convergence pattern in growth rates as countries catch-up. ${ }^{16}$

To verify whether that is indeed the case, we calculate the size of the dispersion in growth rates within each of the different groups and time-clusters of

\footnotetext{
${ }^{15}$ Indeed, the $1.3 \%$ adjusted growth rate in the $1960 \mathrm{~s}$ resulted from a non-adjusted rate of $5.5 \%$ for the Nics versus a rate of $4.2 \%$ at the frontier. In the $1970 \mathrm{~s}$, the corresponding non-adjusted rates were $7.5 \%$ (Nics) and $3.0 \%$ (frontier); in the $1980 \mathrm{~s} 5.8 \%$ (Nics) and $2.1 \%$ (frontier); in the $1990 \mathrm{~s} 4.8 \%$ (Nics) and $2.0 \%$ (frontier); and in the $2000 \mathrm{~s} 3.2 \%$ (Nics) and $1.2 \%$ (frontier). Thus, after the high growth rates obtained in the $1960 \mathrm{~s}-1970 \mathrm{~s}$, between the 1980 s and the 2000 s growth rates diminished 4.2 percentage points for the Nics and only 1.8 percentage points for the frontier.

${ }^{16}$ Growth decelerations are not uncommon at high levels of income. Gordon 2014 points out that it took 28 years (from 1929 to 1957 ) for the US to go from US $\$ 8000$ to US\$16000 per capita, but then it took 31 years (from 1957 to 1988) to go from US $\$ 16000$ to US $\$ 32000$, which suggests that the next doubling of income per capita will occur close to the year 2100 .
} 
countries. Those calculations - not shown in the graph - suggests again a decline, or at most only minor increases, in the volatility of the adjusted growth rates. We calculate the dispersion using once again the absolute value of the coefficient of variation. There are high levels of volatility around the 1970s for STCs and LGCs that preclude a neat assessment, but the reduction of dispersion over time suggests anew the presence of growth convergence clubs among the countries in each classification of our approach. ${ }^{17}$ This issue is analyzed further below in Section 2.5.

All in all, unlike the customary analysis of catching-up which is focused on the ability of backward countries to generate high and permanent rates of growth, ${ }^{18}$ we focus on the relative performance of countries over long periods of time. This approach allows us to unmistakably distinguish between successful cases of catch-up, stagnation and laggardness of backward countries with respect to the countries already at the frontier. The ad hoc $0.75-1.25$ threshold that helps the distinction between these groups does not affect our key conclusion that high growth rates are a necessary but not a sufficient condition for catchingup. Though the higher, the better, what matters is that the growth rates of backward countries are higher relative to the rates at the frontier through the entire process of catching-up (even if the growth gap narrows as backward countries get to the frontier).

\subsection{An Extrapolation Formula}

Catching-up hinges on both the current levels of income and the growth rates of backward countries relative to the frontier. Thus, a formula that puts emphasis on both these facts to calculate the number of years that a country needs to catch-up is suggested in this section. We determine that number by simply extrapolating past levels of income per capita using the average historical growth rate. Of course, these are only rough predictions that do not account by the unpredictable impact of stochastic shocks or the likely policy changes that may occur in an economy over the long-run. ${ }^{19}$ These rough predictions, however, are also illustrative of the most likely catching-up scenarios to be expected with the hitherto available evidence.

Based on continuous compounding, the question to address is how many years $(N)$ would it take for country $i$ 's income per capita $\left(\mathrm{Y}_{i}\right)$ that grows at a continuous rate $\left(\mathrm{g}_{i}\right)$, to catch up with the level of income at the frontier $\left(\mathrm{Y}_{F}\right)$ if the latter grows also at a continuous rate $\left(\mathrm{g}_{F}\right)$ ?

$$
Y_{i} * e^{g_{i} N}=Y_{F} * e^{g_{F} N}
$$

Taking natural logarithms on both sides, and solving for $N$, the following

\footnotetext{
${ }^{17}$ The corresponding calculations are provided in Table 2A.9 in the Appendix at the end of this chapter.

${ }^{18}$ See World Bank 2008.

${ }^{19}$ Summers 2014 and Teuling and Baldwin 2014 are some useful references regarding the difficulties inherent in elaborating long-run predictions.
} 
conditions are obtained

$$
\begin{array}{ll}
N=-y_{F} / y_{i} *\left(g_{F}-g_{i}\right)^{-1} & \mid g_{F}<g_{i} \\
N=-\infty & \mid g_{F}>g_{i}
\end{array}
$$

where lowercases are used to denote the logarithm of income and the minus (-) sign is added to show that the result represents the years a country needs to catch up. In more general terms, the equations above build on the inverse relationship between the growth rate of backward countries and the years they need to catch up, and on the inverse relationship between relative income and the number of years to catch up. Clearly, these calculations are meaningful as long as the growth rate of backward countries exceeds the growth rate at the frontier (eq. 2.1), otherwise the perspectives of catching up fade away (eq. $2.2) \cdot{ }^{20}$

Figure 2.4 shows this relationship for the 133 countries under analysis. We present the actual average rate of growth for each country over the period 19502010. The number of years to catch-up are calculated setting $y_{F}=$ median income in frontier countries (FRCs) and $g_{F}=1.4 \%$ (the minimum growth rate across FRCs countries). Of course, the distribution of countries would shift toward the right had we used $g_{F}=0 \%$ instead (meaning no-growth across FRCs countries) as under this scenario the years needed to catch-up are lesser for each country. But it seems unrealistic to consider the frontier a fixed rather than a moving target to be reached by backward countries - further explanation in this regard follows below.

The leftmost extreme limit is set at -250 years such that countries close to it are deemed unable to catch-up. Horizontal line segments are set to stress the limits to catch-up imposed by the growth at the frontier. We consider four cases, namely unconditional ( $0 \%$ growth at the frontier), minimum $(1.4 \%$, the observed minimum at the frontier), median $(2.6 \%$, the observed median at the frontier), and maximum(4.4\%, the observed maximum at the frontier). Thus, by construction, all FRCs countries fall in the region between the min-max threshold $(1.4 \%-4.4 \%)$.

The implications drawn from the unconditional, minimum, median and maximum scenarios above can be analyzed by looking at the distribution of countries in Figure 2.4. The basic percentage points in excess of the growth rate at the frontier (BP) may be easily gauged for each country from the gap between the dot representing the country and a given threshold. For instance, the unconditional threshold implies that there is no difference between the actual and adjusted growth rates of backward countries: if the actual growth rate is, say, $1 \%$, the adjusted growth is $1 \%-0 \%=1 \%$ and the $\mathrm{BP}$ is 1 (the country falls 1 percentage point over the $0 \%$ threshold). Likewise, if the actual growth rate

\footnotetext{
${ }^{20}$ Consider a two-country case whose only differences are in levels of income and growth rates. Assume country A has an income level of 200 and a constant growth rate of $1 \%$, and country $\mathrm{B}$ has a level of income of 100 and growth rate of $2 \%$. Over the long run, we can expect country B overtakes A as the frontier leader, whereas A will never have any chance to catch up in return unless its growth rate becomes at least slightly higher than $2 \%$.
} 
is, say, $-1 \%$, the $\mathrm{BP}$ is -1 (the country falls 1 percentage point below the $0 \%$ threshold). Notably, we see that even with a growth rate of $0 \%$ at the frontier, many LGCs fall well below the $0 \%$ line (which means that they exhibit negative actual rates of growth in the first place) and group together well to the left of the -250 years limit in the horizontal axis. Clearly, countries under this circumstances are unable to catch-up.

When the threshold of reference is the minimum growth rate at the frontier, it means that the actual growth of backward countries would need to be faster than $1.4 \%$ if they are going to catch-up at any time in the future. In other words, a country growing at an actual rate of $1.4 \%$ would have and adjusted growth rate of $1.4 \%-1.4 \%=0 \%$, and the $\mathrm{BP}$ would be 0 (so that it falls just over the $1.4 \%$ threshold). Many countries, mainly from the LGCs classification, still fail to grow at this rate of $1.4 \%$. Thus, they group together below the minimum threshold of $1.4 \%$ and well to the left of the -250 years limit in the horizontal axis, making evident once more the inability to catch-up that arises for countries growing at a slower pace than frontier countries.



Figure 2.4: Distance to the frontier FRCs, CUCs, STCs, LGCs: The horizontal axis shows the years a country needs to catch-up. Each country is represented with a dot showing its actual average rate of growth over the period 1950-2010. Note that, to be able to catch up at any point, the average rate of growth of the country has to be larger than the growth rate at FRCs countries. The lines at 0\%, 1.4\%, $2.6 \%$ and $4.4 \%$ in the vertical axis depicts some possibilities. Countries that are below the $0 \%$ threshold are unable to catch up at all. 
Unlike the evident inability to cath-up that shows up for most of the LGCs countries, most of the STCs fall shortly below or slightly over the median growth rate of frontier countries. By the median standard, a country growing at an actual rate of, say, $3.1 \%$, has an adjusted growth rate of $3.1 \%-2.6 \%=0.5 \%$, such that the $\mathrm{BP}$ is 0.5 (meaning that the country falls 0.5 percentage points over the $2.6 \%$ threshold). By contrast, if the actual growth rate is, say, $2.1 \%$, the adjusted growth rate is $2.1 \%-2.6 \%=-0.5 \%$, and the BP is -0.5 (the country falls 0.5 percentage point below the $2.6 \%$ threshold). We see that the $2.6 \%+/-0.5 \%$ is indeed the range where most of the STCs lie. The relative stagnation of STCs countries is reflected in their failure to grow faster than the median growth rate of countries at the frontier (incidentally, this assessment remains substantially the same if we refer to the mean instead of the median rate of growth at the frontier).

The remarkable observation in Figure 2.4 is that every country in the CUCs group gets positioned well over the median growth rate of the frontier countries. The well known cases of countries exhibiting rapid economic growth during the last 60 years show up here: China, Botswana, Taiwan, Korea, Singapore, and Hong Kong, all fall over the maximum growth rate shown by the countries at the frontier, $4.4 \%$. And, in fact, we observe some countries that are near fulfillment or already fulfilled the catch-up process (Taiwan, Korea, Singapore, Macao, Hong Kong). This fulfillment of the catching-up process is identified because there are 0 years to catch-up in the horizontal axis.

The inverse relationships between the growth rates - and relative levels of income - of backward countries and the years they would need to catch-up may be evidenced by looking at concrete country cases in Figure 2.4. For instance, though having similar levels of income at US\$9200, Dominica (3.7\%) and Maldives $(5.0 \%)$ have had quite different average growth rates over more than 40 years. As a result, we see that Dominica would require 54 years in order to catchup, whereas Maldives would require 35 years. Similarly, though facing similar growth rates of around $4.0 \%$, Thailand (US\$7121) and Cyprus (US\$20890) have very different levels of income per capita. As a result, Thailand would require 62 years to catch-up, and Cyprus 17 years.

Similarly, the conditions at the frontier have a large effect on determining the years needed to catch-up in Figure 2.4. For instance, had we set $g_{F}=0 \%$ instead of the minimum growth rate across frontier countries $(1.4 \%)$, the years needed to catch-up reduce for Dominica (33 instead of 54 years), Maldives (25 instead of 35 years), Thailand (39 instead of 62 years), and Cyprus (11 instead of 17 years); this reduction is explained because the assumption $g_{F}=0 \%$ implies that the frontier is a fixed target, whereas assuming $g_{F}=1.4 \%$ implies that the frontier is getting away at a positive rate. While predicting the exact rate at which countries will grow in the future is cumbersome, clearly, the latter seems a more realistic scenario.

Likewise, had we use in the calculations of Figure $2.4 y_{F}=\mathrm{US} \$ 12746$ (the 2015 level of income per capita above which a country is considered to have high income in the World Development Indicators) instead of the median across frontier countries (US\$31378), the years to catch-up would narrow further: Do- 
minica (9), Maldives (7), Thailand (15), and Cyprus (+13). In fact, looser conditions might have been imposed in calculating the ability to catching-up in our analytical framework. For instance, the World Bank standards focus on the upgrading of countries to the next level of income. With the figures for 2015 , this would mean a target of US $\$ 1045$ for low income countries (meaning that the next target for LICs is the income at the bottom of the lower middle income countries); for LMICs the target would be US\$4215 (the income at the bottom of the upper middle income countries), and for UMICs the target would be US\$12746. Had we apply a similar reasoning, the result would have been a larger reduction in the number of years to catch-up. Yet, whether one set of assumptions or the other is the most appropriate is an open question.

Notably, under any conditions our results remain that the CUCs countries seem more likely to catch-up in shorter times than the STCs, whereas the LGCs seem to fall further behind. In the first scenario $\left(y_{F}=\right.$ median income and $g_{F}=1.4 \%$ across FRCs countries) a median of 54 years to catch-up arises for the CUCs, in comparison with 191 years for STCs countries and 302 years for LGCs countries. In the second scenario ( $y_{F}=$ median income and $g_{F}=0 \%$ across FRCs countries) a median of 32 years arises for the CUCs, versus 77 years for the STCs and 264 years for LGCs. In the third scenario ( $y_{F}=12746$ and $g_{F}=0 \%$ ) a median of 9 years arise for the CUCs, versus 38 and 227 years for the other two groups, respectively.

\subsection{Conventional Convergence Revisited}

The soundness of the above classification of countries may be assessed also by looking at conventional estimates of $\beta$-convergence. In our assessment, the initial income is the ratio between each country's average income per capita in the 1970s and the average income in FRCs countries. We evaluate whether there is a statistically significant negative association between a country's initial relative income per capita and its growth rate over time. The analysis is based on separate regressions for each country classification (FRCs, CUCs, STCs, LGCs, Nics, HInOECDs, LICs, and Frags) but we do not impose further "conditions" with regard country-specific characteristics. In this sense our analysis may be consider one of "unconditional convergence" as is explained further below. ${ }^{21}$

Figure 2.5 displays the relationship between the initial relative income and the growth rates in the decades of 1970s, 1980s, 1990s, and 2000s (there are four growth rates per country). Linear prediction lines are generated to highlight the convergence pattern within the FRCs countries; between the CUCs and the FRCs; between the STCs and the FRCs; and between the LGCs and the FRCs, respectively. Putting together the CUCs and the FRCs produce steeper

\footnotetext{
${ }^{21} \mathrm{As}$ it is well known, the general property of convergence is conditional. While countries differ with respect to some key variables (saving rates, population growth) the tendency is to grow faster the farther behind they are with respect to their own steady state. When it comes to technology diffusion, conditional convergence assumes that backward countries get benefited from inventions at the frontier whenever the right institutions are in place (Barro and Sala-I-Martin 1997).
} 
downward-sloping prediction lines than is the case when the FRCs countries are alone, which is a clear indication of the convergence pattern between the CUCs and the FRCs countries. Furthermore, we observe that the prediction lines are clearly negatively sloped and steeper for the CUCs than for the STCs, whereas for the LGCs they slope slightly positively. This means that there is a more rapid convergence speed between the CUCs and the FRCs countries than between the STCs and FRCs countries, whereas between the LGCs and the FRCs countries a process of divergence seems more apparent instead. Put otherwise, our analysis suggests a rapid process of unconditional convergence that applies clearly to the case of the most successful catching-up countries, but not in general.

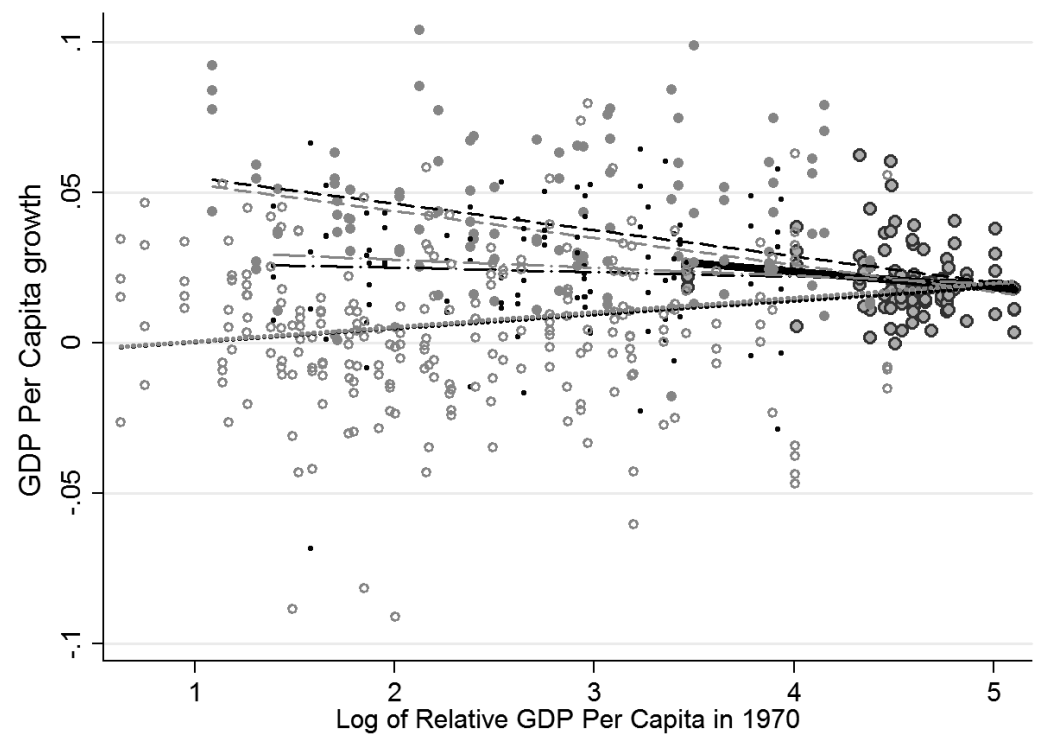

Figure 2.5: Analysis of conventional $\beta$-convergence CUCs, STCs and LGCs vis-à-vis FRCs. The thicker black line and greyest symbols are the FRCs. The dashed lines on the top correspond to CUCs countries as a whole (the black line), and after subtracting the Nics and HInOECDs (the grey line). The dashed-dotted lines in the middle correspond to STCs as a whole (black line) and after subtracting LICs, HInOECDs, and Frags (grey line). The bottommost dotted lines correspond to LGCs countries as a whole and after LICs and Frags are subtracted.

The reason we deem this a process of unconditional convergence should be apparent. Clearly, whether the observed convergence occurs because CUCs countries hold similar country-specific characteristics or institutional conditions that emulate those of the FRCs countries, cannot be deduced safely from the data and the analysis here. That, in fact, is an interesting debate that is underway in growth economics: economists from different backgrounds would opine 


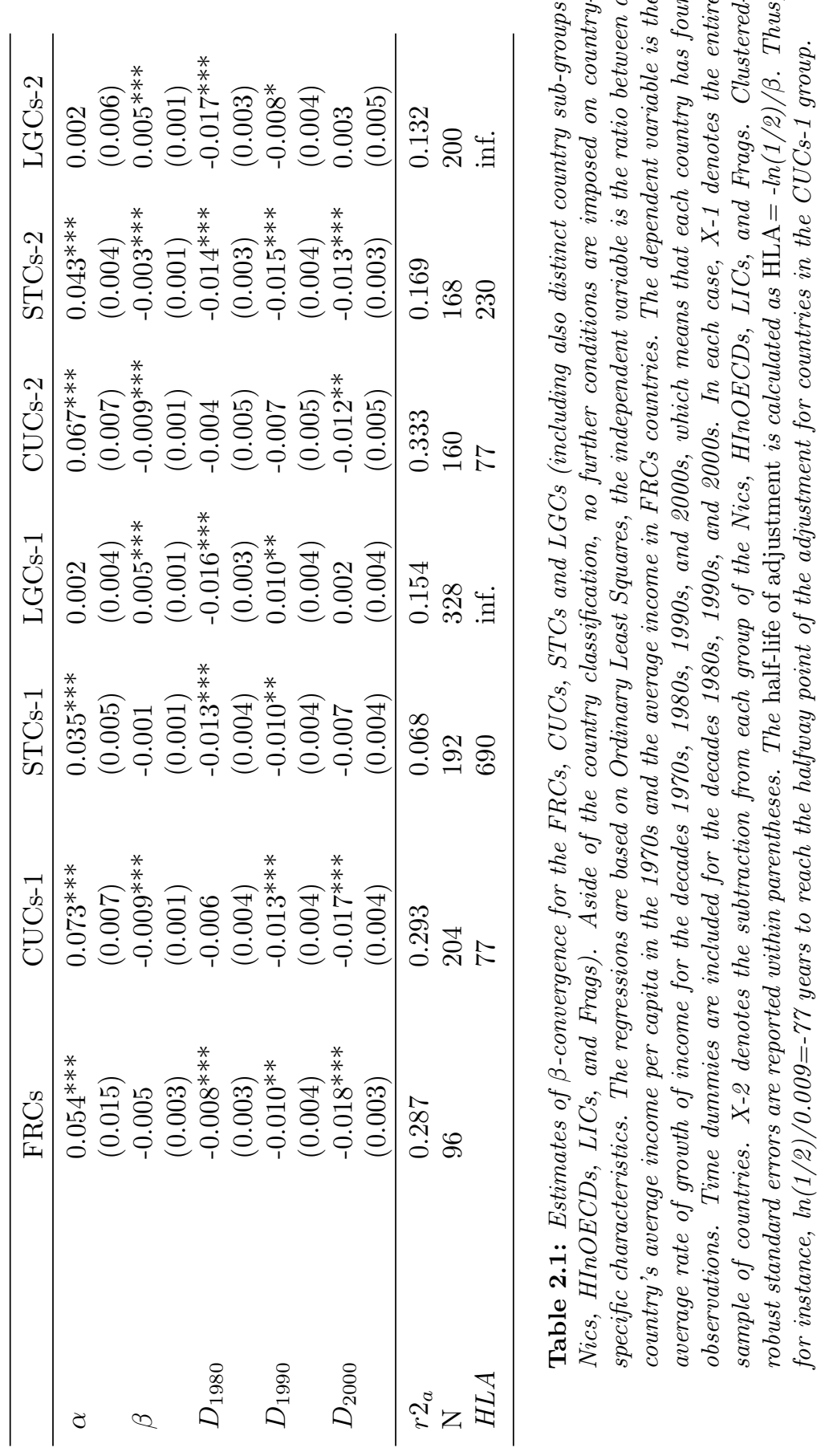


differently if they are asked whether the relative success of the CUCs is because of their ability to copy the institutions, adopt the technologies and emulate the organizational practices and production activities carried out in the most developed countries or, instead, because of their ability to learn and assimilate those technologies before embarking in innovation enterprises suitable to local specific conditions. There would be also quite different answers to the question whether the CUCs succeeded without (or in spite of) government intervention or, precisely, because there were explicit government interventions in place aimed to enforce innovative policies, institutions and strategies according to governmentled national targets. That debate will be the object of discussion in the following chapter.

The findings in Figure 2.5 are confirmed by the conventional estimates of $\beta$-convergence presented in Table 2.1. The regression equation is

$$
\Delta y / y=\alpha+\beta L N(Y 1970)+D_{\tau}+\epsilon
$$

where the initial income, $\mathrm{LN}(\mathrm{Y} 1970)$, is the natural logarithm of the average income per capita in the 1970s divided by the average income of the FRCs countries. The dependent variable is the average rate of growth over the decades of the 1970s, 1980s, 1990s, and 2000s, which means that there are four observation for each country. ${ }^{22} D_{\tau}$ is a set of time dummies per decade $(1980 \mathrm{~s}, 1990 \mathrm{~s}$, 2000s) intended to capture any changes in the average rate of growth explained over time by other than the convergence effect (productivity, business cycles). Finally, $\epsilon$ is the residual term that, we assume, is white noise. Below, our discussion of the empirical evidence is based on the $\beta$-convergence coefficient. The analysis based on the speed of convergence, obviously, does not affect the conclusions. The speed of convergence may be calculated in the usual manner by noting that $\beta=-\left(1-e^{-\lambda, t}\right)$ where $\lambda>0$ measures the rate of convergence. ${ }^{23}$

As the results in Table 2.1 indicate, only countries in the CUCs- 1 , CUCs- 2 and STCs-2 classifications exhibit evidence of unconditional convergence to the levels of income per capita of FRCs. The estimated $\beta$-convergence effect for the CUCs-1 (-0.009) is negative and statistically significant though quite small in magnitude. Yet, the effect remains circa -0.009 for the CUCs- 1 and CUCs-2 classifications - after dropping the most exceptional cases of catching-up (the Nics, and the HInOECDs). By contrast, an statistical significant convergence effect can be obtained for the STCs countries only after dropping out fragile (Frags) and low income countries (LICs). This result is clearly illustrated by the $\beta$-convergence effect under the STCs- 2 classification $(-0.003)$.

The $\beta$-convergence effect is not affected by the inclusion of the decade dummy variables (the coefficient $\beta$ measures the change in average growth per unit change in the initial income, net of the effect of the time dummies). Yet, the regression results indicate a reduction of the average rates of growth over the

\footnotetext{
${ }^{22}$ Alternatively, we might run regressions over a single time period (a cross section regression combining the average growth rates for the four decades $1970 \mathrm{~s}, 1980 \mathrm{~s}, 1990 \mathrm{~s}$ and $2000 \mathrm{~s}$ into a single average), the results in such case are not very different from those reported here.

${ }^{23}$ Durlauf Johnson and Temple 2005.
} 
1980s, 1990s and 2000s. This is deduced from the statistically significant negative effects of the time dummy coefficients - mostly for the FRCs, the CUCs-1 and the STCs-2 classifications. In the case of the CUCs-1, the dummy effect in the 1980s (-0.006) is not statistically different from zero. But the average rate of growth decreases by -0.013 percentage points in the $1990 \mathrm{~s}$ and by -0.017 percentage points in the 2000s. Similarly decreasing growth rates show up for the STCs (mostly in the STCs-2 after dropping the worst-off cases of low income and fragile states), and for the LGCs countries.

The so-called half-life of adjustment, which is the time that it takes a country to eliminate half of the initial gap in income per capita with FRCs, confirms our earlier results above that the CUCs, as a group, is the only one showing meaningful catching-up properties in relatively shorter time periods. The halflife of adjustment is calculated as $H L A=-\ln (1 / 2) / \beta$, where the denominator is the $\beta$-convergence coefficient found in the regression. The results in Table 2.1 show that it takes around 77 years for the CUCs to eliminate half of their initial gap with FRCs countries, whereas for the STCs it takes between 230 and 690 years to eliminate half of theirs. And the evidence of unconditional divergence found for the LGCs implies that no convergence is definitely possible for this group of countries.

As some critics have suggested, there are non-trivial limitations that apply in general to the estimation and statistical properties of convergence coefficients, namely endogeneity, measurement errors, non-linearities, and robustness to control variables. ${ }^{24}$ However, in the analysis of the different patterns of convergence in our country classification, our basic estimates certainly are good enough to serve our purpose regardless those limitations. They provide sufficient evidence to reassuring the soundness of our country classifications: the CUCs countries show relatively stronger convergence effects over the four decades of the 1970s, 1980s, 1990s and 2000s; the STCs countries show a weaker convergence effect; and the LGCs countries show divergence trends instead.

\subsection{Cross-Country Differences in Technology}

A key explanation in the literature of economic growth is that differences in levels of income per capita (and their growth rates) are closely related to differences in the productivity of the work force across countries. And workers' productivity, in turn, is assumed to be closely related to the efficient use of the overall technology available to each country. ${ }^{25}$ Noteworthy, this remains a major explanation to differences in economic growth across countries in spite of most recent alternative approaches, like the so-called Hausman-Rodrick-Velasco Growth Diagnostics Framework or the identification of growth accelerations ap-

\footnotetext{
${ }^{24}$ See Durlauf Johnson and Temple 2005 for a review of the statistical limitations in the estimation of the beta-convergence effect.

${ }^{25}$ Clark and Feenstra 2003. However, the emphasis on the association between economic growth and productivity is not without disagreement. See, for example, Dougherty and Jorgenson 1996, and Jorgenson and Vu 2005.
} 
proach, which provide a rather different approach. In particular, by focusing on the most binding constraints to development that are specific to each country (e.g., Hausman et al, 2005; Hidalgo et al., 2007: Hausman et al, 2011). ${ }^{26}$

In this section, we revisit the received understanding upon these relationships. Based on the classification of countries of this paper, we find that while there are indeed large productivity differences that resemble the overall differences in income per capita across countries, over time the cross-country differences in productivity have changed less than the differences in levels of income.

Further, by breaking down overall productivity changes into efficiency changes (movements toward the frontier) and technical changes (shifts of the frontier itself), we find that, when presented with the same technology frontier, CUCs countries tend to exhibit higher levels of efficiency than STCs and LGCs countries. Our reading of this evidence is that in STCs and LGCs countries productivity growth is mostly led by the inflow of new technology, whereas in the CUCs countries productivity growth is mostly led by a better use of the available technology. Consistent with this analysis, we conclude that there is a need to investigate further the determinants of the distinct productivity contributions associated to foreign and local sources of technology.

In our approach to explaining the link between cross-country differences in levels of income per capita (or their growth rates) and productivity, we consider first the conventional analysis of variance decomposition. Then, we move into an analysis of some commonplace concerns with regard to the measurement of productivity and the corresponding implications upon our understanding regarding the ability of backward countries to grow and catch-up. Finally, we consider the aforementioned split of productivity into efficiency and technical changes.

\subsubsection{Variance Decomposition}

Variance decomposition is a way to gauge how the variance of output per worker across countries relates to the variance of capital and the variance of multifactor productivity (MFP). ${ }^{27}$ We use this technique to determine whether - as would be expected - countries in the CUCs classification exhibit higher rates of productivity than STCs and LGCs countries. That is, we investigate whether the differences in the ability to catch-up among our country classifications are related to productivity differences.

Consider the standard production function measured in per-worker terms, $Y=A K^{\alpha}$, where " $\alpha$ " is the share of capital in total income. Using lowercase to denote the loglinear transform and expressing the equation in growth rates yields, $\Delta y / y=\Delta a / a+\alpha \Delta k / k$. The variance decomposition formula is standard and is given by

$$
\operatorname{var}(\Delta y / y)=\operatorname{var}(\Delta a / a)+\operatorname{var}(\Delta k / k) \alpha^{2}+2 \operatorname{cov}(\Delta a / a, \Delta k / k) \alpha
$$

\footnotetext{
${ }^{26} \mathrm{I}$ am grateful to Carolina Castaldi for comments that call my attenton to this recent literature which. while just recently, has found quite some application in the empirical growth literature.

${ }^{27}$ King and Levine 1994, Caselli 2005.
} 
Applying this decomposition to the entire sample of countries and decade by decade we find the usual result that the variance of the MFP term: $(\operatorname{var}(\Delta a / a))$, accounts for between $80 \%$ to $90 \%$ of the observed dispersion in output growth rates. $^{28}$ Notably, the result shows little change when calculations are done decade by decade (1960-1969, 1970-1979, and so on): MFP remains the main source of the variation in growth rates across countries. ${ }^{29}$

More relevant for our purposes here, however, is the dispersion of the MFP term with respect to the performance of countries at the frontier. To this end, the variance decomposition is calculated year-over-year for each country with respect to the mean of FRCs. Then, we group the contributions of MFP for every classification of countries. The kernel density in Figure 2.6a shows that, in comparison with the STCs and LGCs, the CUCs group has a larger mass to the right of the FRCs countries. Indeed, the mass distribution of the CUCs entirely overlaps the STCs group on the righthand side. And the mass distribution of the LGCs is entirely overlapped by every other group, except for a small mass in the righthand tail of the FRCs.

In other words, with the FRCs kernel as a benchmark, we find much larger contributions of MFP to the variance of output per worker in the CUCs than in the STCs and LGCs countries. In fact, in the STCs countries these contributions are roughly similar to the bechmark, and in the LGCs countries they are evidently much lower, as may be deduced from the left-skewed mass distribution for this group. Notably, this result does not seem to hinge on the performance of extreme country cases as we observe that the kernel densities remain roughly the same after the most extreme country cases are dropped out (see Figure $2.6 \mathrm{~b})$.

Z-test statistics for the difference between means supports the null hypothesis that CUCs are significantly distributed to the right of the frontier-meaning that their productivity growth rates were larger - whereas the difference between the frontier and the STCs is not statistically significant, and the LGCs are significantly to the left of the frontier. Moreover, the difference between CUCs and STCs is statistically significant. And these results hold after adjusting the sample to eliminate the positive influence of the extreme cases. ${ }^{30}$

\footnotetext{
${ }^{28}$ See the analysis in King and Levine 1994, Caselli 2005. Note that these calculations are based on a value of $\alpha=0.33$, and capital and output-per-worker figures are based on PWT V.8. An in-depth analysis of MFP measures is provided in the next section.

${ }^{29}$ An exception is a slight decline of productivity differences observed around the 1970s, which fits well the slowdown of productivity in this decade.

${ }^{30} \mathrm{Z}$-test statistics are obtained as follows: after getting rid of the influence of extreme cases, the null hypothesis that the mean of productivity growth in CUCs and STCs is the same is,

$$
\text { Ho: } \mu_{C U C s}-\mu_{S T C s}=0
$$

which is distributed at the $99 \%$ of confidence with mean, standard deviation, and observations as follows:

$$
(\mu, s d, N)_{C U C s}=(0.013,0.019,55) \text { and }(\mu, s d, N)_{S T C s}=(0.003,0.016,72)
$$

Thus, $(0.013,0.019,55)_{C U C s^{-}}(0.003,0.016,72)_{S T C s}=0.010(\mathrm{P}>|z|=0.0008)$. That is, we reject the null as the probability of finding a difference of means larger than 0.010 between the two variables is smaller than 0.01 . The results decade-per-decade show similar behavior
} 
(a)

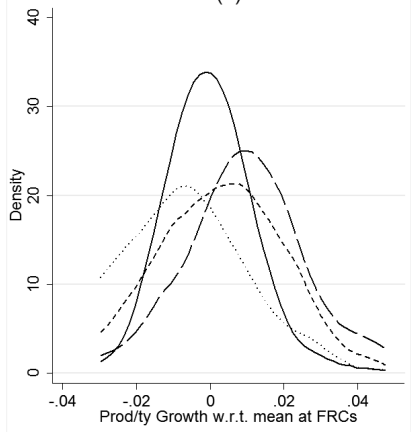

(b)

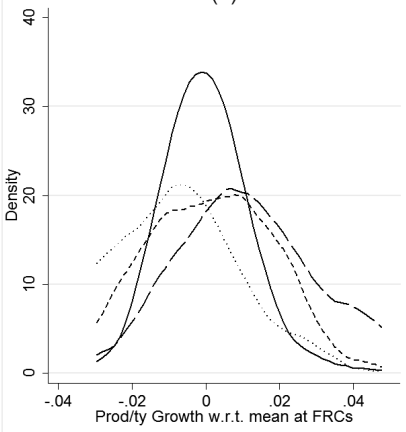

Figure 2.6: Density kernel: dispersion of productivity growth rates with respect to the FRCs' mean. The solid line bounds the density of the FRCs distribution, the long-dashed line the distribution of the CUCs, the short-dashed line the distribution of STCs, and the dotted line the distribution of the LGCs. Panel (a) shows the densities for all countries under FRCs, CUCs, STCs, and LGCs classifications, panel (b) excludes Nics, HInOECDs, LICs, and Frags countries.

\subsubsection{Addressing Concerns on the Measurement of Pro- ductivity}

In this section, we investigate whether the way MFP is accounted for leads to falsify the result that differences in levels of income are well correlated with differences in productivity. We revisit three major criticisms usually raised to the MFP approach, namely: i) misleading patterns introduced by the strict assumption of cross-country and over-time constant factor shares; ${ }^{31}$ ii) distortions due to problems associated with changes in a country's terms of trade; ${ }^{32}$ and iii) misleading insights into productivity across countries resulting from the socalled Gerschenkron effect. ${ }^{33}$ We find that differences in the overall MFP have

except that during the 2000s STCs and LGCs show better performance. The detailed results are available from the author.

${ }^{31}$ Gollin 2002, Pritchett 2000, and Kongsamut et al., 2001.

${ }^{32}$ For example, Levine and Renelt 1991, Bosworth and Collins 2003, Kohli 2004, Kehoe and Ruhl 2008. See also Ziesemer 1995b for a review.

${ }^{33}$ The Gerschenkron effect refers to the difficulties of making adequate comparisons upon the economic contributions of MFP - both over time and across countries-because technological progress is uneven across countries (Nuxoll 1994). In particular, the price of capital goods is lower and tends to decrease faster in advanced than backward countries. Thus, whenever a more-developed-country price index is used-or a more recent set of prices is used as a benchmark for making calculations in real terms-MFP levels of backward countries tend to report higher values than would be the case if each country's own prices were used instead. In other words, correcting for the Gerschenkron effect would lead to lower rates of MFP in 
less leverage than has been attributed in earlier research to explain differences of income per capita across countries.

Using the production function $Y=A K^{\alpha}$, the comparison between a given country " $i$ " and the group of countries at the frontier " $F$ " is given by the following ratio $^{34}$

$$
\left[A_{i} / A_{F}\right]=\left[Y_{i} / Y_{F}\right] /\left[K_{i} / K_{F}\right]^{\alpha}
$$

Note that in calculating productivity differences, we assume a common share of capital, $\alpha=0.33 .{ }^{35}$ Taking natural logs on each side of this equation, we get

$$
\ln \left[A_{i} / A_{F}\right]=\ln \left[Y_{i} / Y_{F}\right]-\alpha \ln \left[K_{i} / K_{F}\right]
$$

Rearranging this expression, we can decompose the differences in output across countries into differences due to capital, and differences due to productivity.

$$
\begin{aligned}
1-\frac{\ln \left[A_{i} / A_{F}\right]}{\ln \left[Y_{i} / Y_{F}\right]} & =\alpha \frac{\ln \left[K_{i} / K_{F}\right]}{\ln \left[Y_{i} / Y_{F}\right]} \\
& =\phi_{k i F}
\end{aligned}
$$

Let us define the ratio

$$
\ln \left[\kappa_{i} / \kappa_{F}\right]=\ln \left[K_{i} / K_{F}\right]-\ln \left[Y_{i} / Y_{F}\right]
$$

such that the righthand component of the last expression may be expressed as ${ }^{36}$

$$
\phi_{k i F}=\alpha+\alpha \frac{\ln \left[\kappa_{i} / \kappa_{F}\right]}{\ln \left[Y_{i} / Y_{F}\right]}
$$

Note that the second term on the right hand side measures the differences in the capital output ratio between country " $i$ " and countries at the frontier " $F$." This term is positive - it is, makes positive contributions to explain the output gap - whenever countries at the frontier have a larger capital output ratio, which can be summed up as follows

$$
\frac{\kappa_{i}}{Y_{i}}<<\frac{\kappa_{F}}{Y_{F}}
$$

Let us define a "percentage shortfall" as the output gap between a country and the frontier

$$
P=1-Y_{i} / Y_{F}
$$

backward countries. See Feenstra et al., 2015 for a technical discussion.

${ }^{34}$ See King and Levine 1994. Note that the analysis here does not use conventional adjustments of labor by human capital. This is because the econometric analysis in the following section is based on the cognitive non-routine category of workers who already are qualified by educational attainment.

${ }^{35}$ Note that changing the value of $\alpha$, i.e., increasing it, gives more weight to the capital contribution in these calculations.

${ }^{36}$ Note that this adjustment implies that if the capital output ratios are the same, there are still cross-country differences due to $\alpha$. 
Thus, from Equation (2.3) the corresponding contributions to the decomposition are obtained, namely the contribution accrued to the capital share component,

$$
\alpha P
$$

the contribution accrued to the capital output ratio,

$$
\left(\alpha \frac{\ln \left[\kappa_{i} / \kappa_{F}\right]}{\ln \left[Y_{i} / Y_{F}\right]}\right) P
$$

and the contribution accrued to productivity (the residual).

This decomposition is used in previous literature to show that, for the poorest countries, the fundamental problem to grow and catch up is associated to investments in capital, whereas for countries near the richest category, it is productivity. To illustrate the approach, in Figure 2.7a countries are split into quintiles based on increasing levels of capital per worker relative to the highest quintile. ${ }^{37}$ We observe a mechanical association between the percentage shortfall and the share of capital. For example, with $\alpha=0.33$ we find that the contribution of the share of capital is $0.33 \times 90 \%=0.30$, or $30 \%$, in the lowest quintile (Q1), and $0.33 \times 50 \%=17 \%$ in the 4 th quintile (Q4). Likewise, the capital output ratio is also affected by $\alpha$ - see the second part on the righthand side of Equation (2.3). In Figure 2.7a, another $10 \%$ of the shortfall in the lowest quintile (Q1), and 1\% of the shortfall in the 4th quintile (Q4), are explained by this component.

Adding up the share of capital and the capital output ratio allows us to obtain the total contribution of capital to the shortfall, i.e. $\phi_{k i F}$. In the lowest quintile, this contribution is $0.43 \times 90 \%=39 \%$, and in the 4th quintile it is $0.34 \times 50 \%=17 \%$. Thus, consistent with the standard analysis, we see that for countries in the lowest quintile insufficient capital seems to be an issue to explain the output gap, while in the subsequent quintiles productivity turns to be more important.

Let us turn now to the same sort of analysis, but using instead the classification of countries in this thesis. Figure $2.7 \mathrm{~b}$ indicates that countries in the LGCs group (group 1 in the horizontal axis) have a larger output shortfall, followed by STCs(2) and $\mathrm{CUCs}(3)$, with respect to the benchmark, the FRCs(4). Now, we find that the output gap of the LGCs (over 80\%), the STCs (circa 75\%), and the CUCs $(60 \%)$ are explained in roughly similar ways: $2 / 3$ by productivity, and $1 / 3$ by capital share. Notably, the capital output ratio play no role now - except for a small contribution to the STCs.

In Figure 2.7c we sweep away extreme country cases (Nics, HInOECDs, LICs, and Frags) - in order to focus on the behavior of middle-income countries (LMICs and UMICs) that can be expected under "normal circumstances." Now,

\footnotetext{
${ }^{37}$ For this standard use of the decomposition, see King and Levine 1994. The relevant data on physical capital stocks and output_rgdpna - are taken from the already referenced PWT V.8 (see Feenstra et al., 2015). Data availability - for capital and labor-imposes limitations on the number of countries available for analysis. There are 24 FRCs, 25 CUCs, 24 STCs, and 58 LGCs.
} 
we observe roughly similar output gaps among country classifications - higher for the CUCs though. As is evident from the figure, the mechanical contribution of the share of capital is roughly the same across country classifications - the exception being the slight contribution of the capital output ratio for STCs.

(a)

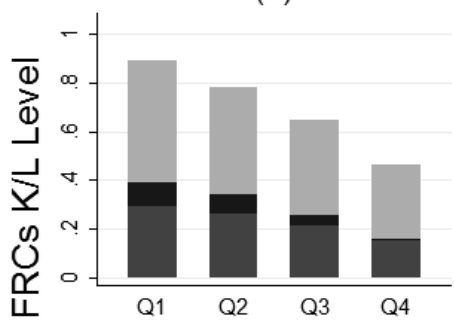

(d)

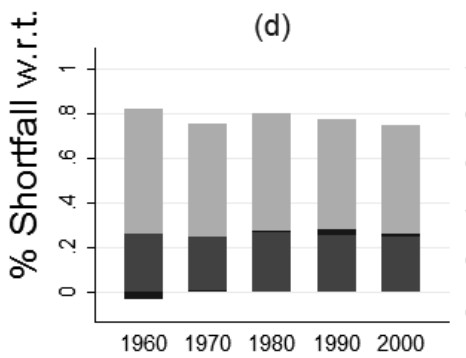

(b)

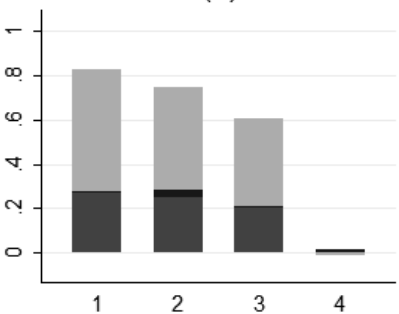

(e)

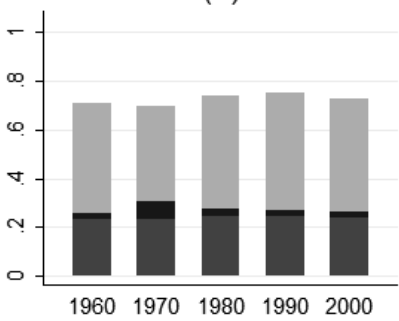

(c)



(f)

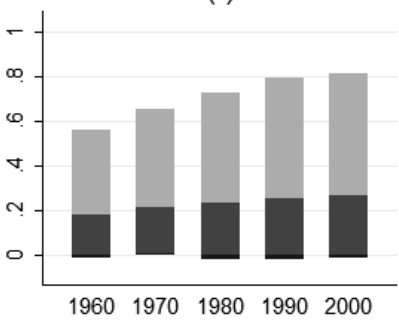

Figure 2.7: Percentage shortfall of CUCs, STCs and LGCs with respect to the FRCs. In all cases, dark-grey, black, and light-grey sections denote the contributions of the capital share, capital output ratio, and MFP, respectively (average across countries). Panels (a)-(c) are based on the average over countries in the period 1980-2010. Panel (a) shows the quintiles split used in previous studies. Panels (b)-(f) return to the classifications in this thesis (LGCs(1), STCs(2), CUCs(3), and FRCs(4)). Panel (b) shows the overall results for countries within each classifications. Panels (c)-(f) drop Nics, HInOECDs, LICs, and Frags. Panels (d)-(f) present the decade-by-decade performance of CUCs, STCs, and LGCs, respectively.

In Figures $2.7 \mathrm{~d}-2.7 \mathrm{f}$ the output gaps are calculated decade by decade - still for the middle-income countries case. We would expect - in line with the analysis in the previous section-large reductions in the gap of CUCs countries, no major changes in the gap of STCs countries, and large increases in the gap of LGCs countries. However, particularly from the 1980s onwards, we observe that the CUCs' gap declined just slightly from around $80 \%$ to circa $75 \%$ (Figure $2.7 \mathrm{~d}$ ), whereas the STCs' gap kept revolving around the $75 \%$ shortfall (Figure 2.7e), and the LGCs' increased from the 1960s to the 1990s and just slightly thereafter (Figure 2.7f). It seems apparent that - in particular for the CUCs 
countries - the productivity achievements implied by the small decline in the output gap are not big enough to explain the much larger increases in relative levels of income per capita discussed for this group of countries in the previous section.

The next question of interest is whether the latter assessments change somehow when we account for the above-mentioned criticisms on the measurement of MFP. Let us set Figures $2.7 \mathrm{~d}-2.7 \mathrm{f}$ a baseline to assess eventual changes in the output gap.

Regarding the risk of misleading patterns introduced by the strict assumption of cross-country and over-time constant factor shares, we already noted that modifications in the value of $\alpha$ in Equation (2.3) lead to trivial results. That is, increasing (reducing) this parameter gives more (less) weight to capital contribution in the calculations of the percentage shortfall. A more substantial modification of this parameter would be to take into account country-specific capital shares. To do so, the following modification to Equation (2.3) is needed ${ }^{38}$

$$
\phi_{k i F}=\alpha_{F}+\beta_{i}+\alpha_{F} \frac{\ln \left[\kappa_{i} / \kappa_{F}\right]}{\ln \left[Y_{i} / Y_{F}\right]}+\beta_{i} \frac{\ln \left[\kappa_{i}\right]}{\ln \left[Y_{i} / Y_{F}\right]}
$$

where $\beta_{i}=\alpha_{i}-\alpha_{F}$, i.e., the difference in the capital share between country "i" and countries at the frontier "F." The contributions to the shortfall are modified accordingly, namely the contribution of the capital share component,

$$
\left(\alpha_{F}+\beta_{i}\right) P
$$

the contribution of the capital output ratio,

$$
\left(\alpha_{F} \frac{\ln \left[\kappa_{i} / \kappa_{F}\right]}{\ln \left[Y_{i} / Y_{F}\right]}+\beta_{i} \frac{\ln \left[\kappa_{i}\right]}{\ln \left[Y_{i} / Y_{F}\right]}\right) P
$$

and productivity (the residual).

The first thing to note is that the use of country-specific capital shares leads to increasing the share of capital. Consider that the average of $\alpha_{F}$ increased from $0.36 \%$ in the $1960 \mathrm{~s}$ to $0.41 \%$ in the $2000 \mathrm{~s}$. In the same decades, the average of $\beta_{i}$ for the CUCs slightly decreased from $0.10 \%$ to $0.09 \%$, for the STCs increased slightly from $0.07 \%$ to $0.08 \%$, and for the LGCs decreased from $0.17 \%$ to $0.13 \%$. In other words, there are larger contribution of the share of capital to the output gap than in the baseline, and more so for LGCs (see Figures 2.8a-2.8c).

With regard to the contribution of the capital output ratio, we observe portions of the contribution of less than zero - in particular for the CUCs and LGCs from the 1980s onward (see Figures 2.8a and 2.8c). As Equation (2.4) indicates, these negative contributions imply that the capital output ratios where larger for these groups and periods than in FRCs countries. In turn, by adding up

\footnotetext{
${ }^{38}$ The use of country-specific capital shares is subject to the problem that the share of capital seems to be larger at lower levels of development, which partly owes to economic structure but also to mismeasurement (see Gollin 2002 and Pritchett 2000).
} 
(a)

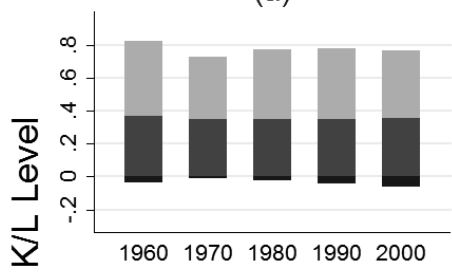

(d)



(b)

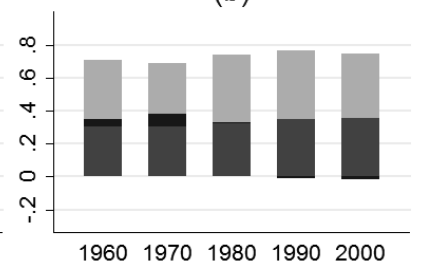

(e)

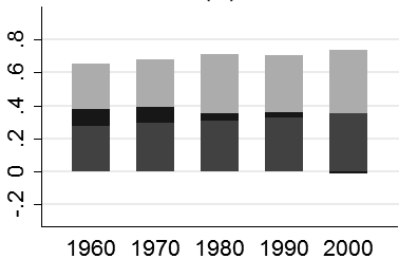

(h)

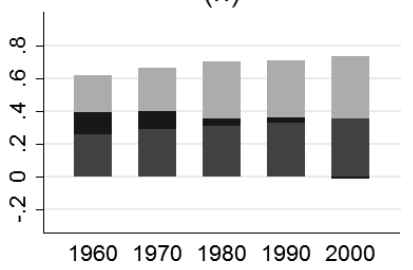

(c)



(f)

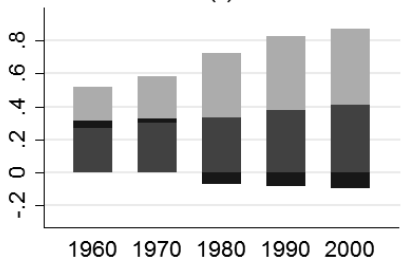

(i)

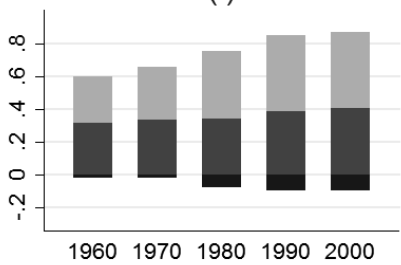

Figure 2.8: Development accounting decomposition of the determinants of countries' percentage shortfall. In all cases, dark-grey, black, and light-grey sections denote the contributions of the capital share, the capital output ratios, and MFP, respectively. Panels (a)-(c) are based on country-specific capital shares. Panels (d)-(f) take into account country-specific shares plus the "Gerschenkron effect." Panels (g)-(i) take into account country-specific capital shares plus the effect of terms of trade. 
both contributions, those accrued to the share of capital and the capital output ratio, it seems apparent that the relative stagnation of STCs and laggardness of LGCs are not - at least from the 1980s onwards - related to investment deficiencies (see Figures 2.8b and 2.8c). At the same time, we still observe small changes in the overall level of productivity that are inconsistent with the much larger changes in income per capita levels discussed in the previous sectionmore specifically in the case of CUCs countries (see Figure 2.8a).

The correction for the Gerschenkron effect is reported in Figures 2.8d-2.8f. ${ }^{39}$ We observe slightly smaller values of the output gap for CUCs and STCs, jointly with an increase in the capital output ratio component for the same countriesparticularly from the 1960s to the 1990s (see Figures 2.8d and 2.8e). Apparently, real output evaluated at each country's prices - rather than at international prices using PPP exchange rates - leads to reduce the ouput gap of CUCs and STCs. In addition, it seems that using each country's prices leads to lower capital output ratios in CUCs and STCs, which is consistent with the fact that the price of capital tends to be higher (and the corresponding quantity lower) in countries off the frontier. ${ }^{40}$ Notably, this adjustment leads to a lower contribution of productivity in explaining changes in the shortfall.

With regard to the effect of terms of trade, we do not find changes worthy of note with respect to the overall dynamics of the shortfall, or the contributions of capital and productivity in CUCs and STCs countries - compare Figures $2.8 \mathrm{~g}$ and $2.8 \mathrm{~h}$ with Figures $2.8 \mathrm{~d}$ and $2.8 \mathrm{e}$, respectively. But we see a slight increase in the shortfall of LGCs in the period of the 1960s-1980s (see Figure 2.8i), which suggests that the terms of trade for this group were weak - that is, through these decades LGCs countries apparently had lower than average prices for exports and/or higher than average prices for imports that ended up weakening their real GDP with respect to the frontier. ${ }^{41}$

All in all, the overall feature of note throughout Figures $2.8 \mathrm{a}-2.8 \mathrm{i}$ is the apparent absence of investment deficiencies as an explanation for the relative stagnation of STCs and laggardness of LGC countries. Capital output ratios seem to have played a role in explaining the shortfall of STCs countries - mainly through the 1960s and the 1970s - but these deficiencies were largely addressed by the 2000s without a corresponding improvement in economic activity as the shortfall even increased over time. In turn, LGCs countries apparently had capital output ratios even larger than FRCs in each decade between the 1980s and $2000 \mathrm{~s}$, but their shortfalls still were the largest.

Most remarkable, however, is that productivity changes over time do not fit the differences in economic achievement that were discussed in the preceding section-particularly with regard to the catching up achievements of the

\footnotetext{
${ }^{39}$ The PWT V.8. provides the data needed to calculate this effect (see Feenstra et al., 2015). We use rgdpo-real GDP on the output side - to address the Gerschenkron effect, and rgdpe-real GDP on the expenditure side- to correct, in addition, for the effect of terms of trade.

${ }^{40}$ Levine and Renelt 1991, Nuxoll 1994, Bosworth and Collins 2003. As pointed out by Feenstra et al., 2015, from consumption theory we know that those goods whose prices move down tend to have quantity increases and viceversa.

${ }^{41}$ See Feenstra et al., 2015.
} 
CUCs. We conclude that as long as the change in overall levels of productivity is not a factor to distinguish between the heterogeneous growth and catching-up achievements of our country classifications, a decomposition to study the economic contributions accrued to distinct sources of productivity - and thus the overall technology available to countries - is warranted.

\subsubsection{Efficiency and Technical Changes}

The technique of data envelopment analysis (DEA) has become instrumental to breaking down overall productivity changes into changes in efficiency (movements toward the frontier), and technical changes (shifts of the frontier itself). Such an approach is useful to make sense of a country's productivity changes that show up as movements to "close the gap" with the frontier and those that are "automatic" in the sense that they move together with the frontier without a marked tendency to reduce the gap. These features of the DEA analysis allow us to gain further insight into the subjects of interest in this thesis, namely the distinct contributions to economic growth that are driven by the adoption of foreign technologies and by local innovation.

Our interpretation is well founded on the methodological characteristics of the DEA technique. In this approach, the technical change component indicates how much each individual country leads to shifts of the frontier, which implies that the frontier is determined by the most productive countries based on the records from all countries in the sample. ${ }^{42}$ Since, in practice, the most important productive technologies are originated in just a small number of countries and then spread worldwide, ${ }^{43}$ it seems sensible to associate the technical change component with the ability of each individual country to "keep up" adopting state of the art technologies.

In turn, the efficiency change component indicates by how much each individual country manages to get closer to the frontier. Because reducing the gap depends essentially on the differential between a country's productivity and productivity at the frontier, it seems appropriate to associate the efficiency change with the ability (or alternatively the failure) of each individual country to make a more novel use of the same technology that is available to all countries, and we take it as an indication of the ability to innovate. ${ }^{44}$

Of course, the distinction between adoption and innovation is much more complex in reality. As has been pointed out earlier - in the introductory part of this thesis-(local) innovation cannot be plausibly held as "independent" of the diffusion/adoption of technological inventions and ideas developed elsewhere. The comparison based on the DEA decomposition provides, however, a neat way to capture the technology issues of the difference in economic growth

\footnotetext{
${ }^{42}$ Fare et al., 1994.

${ }^{43}$ Coe and Helpman 1995, Keller 2002.

${ }^{44}$ Earlier contributions that use the DEA technique in the context of cross-country comparisons are Fare et al., 1994 and Kummar and Russel 2002. Note that we use the notions of efficiency and technical change differently than Fare et al., 1994. They refer to changes in efficiency as catching up and changes in technology as innovation.
} 
across countries that are of importance in our discussion on methodological and statistical grounds, as we show next.

Consider the following problem that relates the (per worker) capital output ratio $(k / y)$ of country " $i$ " to the standards in the frontier " $F$ "

$$
\operatorname{Max}_{u, v} c_{i}=u^{\prime} k_{i} / v^{\prime} y_{i} \text {, s.t. } c_{F}=u^{\prime} k_{F} / v^{\prime} y_{F} \leq 1, u, v \geq 0
$$

where $u, v$ are parameters. Thus, if $c_{i} \geq 1$, country $i$ is efficient relative to the frontier, and inefficient otherwise. The diagram in Figure 2.9, illustrates the logic of this approach. ${ }^{45}$

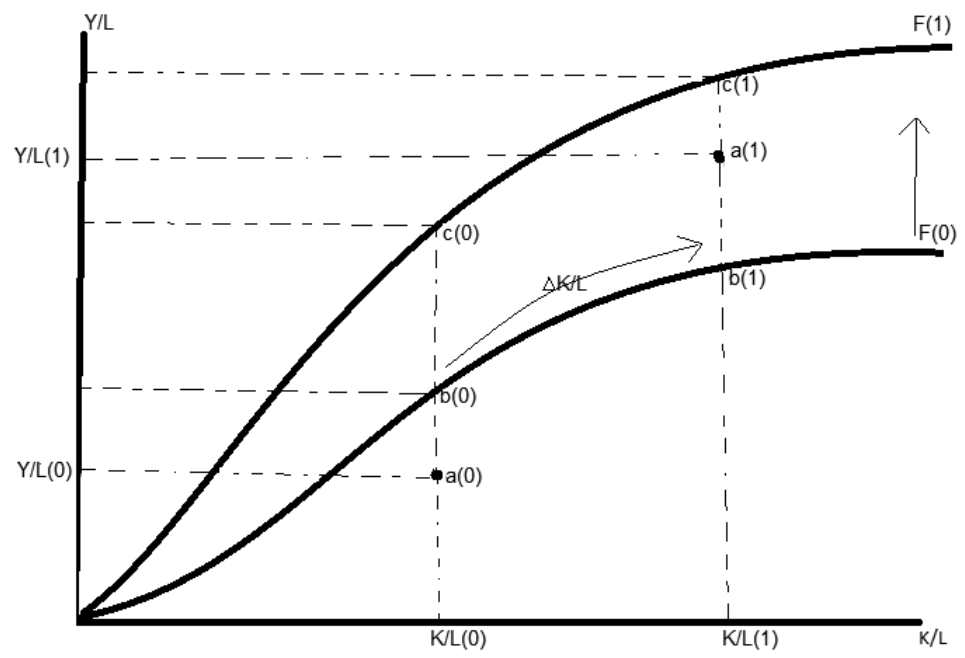

Figure 2.9: Data Envelopment Analysis (Diagram). For a country that moves from $a(0)$ to a(1) the overall change in productivity decomposes into technical and efficiency changes. The technical change (Tech-ch) is given by the distance $[c(1)-b(1)] \div[c(0)-b(0)]$. The efficiency change (Eff-ch) is given by the distance $[a(1)-c(1)] \div[a(0)$ $c(0)]$. The overall change in productivity (MFP-ch) is obtained by multiplying these indices, Tech-ch $\times$ Eff-ch. Output per worker may be recovered by multiplying changes in productivity and changes in capital per worker, i.e., MFP-ch× $k$.

Table 2.2 shows this decomposition for the decades $1980 \mathrm{~s}-2000 \mathrm{~s}$. There are five important elements worth highlighting that prevailed throughout this three decades period:

1. MFP changes of the CUCs were increasing, i.e., from 1.13 in the 1980 s to 1.76 in the $2000 \mathrm{~s}$, and outperformed, by far, the changes of MFP for any other group;

\footnotetext{
${ }^{45}$ Los and Timmer 2005.
} 


\begin{tabular}{lccccccc}
\hline Groups & Decade & N & Eff-ch & Tech-ch & MFP-ch & k/l-ch & A-ch \\
\hline \multirow{2}{*}{ All Countries } & & & & & & \\
\multirow{2}{*}{ FRCs } & 1980 & 24 & 0.994 & 1.047 & 1.041 & 1.069 & 1.051 \\
& 1990 & 24 & 0.902 & 1.277 & 1.150 & 1.194 & 1.177 \\
& 2000 & 24 & 0.893 & 1.402 & 1.248 & 1.314 & 1.280 \\
\hline CUCs & 1980 & 22 & 1.110 & 1.021 & 1.134 & 1.130 & 1.174 \\
& 1990 & 22 & 1.200 & 1.154 & 1.362 & 1.423 & 1.516 \\
& 2000 & 22 & 1.366 & 1.161 & 1.507 & 1.756 & 1.838 \\
\hline \multirow{2}{*}{ STCs } & 1980 & 24 & 0.984 & 1.017 & 1.001 & 1.056 & 1.019 \\
& 1990 & 24 & 0.954 & 1.136 & 1.073 & 1.167 & 1.128 \\
& 2000 & 24 & 1.185 & 1.043 & 1.190 & 1.325 & 1.345 \\
\hline \multirow{2}{*}{ LGCS } & 1980 & 58 & 0.905 & 1.041 & 0.938 & 1.008 & 0.942 \\
& 1990 & 58 & 0.824 & 1.107 & 0.901 & 0.986 & 0.898 \\
& 2000 & 58 & 1.132 & 0.920 & 0.979 & 1.000 & 0.977
\end{tabular}

Lower and Upper Middle-Income Countries

\begin{tabular}{llllllll} 
FRCs & 1980 & 24 & 0.994 & 1.047 & 1.041 & 1.069 & 1.051 \\
& 1990 & 24 & 0.902 & 1.277 & 1.150 & 1.194 & 1.177 \\
& 2000 & 24 & 0.893 & 1.402 & 1.248 & 1.314 & 1.280 \\
\hline CUCs & 1980 & 13 & 1.128 & 1.024 & 1.156 & 1.113 & 1.180 \\
& 1990 & 13 & 1.298 & 1.119 & 1.429 & 1.403 & 1.562 \\
& 2000 & 13 & 1.549 & 1.044 & 1.549 & 1.758 & 1.953 \\
\hline STCs & 1980 & 18 & 0.989 & 1.007 & 0.996 & 1.061 & 1.014 \\
& 1990 & 18 & 0.921 & 1.130 & 1.033 & 1.204 & 1.098 \\
& 2000 & 18 & 1.085 & 1.056 & 1.121 & 1.359 & 1.303 \\
\hline \multirow{2}{*}{ LGCS } & 1980 & 26 & 0.911 & 1.019 & 0.925 & 1.011 & 0.928 \\
& 1990 & 26 & 0.778 & 1.145 & 0.882 & 0.988 & 0.879 \\
& 2000 & 26 & 0.904 & 1.069 & 0.928 & 1.006 & 0.933 \\
\hline
\end{tabular}

Table 2.2: Multi-factorial productivity based on DEA decomposition. The Malmquist-based index of mfp (Mfp-ch) is decomposed into efficiency change (Eff-ch) and technical change (Tech-ch), plus the corresponding changes in capital per worker $(k / l-c h)$. The top panel shows all the countries in the sample. The panel at the bottom excludes extreme cases, i.e., Nics, HInOECDs, Frags and LICs. The last column shows the conventional residual MFP term based on a $C D$ function with $\alpha=0.33$. 
2. the main trigger of this performance by the CUCs countries was efficiency, the indices of efficiency change from the 1980s (1.11) to the 2000s (1.37) were higher and increased faster for this group than any other, i.e., the CUCs were closing the gap with the frontier;

3. the good behavior of the CUCs is associated also to large increases in capital per worker - from 1.13 in the 1980 s to 1.76 in the 2000 s - which implies that even for countries in the catching-up path productivity achievements are closely related to the acquisition of foreign technology;

4. the productivity changes obtained from the DEA framework are similar to those that are obtained from the conventional - growth accounting analysis, which can be seen by comparing the DEA MFP index (MFP-ch) and the productivity index obtained from the conventional approach (Ach);

5. the good performance of CUCs does not hinge only on the exceptional dynamics of Nics and HInOECDs. The lower panel of the table shows that the above insights also hold when these extreme country cases are dropped in order to rely on middle-income countries.

Also of note in Table 2.2 is that MFP changes in FRCs are leveraged mainly on technical changes, which we can relate to the development of new technology at the frontier. In fact, FRC countries systematically define the frontier technology in the DEA methodology analysis - a fact also documented in previous literature using the DEA method. ${ }^{46}$ Finally, it is clear that, over time, all countries managed to improve their productivity performance, though STCs less so than CUCs, and LGCs even less so or not at all. Notably, this is a fact largely consistent with the country classification in this chapter, and provides reassuring empirical support to our argument about the reasons for their distinct dynamics.

\subsection{Concluding Remarks}

This chapter has been instrumental to show that the ability of countries to catch up is a rare event. Even countries classified in other literatures as emerging or rapidly growing because growth has, recently, taken place there at faster rates than in the past would not necessarily classify here as successful catch-up cases. This is so, basically, because the patterns of growth and catch-up would need to be sustainable over long periods of time. We have provided a simple framework for considering differences in these patterns across countries, and established classifications consistent with the fact that-with respect to countries at the frontier-some countries have been successfully catching up, whereas others have remained stagnant, and others have lagged progressively behind.

\footnotetext{
${ }^{46}$ Fare et al., 1994 and Los and Timmer 2005.
} 
The extrapolation formula that we have put forward draws attention to the fact that catching up is a relative and dynamic phenomenon, as the frontier is a moving target. Our analysis has shown that, notwithstanding the final conditions, it would take a longer time period for today laggard and stagnant countries to reach the frontier in comparison with countries that show the catch up pattern. In particular, today laggard countries are between 227 and 302 years short of the catch-up horizon, and stagnant countries between 38 and 191 years. In comparison, countries that show consistent historical catch-up patterns are between 9 and 54 years off the frontier.

Though we find that differences in levels of income per capita and differences in the productivity of the working force are closely correlated across countriesas other studies do - we conclude differently from most analyses in the literature. In particular, we find that changes in overall levels of MFP over time are insufficient to explain why successful catching-up countries have managed to reduce their income gaps. Thus, we argue that differences in the overall level of productivity have less leverage than is commonly understood.

In looking for explanations to this ambiguity, we find that what is most different about catching-up countries has been their increasing efficiency changes over time. Our discussion is conducted in a context where efficiency changes are related to the innovation capability of a country - in comparison with technical changes that we have related to the adoption of foreign technology. We have pointed out, however, that the DEA-based decomposition upon which our calculations are made provides us, to this stage, only with some important insights on the statistical features of technology across countries. Such a decomposition is much more complex in reality on the grounds that, as we have advertised, (local) innovation is not independent of the diffusion/adoption of technological inventions and ideas developed elsewhere.

Based on the empirical evidence that we have drawn in this chapter, our core conclusion is that while productivity achievements across countries are closely related to the advance of the frontier technology, there are important differences in the ability of some countries to "close the gap". Thus, we are in the position to suggest the need for a theoretical account to explain that behavior, namely the ability of countries to innovate and how it relates to the distinct growth and catching-up experiences that have been observed across countries. That shall be our endeavor in the next chapter. 


\section{Appendix 2A}

\begin{tabular}{|c|c|c|c|c|c|c|c|c|}
\hline & country & $1950 \mathrm{~s}$ & $1960 \mathrm{~s}$ & $1970 \mathrm{~s}$ & $1980 \mathrm{~s}$ & $1990 \mathrm{~s}$ & $2000 \mathrm{~s}$ & $\begin{array}{l}\text { Thresho } \\
\text { Ratio }\end{array}$ \\
\hline & \multicolumn{8}{|l|}{ FRCs Countries } \\
\hline 1 & Australia & 142.0 & 127.3 & 114.5 & 108.8 & 106.1 & 107.3 & \\
\hline 2 & Austria & 82.7 & 93.1 & 99.9 & 102.6 & 103.8 & 101.6 & \\
\hline 3 & Belgium & 96.0 & 94.8 & 99.5 & 99.5 & 99.1 & 95.2 & \\
\hline 4 & Canada & 135.4 & 122.2 & 117.8 & 117.0 & 107.0 & 106.2 & \\
\hline 5 & Denmark & 109.3 & 114.7 & 109.0 & 108.1 & 105.5 & 100.0 & \\
\hline 6 & Finland & 78.1 & 81.0 & 86.4 & 93.6 & 86.7 & 92.9 & \\
\hline 7 & France & 86.9 & 93.2 & 99.2 & 98.5 & 94.4 & 87.9 & \\
\hline 8 & Germany & 88.9 & 105.8 & 104.7 & 106.1 & 106.9 & 97.8 & \\
\hline 9 & Greece & 49.5 & 60.9 & 79.9 & 72.9 & 63.9 & 67.7 & \\
\hline 10 & Iceland & 87.4 & 85.4 & 89.1 & 100.3 & 89.1 & 92.8 & \\
\hline 11 & Ireland & 79.4 & 75.5 & 75.9 & 76.1 & 94.3 & 129.0 & \\
\hline 12 & Italy & 69.5 & 80.7 & 90.8 & 95.7 & 95.4 & 86.1 & \\
\hline 13 & Japan & 35.4 & 54.0 & 88.9 & 100.2 & 108.6 & 94.1 & \\
\hline 14 & Luxembourg & 148.2 & 131.2 & 122.6 & 125.3 & 155.6 & 173.1 & \\
\hline 15 & Netherlands & 113.7 & 116.6 & 118.5 & 111.1 & 112.6 & 111.2 & \\
\hline 16 & New Zealand & 121.6 & 114.6 & 93.8 & 83.1 & 74.2 & 72.8 & \\
\hline 17 & Norway & 153.9 & 148.7 & 150.1 & 168.6 & 175.7 & 175.5 & \\
\hline 18 & Portugal & 39.9 & 46.4 & 55.4 & 57.2 & 63.7 & 61.8 & \\
\hline 19 & Spain & 54.0 & 69.6 & 77.6 & 73.3 & 77.3 & 78.9 & \\
\hline 20 & Sweden & 113.5 & 113.6 & 105.6 & 101.2 & 93.0 & 95.8 & \\
\hline 21 & Switzerland & 196.9 & 189.4 & 165.2 & 150.0 & 133.8 & 119.0 & \\
\hline 22 & Turkey & 36.7 & 32.5 & 32.2 & 30.5 & 32.4 & 32.2 & \\
\hline 23 & United Kingdom & 121.6 & 106.4 & 93.6 & 91.2 & 91.9 & 95.1 & \\
\hline 24 & United States & 159.7 & 142.3 & 129.9 & 128.8 & 128.8 & 125.9 & \\
\hline
\end{tabular}

Table 2A.1: Country classifications on the base of income per capita relative to the FRCs average. Each column shows the average income per capita in the decade.

Source: Author calculations based on PWT V8. (We use the variable rgdpcna divided by the country's population) 


\begin{tabular}{|c|c|c|c|c|c|c|c|c|}
\hline & country & $1950 \mathrm{~s}$ & $1960 \mathrm{~s}$ & $1970 \mathrm{~s}$ & $1980 \mathrm{~s}$ & $1990 \mathrm{~s}$ & $2000 \mathrm{~s}$ & $\begin{array}{l}\text { Threshol } \\
\text { Ratio }\end{array}$ \\
\hline & \multicolumn{8}{|l|}{ CUCs Countries } \\
\hline 1 & Botswana & & 4.7 & 8.4 & 14.4 & 21.3 & 26.1 & 5.58 \\
\hline 2 & China & & 3.1 & 3.0 & 4.6 & 8.5 & 16.2 & 5.27 \\
\hline 3 & Korea, Republic of & 16.3 & 15.2 & 21.8 & 34.8 & 57.4 & 73.0 & 4.49 \\
\hline 4 & Taiwan & 19.5 & 21.7 & 30.6 & 46.4 & 69.3 & 81.5 & 4.17 \\
\hline 5 & Singapore & & 31.6 & 49.3 & 71.8 & 97.9 & 108.6 & 3.43 \\
\hline 6 & Maldives & & & 9.2 & 13.9 & 21.3 & 28.1 & 3.06 \\
\hline 7 & Malta & & 20.4 & 33.1 & 46.1 & 56.1 & 58.3 & 2.86 \\
\hline 8 & Thailand & 7.7 & 7.7 & 10.8 & 13.5 & 20.6 & 21.7 & 2.81 \\
\hline 9 & Bhutan & & & 5.5 & 6.4 & 9.9 & 13.2 & 2.42 \\
\hline 10 & Hong Kong & & 48.8 & 60.0 & 88.2 & 107.9 & 111.1 & 2.28 \\
\hline 11 & Malaysia & & 15.4 & 19.0 & 23.1 & 29.2 & 31.2 & 2.02 \\
\hline 12 & St. Kitts \& Nevis & & & 16.8 & 24.1 & 31.8 & 33.7 & 2.00 \\
\hline 13 & Cyprus & 32.1 & 31.7 & 38.6 & 52.7 & 62.5 & 63.6 & 1.98 \\
\hline 14 & Vietnam & & & 3.7 & 4.0 & 5.0 & 7.2 & 1.96 \\
\hline 15 & Macao & & & 63.6 & 90.7 & 98.5 & 114.7 & 1.80 \\
\hline 16 & Grenada & & & 11.0 & 13.4 & 16.1 & 18.3 & 1.66 \\
\hline 17 & St.Vincent \& Gren. & & & 12.2 & 14.0 & 17.9 & 19.9 & 1.63 \\
\hline 18 & Antigua and Barbuda & & & 21.5 & 29.5 & 36.2 & 34.7 & 1.62 \\
\hline 19 & Israel & 45.3 & 54.7 & 79.9 & 74.6 & 76.0 & 72.2 & 1.59 \\
\hline 20 & Egypt & 8.2 & 7.4 & 7.6 & 10.6 & 12.2 & 13.0 & 1.59 \\
\hline 21 & Indonesia & & 6.1 & 5.9 & 7.5 & 9.7 & 9.7 & 1.58 \\
\hline 22 & Tunisia & & 11.7 & 15.1 & 15.7 & 15.7 & 17.8 & 1.53 \\
\hline 23 & Dominica & & & 18.5 & 23.1 & 27.5 & 28.0 & 1.51 \\
\hline 24 & Romania & & 18.6 & 29.6 & 37.5 & 25.3 & 27.6 & 1.48 \\
\hline 25 & Laos & & & 4.1 & 4.4 & 4.8 & 6.0 & 1.45 \\
\hline 26 & Oman & & & 48.2 & 68.9 & 68.2 & 69.9 & 1.45 \\
\hline 27 & Cape Verde & & 6.3 & 5.6 & 5.8 & 6.4 & 8.4 & 1.34 \\
\hline
\end{tabular}

Table 2A.2: Country classifications on the base of income per capita relative to the FRCs average. Each column shows the average income per capita in the decade. Countries in the CUCs classification are determined on the base of the threshold ratio between the last and first decade with information being larger than 1.25, i.e. for Egypt it is 13.03/8.20=1.59, for Vietnam it is 7.22/3.69=1.96

Source: Author calculations based on PWT V8. (We use the variable rgdpcna divided by the country's population) 


\begin{tabular}{|c|c|c|c|c|c|c|c|c|}
\hline & country & $1950 \mathrm{~s}$ & $1960 \mathrm{~s}$ & $1970 \mathrm{~s}$ & $1980 \mathrm{~s}$ & $1990 \mathrm{~s}$ & $2000 \mathrm{~s}$ & $\begin{array}{l}\text { Thresho } \\
\text { Ratio }\end{array}$ \\
\hline & STCs Countries & & & & & & & \\
\hline 1 & St. Lucia & & & 19.2 & 22.6 & 26.2 & 23.3 & 1.22 \\
\hline 2 & Panama & 26.3 & 27.6 & 31.0 & 31.7 & 29.9 & 31.7 & 1.20 \\
\hline 3 & Trinidad \& Tobago & 42.9 & 52.3 & 50.4 & 46.0 & 33.3 & 49.8 & 1.16 \\
\hline 4 & Sri Lanka & 9.1 & 7.4 & 7.0 & 7.9 & 8.9 & 10.5 & 1.16 \\
\hline 5 & Bulgaria & & & 25.3 & 33.5 & 25.9 & 28.9 & 1.14 \\
\hline 6 & Dominican Republic & 18.8 & 16.9 & 18.5 & 18.6 & 17.8 & 20.7 & 1.10 \\
\hline 7 & Belize & & & 19.2 & 17.1 & 18.7 & 20.2 & 1.05 \\
\hline 8 & Brazil & 21.6 & 23.1 & 28.8 & 29.3 & 24.6 & 22.6 & 1.05 \\
\hline 9 & India & 7.4 & 6.4 & 5.2 & 5.2 & 5.9 & 7.5 & 1.01 \\
\hline 10 & Lesotho & & 4.0 & 4.0 & 3.8 & 4.0 & 4.0 & 1.00 \\
\hline 11 & Mongolia & & & 10.8 & 12.5 & 9.4 & 10.2 & 0.94 \\
\hline 12 & Poland & & & 44.1 & 38.9 & 33.6 & 41.2 & 0.93 \\
\hline 13 & Swaziland & & & 12.6 & 12.7 & 13.1 & 11.8 & 0.93 \\
\hline 14 & Hungary & & & 51.3 & 55.1 & 42.8 & 46.4 & 0.90 \\
\hline 15 & Cambodia & & & 4.8 & 2.8 & 3.0 & 4.4 & 0.90 \\
\hline 16 & Mauritius & 29.2 & 18.6 & 15.7 & 17.5 & 22.4 & 25.6 & 0.88 \\
\hline 17 & Sudan & & & 6.4 & 5.0 & 4.6 & 5.5 & 0.86 \\
\hline 18 & Albania & & & 19.7 & 17.7 & 11.8 & 16.6 & 0.84 \\
\hline 19 & Fiji & & 13.6 & 13.7 & 12.2 & 12.0 & 11.4 & 0.84 \\
\hline 20 & Morocco & 10.8 & 10.3 & 9.6 & 9.3 & 8.7 & 8.9 & 0.83 \\
\hline 21 & Pakistan & 8.1 & 6.9 & 6.5 & 6.9 & 6.9 & 6.6 & 0.82 \\
\hline 22 & Chile & 40.6 & 35.1 & 26.4 & 23.6 & 30.0 & 33.4 & 0.82 \\
\hline 23 & Syria & & 14.4 & 14.1 & 14.4 & 12.2 & 11.7 & 0.81 \\
\hline 24 & Costa Rica & 32.4 & 29.5 & 29.9 & 25.1 & 24.5 & 25.3 & 0.78 \\
\hline
\end{tabular}

Table 2A.3: Country classifications on the base of income per capita relative to the FRCs average. Each column shows the average income per capita in the decade. Countries in the STCs classification are determined on the base of the threshold ratio between the last and first decade being larger than 0.75 and smaller than 1.25, i.e. for St. Lucia it is 23.3/19.2=1.22, for Costa Rica it is 25.3/32.4=0.78

Source: Author calculations based on PWT V8. (We use the variable rgdpcna divided by the country's population) 


\begin{tabular}{|c|c|c|c|c|c|c|c|c|}
\hline & country & $1950 \mathrm{~s}$ & $1960 \mathrm{~s}$ & $1970 \mathrm{~s}$ & $1980 \mathrm{~s}$ & $1990 \mathrm{~s}$ & $2000 \mathrm{~s}$ & $\begin{array}{l}\text { Threshol } \\
\text { Ratio } \\
\end{array}$ \\
\hline & LGCs Countries & & & & & & & \\
\hline 1 & Mexico & 48.6 & 47.4 & 46.3 & 45.6 & 38.7 & 36.1 & 0.74 \\
\hline 2 & Mali & & 3.3 & 2.6 & 2.5 & 2.5 & 2.4 & 0.73 \\
\hline 3 & Congo, Republic of & & 11.5 & 12.0 & 14.5 & 10.3 & 8.3 & 0.72 \\
\hline 4 & Mozambique & & 2.5 & 2.1 & 1.5 & 1.3 & 1.8 & 0.70 \\
\hline 5 & Ecuador & 24.6 & 20.4 & 22.1 & 21.6 & 18.3 & 16.9 & 0.69 \\
\hline 6 & Burkina Faso & & 3.9 & 3.3 & 2.8 & 2.5 & 2.6 & 0.66 \\
\hline 7 & Nepal & & 4.8 & 3.5 & 3.1 & 3.2 & 3.1 & 0.65 \\
\hline 8 & Colombia & 30.3 & 24.5 & 23.2 & 22.6 & 21.9 & 19.6 & 0.65 \\
\hline 9 & Malawi & & 2.8 & 3.5 & 2.9 & 2.2 & 1.8 & 0.64 \\
\hline 10 & Gabon & & 52.8 & 87.3 & 65.2 & 49.5 & 33.9 & 0.64 \\
\hline 11 & Suriname & & & 24.3 & 21.2 & 16.1 & 15.1 & 0.62 \\
\hline 12 & Benin & & 6.3 & 5.1 & 4.8 & 4.1 & 3.8 & 0.61 \\
\hline 13 & Bangladesh & & 6.3 & 4.0 & 3.4 & 3.3 & 3.7 & 0.59 \\
\hline 14 & Tanzania & & 5.0 & 4.2 & 3.1 & 2.8 & 2.9 & 0.59 \\
\hline 15 & Paraguay & 21.6 & 16.6 & 16.1 & 18.4 & 15.7 & 12.1 & 0.56 \\
\hline 16 & Iraq & & & 19.4 & 18.2 & 9.1 & 10.7 & 0.55 \\
\hline 17 & Lebanon & & & 55.1 & 36.8 & 31.3 & 30.2 & 0.55 \\
\hline 18 & Guatemala & 21.3 & 17.9 & 17.6 & 14.6 & 12.5 & 11.5 & 0.54 \\
\hline 19 & Mauritania & & 10.6 & 11.1 & 8.1 & 6.4 & 5.5 & 0.52 \\
\hline 20 & Philippines & 17.8 & 15.7 & 13.9 & 12.1 & 9.6 & 9.2 & 0.52 \\
\hline 21 & El Salvador & 2.6 & 2.2 & 1.9 & 1.3 & 1.3 & 1.3 & 0.51 \\
\hline 22 & Angola & & & 18.8 & 12.0 & 8.1 & 9.5 & 0.51 \\
\hline 23 & Sao Tome and Principe & & & 8.8 & 7.2 & 4.9 & 4.5 & 0.51 \\
\hline 24 & Namibia & & 25.1 & 22.3 & 17.2 & 13.2 & 12.7 & 0.50 \\
\hline 25 & Rwanda & & 5.6 & 4.2 & 4.1 & 2.8 & 2.8 & 0.50 \\
\hline 26 & Jordan & & 27.4 & 16.1 & 19.1 & 12.7 & 13.3 & 0.49 \\
\hline 27 & Cameroon & & 11.4 & 9.7 & 10.2 & 5.9 & 5.2 & 0.46 \\
\hline 28 & Burundi & & 3.4 & 3.2 & 2.9 & 2.2 & 1.5 & 0.46 \\
\hline 29 & Chad & & 8.7 & 5.9 & 3.9 & 3.6 & 4.0 & 0.46 \\
\hline 30 & Uruguay & 58.2 & 39.9 & 31.9 & 29.3 & 29.7 & 26.4 & 0.45 \\
\hline 31 & Jamaica & & 29.2 & 24.0 & 16.1 & 16.2 & 13.2 & 0.45 \\
\hline 32 & Peru & 38.5 & 36.6 & 30.1 & 23.4 & 16.6 & 17.3 & 0.45 \\
\hline 33 & Argentina & 67.1 & 56.4 & 49.0 & 37.1 & 32.7 & 29.8 & 0.44 \\
\hline 34 & Guinea & & 7.0 & 4.6 & 4.1 & 3.3 & 3.1 & 0.44 \\
\hline 35 & South Africa & 48.6 & 43.9 & 37.0 & 30.4 & 22.3 & 21.0 & 0.43 \\
\hline 36 & Ghana & & 12.6 & 9.0 & 5.8 & 5.3 & 5.3 & 0.42 \\
\hline 37 & Iran & & 73.1 & 54.9 & 32.9 & 28.2 & 30.3 & 0.41 \\
\hline 38 & Comoros & & 7.1 & 5.9 & 5.4 & 3.9 & 2.9 & 0.41 \\
\hline 39 & Honduras & 22.0 & 15.8 & 12.8 & 11.1 & 9.4 & 8.8 & 0.40 \\
\hline 40 & Uganda & 8.3 & 6.5 & 4.6 & 2.6 & 2.7 & 3.1 & 0.38 \\
\hline 41 & Ethiopia & 4.7 & 4.3 & 3.1 & 2.4 & 1.6 & 1.7 & 0.36 \\
\hline 42 & Zimbabwe & & 31.1 & 28.5 & 21.9 & 18.4 & 11.2 & 0.36 \\
\hline 43 & Gambia, The & & 12.3 & 8.6 & 6.8 & 5.1 & 4.4 & 0.36 \\
\hline 44 & Senegal & & 12.0 & 7.6 & 5.9 & 4.6 & 4.2 & 0.35 \\
\hline 45 & Nigeria & 12.9 & 10.2 & 8.7 & 5.4 & 4.0 & 4.5 & 0.35 \\
\hline 46 & Cote d'Ivoire & & 12.4 & 12.1 & 8.1 & 5.8 & 4.3 & 0.35 \\
\hline 47 & Kenya & 11.0 & 8.2 & 6.1 & 5.4 & 4.4 & 3.6 & 0.32 \\
\hline 48 & Togo & & 7.8 & 6.8 & 4.6 & 3.4 & 2.4 & 0.31 \\
\hline 49 & Bolivia & 32.8 & 23.4 & 17.6 & 12.5 & 10.5 & 9.6 & 0.29 \\
\hline 50 & Sierra Leone & & 7.6 & 6.3 & 5.3 & 3.2 & 2.2 & 0.29 \\
\hline 51 & Zambia & & 13.1 & 9.8 & 6.2 & 4.0 & 3.3 & 0.25 \\
\hline 52 & Central African Rep. & & 7.7 & 5.2 & 3.5 & 2.5 & 1.9 & 0.24 \\
\hline 53 & Madagascar & & 10.1 & 7.2 & 4.6 & 3.1 & 2.5 & 0.24 \\
\hline 54 & Djibouti & & & 24.4 & 11.8 & 7.0 & 5.6 & 0.23 \\
\hline 55 & Guinea-Bissau & & 11.0 & 6.0 & 4.0 & 3.5 & 2.5 & 0.23 \\
\hline 56 & Niger & & 8.5 & 4.9 & 3.2 & 2.0 & 1.6 & 0.19 \\
\hline 57 & Liberia & & & 7.4 & 4.8 & 1.1 & 1.2 & 0.17 \\
\hline 58 & Congo, Dem. Rep. & 8.7 & 6.5 & 4.4 & 2.7 & 1.2 & 0.7 & 0.08 \\
\hline
\end{tabular}

Table 2A.4: Country classifications on the base of income per capita relative to the FRCs average. The LGCs is determined on the base of a threshold ratio smaller than 0.75.

Source: Author calculations based on PWT V8. 


\begin{tabular}{|c|c|c|c|c|c|c|c|}
\hline & country & Nics & LIC & LMI & UMI & HInonOECDs & Frags \\
\hline & CUCs Countries & & & & & & \\
\hline 1 & Egypt & & & 1 & & & 1 \\
\hline 2 & Thailand & & & & 1 & & \\
\hline 3 & Cyprus & & & & & 1 & \\
\hline 4 & Taiwan & 1 & & & & 1 & \\
\hline 5 & Israel & & & & & & \\
\hline 6 & Cape Verde & & & 1 & & & \\
\hline 7 & Indonesia & & & 1 & & & \\
\hline 8 & Botswana & & & & 1 & & \\
\hline 9 & China & & & & 1 & & \\
\hline 10 & Malaysia & & & & 1 & & \\
\hline 11 & Romania & & & & 1 & & \\
\hline 12 & Tunisia & & & & 1 & & \\
\hline 13 & Hong Kong & 1 & & & & 1 & \\
\hline 14 & Singapore & 1 & & & & 1 & \\
\hline 15 & Malta & & & & & 1 & \\
\hline 16 & Korea, Republic of & 1 & & & & & \\
\hline 17 & Bhutan & & & 1 & & & \\
\hline 18 & Laos & & & 1 & & & \\
\hline 19 & Vietnam & & & 1 & & & \\
\hline 20 & Dominica & & & & 1 & & \\
\hline 21 & Grenada & & & & 1 & & \\
\hline 22 & Maldives & & & & 1 & & \\
\hline 23 & St.Vincent \& Grenadines & & & & 1 & & \\
\hline 24 & Antigua and Barbuda & & & & & 1 & \\
\hline 25 & Macao & & & & & 1 & \\
\hline 26 & Oman & & & & & 1 & \\
\hline 27 & St. Kitts \& Nevis & & & & & 1 & \\
\hline
\end{tabular}

Table 2A.5: CUCs countries subgroups. Classification into the Low-IncomeCountries (LIC), Lower Middle Income (LMI), Upper Middle Income (UMI), HighIncome-non-OECD-Countries (HInOECDs), South-East Nics (Nics), and fragile states (Frags). Income classifications are drawn from World Bank income classifications, fragile countries are classified according to the Fund for Peace and the magazine Foreign Policy. Countries on display are those considered to be under alert, high alert, and very high alert. 


\begin{tabular}{|c|c|c|c|c|c|c|}
\hline & country & LIC & LMI & UMI & HInonOECDs & Frags \\
\hline & STCs Countries & & & & & \\
\hline 1 & Pakistan & & 1 & & & 1 \\
\hline 2 & Sri Lanka & & 1 & & & 1 \\
\hline 3 & India & & 1 & & & \\
\hline 4 & Morocco & & 1 & & & \\
\hline 5 & Brazil & & & 1 & & \\
\hline 6 & Costa Rica & & & 1 & & \\
\hline 7 & Dominican Republic & & & 1 & & \\
\hline 8 & Mauritius & & & 1 & & \\
\hline 9 & Panama & & & 1 & & \\
\hline 10 & Trinidad \& Tobago & & & & 1 & \\
\hline 11 & Chile & & & & & \\
\hline 12 & Syria & & 1 & & & 1 \\
\hline 13 & Lesotho & & 1 & & & \\
\hline 14 & Fiji & & & 1 & & \\
\hline 15 & Cambodia & 1 & & & & \\
\hline 16 & Sudan & & 1 & & & 1 \\
\hline 17 & Mongolia & & 1 & & & \\
\hline 18 & Swaziland & & 1 & & & \\
\hline 19 & Albania & & & 1 & & \\
\hline 20 & Belize & & & 1 & & \\
\hline 21 & Bulgaria & & & 1 & & \\
\hline 22 & St. Lucia & & & 1 & & \\
\hline 23 & Hungary & & & & & \\
\hline 24 & Poland & & & & & \\
\hline
\end{tabular}

Table 2A.6: STCs countries subgroups. Classification into the Low-Income-Countries $(L I C)$, Lower Middle Income (LMI), Upper Middle Income (UMI), High-Income-nonOECD-Countries (HInOECDs), and fragile states (Frags). Income classifications are drawn from World Bank income classifications, fragile countries are classified according to the Fund for Peace and the magazine Foreign Policy. Countries on display are those considered to be under alert, high alert, and very high alert. 


\begin{tabular}{|c|c|c|c|c|c|c|}
\hline & country & LIC & LMI & UMI & HInonOECDs & Frags \\
\hline & LGCs Countries & & & & & \\
\hline 1 & Congo, Dem. Rep. & 1 & & & & 1 \\
\hline 2 & Ethiopia & 1 & & & & 1 \\
\hline 3 & Kenya & 1 & & & & 1 \\
\hline 4 & Uganda & 1 & & & & 1 \\
\hline 5 & Nigeria & & 1 & & & 1 \\
\hline 6 & Bolivia & & 1 & & & \\
\hline 7 & El Salvador & & 1 & & & \\
\hline 8 & Guatemala & & 1 & & & \\
\hline 9 & Honduras & & 1 & & & \\
\hline 10 & Paraguay & & 1 & & & \\
\hline 11 & Philippines & & 1 & & & \\
\hline 12 & Argentina & & & 1 & & \\
\hline 13 & Colombia & & & 1 & & \\
\hline 14 & Ecuador & & & 1 & & \\
\hline 15 & Peru & & & 1 & & \\
\hline 16 & South Africa & & & 1 & & \\
\hline 17 & Uruguay & & & & 1 & \\
\hline 18 & Mexico & & & & & \\
\hline 19 & Bangladesh & 1 & & & & 1 \\
\hline 20 & Burundi & 1 & & & & 1 \\
\hline 21 & Central African Rep. & 1 & & & & 1 \\
\hline 22 & Chad & 1 & & & & 1 \\
\hline 23 & Guinea & 1 & & & & 1 \\
\hline 24 & Guinea-Bissau & 1 & & & & 1 \\
\hline 25 & Nepal & 1 & & & & 1 \\
\hline 26 & Niger & 1 & & & & 1 \\
\hline 27 & Rwanda & 1 & & & & 1 \\
\hline 28 & Zimbabwe & 1 & & & & 1 \\
\hline 29 & Benin & 1 & & & & \\
\hline 30 & Burkina Faso & 1 & & & & \\
\hline 31 & Comoros & 1 & & & & \\
\hline 32 & Gambia, The & 1 & & & & \\
\hline 33 & Madagascar & 1 & & & & \\
\hline 34 & Malawi & 1 & & & & \\
\hline 35 & Mali & 1 & & & & \\
\hline 36 & Mozambique & 1 & & & & \\
\hline 37 & Sierra Leone & 1 & & & & \\
\hline 38 & Tanzania & 1 & & & & \\
\hline 39 & Togo & 1 & & & & \\
\hline 40 & Cameroon & & 1 & & & 1 \\
\hline 41 & Cote d'Ivoire & & 1 & & & 1 \\
\hline 42 & Mauritania & & 1 & & & 1 \\
\hline 43 & Congo, Republic of & & 1 & & & \\
\hline 44 & Ghana & & 1 & & & \\
\hline 45 & Senegal & & 1 & & & \\
\hline 46 & Zambia & & 1 & & & \\
\hline 47 & Gabon & & & 1 & & \\
\hline 48 & Iran & & & 1 & & \\
\hline 49 & Jamaica & & & 1 & & \\
\hline 50 & Jordan & & & 1 & & \\
\hline 51 & Namibia & & & 1 & & \\
\hline 52 & Liberia & 1 & & & & 1 \\
\hline 53 & Djibouti & & 1 & & & \\
\hline 54 & Sao Tome and Principe & & 1 & & & \\
\hline 55 & Iraq & & & 1 & & 1 \\
\hline 56 & Angola & & & 1 & & \\
\hline 57 & Lebanon & & & 1 & & \\
\hline 58 & Suriname & & & 1 & & \\
\hline
\end{tabular}

Table 2A.7: LGCs countries subgroups. Classification into the Low-IncomeCountries (LIC), Lower Middle Income (LMI), Upper Middle Income (UMI), HighIncome-non-OECD-Countries (HInOECDs), and fragile states (Frags). 


\begin{tabular}{|c|c|c|c|c|c|c|c|c|}
\hline Group & Decade & Countries & mean & $\mathrm{sd}$ & $\max$ & $\min$ & median & $\mathrm{CV}$ \\
\hline \multicolumn{9}{|l|}{ Cluster 1} \\
\hline $\begin{array}{l}\text { CUCs } \\
\text { (Excluding the Nics) }\end{array}$ & $\begin{array}{l}1950 \\
1960 \\
1970 \\
1980 \\
1990 \\
2000\end{array}$ & 4 & $\begin{array}{l}23.34 \\
25.34 \\
34.22 \\
37.85 \\
42.85 \\
42.63\end{array}$ & $\begin{array}{l}18.57 \\
22.62 \\
33.51 \\
31.13 \\
31.19 \\
29.60\end{array}$ & $\begin{array}{l}45.35 \\
54.67 \\
79.93 \\
74.58 \\
76.03 \\
72.22\end{array}$ & $\begin{array}{l}7.70 \\
7.35 \\
7.57 \\
10.59 \\
12.24 \\
13.03\end{array}$ & $\begin{array}{l}20.15 \\
19.67 \\
24.68 \\
33.12 \\
41.56 \\
42.62\end{array}$ & $\begin{array}{l}0.80 \\
0.89 \\
0.98 \\
0.82 \\
0.73 \\
0.69\end{array}$ \\
\hline STCs & $\begin{array}{l}1950 \\
1960 \\
1970 \\
1980 \\
1990 \\
2000\end{array}$ & 11 & $\begin{array}{l}22.47 \\
21.29 \\
20.82 \\
20.09 \\
19.36 \\
22.04\end{array}$ & $\begin{array}{l}12.92 \\
14.24 \\
13.97 \\
12.65 \\
10.21 \\
13.30\end{array}$ & $\begin{array}{l}42.88 \\
52.28 \\
50.44 \\
46.05 \\
33.33 \\
49.75\end{array}$ & $\begin{array}{l}7.43 \\
6.45 \\
5.23 \\
5.16 \\
5.91 \\
6.65\end{array}$ & $\begin{array}{l}21.59 \\
18.55 \\
18.48 \\
18.58 \\
22.43 \\
22.60\end{array}$ & $\begin{array}{l}0.57 \\
0.67 \\
0.67 \\
0.63 \\
0.53 \\
0.60\end{array}$ \\
\hline $\begin{array}{l}\text { LGCs } \\
\text { (Incl. Frags and LICs) }\end{array}$ & $\begin{array}{l}1950 \\
1960 \\
1970 \\
1980 \\
1990 \\
2000\end{array}$ & 18 & $\begin{array}{l}26.65 \\
22.03 \\
19.24 \\
16.59 \\
14.06 \\
12.95\end{array}$ & $\begin{array}{l}18.94 \\
16.25 \\
14.55 \\
12.99 \\
11.44 \\
10.46\end{array}$ & $\begin{array}{l}67.09 \\
56.44 \\
49.00 \\
45.59 \\
38.74 \\
36.13\end{array}$ & $\begin{array}{l}2.55 \\
2.16 \\
1.87 \\
1.29 \\
1.22 \\
0.66\end{array}$ & $\begin{array}{l}21.81 \\
17.26 \\
16.83 \\
13.53 \\
11.50 \\
10.55\end{array}$ & $\begin{array}{l}0.71 \\
0.74 \\
0.76 \\
0.78 \\
0.81 \\
0.81\end{array}$ \\
\hline \multicolumn{9}{|l|}{ Cluster 2} \\
\hline $\begin{array}{l}\text { CUCs } \\
\text { (Excluding the Nics) }\end{array}$ & $\begin{array}{l}1960 \\
1970 \\
1980 \\
1990 \\
2000\end{array}$ & 8 & $\begin{array}{l}10.78 \\
14.95 \\
19.34 \\
21.53 \\
24.42\end{array}$ & $\begin{array}{l}6.70 \\
11.45 \\
15.28 \\
16.23 \\
15.98\end{array}$ & $\begin{array}{l}20.36 \\
33.09 \\
46.07 \\
56.12 \\
58.26\end{array}$ & $\begin{array}{l}3.08 \\
2.96 \\
4.63 \\
6.39 \\
8.44\end{array}$ & $\begin{array}{l}8.97 \\
11.71 \\
15.06 \\
18.49 \\
21.98\end{array}$ & $\begin{array}{l}0.62 \\
0.77 \\
0.79 \\
0.75 \\
0.65\end{array}$ \\
\hline STCs & $\begin{array}{l}1960 \\
1970 \\
1980 \\
1990 \\
2000\end{array}$ & 3 & $\begin{array}{l}10.66 \\
10.62 \\
10.13 \\
9.39 \\
9.02\end{array}$ & $\begin{array}{l}5.81 \\
5.71 \\
5.55 \\
4.67 \\
4.38\end{array}$ & $\begin{array}{l}14.44 \\
14.13 \\
14.35 \\
12.17 \\
11.71\end{array}$ & $\begin{array}{l}3.97 \\
4.02 \\
3.84 \\
4.00 \\
3.97\end{array}$ & $\begin{array}{l}13.57 \\
13.70 \\
12.20 \\
11.99 \\
11.39\end{array}$ & $\begin{array}{l}0.54 \\
0.54 \\
0.55 \\
0.50 \\
0.49\end{array}$ \\
\hline $\begin{array}{l}\text { LGCs } \\
\text { (Incl. Frags and LICs) }\end{array}$ & $\begin{array}{l}1960 \\
1970 \\
1980 \\
1990 \\
2000\end{array}$ & 33 & $\begin{array}{l}13.76 \\
12.17 \\
9.32 \\
7.30 \\
6.21\end{array}$ & $\begin{array}{l}14.89 \\
16.93 \\
12.18 \\
9.52 \\
7.49\end{array}$ & $\begin{array}{l}73.12 \\
87.33 \\
65.24 \\
49.52 \\
33.91\end{array}$ & $\begin{array}{l}2.53 \\
2.11 \\
1.48 \\
1.35 \\
1.53\end{array}$ & $\begin{array}{l}8.68 \\
6.33 \\
4.82 \\
3.62 \\
3.34\end{array}$ & $\begin{array}{l}1.08 \\
1.39 \\
1.31 \\
1.30 \\
1.21\end{array}$ \\
\hline Cluster 3 & & & & & & & & \\
\hline $\begin{array}{l}\text { CUCs } \\
\text { (Excluding the Nics) }\end{array}$ & $\begin{array}{l}1970 \\
1980 \\
1990 \\
2000\end{array}$ & 11 & $\begin{array}{l}19.47 \\
26.58 \\
30.65 \\
33.54\end{array}$ & $\begin{array}{l}19.23 \\
27.98 \\
28.75 \\
30.84\end{array}$ & $\begin{array}{l}63.64 \\
90.70 \\
98.46 \\
110.00\end{array}$ & $\begin{array}{l}3.69 \\
4.03 \\
4.79 \\
5.97\end{array}$ & $\begin{array}{l}12.18 \\
13.96 \\
21.34 \\
27.97\end{array}$ & $\begin{array}{l}0.99 \\
1.05 \\
0.94 \\
0.92\end{array}$ \\
\hline STCs & $\begin{array}{l}1970 \\
1980 \\
1990 \\
2000\end{array}$ & 10 & $\begin{array}{l}21.34 \\
21.79 \\
18.91 \\
20.83\end{array}$ & $\begin{array}{l}15.36 \\
16.30 \\
13.00 \\
14.36\end{array}$ & $\begin{array}{l}51.28 \\
55.10 \\
42.78 \\
46.36\end{array}$ & $\begin{array}{l}4.84 \\
2.82 \\
3.01 \\
4.36\end{array}$ & $\begin{array}{l}19.16 \\
17.42 \\
15.91 \\
18.39\end{array}$ & $\begin{array}{l}0.72 \\
0.75 \\
0.69 \\
0.69\end{array}$ \\
\hline $\begin{array}{l}\text { LGCs } \\
\text { (Incl. Frags and LICs) }\end{array}$ & $\begin{array}{l}1970 \\
1980 \\
1990 \\
2000\end{array}$ & 7 & $\begin{array}{l}22.59 \\
15.99 \\
11.09 \\
10.97\end{array}$ & $\begin{array}{l}15.84 \\
10.83 \\
10.00 \\
9.60\end{array}$ & $\begin{array}{l}55.05 \\
36.85 \\
31.28 \\
30.16\end{array}$ & $\begin{array}{l}7.41 \\
4.75 \\
1.13 \\
1.23\end{array}$ & $\begin{array}{l}19.44 \\
12.00 \\
8.09 \\
9.54\end{array}$ & $\begin{array}{l}0.70 \\
0.68 \\
0.90 \\
0.88\end{array}$ \\
\hline
\end{tabular}

Table 2A.8: Distribution Statistics for the relative levels of income. Clusters are formed for countries with data over the same decades. CV is the coefficient of variation (abs. value).

Source: Author calculations. 


\begin{tabular}{|c|c|c|c|c|c|c|c|c|}
\hline Group & Decade & Countries & mean & $\mathrm{sd}$ & $\max$ & $\min$ & median & $\mathrm{CV}$ \\
\hline \multicolumn{9}{|l|}{ Cluster 1} \\
\hline $\begin{array}{l}\text { CUCs } \\
\text { (Excluding the Nics) }\end{array}$ & $\begin{array}{l}1950 \\
1960 \\
1970 \\
1980 \\
1990 \\
2000\end{array}$ & 4 & $\begin{array}{l}-1.29 \\
1.06 \\
1.89 \\
1.89 \\
1.09 \\
1.09\end{array}$ & $\begin{array}{l}2.70 \\
2.42 \\
1.64 \\
1.83 \\
0.68 \\
0.93\end{array}$ & $\begin{array}{l}1.13 \\
4.33 \\
3.74 \\
2.93 \\
2.03 \\
1.99\end{array}$ & $\begin{array}{l}-4.71 \\
-1.47 \\
-0.24 \\
-0.85 \\
0.48 \\
0.17\end{array}$ & $\begin{array}{l}-0.80 \\
0.69 \\
2.04 \\
2.75 \\
0.91 \\
1.10\end{array}$ & $\begin{array}{l}2.09 \\
2.28 \\
0.87 \\
0.97 \\
0.63 \\
0.86\end{array}$ \\
\hline STCs & $\begin{array}{l}1950 \\
1960 \\
1970 \\
1980 \\
1990 \\
2000\end{array}$ & 11 & $\begin{array}{l}-1.66 \\
-1.26 \\
0.17 \\
-0.74 \\
0.80 \\
2.33\end{array}$ & $\begin{array}{l}2.29 \\
1.68 \\
1.88 \\
1.88 \\
1.42 \\
1.16\end{array}$ & $\begin{array}{l}2.62 \\
0.46 \\
3.06 \\
1.41 \\
2.51 \\
4.55\end{array}$ & $\begin{array}{l}-5.17 \\
-5.55 \\
-2.85 \\
-5.00 \\
-1.92 \\
0.87\end{array}$ & $\begin{array}{l}-1.69 \\
-0.83 \\
0.30 \\
-0.65 \\
1.18 \\
2.29\end{array}$ & $\begin{array}{l}1.38 \\
1.33 \\
11.25 \\
2.55 \\
1.78 \\
0.50\end{array}$ \\
\hline $\begin{array}{l}\text { LGCs } \\
\text { (Incl. Frags and LICs) }\end{array}$ & $\begin{array}{l}1950 \\
1960 \\
1970 \\
1980 \\
1990 \\
2000\end{array}$ & 18 & $\begin{array}{l}-1.80 \\
-2.57 \\
-1.31 \\
-3.05 \\
-1.47 \\
1.10\end{array}$ & $\begin{array}{l}1.45 \\
1.17 \\
2.60 \\
1.46 \\
2.73 \\
1.54\end{array}$ & $\begin{array}{l}0.57 \\
-0.72 \\
2.82 \\
-0.93 \\
1.72 \\
4.61\end{array}$ & $\begin{array}{l}-5.24 \\
-4.87 \\
-7.28 \\
-6.44 \\
-10.83 \\
-0.95\end{array}$ & $\begin{array}{l}-1.90 \\
-2.41 \\
-0.71 \\
-2.73 \\
-1.35 \\
1.09\end{array}$ & $\begin{array}{l}0.80 \\
0.46 \\
1.99 \\
0.48 \\
1.85 \\
1.41\end{array}$ \\
\hline \multicolumn{9}{|l|}{ Cluster 2} \\
\hline $\begin{array}{l}\text { CUCs } \\
\text { (Excluding the Nics) }\end{array}$ & $\begin{array}{l}1960 \\
1970 \\
1980 \\
1990 \\
2000\end{array}$ & 8 & $\begin{array}{l}-1.08 \\
3.47 \\
1.92 \\
1.63 \\
2.84\end{array}$ & $\begin{array}{l}2.53 \\
3.34 \\
2.79 \\
2.76 \\
2.39\end{array}$ & $\begin{array}{l}3.41 \\
7.43 \\
6.41 \\
6.39 \\
7.99\end{array}$ & $\begin{array}{l}-4.29 \\
-2.88 \\
-1.04 \\
-3.78 \\
0.07\end{array}$ & $\begin{array}{l}-1.33 \\
3.67 \\
1.36 \\
1.72 \\
2.41\end{array}$ & $\begin{array}{l}2.34 \\
0.96 \\
1.45 \\
1.69 \\
0.84\end{array}$ \\
\hline STCs & $\begin{array}{l}1960 \\
1970 \\
1980 \\
1990 \\
2000\end{array}$ & 3 & $\begin{array}{l}-1.51 \\
1.17 \\
-2.36 \\
0.41 \\
0.76\end{array}$ & $\begin{array}{l}1.09 \\
0.37 \\
1.26 \\
0.95 \\
0.64\end{array}$ & $\begin{array}{l}-0.80 \\
1.56 \\
-1.37 \\
1.44 \\
1.35\end{array}$ & $\begin{array}{l}-2.76 \\
0.82 \\
-3.78 \\
-0.41 \\
0.08\end{array}$ & $\begin{array}{l}-0.98 \\
1.13 \\
-1.92 \\
0.19 \\
0.85\end{array}$ & $\begin{array}{l}0.72 \\
0.32 \\
0.54 \\
2.33 \\
0.84\end{array}$ \\
\hline $\begin{array}{l}\text { LGCs } \\
\text { (Incl. Frags and LICs) }\end{array}$ & $\begin{array}{l}1960 \\
1970 \\
1980 \\
1990 \\
2000\end{array}$ & 33 & $\begin{array}{l}-2.28 \\
-2.34 \\
-2.81 \\
-2.09 \\
0.40\end{array}$ & $\begin{array}{l}2.63 \\
2.15 \\
1.66 \\
2.11 \\
1.91\end{array}$ & $\begin{array}{l}3.78 \\
2.61 \\
1.03 \\
1.23 \\
3.60\end{array}$ & $\begin{array}{l}-6.44 \\
-6.73 \\
-6.33 \\
-10.15 \\
-3.93\end{array}$ & $\begin{array}{l}-3.03 \\
-2.42 \\
-2.92 \\
-1.96 \\
0.10\end{array}$ & $\begin{array}{l}1.15 \\
0.92 \\
0.59 \\
1.01 \\
4.76\end{array}$ \\
\hline Cluster 3 & & & & & & & & \\
\hline $\begin{array}{l}\text { CUCs } \\
\text { (Excluding the Nics) }\end{array}$ & $\begin{array}{l}1970 \\
1980 \\
1990 \\
2000\end{array}$ & 11 & $\begin{array}{l}0.57 \\
2.97 \\
1.44 \\
2.51\end{array}$ & $\begin{array}{l}2.59 \\
1.89 \\
1.68 \\
1.92\end{array}$ & $\begin{array}{l}4.92 \\
5.58 \\
4.04 \\
5.82\end{array}$ & $\begin{array}{l}-2.72 \\
0.31 \\
-1.12 \\
0.28\end{array}$ & $\begin{array}{l}-0.26 \\
3.05 \\
1.45 \\
1.67\end{array}$ & $\begin{array}{l}4.55 \\
0.64 \\
1.17 \\
0.77\end{array}$ \\
\hline STCs & $\begin{array}{l}1970 \\
1980 \\
1990 \\
2000\end{array}$ & 10 & $\begin{array}{l}-0.29 \\
-0.41 \\
-1.09 \\
2.50\end{array}$ & $\begin{array}{l}3.82 \\
1.73 \\
1.80 \\
1.82\end{array}$ & $\begin{array}{l}3.47 \\
2.05 \\
1.02 \\
5.41\end{array}$ & $\begin{array}{l}-9.81 \\
-2.96 \\
-4.26 \\
-0.05\end{array}$ & $\begin{array}{l}0.77 \\
-0.48 \\
-0.58 \\
2.89\end{array}$ & $\begin{array}{l}13.24 \\
4.26 \\
1.65 \\
0.73\end{array}$ \\
\hline $\begin{array}{l}\text { LGCs } \\
\text { (Incl. Frags and LICs) }\end{array}$ & $\begin{array}{l}1970 \\
1980 \\
1990 \\
2000\end{array}$ & 7 & $\begin{array}{l}-2.38 \\
-4.83 \\
-3.05 \\
1.49\end{array}$ & $\begin{array}{l}5.09 \\
1.73 \\
4.51 \\
2.54\end{array}$ & $\begin{array}{l}4.97 \\
-2.46 \\
4.29 \\
6.16\end{array}$ & $\begin{array}{l}-9.00 \\
-6.80 \\
-11.11 \\
-1.34\end{array}$ & $\begin{array}{l}-2.44 \\
-5.46 \\
-3.04 \\
1.90\end{array}$ & $\begin{array}{l}2.14 \\
0.36 \\
1.48 \\
1.71\end{array}$ \\
\hline
\end{tabular}

Table 2A.9: Distribution Statistics: basic points of difference relative to the frontier. Clusters are for countries with data over the same decades. CV is the coefficient of variation (abs. value).

Source: Author calculations. 


\section{Chapter 3}

\section{The Theory of Technology and Growth}

\subsection{Introduction}

The purpose of this chapter is to revisit the debate on the role of technology in explaining (per capita) income and income growth differences across countries. We focus on the distinct contributions of technology adoption and innovation from the perspective of the major theoretical developments included in our discussion, namely the mainstream neoclassical economics, on one side, and the evolutionary economics and national innovation systems - NIS framework, on the other. ${ }^{1,2}$ More specifically, we discuss the controversy arising from the critiques of evolutionary economists to the neoclassical analysis of technology diffusion as the major engine of growth and catching up for less developed countries, therefore neglecting the importance of learning and assimilation that

\footnotetext{
${ }^{1}$ Our focus is on the distinct contributions of foreign and domestic sources of technology found in, among others, Coe and Helpman 1995, Verspagen 1997, and Keller 2002, 2004. As we pointed out before in Chapter 1, the thread of the debate on the relationship between technology and the differences in economic performance between most and less developed countries goes back, at least in the modern discussion, to Abramovitz 1986, Baumol 1986 and Gerschenkron 1962. Earlier contributions have been attributed to Veblen 1915, the German Historical School during the 19th century, and the so-called Hume-Tucker debate around 1750.

${ }^{2}$ As we pointed out in Chapter 1, the mainstream view in our discussion refers to the neoclassical debate on convergence spurred by the Solow model (Solow 1956, Romer 1994, Jones 2005, Ang and Madsen 2011 and Aghion et al., 2013). The evolutionary view is represented here mostly by the recent contributions spurred by Nelson and Winter 1982 (see Nelson et al., 2018 for a recent appraisal). Yet, the evolutionary line of thinking is traced back to Schumpeter 1934, 1950, Veblen 1898, the tenets of the German Historical School (Fagerberg 2003) and even the thought of classical economists such as Malthus and Marshall (Nelson and Winter 1982, Dosi and Nelson 1994). Finally, our discussion of the NIS literature follows from the ideas presented by, among others, Freeman 1987, Nelson 1993 and Lundvall 1992, 1993, 2007. But, again, we note that the systemic approach characteristic of this approach goes back to Schumpeter (Fagerberg 2003) and further back to Friedrich List 1841 (Soete, Verspagen and ter Weel 2010).
} 
characterize the innovation activities carried out in countries off the frontier. ${ }^{3}$ And we discuss also the systemic interdependencies that supersede in the NIS framework the conventional attention to "market failures". 4

The importance of technology in explaining growth differences across countries is apparent. On some accounts, productivity differences, which a vast amount of the specialized literature agrees to equalize with technology differences, are held to explain up to between $60 \%$ and $90 \%$ of the growth differences and more than $90 \%$ of the difference in levels of income between poor and rich countries. $^{5}$

Yet, while the preeminence of technology in explaining growth outcomes is generally accepted, where the neoclassical and evolutionary economists differ is when it comes to accounting for the sources of technology explaining income and income growth differences across countries. Whether technology is associated with artifacts or with ideas, ${ }^{6}$ mainstream economists have tended to associate the growth achievements of less development countries, exclusively, with their ability to adopt/imitate the technology and production practices of countries at the frontier. ${ }^{7}$ Some evidence in this context suggests that foreign technology accounts for more than $90 \%$, and even as much as $99 \%$, of the productivity of countries in the receiving end. ${ }^{8}$

Evolutionary economists, and also NIS advocates, do not dispute the importance of technology diffusion. They even concede that adoption/imitation are important sources of the innovation issues and networking innovation activities that concern them much more. They, however, dispute the preeminence of adoption/imitation over the role and conduct of the innovation activity/policy in less developed countries.

From the evolutionary perspective, the alleged preeminence of technology transfers for development outcomes neglects the entrepreneurial features and the importance of learning and assimilation which they associate to innovation and put forward as the true engine of the growth achievements in less developed countries that have succeeded to catch-up. ${ }^{9}$ The complex link between adoption and innovation activities in the evolutionary account of economic development is neatly summarized by Nelson 2008 who points out: "The innovation in catching up involves bringing in and learning to master ways of doing things that may have been used for some time in the advanced economies". ${ }^{10}$

\footnotetext{
${ }^{3}$ Pack and Nelson 1999, Nelson 2008.

${ }^{4}$ Lee and Malerba 2018.

${ }^{5}$ Easterly and Levine 2001. The preeminence of technology, however, is by no means uncontested, see Jorgenson et al., 1987, Dougherty and Jorgenson 1996, Kumar and Russell 2002, and Jorgenson and $\mathrm{Vu} 2005$, among others.

${ }^{6}$ Romer 1994, Mankiw et al., 1995.

${ }^{7}$ The controversial nature of the discussion within mainstream realms in this context is widely documented, see for example, Barro 1991, Pritchett 1997, Lucas 2000, Baumol 2002, Rodrik 2011, Spence 2011, Phelps 2016.

${ }^{8}$ Keller 2004, this figure refers to the comparison of estimates upon the relative productivity elasticity to foreign/domestic R\&D in a small sample of nine rich countries. Some counterevidence is found in Bernard and Jones 1996a.

${ }^{9}$ Pack and Nelson 1999, Nelson 2008.

${ }^{10}$ Nelson 2008.
} 
Certainly the mainstream does not deny the economic impacts of innovation. In fact, its analysis in this regard lies on the same Schumpeterian views of innovation/entrepreneurship as in evolutionary economics. ${ }^{11}$ And, after the famous Jones' Critique innovation-based growth models have gained considerable attention in the modern analysis that explores the determinants of long-run growth. ${ }^{12}$ There are, however, two major areas of difference between both theoretical traditions that are important: the first relates to the process of how innovation occurs in the first place; the second relates to the relative importance of innovation in explaining the growth achievements of less developed countries, as this has been an area of neglect in the mainstream approach. As pointed out by Fagerberg et al., 2010: "TThe] popular perception of innovation [...] is that it has to do with developing [...] advanced solutions for sophisticated well off costumer [and] carried out by highly educated labor [...] with strong ties to leading centers of excellence in the scientific world. Hence innovation in this sense is a 'first world' activity" . ${ }^{13}$

Altogether, our point is that, in trying to assess the economic contributions of adoption and innovation for catching up, we are faced with the concern central to this thesis: reasonable answers stem from premises grounded on contesting theoretical frameworks. The review below aims for a close examination of these theoretical issues.

Let us pose in a more concrete way what we claim are the core contributions of this chapter:

First and foremost, we aim to provide an integrated framework for understanding what economists from different backgrounds think technology is, and the relationship between technology and growth. The notion of technology, even in the narrow field of growth economics, usually reflects quite different meanings among different economists (e.g., productivity, artifacts, ideas, high-tech inventions, small innovations). ${ }^{14}$ Thus, to overcome the hurdle imposed on our review by conflicting definitions and provide a more cogent scenario for analyzing the impact of technology on the growth process, it is necessary in the first place to put together the different concepts and interpretations of technology both from the viewpoint of the neoclassical/endogenous growth theory and the evolutionary/NIS theories.

Second, we use the above conceptual definitions of technology to draw a distinction between the economic impacts of adoption (of foreign technology) and (local) innovation, which is one of the key subjects creating major - if little promulgated - contention between the mainstream and the evolutionary and NIS frameworks. We discuss various arguments to show the contrast between the mainstream's prominence of technology transfer as a major engine of growth

\footnotetext{
${ }^{11}$ Baumol 2002, Aghion and Howitt 2006, Aghion Akcigit and Howitt 2013.

${ }^{12}$ Jones 1995, Ang and Madsen 2011.

${ }^{13}$ Fagerberg et al., 2010.

${ }^{14}$ About the very distinct connotations of technology see Romer 1993, 1994, Lucas 1988, Verspagen 1992, Fagerberg 1994, Schneider and Ziesemer 1995, and Fagerberg, Srholec and Verspagen 2010. For the different connotations of technology in empirical assessments see, for instance, Ha and Howitt 2007, Levine and Renelt 1992, Bosworth and Collins 2003, Griliches and Mairesse 1995 and Hauk and Wacziarg 2009.
} 
in backward countries and the evolutionary contention that the true driver of growth is (local) innovation - the ability to translate technology into new and ever-changing commercial applications - even if the latter takes place along major technology trajectories (steam engine, electricity, electronics, ICT, nanotechnology, biotechnology). Lastly, we also stress the systemic aspects of innovation that are at the core of the NIS perspective.

Our third contribution relates to the distinct policy implications of these competing views on the relationship between technology and the economy. In doing so, we discuss how the disagreement relates to contrasting theoretical assumptions with regard to, among other things, the idea that the economy is populated by rational "optimizing" individuals and the effectiveness of markets to coordinate the economic activity, both of which result in competing interpretations about the proper role of government in matters of innovation policy. In particular, we argue that the policy implications that derive from the evolutionary and NIS approaches are not different, but they both differ from the mainstream because the role of government also differs. Below, we narrow these policy implication from perspective of NIS approach into three key aspects of sponsorship, leadership and coordination and discuss why these aspects stand in stark contrast to the policy implications drawn from the mainstream analysis which place stress on ideas of distance to the frontier and advantage of backwardness.

The chapter proceeds as follows. Section 3.2 discusses the conceptual understanding of technology. Section 3.3 provides the baselines of the controversy between the mainstream and the evolutionary and NIS frameworks over the fundamental aspects of technology that positively affect the growth and catch up processes. Section 3.4 addresses the implications of this controversy in terms of the ability of less developed countries to realize their advantage of backwardness. Section 3.5 elaborates on the distinct policy implications of the contesting theoretical frameworks under discussion. Finally, Section 3.6 offer some concluding remarks.

\subsection{The Economics of Technology}

In spite of it being one of the most often cited concepts, the definition of technology receives only occasional attention in the economic literature. ${ }^{15}$ The costumary practice is to relate technology to "something" that increases productive efficiency, offsetting the tendency of other factors (capital, labor) to yield decreasing returns. Starting from this relation, most writers focus on the technology features that lead to sustained rates of growth over the long-run,

\footnotetext{
${ }^{15}$ Freeman 1994, Bernard and Jones 1996b. Indeed, a safe definition of what technology is troubles scientists of all fields. Someone has defined it simply as "...anything that was invented after you were born..." and a whole branch of sociology has been devoted to the case of technology as a "social construct," a contention that technology is forged through the organization, functioning, and needs of the society at large. Mokyr 2014, has posed that "...the exact interaction between science and technology is a subtle and complex one, time-variant, and culture-specific."
} 
and endeavor to find out whether, or to what extent, those features arise as a result of positive spillovers or purposeful entrepreneurship swayed by market incentives.

That endeavor has resulted in many-fold competing notions of technology, which paradoxically makes it clumsier, rather than simpler, to understand which are the actual aspects of technology that matter to boost economic growth. Even more crucial, it makes harder to understand which are the fundamental aspects of technology that matter to explain the differences in economic performance across countries (e.g., in terms of per capita income or growth rates).

The view of technology as "something" that is primarily embodied in artifacts has played a major role in this debate for a long time. In fact, the embodiment notion remains center stage in the research, or at least part of the research, that explores the determinants and the economic impact of technology diffusion (e.g., the capital accumulation debate). ${ }^{16}$ Yet, many writers point out as well the significant impact of disembodied technical changes in fostering economic growth - which is based on the argument that even without changes in the quality/number of factors of production, efficiency gains might accrue by making a better use of the installed capacity. From this perspective, the allocation and combination of productive factors into their best possible use, rather than just the overall acumulation of them, is a major technology problem that all countries need to address. ${ }^{17}$

So, even though in practice they denote different processes, "technological change", "technology progress", and "productivity" turn out to be used as interchangeable terms stressing the nature of technology as the ability to produce more output from a given set of inputs. ${ }^{18}$ From this perspective, a process of "machine-automation" aimed to the elimination of routine work enhancing higher efficiency in activities that rely on repetitive processes counts as much as productivity improvements accrued to the availability of better qualified workers or the simple reorganization of the production activity.

In addition to these widespread notions, in growth economics technology is featured overall as a process of knowledge creation which occurs either through purposeful private R\&D activities in the business sector or through economywide investments in human capital (education). ${ }^{19}$ The contemporary consensus in growth theory views technology as "something" that improves productivity and hinges fundamentally on the creation of "ideas": blueprints that offset the curse of decreasing returns to capital, allowing the economy to obtain endoge-

\footnotetext{
${ }^{16}$ De Long and Summers 1991, provide evidence of a close relationship between investments in physical assets and economic growth; and Kumar and Russell 2002 hold that capital deepening explains most of the observed cross-country growth differences (84\%). The qualityadjusted capital (physical and human) pioneered by Dale Jorgenson are deemed to account for the contributions of technology that are embodied but usually overlooked in the conventional growth accounting method (Jorgenson et al., 1987, Jorgenson and Vu 2005, 2010).

${ }^{17}$ Research by Pages 2010 and McMillan and Rodrik 2012 suggests that for many developing countries the technology problem of major importance is structural change: a process aimed to shifting resources from less to more productive activities/sectors of the economy.

${ }^{18}$ Gomulka 1990.

${ }^{19}$ Romer 1990, 1993, 1994, Lucas 1988.
} 
nous exponential growth. ${ }^{20}$

The reasoning behind the twist from the "machine view" to the "ideas view" is compelling: giving one laptop to one worker makes that worker more productive (provided she knows how to use it), yet creating a new algorithm (e.g., to ease internet access) makes everybody better off. In the first case, efficiency gains hinge on the number of laptops per worker; in the second, the gains depend on the aggregate stock of ideas, not only the number of ideas per worker. Unlike the laptop, the use of the algorithm for one person does not prevent any other person of using the same algorithm at the same time. ${ }^{21}$

One limitation of this perspective, however, is the widespread association of "ideas" exclusively with advanced scientific and technological endeavors at the frontier of knowledge. That is, mainstream economists regard "ideas" largely as technology breakthroughs that boost productivity (machines and equipment, business models, organizational methods, sophisticated intermediate products), and stress the benefits of diffusion and adoption of frontier ideas for countries that want to catch up. ${ }^{22}$ This, according to evolutionary theorists, is a "narrow" view in need of further refinement as innovation - the attempt to try out new ways of doing things even if they have been in used for some time elsewhere - is an aspect of all economic activities, including low-tech industries; and therefore there are (potentially large) growth effects also in the innovations activities conducted in less developed countries. ${ }^{23}$

The evolutionary approach to explaining the role of innovation in boosting economic growth holds that once producers have developed a variety of new products, a selection process takes place by consumers in the marketplace. The selection process involves substantial competition with other producers and determines whether or not the new products are going to be successful. The market success of a new product, however, is inevitably a temporary issue. Even if the new products that survive competition do well for the first generation, they may do less well for the second generation, and still less for the third, and so on. In other words, if they are not at least slightly modified the "popularity" of the new products is a decreasing function of the time a product has been in the market. At length, the pressures of competition and the consumers' craze for the "new" compel producers to permanently seek for newer market strategies and novel products. ${ }^{24}$

Thus, according to the perspective of evolutionary economics, even though the discovery/invention of major technologies helps to resolve the productivity problem, the problem that remains is what to produce: how to take advantage of the production possibilities opened up by the new inventions. And from this perspective, the process of economic growth is overall a reflection of the ability of

\footnotetext{
${ }^{20}$ Romer 1993, Jones 2005.

${ }^{21}$ Jones 2005.

${ }^{22}$ Romer 1994, Mankiw et al., 1995, Sachs and Warner 1995, Grossman and Helpman 2001, Sachs and McArthur 2002, Parente and Prescott 1994, 2002.

${ }^{23}$ Nelson 2008.

${ }^{24}$ Nelson and Winter 1982, 2002. See also Urban 1996 and Elmaraghy et al., 2013. A similar emphasis as ours on the role of innovation is found in Baumol 2002.
} 
entrepreneurs to use the most sophisticated technologies to produce innovative products aimed to create or maintain consumers' demand.

However, trying to encapsulate the notion of innovation is a cumbersome issue. For one thing, there is a plain recognition within evolutionary economics that there are (probably) many instances where what is called "innovation" corresponds simply to the adoption or imitation of products or practices originated in the leading nations. ${ }^{25}$ Then, there is a striking amount of dimensions in which the innovation issue can be analyzed. As Fagerberg et al., have pointed out, low-tech innovation may be related with any improvements in logistics, distribution, marketing, and new business models, whose main purpose is to increase productive efficiency - not necessarily to produce new goods. ${ }^{26}$ Finally, many innovation studies have extended the discussion to product, process, organizational, and marketing innovations, innovations resulting from emerging technologies, "open innovations" and "disruptive innovations" which clearly makes harder to claim a fair academic understanding of the workings of this source of technology progress. ${ }^{27}$

Thus, rather than relying on complex definitional issues, we find it more appropriate to adopt a broader view of innovation in our discussion. Therefore, we refer to innovation as (localized) commercial applications of technology which are featured by the continuous improvement to any of the production processes, inputs and outputs. We do think of this view of innovation as the dominant strategy for producers to survive the pressures of competition and selection. And we do think of our broad view as bringing together supply and demand views of technology $;^{28}$ the importance of innovation over price competition; ${ }^{29}$ the view of innovation in the theory of monopolistic competition with differentiated products ${ }^{30}$ the modern emphasis on innovation-based growth models; ${ }^{31}$ and, of course, the evolutionary perspective on innovation. ${ }^{32}$

In our view, the conceptual distinction between adoption and innovation elaborated in this section is in order to better the understanding on the determinants of growth and catching-up. Yet, we also need to understand the nature of the differences regarding the theoretical frameworks on which these competing notions of technology are addressed. That is the focus of the next section.

\footnotetext{
${ }^{25}$ Nelson 2008, Lee and Malerba 2018.

${ }^{26}$ Fagerberg et al., 2010.

${ }^{27}$ The proliferation of terms related with the notion of innovation is said to have surpassed the indicators and definitions in the Oslo Manual (Gault 2014).

${ }^{28}$ Schmookler 1966; Kelly 2002.

${ }^{29}$ Schumpeter 1934, 1950, Baumol 2002, Lundvall 2007.

${ }^{30}$ Dixit and Stiglitz 1977; Romer 1994.

${ }^{31}$ Aghion, Akcigit and Howitt 2013.

${ }^{32}$ Nelson and Winter 1982; Nelson and Winter 2002; Nelson 2008; Fagerber et al., 2010.
} 


\subsection{Technology and Growth Theory}

Starting in the second half of the twentieth century, the modern debate on catching-up and convergence issues has been related to the efforts of less developed countries to reach the levels of social and economic development of the so-called "mature industrialized countries". ${ }^{33}$ The theoretical perspective on these efforts can be split into models/theories focused on the levels of physical and human capital - a line of research spurred by the Solow model - and the research on institutional and social structures that appear to hold back some countries. $^{34}$

The intellectual reluctance with the general property of (conditional) convergence predicted by the Solow model led to further developments under the endogenous literature, one of whose main predictions was that income per capita differentials across rich and poor countries can persist indefinitely. ${ }^{35}$ The new theory had important implications for the analysis of the convergence possibilities of less developed countries and, among the new insights inspired by this research, the issue of technology diffusion began to receive a deal of attention. Building on earlier ideas by Gerschenkron 1962, Baumol 1986 and Abramovitz 1986, subsequent models started to investigate the existence, causes and consequences of economic backwardness, and to study the benefits accrued to poor countries through the spread of technology from the frontier. ${ }^{36}$ Conventional models of diffusion, however, did not pay attention (at least not enough) to the historical analysis, social capabilities and institutional factors that form the hallmark of the contributions by Gerschenkron, Baumol and Abramovitz. Instead, most of those same aspects were developed in a set of contributions by, among others, Katz 1984, Lall 1987, Verspagen 1991, Fagerberg 1995, and Pack and Nelson 1999.

Certainly, not all the research conducted in the field may be classified in these terms. But some of the major contributions that, in parallel or even prior contributions to the mainstream, have influenced the analysis of the technology aspects enhancing economic growth and catch-up, relate to the evolutionary economics emphasis on the process of capability building, learning and assimilation $;^{37}$ and the systemic factors that lay at the heart of the NIS approach. ${ }^{38}$

Our aim, in what follows of this section, is to provide a more in-depth discussion and comparison of the theoretical developments under each of these strands of the research, namely, the mainstream approach presented in the theory of growth and the models of technology diffusion, vis-à-vis the evolutionary literature and the national innovation systems framework.

\footnotetext{
${ }^{33}$ Fei and Ranis 1997.

${ }^{34}$ Fagerberg 1995, Spence 2011, Stiglitz 2014, Lee and Malerba 2018.

${ }^{35}$ Romer 1993.

${ }^{36}$ Barro and Sala-i-Martin 1997, Edwards 1998, Acemoglu et al., 2006, Zilibotti 2008, Aghion et al., 2013. The key features that characterize the mainstream perspective in both types of models, namely models of growth and models of diffusion, have been amply documented in the literature (e.g., Durlauf and Quah 1999).

${ }^{37}$ Nelson and Winter 1982, Pack and Nelson 1999.

${ }^{38}$ Freeman 1987, Lundval 1992, 1993, Nelson 1993.
} 
Let us begin with the conventional approach.

\section{The Theory of Growth}

The key mechanism that explains economic growth over the long-run in the neoclassical theory is technology. In the seminal model of Solow the technology parameter, A, was originally thought of as "something" exogenous that positively affects the amount of output per worker. Later, with the emergence of what we can refer to as early endogenous growth models (EEMs) and AK models, technology was thought of as an endogenous factor. ${ }^{39}$ The positive effects of technology on production, however, was not considered as an outcome of deliberate choices by individual producers but rather as an unintended consequence of the aggregate level of technology (e.g., knowledge externalities). In the modern approach to the theory of growth technology is fully endogenized as the outcome of purposeful investments by entrepreneurs to develop and accumulate knowledge in order to maximize profits. These are the so-called R\&D-based and ideas-based endogenous growth models. ${ }^{40}$

The latter class of models commands further distinction. First generation models (FGMs) are associated with the idea that technology leads to "persistent" and "increasing" rates of growth in the long run. ${ }^{41}$ These models have been abandoned as a devastating consequence of the famous Jones' Critique and replaced by second-generation models (SGMs), a number of technically more appealing models which seek to explain what determines the observed empirical regularities of diminishing returns to technology investments. ${ }^{42}$ At present, SGMs split into the so-called semi-endogenous and product-variety Schumpeterian growth models. ${ }^{43}$

To recap, the seminal assumption of technology as an exogenous factor of production is formulated - assuming the existence of an aggregate production function - in the following manner

$$
Y=A f(K, L)
$$

where $\mathrm{Y}, \mathrm{K}$, and L denote the national levels of output, physical capital, and labor, and where " $A$ " stands for the unexplained contribution of technological progress.

\footnotetext{
${ }^{39}$ The EEMs classification includes many growth models that through the 1950s, 1970s and 1980s attempted to endogeneize technical progress, some examples are: the learning-by-doing approach of Arrow 1962, the model of inventive activity of Shell 1966, the two sectors models of Uzawa 1965, and Phelps 1966, and the Keynesian model of Kaldor and Mirless 1962. These models greatly influenced the development of the "new growth theory." See Romer 1986, and Schneider and Ziesemer 1995 for reviews of the earlier contributions.

${ }^{40}$ Romer 1994, Ha and Howitt 2007, Jones 2005.

${ }^{41}$ Examples include models of product variety and quality ladders, i.e., with an increasing number or a higher quality-set of intermediate inputs (Romer 1990, Grossman and Helpman 2001).

42 Jones 1995, the critique points out that the predictions of FGMs are inconsistent with the empirical evidence, namely while the resources devoted to R\&D trend increasingly upwards in most developed countries, productivity growth rates do not follow a similar trend.

${ }^{43}$ Jones 1995, 2005, Ang and Madsen 2011, Aghion et al., 2013.
} 
The emphasis on technological spillovers (externalities) in EEMs and AK models was set up as a mechanism to compensate for the effect of diminishing returns to capital accumulation. The production function for each producer $(\mathrm{j})$ is expressed as

$$
Y_{j}=A(R) f\left(K_{j}, L_{j}\right)
$$

where " $\mathrm{R}$ " denotes spillover benefits from technology-related investments through the whole economy: education, firm-market interactions, or public infrastructure (e.g., roads, airports, public services). ${ }^{44}$ Human capital, however, has been the subject of much research in this class of models. ${ }^{45}$

The endogenous growth literature advanced over the spillovers approach with a rationale that technology progress hinges fundamentally on private investors' market-determined choices. The production function - in the class of FGMswas written down as

$$
Y_{j}=A(R) f\left(R_{j}, K_{j}, L_{j}\right)
$$

where " $R_{j}$ denotes the producer $j^{\prime} s$ investments in R\&D. In FGMs a framework of monopolistic competition is established within which aggregate production depends on many firms, each with monopoly power. ${ }^{46}$ An important implication of these models was that public policy was warranted to influence R\&D investments in the private sector, e.g., through subsidies and taxes. ${ }^{47}$

Given the lack of empirical support for FGMs, SGMs were set up to investigate what determines the limits of increasing returns, and the suitable policy interventions to deal with this problem.

Given the simple structure of the standard production function, this line of inquiry took either of two directions: i) assuming some limit to the ability of R\&D to generate new knowledge, which recalls an upper bound constraint to knowledge production that was anticipated earlier in AK models; ${ }^{48}$ or ii) assuming some limit to increasing returns in the production of final goods (where R\&D features as an input). The first alternative is currently the hallmark of semi-endogenous growth models ${ }^{49}$ the second is found in recent developments

\footnotetext{
${ }^{44}$ See Romer 1986, 1994, Lucas 1988, Barro 1990, and Ziesemer 1995a.

${ }^{45}$ Human capital has both private and social effects. Better qualified workers are more productive, and thus earn higher private earnings - which means higher savings and consumption expenditures. In addition, more qualified workers are a source of technological spillover that benefit the society at large. Private effects affect the short-run of the economy, i.e., they affect the level but not the long-run growth of output per capita-which means that they generate high rates of growth along the transitional dynamics to a new steady state but the effects decay asymptotically to zero. Social effects affect the long-run because social accumulation of knowledge extends over time (growth effects). See Nelson and Phelps 1966, Lucas 1988, Romer 1990, Barro and Sala-I-Martin 1997, Benhabib and Spiegel 2005 and Aghion et al., 2013. See also Schneider and Ziesemer 1995 for a review of earlier literature.

${ }^{46}$ Romer 1994. The monopolistic approach builds upon earlier developments by Dixit and Stiglitz 1977.

${ }^{47}$ Ziesemer 1991, Romer 1993, 1994.

${ }^{48}$ Romer (1986) developed a model with increasing returns in the production of final goods and decreasing returns in the production of knowledge. The latter feature is based on the assumption that each time it is more difficult to increase the stock of knowledge as, for example, doubling the amount of inputs into research will not double the amount of new knowledge. See also Gong, Greiner, and Semmler, 2004.

${ }^{49}$ Jones 2005, Kortum 1997
} 
of the so-called Schumpeterian growth models. ${ }^{50}$

The semi-endogenous growth literature holds that an increasing amount of resources is needed to compensate for the diminishing returns to knowledge accumulation and to keep the economy growing. So, if the production of technology is a function of the number of researchers, which in turn is some share of total population, it leads to the implication that in the long-run economic growth stems from a country's (population) size.

$$
A=A\left(L_{R}\right)
$$

Where $L_{R}$ denotes the share of the working force devoted to R\&D activities. A further implication of the semi-endogenous growth models is that economic growth is unresponsive to taxes and other public interventions as the impact of these policy instruments vanishes asymptotically. ${ }^{51}$

The key assumption in the class of Schumpeterian growth models, on the other side, is that there is a process of creative destruction that ends up reducing the preeminence of increasing returns. The effectiveness of R\&D investments vanishes as the economy expands because new innovations are more costly due to their increasing complexity. In addition, the proliferation of product varieties implies that the investments in R\&D spread each time over a much larger and slightly differentiated set of products. Unlike the semi-endogenous class of models, the Schumpeterian models hold that long-run growth is highly responsive to policy incentives. Because the success of investments in innovation is uncertain, it requires incentives for firms to devote more resources to R\&D activities.

To sum up, the ongoing debate between semi-endogenous and Schumpeterian growth models demonstrates that - even within mainstream economicsthe nature of technology progress, its impact on economic growth and the role of public policy in this regard are not yet safely established. ${ }^{52}$ The competing but contrasting theoretical interpretations of these issues has raised scepticism among many economists about the use of technology policy as a tool to foster economic growth, and the lack of clear empirical support for either theory provides further grounds for this disbelief. ${ }^{53}$

Let us turn our attention now to the models that emphasize on the mechanics of technology diffusion.

\footnotetext{
${ }^{50}$ Aghion et al., 2013.

${ }^{51}$ Semi-endogenous growth literature would face difficulty explaining the successful development of several low-population countries - for example, Singapore, Botswana, and Austria. Another issue of debate is the extent to which population dynamics may be considered exogenous in growth models, and the arguments raised by population-pessimists-so-called Malthusians and neo-Malthusians - and population optimists (see Simon 1998). See Prettner and Trimborn 2016 for a recent assessment.

${ }^{52}$ Note, for instance, the contrasting views in Jones 2005 and Romer 2000, with regard the use of subsidies to encourage innovation. See, also, Kremer 1998 on the use of patent rights in light of distortions generated in the pharmaceutical industry. And the Boldrin and Levine 2002 suggestions to restrict or eliminate patent rights altogether.

${ }^{53}$ See Gong et al., 2004, Jones 2005, Ha and Howitt 2007, and Ang and Madsen 2011, for recent empirical tests of these models.
} 


\section{Models of Diffusion}

The endogenous growth literature's critical advance over the earlier neoclassical model was to help shape the understanding that the production of technology not only hinges on market incentives - namely the ability of investors to capture (at least some of) the returns of their technology investment-but also on policies and institutions that provide further incentives and fix the gap between social and private returns to technology investments. Yet, when it comes to the analysis of the different impacts of foreign and local sources of technology, the dominant theoretical framework is associated with models of technology diffusion. ${ }^{54}$

The widespread understanding driven by these models is that the key technologies that matter to generate economic growth are invented at the frontier and spread to backward countries through diverse channels (imports of machines and equipment, learning by exporting, foreign direct investment, licensing). This line of reasoning became popular under the hypothesis of advantage of backwardness and is now the core of Schumpeterian-based models of distance to the frontier. ${ }^{55}$ Yet a similar line of reasoning is found in other theoretical models, e.g., the so-called North-South models, ${ }^{56}$ and leader/follower models. ${ }^{57}$

In this perspective, the potential of backward countries to grow and catch up is influenced by their absorptive capacities. A considerable research effort in this area, namely the way absorptive capacities may be developed in order to exploit the advantages provided by foreign technology advances, has been on human capital issues, ${ }^{58}$ and the institutional (free market) conditions that influence private investment decisions. ${ }^{59}$ Thus, the logic in this class of models may be formulated in the following manner

$$
A_{B}=\bar{A} f\left(H_{B} \mid I_{B}\right)
$$

where the subscript denotes backward countries, "A" with the upper bar is the frontier's level of technology, " $H$ " denotes human capital, and "I" stands for the institutional environment. For many economists the combination of technology diffusion with indigenous absorptive capabilities is a crucial part of

\footnotetext{
${ }^{54}$ Barro and Sala-I-Martin 1997, Benhabib and Spiegel 2005, Acemoglu 2009, Acemoglu et al., 2006, Aghion et al., 2013, among others.

${ }^{55}$ The hypothesis of advantage of backwardness dates back to Gerschenkron (1962). For examples of models of distance to the frontier see Acemoglu et al., 2006 and Aghion et al., 2013.

${ }^{56}$ Acemoglu et al., 2012; Acemoglu 2014.

${ }^{57}$ Stiglitz 2014.

${ }^{58}$ Lucas 1988, Lucas 2009, Romer 1993, Benhabib and Spiegel 2005, Vandenbussche, Aghion and Meghir 2006, Stokey 2012.

${ }^{59}$ Hall and Jones 1999, Jones 2005, Acemogu et al., 2006. According to Barro 1997, technology transfers and thus long-run growth is influenced by trade policies and openness, the provision of infrastructure and financial markets, policies that affect taxation and incentives, the protection of intellectual property rights, and the maintenance of law and order.
} 
the explanation of why there are some countries that manage to grow and catch up and others that fail to do so. ${ }^{60}$

Another distinctive feature of models of technology diffusion is a sequential view in which technology progress is considered to go from a focus on adoption and imitation in early stages to a focus on innovation in late stages, and where each stage warrants a different type of government intervention. For example, non-competitive arrangements (monopolistic rights) and active government intervention are justified to encourage risky investments during the adoption stage. But these measures are seen as unsuitable to encourage innovation, which is regarded an activity that hinges on limited government intervention, marketconforming policies, and strong market competition. ${ }^{61}$

It is worth mentioning that not all models of technology diffusion follow the line of reasoning we have just outlined. Some of mainstream economists have formulated models that address issues of diffusion from a "pure economics" perspective - without explicit reference to institutional and policy intervention features. ${ }^{62}$ And, of course, there are also models that provide a rigorous mathematical treatment of the micro-foundations of technology diffusion even without engaging in cross country analytical issues. ${ }^{63}$ Yet, in our view, the main theoretical objection to the various analytical models outlined above has been raised by the evolutionary/NIS approaches to the economics of technology. Below we examine what the disagreements are about.

\section{The Evolutionary Approach}

Mainstream economics sticks to the analysis of well-behaved market equilibrium solutions achieved by rational, perfectly flexible, and foresighted maximizing individuals making choices over clearly defined scenarios. On the supply side, the decentralized actions of optimizing producers acting under either perfect or imperfect competition settings ensure that all profitable options are fully exhausted given a set of constraints. And these microeconomic foundations form the basis for the analysis of all macroeconomic issues, including the analysis of the relationship between technology and economic growth in cross country settings.

Evolutionary theorists question the ability of markets to generate optimal solutions in the first place, and then the reasonability of the assumptions held

\footnotetext{
${ }^{60}$ Parente and Prescott 1994, 2002, Acemoglu et al., 2006, Damsgaard and Krusell 2010, Stokey 2012, Aghion et al., 2013.

${ }^{61}$ Acemoglu and Robinson 2000, Acemoglu et al., 2006. Aghion, Howitt and Mayer-Foulkes 2005, and Stokey 2012. According to Zilibotti 2008, the failure of Latin-American countries to successfully catch up as their East Asian counterparts - starting on equal footing - did, hinges on a failure to evolve from the stage of adoption under a protectionist framework of import substitution to a more competitive, innovation-friendly export-oriented strategy. For a similar rationale, in the context of Asian economies, see Sachs and McArthur 2002.

${ }^{62}$ Benhabib and Perli 1994, Xie 1994, Benhabib, Perla and Tonetti 2014.

${ }^{63}$ Perla and Tonetti 2014, Lucas and Moll 2014, Acemoglu and Cao 2015, Perla Tonetti and Waugh 2015, and Luttmer 2015. See Achdou et al., 2014 for a recent review of this class of models. A model that combines elements of technology diffusion and firm behavior in cross-country settings is Benhabib, Perla and Tonetti 2014.
} 
in their support. In addition, the competitive environment in the evolutionary approach is radically different. Basically, because there are not well defined opportunity sets. The relevant knowledge is split among different actors (consumers, producers, businesses, public organizations, universities) so that when individuals make choices they are mostly in possession of incomplete information, unaware of the best alternatives, if any. In addition, decision-makers are also influenced by their own beliefs and by contextual circumstances (culture, society, institutions). In conditions of uncertainty, the economy expands as some producers make profitable decisions - even if not optimal - or contracts as they make unprofitable ones. Thus, contrary to the tenets of the conventional analysis, bounded rationality and imperfect foresightedness limit the ability of individuals to reach optimal solutions. ${ }^{64}$

The evolutionary analysis of technological change and economic growth is one of the most important lines of research in this approach. It holds that, instead of responding optimally to changes in market conditions (consumer's preferences, resource availability, productive technologies), the entrepreneurs' ability to make their best choices would be constrained by lock-in and pathdependence effects. The strong heterogeneity in the market implies that some firms are better than others at acquiring/exploiting technological opportunities. And even for the best producers, they would probably prefer to stick to known routines and technologies for long periods of time as the adjustment to new conditions, and the economic benefits of doing so, can be realized only when the economic system as a whole evolves and adapts to those conditions. Thus, rather than on continuous equilibrium, along the process of technological change entrepreneurs are permanently out-of-equilibrium, and adjust to changing conditions only sporadically. ${ }^{65}$

As we already discussed in Section 3.2, consumer's selection and producers' competition are inherent in the nature of the market. The challenge for entrepreneurs is to use technology efficiently to produce more products (rather than more of the same products). This is because, in order to meet the consumer's search for the "new" and overcome the pressures of competition, entrepreneurs need to develop "new varieties" of their products permanentlyeach variety slightly differentiated not only from those of other firms but also from previous versions of their own. This proposition implies that innovation is not exclusive to leading industries that invest intensively in R\&D.

Whereas high-tech innovations (biotechnology, nanotechnology, ICT) certainly require heavy $R \& D$ investments and have mostly a large impact on the rate of economic growth, low-tech innovations provide, in the view of evolutionary economists, another important source of increasing returns and economic growth. The latter are frequently - though not necessarily always - non R\&Dbased innovations focused on solving relatively simple problems (location of production, marketing and logistic strategies, new designs, new product con-

\footnotetext{
${ }^{64}$ Nelson and Winter 1982, 2002. See also Simon 1979 for a general discussion of bounded rationality. See Thaler 2015 for a discussion of bounded rationality in consumers' decision making.

${ }^{65}$ Nelson and Winter 2002, Nelson 2008. See also Arthur 1994, Arthur et al., 1997.
} 
cepts and other "minor" issues); they take place often - though not necessarily always - in low skill labor sectors (food, textiles, footwear, furniture) and generally involve a wide range of activities (sales, acquisitions, communications). ${ }^{66}$ In sum, low-tech innovations define a large set of creative activities that is consistent with the theoretical tenets of a broad view of innovation in the evolutionary approach. ${ }^{67}$

With the broad view of innovation presented by the evolutionary theory, the framework for analyzing the effects of technology on the economy needs to be modified. We draw attention to three main aspects in this regard.

First is the interaction between (local) innovation and technology diffusion. Evolutionary theorists highlight the view that "innovation", finding "new ways of doing things in a localized context", requires learning and assimilation rather than the simple imitation of processes and practices that are common use elsewhere. ${ }^{68}$ Second is the issue that innovation is a "systemic" concept. It has to do with the evolutionary view that this is a process that commands strong interaction between innovations conducted in different parts of the economic system, which might or might not involve pecuniary transactions. ${ }^{69}$ Third is the emphasis of evolutionary economists that the process of innovation requires considerable intervention by the government regardless of conventional market failures considerations. ${ }^{70}$ Basically, this implies the need for a systematic effort by the government to upgrade the contextual environment (socio-cultural, technological, institutional and policy aspects) and curb the limitations to the innovation initiatives of the private sector. Further elaboration on this issue follows below.

Our interpretation of the extensive evolutionary literature on this topic is that while technology diffusion brings in new ways of production-which fundamentally allow to produce more and/or cheaper - or even ideas on new products, new forms or organization and so on, those benefits are not "automatic". Deliberate choices at the receiving end of the diffusion channel are necessary to enhance the economic impact of the introduction of new technology. From this viewpoint, while technology diffusion relates to high-tech activities and is important to set technology trajectories or "technological regimes" that allow backward countries to achieve their targets, the production of innovation hinges overall on low-tech activities where entrepreneurial skills to create, increase or improve the commercial applications of technology are a necessary precondition.

\footnotetext{
${ }^{66}$ Herstatt and von Hippel 1992, Scott 2006, Hirsch-Kreinsen 2008, Foray and Lissoni 2010, Huang, Arundel and Hollanders 2010, Stephan 2002, 2010.

${ }^{67}$ Nelson 2008, Fagerberg et al., 2010. This broad view of innovation is now the core of policy making, measurement and evaluation of innovation in the empirical front. For example, innovation is deemed to comprise technologically new or significantly improved products (goods and services) and processes, for example, the design of new products, the introduction of new equipment, the logistic and marketing processes that allow to put the new products in the market, or create a demand where it did not exist before, and purely organizational and business practices. See the Bogota Manual (RICYT 2005), the Oslo Manual (OECD 2005) and World Bank 2010.

${ }^{68}$ Pack and Nelson 1999, Nelson 2008, Fagerberg et al., 2010.

${ }^{69}$ Nelson and Winter 1982, Fagerberg 2003, Nelson 2008, Foray and Lissoni 2010.

${ }^{70}$ Nelson and Winter 1982, pp. 385-395.
} 


\section{National Innovation Systems}

There is a considerable body of literature dealing with such subjects as the product life-cycle, induced innovations, localized technological change, social capabilities, technological capabilities, and absorptive capacities, that has been put forth to analyze a variety of factors that promote/dampen either the innovative potential or the technological upgrading of the business sector in backward countries: factors' endowment, technical know-how, social-cultural context, public policies, institutions, political competition, and so on. ${ }^{71}$ However commendable and sometimes also based on similar Schumpeterian notions of innovation, these strands of the literature generally lack specific discussion of the kind of issues we are concentrated on, namely the role of (local) innovation, its interaction with the process of technology diffusion, and the role of government in this context.

An alternative literature that is more closely related to our discussion is the so-called national innovation system approach-which is deemed to cope with all market and non-market interactions that play a role to foster innovation. ${ }^{72}$ From this perspective, the ability to catch up technologically and economically hinges on the ability of countries to organize the innovation activity at the widest economic extent. Hereafter, we refer to this perspective as the NIS framework.

The NIS framework may be held to bring in two main objectives. The first is to provide a language aimed at the description and comparison of national institutions, competencies, programs, policy strategies and market/non market incentive structures that play a role in generating and spreading technological knowledge (as a resource), facilitate learning (as a process), and boost innovation (as a product). The second is to shape an alternative view to the theory of technical change, whose distinctive feature is government leadership of the whole innovation process. In the latest sense, this framework seeks to explain the determinants and nature of innovation as the major economic engine, and the way the state may enhance the innovation process in order to influence economic growth. ${ }^{73}$

The contentions of the evolutionary economics on the relationship between technology diffusion, innovation and economic growth; and also the literature developed under the NIS framework in this regard, have both received scarce to no mention in the mainstream growth theory thus far. ${ }^{74}$ However, the converse is also true with the evolutionary and NIS literatures ignoring, or downplaying, the neoclassical view on technology progress and the role of innovation in that

\footnotetext{
${ }^{71}$ Atkinson and Stiglitz 1969, Abramovitz 1986, Cohen and Levinthal 1989, Basu and Weil 1998, Acemoglu and Robinson 2000, Basu and Fernald 2002, Parente and Prescott 2002, Cohen 2010, Archibugi and Coco 2004, Fagerberg et al., 2010, Lin and Monga 2011, Acemoglu 2014.

${ }^{72}$ Nelson 1993, Freeman 1987, 1995, Lundvall 2007, Soete et al., 2010.

${ }^{73}$ See Lundvall 2007. See Wirkierman et al., 2018 for a recent overview.

${ }^{74}$ To the best of our knowledge, the NIS framework has received scarce mention, alongside other references to the evolutionary approach, in Romer 1993, 1994. Acemoglu et al., 2012 and Stiglitz 2014 also refer either implicitly or explicitly to the systems approach in the discussion upon the institutional arrangement proper to fostering innovation-led cross-country growth.
} 
context. $^{75}$ We now briefly review what, in our view, determines this mutual neglect.

One area of disagreement, as we have mentioned above, is on matters of government intervention. The conventional mindset is driven by ideas of political liberalism from classical economics. In this tradition a limited role of government is sine qua non for economic prosperity. Along the provision of public goods and the enforcement of free-market institutions (property rights) the most prominent role for the government in this literature is to provide market-based incentives to entrepreneurs. By contrast both, the evolutionary and NIS frameworks, hold that appropriate government actions are needed to facilitate/guide the innovation process. As suggested above, from the evolutionary viewpoint, government action has an important role in promoting innovation regardless the conventional market failures rationale. As Nelson and Winter 1982, point out: "Thinking about the role of government should hinge on assessing the way in which active policies can modify incentives or fill out the RED endeavor so that the [research] portfolio makes sense from a social point of view". 76 Likewise, from the NIS perspective, its proponents hold - on the basis of looking at the historical evidence and the analysis of numerous country case studiesthat substantial intervention is needed to encourage the appropriate level of innovation and create/enhance competitive advantages overall when it comes to competition in the international market. ${ }^{77}$

Another crucial reason for the disagreement is a critique associated with the lack of technical/mathematical sophistication, particularly in the case of the NIS framework, which mainstream economists deem necessary to examine the most substantive questions on the factors and conditions determining economic growth over the long-run. ${ }^{78}$ It is certainly the case that the NIS analytical approach is largely based on nontechnical accounts of the nature and determinants of innovation, and its role on the economy. ${ }^{79}$ Yet, we notice that formal modelling is a well-established practice in the evolutionary approach even though this practice is with quite a different set of mathematical tools than those based on

\footnotetext{
${ }^{75}$ Nelson 2008, Dosi and Nelson 2010, Fagerberg et al., 2010, Soete et al., 2010, Lee and Malerba 2018. Lundvall 2007 pp. 109(ss), citing Arrow, pinpoints that, indeed, innovation is not suitable for mainstream ways of thinking of rational and maximizing individuals, as "...innovation has as its most fundamental characteristic that it gives rise to something that is not known in advance - and it is not possible to apply the principles of rational choice if the choice set is not defined in advance." See, also, Nelson and Winter 2002 and Soete, Verspagen and ter Weel 2010.

${ }^{76}$ Nelson and Winter 1982, pp. 187.

${ }^{77}$ Freeman 1995 and Lundvall 2007.

${ }^{78}$ See, for instance, Romer 1993, 1994.

${ }^{79}$ The NIS approach overturns the emphasis on equilibrium optimization and privileges instead the qualitative over the quantitative assessment in numerous and exhaustive country case studies. A method of analysis that resembles the so-called method of Appreciative Theorizing put forward by Nelson and Winter 1982. NIS systems are considered highly localized, and with large variation across countries, which implies that any attempt to perform quantitative or aggregate analyses is misleading. For example, in some cases, government interacts mainly with large firms (e.g., chaebols in South Korea, keiretsu in Japan), in others it builds upon networks of small firms (e.g., the Italian industrial districts). See Nelson 1993, Freeman 1995, Lundvall 2007, Soete et al., 2010 and Stiglitz 2014 for further references.
} 
conventional maximization and equilibrium. ${ }^{80}$ Extending these developments, namely Markow chains, game theory and the analysis of conditions affecting the equilibrium/disequilibrium properties of the economic system, in order to study the NIS approach to innovation is an open area for future research.

It is apparent, on the other side, that the core advantage of the NIS approach is that it provides a way to organizing numerous types of innovation policies and innovation related strategies that have been extensively suggested in the literature. ${ }^{81}$ In more general terms, it is a framework suitable for the analysis of innovation under alternative political systems. ${ }^{82}$ Therefore, it is instrumental to overcome the "pure economics" analytical approach that features prominently in mainstream economics, and also to complement the approach undertaken in the literature that focuses on institutional barriers that hinder entrepreneurship in less developed countries. ${ }^{83}$

But still it seems fair to recognize that the comparison between the evolutionary, NIS and mainstream approaches that we have depicted above surely is much more complex than we have been able to illustrate. For one, we cannot equate different growth models as belonging all and 'indistinctly' to the mainstream category. Additionally, there are, perhaps, many overlapping areas between what we refer to as 'evolutionary view of innovation' and the way the research on this front is conducted in what we refer to as the mainstream. ${ }^{84}$

Moreover, in our view, neither the mainstream approach, on one side, nor the evolutionary and NIS approaches, on the other, may be regarded individually a complete account of the key issues that matter in the academic understanding of the relationship between technology and economic growth. At its best, each approach can be seen as offering a partial understanding of the different aspects that need to be considered when we think of the economics of innovation.

The inter-temporal optimization and dynamic analysis that characterize the mainstream approach is certainly suitable to understand the long-run impacts of technology policy. In that sense, this approach overcomes the static nature of economic analysis characteristic of the NIS framework. However, the "broad" view of innovation that is discussed in the evolutionary approach, and

\footnotetext{
${ }^{80}$ See the sequence of publications on "The economy as an evolving complex system": Anderson, Arrow and Pines 1988, Arthur, Durlauf and Lane 1997, Blume and Durlauf 2005. See also Safarzyńska and van Den Bergh 2010. For an approach and references to evolutionary games see Kandori, Mailath, and Rob 1993, Medio and Negroni 1996, and Silverberg and Lehnert 1993, 1996. There are also various growth models that build on evolutionary perspectives: Verspagen 1993, Silverberg and Verspagen 1995, Silverberg 1997. See Nelson and Winter 2002 for further references.

${ }^{81} \mathrm{See}$, for instance, the large number of papers presented in the proceedings of Innovation Policy and the Economy sponsored by the National Bureau of Economic Research-NBER (Lerner and Stern 2019), the distinct aims of a range of existing government agencies to promote innovation (Breznitz, Orston and Samford 2018); and the variety of National Innovation Systems analyzed by Wirkierman et al., 2018.

${ }^{82}$ Hall 2001, Hall and Soskice 2003, Acemoglu et al., 2012, Stiglitz 2014.

${ }^{83}$ Barro 1997, Parente and Prescott 1994, 2002, Acemoglu and Robinson 2000, Damsgaard and Krusell 2010, Lin and Monga 2011, Stokey 2012.

${ }^{84}$ The author gratefully acknowledge comments by Carolina Castaldi that helped to realize the complexity in trying to neatly distinguish between mainstream and non-mainstream categories.
} 
the institutional-comparative focus of analysis that has become customary under the NIS framework, are also highly relevant. In the first case, to better the academic understanding of this research subject. In the second, to stress the importance of the complex network of interconnected institutions related to the production of innovations at the national level. Furthermore, the NIS seems a more plausible framework to represent the systemic nature of innovation, which to a large extent involves non-monetary transaction between parts of the system and hinges largely on the capacity of the government to lead the innovation process beyond the fixing of market failures.

Therefore, a unified theoretical framework that takes into account elements of the three approaches (the mainstream, the evolutionary and the NIS) seems warranted if one is really interested in explaining the fundamental role of technology as an "engine" of perpetual growth, and in providing sound justification for policy interventions in this regard. Below, we briefly reflect on the main implications of our assessment to enhance the understanding of the actual benefits of economic backwardness.

\subsection{Advantage of Backwardness Revisited}

One of the most controversial elements mentioned above is undoubtedly the emphasis on a government-led innovation approach. ${ }^{85}$ NIS economists agree that such considerations as imperfect information, incomplete, imperfect or total absence of markets (e.g., patent protection, risk finance, skilled labor), which hinder the benefits of the investment, are major "market failures" that hold back innovation. But, as they point out, the ultimate problem with the promotion of innovation is associated with its "systemic" nature. ${ }^{86}$

Writers in the NIS tradition argue, for instance, that even if property rights are well defined, human capital (education) and (efficient) financial markets are in place, and policy tools (subsidies/taxes) are available, innovation may still be precluded by the fact that the government, the education system, the entrepreneur and the investor are all different parties. ${ }^{87}$ The systemic failures aspect that is overlooked frequently in the conventional analysis focused on market failures is that, subsidies and property rights notwithstanding, there may still be low investments in innovation if financial agencies, however efficient, are reluctant to support certain projects, or if they are more risk-averse than entrepreneurs themselves are; or if the education system, however sound, falls short of enhancing the kind of qualifications that the production system

\footnotetext{
${ }^{85}$ From the mainstream viewpoint, government intervention is not (always) warranted (Le Grand 1991, Stiglitz 2008). The problem, as suggested in early research on this front, is that although intervention might be instrumental to address some market failures, it may, as well, generate higher welfare losses if the failures are exogenous to the market which, therefore, do not justify the need for policy intervention as, in that case, there is not safe guarantee of reaching superior Pareto solutions (Bullard and Butler 1993).

${ }^{86}$ Freeman 1987, Fagerberg 2003, Lundvall 1992, 1993, 2007, Hall and Rosenberg 2010, Soete et al., 2010, Lee and Malerba 2018.

${ }^{87}$ Lundvall 2007, Soete et al., 2010.
} 
requires. Unlike the systems approach, the market failures approach frequently fails to address the mismatches and misalignments between policies and actors in the system due to its focus on specific goals: for instance, while the absence of property rights discourages the production of new knowledge, the solution of granting patents in many cases ends up reducing, rather than increasing, innovation by reducing the spread of knowledge. ${ }^{88}$

Thus, the systemic nature of innovation provides the NIS framework with a basis to justify the need for active government intervention. For instance, it justifies the need for a close interaction between public and private sectors to initiate, import, modify and diffuse new technologies; it also justifies the need for for financing mechanisms funded by the public sector when and if venture capital finance is not efficiently provided by the market; and finally, it justifies the need for the coordination of complementary innovation-related activities conducted by education and training institutions, universities and technical institutes, public institutions, industry associations, and so on, and for the enforcement of networking mechanisms between upstream and downstream production sectors. ${ }^{89}$

Accordingly, the NIS framework is based on three fundamental premises:

(i) the proposition that the economic contributions of technology depend critically on the innovative activity carried out not only by private business entrepreneurs but also by universities, technical institutes and the public sector;

(ii) the proposition that government financing plays a large role in fostering innovation at all levels, basically because other sources of financing (banks, stock market) are generally risk-averse, less inclined to finance projects that carry out significant uncertainty;

(iii) the proposition that innovation is positively affected by the systemic coordination of innovative activities regardless whether pecuniary transactions are involved or not-through business networking, public-private alliances, education projects, and so on.

Formally, the NIS framework establishes that, given a technology trajectory $(\bar{A})$, innovation in backward countries $\left(A_{B}\right)$ hinges on private business innovations $(\mathrm{Z})$, government-led innovation projects $(\tilde{Z})$, government coordination $(\tilde{N})$, and government financial support $(\tilde{z})$.

$$
A_{B}=f(Z, \tilde{z}, \tilde{Z}, \tilde{N} \mid \bar{A})
$$

It is worth noting that the NIS framework does not dispute the view that backward countries' growth and catching up processes are benefited by developments that take place in leading countries (inventions, ideas, business models, entrepreneurial practices, and so on). But rather than emphasizing on measures

\footnotetext{
${ }^{88}$ Kremer 1998, Boldrin and Levine 2002.

${ }^{89}$ Nelson and Winter 1982, 2002, Freeman 1987, 1994, 1995, Nelson 1993, Lundvall 1992, 1993, 2007, Soete et al., 2010.
} 
to enhance absorptive capacities that are widespread in the literature (human capital, infrastructure, institutions) ${ }^{90}$ or accepting the usual tenet that innovation becomes an issue only at advanced stages of development, ${ }^{91}$ the NIS supporters stand out for their critical point that the government, rather than the market, is better positioned to drive the innovation process.

The role of government in the NIS framework is an increasing field of research. ${ }^{92}$ And the numerous studies in this field support the view that the NIS framework is an important way to enhance, international competitiveness and technology specialization patterns other than through conventional price mechanisms. ${ }^{93}$ However, we need to recognize that in more general terms what matters is the method of analysis in this approach. Some studies that are not based on the NIS framework but push in the same direction reach a similar conclusion: appropriate interventions by the government are an important element to encourage private investments in innovation and knowledge sharing at the economy-wide level. ${ }^{94}$

Among the various arguments one could elaborate upon to accommodate the view that active government intervention is instrumental to enhance the potential for catching up, one is the fact that technology itself is a source of comparative advantage. This is an interesting research subject that has received much attention in micro and macro economic literatures. Rather than a idealized view of technology as a global "pool of ideas", these studies investigate, for instance, the limits of knowledge diffusion given the undeniable reluctance of innovators to share the production secrets that give them the opportunity to capture proprietary rents. ${ }^{95}$

A clear implication of this literature for the analysis of technology and economic growth in cross-country settings is that along the widespread emphasis on

\footnotetext{
${ }^{90}$ Barro 1991, Levine and Renelt 1992, Parente and Prescott 1994, Coe and Helpman 1995, Coe, Helpman, and Hoffmaister 1995, Barro and Sala-I-Martin 1997, Hall and Jones 1999, Easterly and Levine 2001, Benhabib and Spiegel 2005, Jorgenson and Vu 2010, Madsen, Islam, and Ang 2010. The benefits of technology diffusion are associated in this literature to policies that facilitate international integration - through trade, foreign direct investment, and so on (Romer 1993, 1994, Sachs and Warner 1995, Grossman and Helpman 2001, Keller 2002, 2004, Lucas 2009).

${ }^{91}$ For example, Barro and Sala-i-Martin 1997, Sachs and McArthur 2002, Acemoglu et al., 2006, Aghion et al., 2013, and Lee 2013.

${ }^{92}$ Nelson 1993, Breznitz 2007, Mazzucato 2013, Mazzucato and Penna 2015, Breznitz et al., 2018, Lee and Malerba 2018.

${ }^{93}$ Lundvall 2007.

${ }^{94}$ Wade 1996, Kasahara 2004, Cimoli et al., 2010, Timmer et al., 2010, Lin, Monga et al., 2011, Stiglitz 2014.

${ }^{95}$ Dinopoulos and Syropoulos 2007 analyze how the use of strategies to protect property rents (patents, infringement litigations, delays in the introduction of new products, and so on) discourages innovation. Hobday 1995 points out that original R\&D tends to concentrate inrather than outside- headquarters (with some exceptions in pharmaceuticals and electronics). Outsoursing of R\&D activities is concentrated mostly on local design modifications in order to meet national regulations or on monitoring local advances in science and technology. Even large firms such as Samsung depended (by 1995) on original equipment manufacturing (OEM) by technology leaders for much of their consumer goods sales, whereas in Taiwan and Hong Kong, despite the growth of design skills, OEM and joint ventures with the market leaders still accounted for a large proportion of total electronics output.
} 
price-competitiveness (cheap labor, tax reductions, currency devaluations) and absorptive capacities, the ability to overcome backwardness hinges to a large extent on national strategies to generate non-price competitiveness, which means competitiveness based on innovation. ${ }^{96}$ Accordingly, competition and integration in global technology markets require discretionary policy strategies at the country level in order to overcome the limitations imposed by the economy's endowments. The latter has been a major concern in the development literature given the observed patterns of specialization and trade, characterized by the fact that the technology leading countries tend to concentrate on high-tech and knowledge-intensive production activities, whereas capital and labor-intensive activities are outsourced to backward countries. ${ }^{97}$

The discussion above leads to non-trivial policy implications. For one thing, the fact that currently most backward countries tend to privilege adoption over innovation policies relates to a view consistent with the mainstream tenet that increasing economic growth hinges on technology transfer, for which a focus on typical market incentives and absorptive capacities suffice. By contrast, the NIS framework implies more room for government action, and such approach has gained increasing recognition in the context of the development policy since it emerged around the 1980s. ${ }^{98}$ Below we analyze the main policy implications that derive from this approach.

\subsection{Policy Implications}

The debate on the proper role of government intervention in the economy is an old question that goes back to Adam Smith (1776) himself. However, asking it is still warranted, because the role of government is one of the important policy questions - if not the most important - whenever economists deal with issues of growth and catching up. ${ }^{99}$

Mainstream economics' suggestion to restrain active intervention is based on premises that are well known - namely, that intervention reduces the efficiency of the price system and provides opportunities for corruption practices (rent-seeking). To the extent that those premises are in the received theory of growth, policy makers - mainly in backward countries - are advised to design and enforce policies and institutions that stick to the efficient market hypothesis (which entails low or limited government intervention). Consequently, they tend to pursue their advantage of backwardness by favoring adoption - over innovation - policies using market incentives (e.g., taxes, subsidies) but avoiding

\footnotetext{
${ }^{96}$ Lundvall 2007.

${ }^{97}$ See Baldwin 1971, Madsen et al., 2010, and Nishioka 2013. See also the map of export trends in Hausmann et al., 2011. Lall 2000, shows that, as of 1998, just 10 countries accounted for over $80 \%$ of total exports worldwide, and this share rose with technological sophistication to reach $96 \%$ for the top 10 exporters of high technology products. By contrast, the share of world exports has declined for low-tech products, i.e., from $43 \%$ to $26 \%$ between 1985 and 1998 for resource-based and primary products.

${ }^{98}$ Soete Verspagen and ter Weel 2010, World Bank 2010, Lin, Monga et al., 2011.

${ }^{99}$ See, for instance, Stiglitz and Heertje 1989, Lin, Monga et al., 2011.
} 
intervention in other ways. This is most likely to be the case even in situations where the theory recognizes a role for the government in the economy. Note, for instance, that the support in the endogenous growth literature for public expenditures in education, R\&D programs and infrastructure (roads, airports, public services), are generally met with varying degrees of skepticism, as the following quote from Paul Romer reflects

...A lot of people see endogenous growth theory as a blanket seal of approval for all of their favorite government interventions, many of which are very wrong-headed. For example ... Infrastructure... should be provided in the same way that we provide other physical goods, with market incentives and strong property rights. A move towards privatization of infrastructure provision is exactly the right way to go. The government should be much less involved in infrastructure provision. ... Another is the notion that the government should directly subsidize particular research programs to produce particular kinds of ideas. If you compare that mechanism with the mechanism of subsidizing human capital and letting the market mechanism allocate where the human capital goes and what ideas get developed, the human-capital-based approach works better. ${ }^{100}$

The NIS framework, on the other hand, points toward the need for the government to lead the innovation process. Which, however, is not a plea for the state to replace the market as long as the ultimate goal in the NIS framework is to boost rather than discourage private sector innovation.

In other words, the NIS view is amenable to tenets that uphold overall economic stability, enforcement of property rights, and market competition. But, as we have discussed above, this framework does not imply that intervention should be confined to offset market failures. And NIS researchers do not accept that market price interventions (taxes, subsidies, and so on) fully describe the way innovation policy is conducted in countries at the frontier of technology. ${ }^{101}$ On the contrary, they hold that active intervention in the way described by the NIS framework has been, and still is, widely used to foster innovation, economic growth and catching up in developed countries - which they believe clearly suggest that backward countries have a great deal to learn from those practices. ${ }^{102}$

Let us elaborate upon a more detailed discussion of the NIS mechanisms. On the basis of an extensive literature review, we propose to narrow the aim of this framework to three crucial aspects, namely sponsorship, leadership and coordination. ${ }^{103}$

\footnotetext{
${ }^{100}$ Snowdon and Vane, 2005, pp. 690, Interview with Paul Romer.

${ }^{101}$ Nelson 2008

102 Nelson and Rosenberg 1993.

${ }^{103}$ Nelson 1993, Freeman 1995, Lundvall 2007, Soete et al., 2010, Mazzucato 2013, and Stiglitz 2014.
} 


\subsubsection{Sponsorship}

In the NIS approach, government has a role in facilitating the financing that allows innovation projects to succeed. Financial support to private business innovation touches, of course, on many standard arguments of "failures" in the financial market, as well as on issues of financial regulation, monetary policy, and more generally, macroeconomic stability. The NIS argument, however, is that beyond fixing market failures, innovation requires risk capital that private innovators are generally unable to incur, and traditional financial institutions frequently have no incentive to provide. ${ }^{104}$ Indeed, it is generally acknowledged that innovation activities are hardly financed in competitive market settings.

The sponsorship mechanism in the NIS framework entails a broad range of public activities and programs designed to financially funding private innovation initiatives. This includes the direct financing of basic research, scientific projects or scientific institutions (through fellowships, grants, awards), and government procurement expenditures (the government acting on the demand side) which allow private investors to bypass the restrictions imposed by financial markets and have a direct impact on the technology investments of the business sector. ${ }^{105}$

It is worth emphasizing in this discussion that whilst financial incentives to innovation are a well established practice in the most advanced countries, they are weakly institutionalized in backward countries. Along the obvious case of resource constraints in many countries, this lack of financing schemes relates to the fact that the theoretical underpinnings of systemic innovation - in the broad sense we have been discussing here - and the ways to finance it, are not informed by the received theory of economic growth.

Certainly, the financial practices to boost innovation that are described in the NIS literature are not unique to this analytical framework. A stylized fact that characterizes the financial landscape of technology activities is that large R\&D projects enjoy various sources of finance: through public funds, the stock market or credit institutions, whereas small innovation projects rely on venture capital as they frequently they do not fit neither the stock market's nor the commercial banks' criteria for commercial credit or other forms of financing. ${ }^{106}$ In fact, the widespread reluctance of financial markets to sponsor innovation projects unless proper guarantees (collateral assets) and/or convincing cost-benefit analyses are fulfilled provide quite a generalizable argument for the development of venture capital markets instead. ${ }^{107}$

Yet, the creation of venture financial markets is a necessary but not a sufficient condition to ensure that financial resources for innovation are efficiently provided by the market. There is a number of reasons as to why this might be the case: first, in many instances this alternative, namely venture financing, is not available to those firms that need it more (startups and new entrants that begin to explore the market); second, venture financing is frequently a function

\footnotetext{
${ }^{104}$ Lundvall 2007, Mazzucato 2013, and Stiglitz 2014.

${ }^{105}$ Cohen 2010, Foray and Lissoni 2010, Stephan 2010.

${ }^{106}$ Cohen 2010, Hall and Lerner 2010.

${ }^{107}$ Almus and Czarnitzki 2003, Dosi et al., 2006, Hall and Lerner 2010, Becker and Hall 2013.
} 
of the stage of development of a new product or process; and third, more often than not venture financing by private investors depend on the event that innovators are worthy of receiving third-party funds. In this context, public funds and publicly guaranteed finance for innovation turn out to be the most obvious sources. And this proposition is even more applicable to backward countries given the small scale or actual absence of venture capital markets in those countries. ${ }^{108}$

In advanced countries, like the major OECD countries, the financing of innovation through public channels has a long history as governments in general have supported the view that innovation commands the use of risk capital. This includes investment funds which are guaranteed or assigned directly by the government in soft conditions through a variety of mechanisms. ${ }^{109}$ As Mokyr 2010, pointed out: 'it is clear that there [is] more than one way to skin [the] cat,' in the sense that there are many ways activist governments have over time financed innovation activities: tax reliefs, exemptions and deductions, tariff protection, non-payable allowances. In spite of the widespread criticism related to the "picking-winners" problem, in many cases these activist interventions are program or sector specific.

Finally, it is worth noting that the broad practice of sponsorship in countries at the frontier and countries that have managed to catch up is broadly documented. Some examples that are recurrent in the literature are: the US National Science Foundation funding role in the research that led to the development of Google's platform, the role of the Small Business Innovation Research Program in providing venture capital to start-ups in the US economy, and the UK Medical Research Council funding that led to development of molecular antibodies that are at the frontier of research in biotechnology. ${ }^{110}$ Similar examples are common with regard to the financial aspect of innovation systems in Japan, Taiwan, and South Korea, among others. ${ }^{111}$

\subsubsection{Leadership}

The argument that innovation carried out by the public sector itself plays a leading role in increasing innovation capabilities, and even the commercialization advantage of key activities in the private sector, is another essential feature of the NIS framework. In the growth literature there is large, though not full, consensus that the government should undertake investments in research programs that by their nature are unattractive for the private sector. This includes, of course, basic sciences and pioneering fields (the internet, nanotech, biotech).

The point highlighted by the NIS mechanism of leadership, widely supported on anecdotal evidence, is that the pioneering research initiated by the government itself and then handed over to spur a variety of activities in the business

\footnotetext{
${ }^{108}$ The limited role of the venture capital market is a feature even in advanced economies, see Mazzucato 2013, Stiglitz 2014.

${ }^{109}$ Hall and Lerner 2010, Mazzucato 2013.

${ }^{110}$ Mowery and Rosenberg 1993, Cohen 2010, Mazzucato 2013.

${ }^{111}$ Kim 1980, 1993, Freeman 1995, and Wade 2009.
} 
sector (agriculture, electronics, medicine, transport) has given rise in many instances to marketable innovations which have been key drivers of disruptive innovations leading to long run growth and further innovation. ${ }^{112}$

Although the focus on the economic impact of government research activities is not an exclusive concern of the NIS framework, there are key differences between mainstream and NIS economists in this regard. It is generally accepted that research conducted in public laboratories is a centerpiece in increasing basic science and technology knowledge, and in enhancing the conditions that lead to the introduction of new technologies by the private sector. The leadership argument holds, however, that - unlike widespread mainstream theoretical tenets - in countries at the frontier of technology, the government itself, in many instances, conducts research that benefits either directly or indirectly the business sector - rather than just enabling the market "conditions" that spur innovation. ${ }^{113}$

From the NIS perspective, public research has large external effects on the private sector commercial innovation activity. Technology originated in the public sector - and subsequently handed out to the private sector - allows the latter to take over only the more profitable commercialization role without the cost of investment. Moreover, public research has been extensively argued to have large influence on the kind and direction of innovation activities conducted in the private sector, and even to lead to the creation of new markets where they did not exist before. ${ }^{114}$

Researchers have largely discussed that a key factor to explain the economic growth performance of even the most capitalist US economy has been the research conducted by the federal government. In many cases this discussion relates to the economic impact of technologies that were linked earlier to military purposes, but research conducted in government labs, or directly sponsored by the government, and subsequently disseminated to the business sector for commercial purpose is widely documented. ${ }^{115}$ A recent assessment of the research notes that:

...An extensively studied extraindustry influence on technological opportunity is that of government. In numerous sectors, notably agriculture, aircraft, electronics, and medicine, government has contributed to reducing the private cost of innovation and has influenced the direction of industrial research by its own research, by its support of academic research, by subsidizing and sponsoring private sector research and by disseminating technological knowledge developed in its own labs and elsewhere. The distribution of government expenditures on RGD across industries is highly skewed, especially in the United States, where industries supplying the military, and, more recently, universities conducting research in the life sciences, are the principal

\footnotetext{
${ }^{112}$ Cohen 2010, Mokyr 2010, Mazzucato 2013.

${ }^{113}$ Mazzucato and Penna 2015, Breznitz, Ornston and Samford 2018.

${ }^{114}$ Viotti 2002, Trajtenberg 2002, Mazzucato 2013.

${ }^{115}$ Mowery and Rosenberg 1993, and Mazzucato 2013.
} 
recipients of $R E B D$ support. Although its direct role in creating and disseminating knowledge is substantial in some sectors, its indirect influence is also felt through a variety of other channels that have different impacts across industries. Most important is the impact of government demand on the rate and direction of innovation. ${ }^{116}$

Another example in regard to government leadership is the NIS project itself, which emerged from the concern in industrialized countries over finding alternatives aimed to enhance competitiveness and growth prospects. The NIS initiative, in this context, is considered to be a way toward understanding the determinants and enhancing the creation and diffusion of knowledge throughout the economy. ${ }^{117}$ This concern has been central to support a permanent production of country-based studies and the standardization of performance indicators focused on patterns of knowledge and innovative potentials that allow comparison across countries. ${ }^{118}$

\subsubsection{Coordination}

Coordination, like the other two aspects of the NIS framework that we have analyzed above, is a broadly used concept in the economic literature. In the NIS perspective, we have framed it as a way to ensure that the productive effects of innovation extend across all sectors of activity and benefit the whole economy through all kinds of market and non-market mechanisms (research networks, value chains, public private partnerships, laboratories for applied research in support of small and medium enterprises). ${ }^{119}$

Coordination failures have been largely featured in mainstream economics simply as market failures: situations where the economy exhibits low levels of activity because of a divergence between actual private and socially optimal investment decisions. ${ }^{120}$ Accordingly, these have been argued situations warranting some type of government intervention, though the form and duration of such interventions remain issues of debate. It is precisely with regard to these two aspects that the NIS approach differs from mainstream economics.

Regarding the form of government intervention, it operates either through policies that influence the allocation of resources, or policies that encourage sectoral complementarities (or a combination of both). Mainstream economics relies mostly on the allocation mechanism. From this perspective, coordination failures - the lack of "synergism" or "complementarity" between different economic activities - are deemed to arise simply from price rigidities and might be overcome simply through active monetary policies to improve the coordination of price adjustments. ${ }^{121}$ It seems apparent that under the allocation mecha-

\footnotetext{
${ }^{116}$ Cohen 2010, pp. 179.

${ }^{117}$ Freeman 1987, 1995, 2004, OECD 2013.

${ }^{118}$ Mairesse and Mohnen 2010, Soete et al., 2010.

${ }^{119}$ Foray and Lissoni 2010, Stephan 2010.

${ }^{120}$ Bohn and Gorton 1993.

${ }^{121}$ Ball and Romer 1991, Mankiw and Romer 1997.
} 
nism, the key incentive to boost innovation hinges on the ability of government to coordinate price changes throughout all sectors of activity.

The NIS framework focuses instead on the potentials of the complementarity approach. The rationale is similar to the "big-push" approach: investments in innovation in one sector may fail to occur whenever complementary investments are not made in other sectors. ${ }^{122}$ The interactive nature of innovation in this approach - where innovation is conducted partly by firms in the business sector, and partly by non-market organizations (e.g., universities, government labs) domestically and abroad-implies government interventions other than through market mechanisms. Typically, this involves aspects of networking and collaboration between the distinct parts of the system, and policies to encourage knowledge transfers from international sources. ${ }^{123}$ These aspects are not disputed by the mainstream theory, but the latter's view of them is to enhance market transactions, whereas the NIS approach holds them as nonmarket channels of technology transfer. ${ }^{124}$ That is, in the NIS framework, issues of networking and collaboration do not hinge on price incentives, or at least not necessarily.

Regarding the duration aspect, the mainstream view is that any intervention to adjust coordination failures should be limited to the time necessary to get the economy out of the situation with low levels of activity. ${ }^{125}$ By contrast, as we have already pointed out, government coordination is a permanent feature of the NIS approach beyond the concern to fixing market failures. The latter argument is highlighted also from the perspective of evolutionary economics. As pointed out by Nelson 2008, innovation, economic growth and catching up are ever-changing phenomena, which means that they cannot be properly assessed as if they were states of equilibrium. ${ }^{126}$

Summing up, the view of innovation as a process led by government coordination rather than as an outcome of the logic of the market is a crucial hallmark of the NIS approach. And, noticeably, the notion of coordination underlying both the NIS and evolutionary frameworks, is held as something more complex than temporal interventions for the sake of addressing market failures. Under the systemic NIS approach, governments need permanently to enact broad policy directions, establish/adjust the institutional framework, and generate networks to promote the creation and diffusion of innovation. Thus, governments are regarded as key to influencing the entire national innovation process; the degree to which countries are (un)able to thread the whole NIS is

\footnotetext{
${ }_{122}$ Murphy, Shleifer, and Vishny 1989, Soete et al., 2010.

${ }^{123}$ The importance of the coordination mechanism is highlighted as well from the evolutionary viewpoint, Nelson and Winter 1982 (pp. 358) pointing out that 'Nothing in those [welfare] theorems says that planning or regulation cannot be made to work (optimally)'.

${ }^{124}$ Soete et al., 2010.

${ }^{125}$ Murphy, Shleifer, and Vishny 1989 holds that in the face of coordination failures government intervention may help to move the economy from any "inferior" toward a "superior" equilibrium. That is, consistent with the market-failure approach, they hold that the temporal intervention of the government must cease at the point where the market has reached a "superior" equilibrium. See also Ball and Romer 1991.

${ }^{126}$ Nelson 2008.
} 
symptomatic in understanding their growth and catching-up performance. ${ }^{127}$

\subsection{Concluding Remarks}

The review in this section has sought to contribute to the research effort to understand the economic impacts of technology diffusion and local technology in backward countries. In doing so, we have started by looking at the actual understanding and use of the notion of technology in mainstream economics and have called attention to the major shortcomings of that view that prevent us from a serious analysis of the importance of innovation in studying the determinants of economic growth.

Then we emphasized the importance of broadening the definition of innovation to include both mainstream views of technology and novel contributions in this regard by the evolutionary and NIS theories; we have discussed how these distinct sources of technology (foreign technology and local innovation) are embedded in the theory, and how the contesting theoretical frameworks put forward by the mainstream, on one side, and the evolutionary and NIS perspectives, on the other, lead to a different understanding of the determinants of economic growth, and the prospects of backward countries to catching up; finally, we have elaborated on the corresponding policy implications.

In particular, with regard the last point above, we have stressed that the conceptual and methodological differences between the mainstream and the evolutionary and NIS perspectives have clear implications for the understanding of the notion of advantage of backwardness and its corresponding policy implications. We have pointed out that the evolutionary perspective supports the view that innovation-broadly defined - offers a better explanation of the growth and catching up processes in backward countries, hence it calls for the design and enforcement of a coherent set of economic policies to encourage innovation in the private sector. In this regard, the NIS framework - whose fundamental premises have been narrowed here to what we hold are the three essential aspects of sponsorship, leadership and coordination - departs from the conventional view that ask for limited government intervention on the economy instead.

To the extent that those conceptual, methodological, and even ideological, differences between the mainstream and the evolutionary and NIS perspectives preclude a fair academic understanding of what are the true determinants of growth and catching up - and more so when it comes to the case of backward

\footnotetext{
${ }^{127}$ There are at least two important criticisms to government intervention in the economy: First is the possibility of "government failures", as mainstream economics holds that intervention can do more harm than good to the economy. That possibility is not neglected neither by the NIS authors, who point to many instances where government intervention has resulted in big failures, nor evolutionary economist. Moreau 2004, for instance, highlights the need of government action '...in the more realistic framework of the economic system displayed by the evolutionary approach' even though the success of public intervention is truly uncertain. The second important criticism we alluded to, refers to the possibility of political constraints which are more likely to arise in less developed countries, for example, in the form of barriers to technology adoption raised by special interests (Parente and Prescott 1994).
} 
countries - our attempt has been to provide a more coherent basis for the analysis of innovation and economic growth, and the role of the government in this context.

In the next chapter we endeavor to elaborate a model suitable for analyzing those issues. 


\section{Chapter 4}

\section{A Formal Model of Growth and Catching up}

\subsection{Introduction}

This chapter develops a model that puts together the mainstream, evolutionary and NIS perspectives on the ability of countries to catch up. ${ }^{1}$ In the model, growth and catching up hinge on the interaction between the diffusion/adoption of foreign technology and (local) innovation. In the perspective of evolutionary economics that we have discussed in the previous chapter, we rely on a broad notion of innovation that includes both low-tech and high-tech innovations; and we hold that the interplay between adoption and innovation is strongly influenced by the institutional/policy conditions in the domestic economy, which we relate to the NIS literature. In particular, we highlight the role of what has become widespread as the public financial sponsorship of innovation. ${ }^{2}$

Our theoretical framework adds to recent models exploring the dynamics of adoption and innovation. ${ }^{3}$ Like those models, the one presented here is a model of endogenous growth with technology diffusion. Unlike them, however, we do not hold that adoption and innovation are sequential stages where backward countries first profit on the economies of scale that are boosted by the inflow of output-augmenting and cost-reducing foreign technologies and, only upon reaching high levels of development, are in the position to innovate. Quite to

\footnotetext{
${ }^{1}$ As it has been pointed out in previous chapters, the mainstream view in our discussion relates to the theoretical developments after the Solow model (Solow 1956, Lucas 1988, Romer 1994, Jones 2005, Acemoglu 2014). The evolutionary view relates mostly to the literature that followed from insights presented in Nelson and Winter 1982, (see Nelson et al., 2018). And the NIS literature follows from the ideas prominently presented by Freeman 1987, Nelson 1993, Lundvall 1992, 1993, 2007 and Soete et al., 2010. The recent discussion in these literatures is traced back to many other references provided earlier (Chapter 1) which we omit here to avoid repetition.

${ }^{2} 2010$, Mazzucato 2013, Kerr and Nanda 2015, Mazzucato and Penna 2015, Gush, Jaffe, Larsen and Laws 2017, Breznitz et al., 2018.

${ }^{3}$ Damsgaard and Krusell 2010, Stokey 2012, Benhabib et al., 2014, 2017, Perla et al., 2015.
} 
the contrary, we highlight that innovation occurs at all times and is in fact the dominant strategy for producers to survive the pressures of market selection and market competition.

Our approach also contributes to the research and debate about the appropriate policy/institutional measures to support innovation. ${ }^{4}$ In particular, we hold that the process of local innovation requires a role of the state that goes beyond mere market-conforming considerations that are usually highlighted in mainstream economics. ${ }^{5}$

It is noteworthy that in Chapter 3, we have established - on the basis of an extensive review of the literature - that the NIS framework provides a sound theoretical framework to justify government interventionist policies aimed to enhance innovation. We classified the key mechanisms of intervention into three aspects: Leadership, which relates to public innovation and collaboration with the private sector; coordination, which summarizes a wide range of strategies designed by the government to encourage the spread of innovation at the wide economy level; and sponsorship, which copes with a broad range of public programs to financially support private innovation initiatives. ${ }^{6}$ Our focus here to modelling the sponsorship mechanism is an attempt to provide theoretical foundations to what has become the most widespread practice to foster the production of innovation.

As we have anticipated, the notions of adoption and innovation on which we elaborate here are informed by the evolutionary theory and the NIS literature. However, in spite of the widespread criticism by evolutionary economists to orthodox maximization/equilibrium approaches and differently from the, mostly, static nature of economic analysis that characterizes the NIS approach, our approach sticks to the intertemporal optimization and dynamic analysis that is customarily employed when the purpose is to study the long-run impacts of technology on economic growth. In addition, in the model below, the process of intertemporal optimization is carried out by private agents. Thus, our approach differs also from - in fact it is supplemental to - the institutional-comparative focus of analysis that has become customary under the NIS approach.

In the following section, Section 4.2, we trace earlier models of growth and catching up through adoption and innovation in order to contextualize our ap-

\footnotetext{
${ }^{4}$ Acemoglu, Akcigit, Alp, Bloom, and Kerr 2013, Gorodnichenko and Schnitzer 2013, Khan 2015, Akcigit, Hanley, Stantcheva 2016.

${ }^{5}$ This market-conforming setting is usually described as involving pure pecuniary transactions, and confines the role of government to fiscal and monetary policies (e.g., taxes, subsidies), fixing market failures, and enforcing conventional absorption capabilities and market institutions (property rights, market integration, financial development). See, for instance, Barro 1997, Rodrik 2005, World Bank 2008, Lucas 2009, Spence 2011, Acemoglu et al., 2012, Stokey 2012. While it does not deny the importance of those conditions, the NIS perspective holds - upon the basis of numerous country case studies - that successful cases of growth and catch-up are related to a more activist role of the state: influencing the establishment of key business models and economic activities, carrying on R\&D activities and funding new industries on its own, financing venture capital entrepreneurship, and so on (Nelson 1993, Lundvall 2007, Soete et al., 2010).

${ }^{6}$ See, among many others, Nelson 1993, 2008, Freeman 1987, 1995, 2004. Lundvall 2007, Soete et al., 2010, Mazzucato 2013, and Stiglitz 2014.
} 
proach. In Section 4.3, we lay out the basic setup of the model in this chapter. In Section 4.4 we describe how the government sponsorship mechanism affects the level of domestic innovation and the process of catching up. In Section 4.5 we develop the solution of the optimization problem using optimal control techniques. In Section 4.5 we provide some concluding remarks.

\subsection{Related Literature}

Our aim in this section is to draw attention to some recent and most representative contributions that investigate the dynamics and economic impacts of these distinct sources of a country's technology.

First, note that a great deal of the mainstream literature building on the distinction between technology diffusion/adoption/imitation on one side, and the development of original innovations on the other, originates in microeconomic models. ${ }^{7}$ The theoretical reasoning underlying these models is that R\&D investments in laggard firms are necessary to enhance the process of technology diffusion. ${ }^{8}$

Interestingly, some aggregate models of economic growth simply extend this logic to the interaction between adopters and innovators with different countries. ${ }^{9}$ In such setting each country's technology choices are motivated by purely economic reasons, for example, free-rider incentives that make it optimal for some countries to purposely limit their own innovation investments - and fall behind - in order to grow through the adoption channel, whereas more advanced countries innovate and push the frontier ahead. ${ }^{10}$

In more general terms, however, the widespread understanding in formal models of economic growth is that for developing countries growth and catching up are determined by the inflow of foreign technology - even if the benefits of adoption are modulated by local circumstances. ${ }^{11}$ This idea is underlined by the notion of advantage of backwardness according to which technology progress in countries falling behind is exogenously given by the advances at the frontier. ${ }^{12}$ From this viewpoint, the benefits brought in by the adoption of foreign technology depend on the distance to the frontier: the greater the distance the higher the benefits - as there is more room to grow. Within this framework, to be able

\footnotetext{
${ }^{7}$ Cohen and Levinthal 1989, Jovanovic and Nyarko 1996, Griffith, Redding, and van Reenen 2004, Perla and Tonetti 2014, Perla, Tonetti and Waugh 2015, Luttmer 2015 and Acemoglu and Cao 2015.

${ }^{8}$ Alternatively, this literature emphasizes the logic usual in search theoretical models: individual innovators are subject to a stochastic flow of new ideas from the frontier. When they receive an idea that is better than the one they are now producing with, they adopt it and it becomes their current state. Otherwise, their state remains unchanged. (See, for instance, Kortum 1997, Alvarez et al., 2014, and Lucas and Moll 2014).

${ }^{9}$ For example, Benhabib et al., 2014, Alvarez et al., 2014.

${ }^{10}$ Benhabib et al., 2014.

${ }^{11}$ See, for instance, Easterly et al., 1993.

${ }^{12}$ Gerschenkron 1962, Acemoglu et al., 2006. Brezis, Krugman and Tsiddon 1993, propose a model where the advantage of backwardness leads to shifts in leadership. New technologies benefit much more lagging nations and allow them to leapfrog and take the leadership.
} 
to reap the benefits of the technology advance abroad, backward countries need to enhance their absorptive capacities (through investments in human capital and infrastructure, and enforcing market institutions), and overcome the constraints to technology adoption imposed by domestic political circumstances. ${ }^{13}$

The idea that technology diffusion requires of the backward country investments aimed to master/adapt foreign technologies to the local environment may be traced back at least to the notion of "localized technological change." 14 According to this perspective, the improvement brought in by new technologies is specific to particular production techniques, which implies that the technology advance at the frontier can turn out to be inappropriate in backward country settings. Or at least that firms in developing countries would only learn and bring in technologies that are closely related with the factors' endowment of the economy and their own production activities. ${ }^{15}$ A recent update of this theory has broadened the analysis to include the so-called "induced innovations" and "directed technological changes." 16 In short, these are concepts of technology that may be described as attempts to show that technology change either improves or gets influenced by a country's factor endowment: new technologies are chosen either to improve a country's well-known techniques, to compensate for factors that are scarce, or to augment a given factor's productivity. ${ }^{17}$

Most, mainstream, growth models that place stress on issues of adoption and innovation build on the same insights provided by the above lines of research. ${ }^{18}$ That is, in most of the conventional models of this kind, the key aspects shaping the ability of countries to grow and catch up out of the advance of technology are their own investment in human capital, and the spillovers from the corresponding investments in more advanced countries, whose impact hinge on the congruence between foreign and local technology. ${ }^{19}$ The essential - though straightforward -implication is the need to allocate resources for investments in education and training of the work force. ${ }^{20}$

The other, recurrent, feature in existing models is that they relate the ability of countries to foster technology - and then economic growth and catch up - to their institutional/policy framework. The neoclassical context repre-

\footnotetext{
${ }^{13}$ See, for instance, Caselli 2005, Caselli and Coleman 2006, Acemoglu et al., 2006, Aghion and Howitt 2006, Stokey 2012, and Acemoglu et al., 2012. For earlier developments, see Nelson and Phelps 1966 and Gerschenkron 1962. Parente and Prescott 1994, provide the usual motivation for the role of political barriers.

${ }^{14}$ Atkinson and Stiglitz 1969.

${ }^{15}$ Basu and Weil 1998, Basu and Fernald 2002.

${ }^{16}$ Acemoglu 2014.

${ }^{17}$ See Acemoglu 2014 and the references therein.

${ }^{18}$ Damsgaard and Krusell 2010, Vandenbussche, Aghion and Meghir 2006, Stokey 2012, Benhabib et al., 2014.

${ }^{19}$ Grossman and Helpman 2001, Vandenbussche, Aghion and Meghir 2006, Damsgaard and Krusell 2010, Stokey 2012, Benhabib et al., 2014.

${ }^{20}$ In order to test this proposition some theoretical models are tied up with a quantitative assessment of the argument, for instance, the potential for adoption (or imitation) is gauged from a country's share of population with up to secondary education; in turn, higher levels of education are associated with the potential to produce innovations of its own (Vandenbussche, Aghion and Meghir 2006).
} 
sented in these models - we already pointed out - may be described as a marketconforming set of institutions (property rights, international integration, financial institutions) and policies (taxes, subsidies) that provide incentives for the business sector firms to thrive on innovation. ${ }^{21}$ Models that relate the failure to adopt foreign technology to (local) political circumstances belong to this kind. In short, those models hold that (local) political elites may deliberately block the adoption of new technologies - or the enforcement of any set of institutions and policy conditions in this regard - for fear that the new set of conditions would lead to the reduction of their political power. ${ }^{22}$

In summary, most existing models of growth and catching up tend to emphasize on some of the important though relatively simple set of conditions that are needed to foster "virtuous circles" of technology investments and economic growth. A widespread criticism of those models is on their pretension of "universal validity" which makes them unable to predict the consequences of the alternative policy regimes that are usually embraced by countries in order to foster the production of technology and innovation. ${ }^{23}$ Evolutionary models that focus on the interaction between technology diffusion and domestic technology, may be seen as an attempt to fill in this gap. ${ }^{24}$

The model presented in this chapter adheres to the latter kind of models. Consisting with the discussion in Chapter 3, we rely on a clear-cut distinction between adoption and innovation. Whereas in most of the above models technology is broadly equated to R\&D activities and human capital issues, the model presented here sticks to the thesis - now widespread in development policy debates - that innovation defines broadly the ability to produce "something new" in a certain context, in particular "something" that has economic value and whose production depends in many instances on non-R\&D related activities. ${ }^{25}$ However, rather than an optimal portfolio of adoption and innovation, we hold that these two sources of technology are intertwined with each other, therefore, it is the interplay between adoption and innovation what determines the ability of backward countries to catch up.

To better understand the key distinction between these two sources of a country's technology, we propose to associate technology adoption with the inflow of high-tech developments which are carried out in the most advanced countries (ICT, nano-tech, bio-tech, machines and equipment). In turn, we propose to associate the notion of local innovation with low-tech developmentsthe applications of existing technology to the design, production, marketing and distribution of final consumer products.

We do think that this distinction between technology adoption and inno-

\footnotetext{
${ }^{21}$ Romer 1993, Grossman and Helpman 2001, Lucas 2009, Acemoglu et al., 2012, Stokey 2012.

${ }^{22}$ Parente and Prescott 1994, 2002, Acemoglu and Robinson 2000, 2003, Damsgaard and Krusell 2010, Stokey 2012.

${ }^{23}$ Hall 2001, Hall and Soskice 2003.

${ }^{24}$ Dosi et al., 1994. Cimoli and Soete 1992, and Kelly 2002, Castellaci 2008 and Ertur and Koch 2011.

${ }^{25}$ Nelson and Winter 2002, Lundvall 2007, Nelson 2008, Fagerberg et al., 2010, World Bank 2010 .
} 
vation not only makes good sense; it also helps to reconcile the different emphases that are given to these distinct aspects of technology in the mainstream and in the evolutionary and NIS frameworks. ${ }^{26}$ By associating technology diffusion/adoption with high-tech activities and (local) innovation with low-tech activities, our aim is twofold. First, to highlight what we consider the most salient stylized feature of technology diffusion, which is that key technological breakthroughs are actually produced in a handful of countries at the frontier. ${ }^{27}$ Second, to call attention to the, frequently neglected, fact that lots of market innovation activities that not necessarily even count as technology breakthroughs, have a large impact on economic activity and appear to be an essential aspect of market competition. ${ }^{28}$ Many examples from the business literature emphasize that innovation (leading to product-variety), rather than the sole attention to price/cost margins, is the key element to survive the pressures of selection and competition. Producers are aware that first, and even second, generation versions of a given product may do well but, at large, competitiveness stems from matching the consumers' never-ending craze for the new. ${ }^{29}$ Therefore, investing in innovation, rather than in cost-reducing technologies, appears to be more important at the firm level in spite of it being a high-risk business. ${ }^{30}$

Thus, the emphasis on innovation as the most determining factor of economic growth and catching-up seems well grounded on actual business practices. And it does not contradict the view that the adoption of frontier technology leads to significant gains in productivity. Our point here is that the ability to produce more out of the same inputs, or to reduce production costs, plays an important role in first-generation products. However, this advantage is common to all countries (a technology trajectory); and the benefits of scale decline over time (in second and third-generation versions of the same product). This might be, at least partially, a reason why the standard view of efficiency cannot generate long-run growth and catching-up without a focus on the ability of backward countries to innovate.

Another key difference in the model presented below with respect to those in the mainstream tradition discussed earlier regards to the institutional/policy

\footnotetext{
${ }^{26}$ As has been pointed out in previous chapters, the long lasting tenet in the received theory of economic growth is that the ability of backward countries to catching up depends basically on the adoption/imitation of "best practices" and inventions that have been developed in highly advanced countries (De Long and Summers 1991, Romer 1993, Mankiw et al., 1995, Keller 2002, Caselli and Wilson 2004). That view is in strong contrast with the importance of learning and assimilation that characterizes the entrepreneurial environment in the evolutionary approach (Nelson and Winter 1982, 2002, Nelson 2008), and also in contrast with the focus on the systemic interdependencies between different parts of the innovation system in the NIS approach (Fagerberg 2003, Lee and Malerba 2018).

${ }^{27}$ Keller 2004.

${ }^{28}$ Herstatt and von Hippel 1992, Hirsch-Kreinsen 2008, Som and Kirner 2016.

${ }^{29}$ From this perspective, lengthening/shortening the hemline of women's apparel, adding fruit and flavors to a yogurt or packing it in single server containers, or changing the design of automotive bumpers, count as much as new android apps, e-commerce and social media networking to spur business profits. See Gatignon, Gotteland, Haon and Zimmer 2015.

${ }^{30}$ Failure rates behind actual cases of success ranging up to $90 \%$ even before new products are launched to the market or before new processes actually implemented (Castellion and Markham 2013).
} 
framework. In particular, we set up a framework where innovation is explicitly affected by the government financial sponsorship mechanism of the NIS framework that we have aimed to characterized in Chapter 3.

\subsection{The Model Setup}

Consider a context where productivity differences between country " $i$ " and the frontier are proportional to differences in technology. ${ }^{31}$

$$
y_{i}(t) / \bar{y}(t) \approx A_{i}(t) / \bar{A}(t)
$$

where $y_{i}(t)=Y_{i}(t) / L_{i}(t)$, and $\bar{y}_{i}(t)=\bar{Y}_{i}(t) / \bar{L}_{i}(t)$. We define the frontier, $\bar{A}$, to consist of high-tech developments that are available to all countries. Thus countries strive to reach the frontier enhancing the capacity to produce local innovation. " $A_{i}$ " broadly defines the ability of country " $i$ " to seize the opportunities associated with both technology diffusion and the ability to produce indigenous innovations. ${ }^{32}$ Thus, from the viewpoint of backward countries, $\bar{A}(t)$ is exogenously given whereas $A_{i}(t)$ is endogenously determined.

We assume also that $A_{i}(t)$ denotes the economy-wide aggregate level of innovation accumulated across all economic activities $(j)$ and over time $(\iota)$

$$
A_{i}(t)=\iint_{0}^{1} P A(j, \iota) d j d \iota
$$

where sectoral innovations are normalized in a $0-1$ range, and $\mathrm{P}$ is an arbitrary scale factor. The idea here, following from the literature on the so-called economics of ideas, is that the current level of innovation is a composite of the experience and knowledge accumulated over all economic sectors over time. ${ }^{33}$

Country $i$ 's final output is produced according to the following production function

$$
Y_{i}(t)=f\left\{A_{i}(t), L_{i}(t)\right\}
$$

The technology from the frontier, $\bar{A}$, influences this production function indirectly through its impact on the dynamics of innovation - as we see below. ${ }^{34}$

While having labor (L) in the production function seems more natural, the analysis of the economics of innovation is commonly focused on the productivity effects of investing on this kind of activities. Therefore, in what follows, we model the economy in per worker, or intensive, form. In general, to avoid misinterpretation, we assume that $\mathrm{L}=1$. For further simplification, we assume,

\footnotetext{
${ }^{31}$ Alternatively, we might stipulate that differences in output-per-worker across countries are proportional to differences in productivity, which in turn are proportional to differences in technology.

${ }^{32}$ While this is a non-trivial aspect in the growth literature, throughout we hold the strong assumption that the countries in our analysis do not exhibit absorptive constraints, namely human capital, standard market institutions, political conditions.

${ }^{33}$ Romer 1993, Jones 2005, Stokey 2012.

${ }^{34}$ The author is grateful to Adriaan van Zon for helpful discussion which led to clarify this effect.
} 
that all labor is employed in the production of innovation, that labor size and population size are the same, and that the rate of growth of population is zero. These simplifications allow us to jump from productivity considerations to the welfare implications of our analysis without a concern for the distinct scales of the variables and simplify the constraints on our optimization approach (the reasons to be explained shortly below).

The production function in per worker terms is

$$
y_{i}(t)=f\left\{A_{i}(t)\right\}
$$

where $f\{0\}=0, f^{\prime}>0, f^{\prime \prime} \leq 0 .{ }^{35}$ Note that while output is in per-worker units in Equation (4.1), innovation is still measured at the levels of the variable. This implies that, at the economy-wide level, productivity depends on the absolute level of innovation rather than on per-worker innovations, a feature that has been established earlier in the literature of economic growth. ${ }^{36}$ Suppose, for instance, that the production function is given by ${ }^{37}$

$$
Y_{i}(t)=f\left\{A_{i}(t), L_{i}(t)\right\}=A_{i}(t)^{\alpha} L_{i}(t), \quad 0<\alpha \leq 1
$$

where there are constant returns to the labor factor and increasing returns to labor and the level of innovation taken together. Written in per worker terms, this production function becomes

$$
y_{i}(t)=f\left\{A_{i}(t)\right\}=A_{i}(t)^{\alpha}, \quad 0<\alpha \leq 1
$$

\subsubsection{The problem of the representative agent}

Let us assume a representative agent in the private sector who wants to maximize the value of some utility function $U(C)$. In an economy without government consumption and with balanced trade, the real value of consumption is given by the following identity (hereafter, when it does not lead to confusion, we suppress subscripts to avoid over-notation)

$$
C=Y-S
$$

where $Y=y L, C=c L$ and $S=s L$ are the aggregate levels of output, consumption and savings, and " $y$ " " $c$ " and " $s$ " are their per worker counterparts. The macroeconomic equilibrium is reached under the assumption of both external and budget balance. This leads to the resource constraint condition that, at the economy-wide level, private savings equal private investments.

\footnotetext{
${ }^{35}$ The view of production functions with endogenous technology and increasing returns (See Romer 1986, 1990, 1994, Grossman and Helpman 2001) was abandoned after the Jones critique (1995). In light of the empirical evidence, the modern debate is about the suitable determinants of decreasing returns to technology investments (Jones 2005, Ang and Madsen 2014, Aghion et al., 2013. See Section 3.3. Chapter 3 of this thesis for a brief detail of the discussion). In the context of innovation it also seems more natural to think that innovation is subject to decreasing returns (See Gordon 2014).

${ }^{36}$ Romer 1994, Jones 2005.

${ }^{37}$ See Jones 2005, pp. 1070 ff.
} 
Following Turnovsky (1996), we assume that investment is subject to adjustment costs so that investment resources are limited by the constraint

$$
S=I+\kappa I^{2}, \quad 0<\kappa
$$

where the first term on the righthand side of the last expression is "effective investment" and the second term shows the role of the adjustment cost. ${ }^{38}$ This functional form is derived from the Tobin's $Q$ theory and motivated as a convex quadratic adjustment investment cost. ${ }^{39}$ Intuitively, the implementation of new innovations is a disruptive process leading to a lost of output, and this cost rises more than proportionally with the level of investment (e.g., production has to stop while new machines are installed and the more machines are there, the higher the cost).

For expositional purposes, we relate savings and investment, inclusive of adjustment costs, through the investment cost function $b(\mathbf{I})$ and write it in per worker terms as follows

$$
s=b\{\mathbf{I}\}=\mathbf{I}+\kappa \mathbf{I}^{2}, \quad 0<\kappa
$$

where $\mathbf{I}=I / L, b\{0\}=0, b^{\prime}>0$, and $b^{\prime \prime}>0$. Consistent with our assumptions, this specification implies that the marginal cost of innovation is positive and increasing in the size of innovation.

Writing Equation (4.3) in per worker terms too, and using Equations (4.1) and (4.4), the objective of the agent is to maximize the utility of the value of consumption given by

$$
\begin{aligned}
c & =y-s \\
& =f\{A\}-b\{\mathbf{I}\} \\
& =f\{A\}-\mathbf{I}-\kappa \mathbf{I}^{2}
\end{aligned}
$$

To complete our model description, following Jones 2005, we define the function

$$
B=h\{A\} L=A^{\beta} L, \quad \beta>0
$$

where $B$ denotes the production of new innovations and $h\{A\}$ denotes innovativeness per worker. ${ }^{40}$ Thus, in our simplified framework, if $A$ is the stock of innovation, $A^{\beta}$ is the amount of innovation per worker. Notice the similarity between this equation and the production function established earlier, both

\footnotetext{
${ }^{38}$ The author gratefully acknowledges useful comments and suggestions by Joan Muysken and Adriaan van Zon which led to clarify the role of adjustment costs in macroeconomic settings.

${ }^{39}$ Tobin 1969, Abel 1982, Turnovsky 1996, Heijdra 2009, pp. 40 ff. and Romer 2019, pp. $420 \mathrm{ff}$. This treatment of investment has been extensively applied in the investment literature. An often-cited empirical application is Summers et al., 1981. The distinguishing feature of most studies in this context is its partial equilibrium approach (without an analysis of the growth and welfare effects). In our analysis, following Turnovsky 1996, we consider that the same reasoning can be applied to the maximization of the consumption utility function of the economy as a whole.

${ }^{40}$ Jones 2005, pp. 1070 ff.
} 
$Y=A^{\alpha} L$ and $B=A^{\beta} L$ involve constant returns to labor and both include increasing returns to labor and innovation taken together, which is so because innovation is also a production good. Notice also that $\beta>0$ implies that the production of new innovations depends positively on past innovation. ${ }^{41}$

To simplify further, we assume $\beta=1$, hence, given an amount of labor, doubling the amount of past innovations (an input) leads to double the amount of new innovation (an output) - the "moore law" is at work in the context of innovation. Setting $\beta=1$, the production of new innovations function becomes

$$
B=A L
$$

Notice, lastly, that as we have established $L=1$ earlier, this leads to the conclusion that $B=A$. Thus, what is the purpose of setting up the function $B$ in the first place?

The purpose, as shall be evident shortly, is to get rid of any scale effects arising from the fact that, while innovation is a stock in Equation (4.2), the production of innovation is defined in per-worker terms. Clearly, the assumption $L=1$ is not innocuous: since labor (and population) grows at some constant rate, there would be still necessary to ensure that innovation expenditures and income keep growing at least at this rate too (like in models with physical capital where the concern is to ensure that there are sufficient investments to endow each worker with the same amount of capital). Furthermore, population growth is at the center of the modern debate between semi-endogenous and neo-Schumpeterian economists. ${ }^{42}$ But, while we acknowledge that scale effects indeed matter, the normalization of labor suffices our main purpose, namely, to illustrate the potential relevance of public finance in the promotion of business innovation.

Using the function $B=A L$, we introduce a rule of change for innovation based on the standard approach in models of technology diffusion (which allows us to capture the influence of frontier technology). ${ }^{43}$ To begin with, taking the time derivative of this function, we obtain

$$
\dot{B}=\dot{A} L+A \dot{L}
$$

Then, we assume that, at the economy wide level, innovation changes over time

\footnotetext{
${ }^{41}$ As Jones 2005 explains, whereas $\beta>0$ implies a "standing on the shoulders of giants effect", $\beta<0$ is also possible, but this implies that new innovations are negatively affected by past innovation. This "fishing pond" effect implies that innovation becomes increasingly more difficult over time, namely, if the pond is stocked with only 100 fishes, it would be increasingly difficult to catch each new fish.

${ }^{42}$ The semi-endogenous and neo-Schumpeterian models were discussed in Chapter 3 of this thesis

${ }^{43}$ Sharif \& Ramanathan 1981, Stokey 2012, Banks 2013, Benhabib et al., 2014.
} 
according the following rule of motion ${ }^{44}$

$$
\dot{A} L+A \dot{L}=I A\left[1-\left(\frac{A}{\bar{A}}\right)^{v}\right]-D A-V A
$$

where $v, D$ and $V$ are parameters exogenously given that capture the different implications of the rate of diffusion, the obsolescence of past innovations and the expansion of the technology frontier, as is explained further below. Notice that only "effective investment" are considered in the equation of motion of innovation. This feature of the cost of the adjustment literature holds because what investors can control at each moment of time is the effective amount of investment, not the adjustment cost. ${ }^{45}$

Dividing everywhere by the labor size, the last equation can be condensed into the following differential equation in the per worker terms

$$
\dot{A}=\mathbf{I} A\left[1-\left(\frac{A}{\bar{A}}\right)^{v}\right]-\delta A-\varphi A-\eta A
$$

where $\eta=\frac{\dot{L}}{L}$ denotes the growth rate of the labor force, and $\delta$ and $\varphi$ denote the per worker versions of the obsolescence and the expansion of the frontier. We keep the simplifying assumptions that $\eta=0$ and $L=1$, and write the logistic equation governing the dynamics of innovation as follows

$$
\frac{\dot{A}}{A}=\mathbf{I}\left[1-\left(\frac{A}{\bar{A}}\right)^{v}\right]-\delta-\varphi, \quad 0<v, \delta, \varphi<1
$$

where the rate of change of innovation is determined by effective investment expenditures, "I", and the technology available from the frontier " $\bar{A}$ ". ${ }^{46}$ Technology diffusion is modulated by the parameter $v$, the closer it is to $1(0)$, the higher (slower) the spread of technologies originated at the frontier. ${ }^{47}$ Assuming $v=1$ implies that all innovations occurring at the frontier are "instantly" available for countries off the frontier. The term $\delta$ is a constant that accounts

\footnotetext{
${ }^{44}$ This is a logistic pattern of diffusion that is widespread in the literature, see Sharif \& Ramanathan 1981, Stokey 2012, Banks 2013, Benhabib et al., 2014 and Luttmer 2015. An exposition of the growth and catching up effects of the logistic pattern of technology diffusion in the context of human capital is in Benhabib and Spiegel 2005.

${ }^{45}$ Hayashi 1982.

${ }^{46}$ From an economic viewpoint, frontier technology is available to the receiving country through diverse means (e.g., imports of machines and equipment, foreign direct investment, licensing). Clearly, there are many implications that would need to be considered under the assumptions that we have established in the model. For instance, investment inflows have potential consequences for the assumption of balanced trade and (balanced) fiscal accounts (investment inflows may lead to current account deficits given the compensations to be paid for capital services, or if they boost the demand for imports). To simplify the analysis, we will think that financial flows have at most only a slight effect on our model assumptions about external and fiscal budget balances.

${ }^{47} \mathrm{~A}$ major setback identified in studies of technology diffusion is that frontier technologies do not fully nor instantly spread to countries off the frontier. See, for instance, Comin and Mestieri 2014.
} 
for the obsolescence of past innovations. ${ }^{48}$ And the term $\varphi$ accounts for the fact that the frontier grows at some rate, which may be assumed constant as long as growth at the frontier is not controlled by the countries falling behind. ${ }^{49}$

Notice that starting with $\mathrm{A}=0$, countries falling behind might eventually (asymptotically) catch up with the frontier provided $\mathbf{I}>\delta+\varphi$; otherwise they might stagnate whenever $\mathbf{I}=\delta+\varphi$, or continue falling behind as $\mathbf{I}<\delta+\varphi$. To see this, note from Equation (4.6) that $\dot{A} / A \stackrel{a}{=}-(\delta+\varphi)$ as $A / \bar{A} \stackrel{a}{\rightarrow} 1$ (where $\stackrel{a}{\rightarrow}$ indicates asymptotic approach). This means that the rate of growth of $A$ is slowed down in the vicinity of the frontier by the obsolescence rate and the rate of growth at the frontier. On the other side, when $A$ is too small the expected growth rate of innovation is exponentially determined by the behavior of $\mathbf{I}-(\delta+\varphi): \dot{A} / A \stackrel{a}{=} \mathbf{I}-(\delta+\varphi)$ as $A / \bar{A} \stackrel{a}{\rightarrow} 0$.

On the other side, $v=1$ and $\varphi=\delta=0$ leads to the standard logistic differential equation: $\dot{A}=\mathbf{I} A\left[1-\left(\frac{A}{A}\right)\right]$. The point where this function is at its maximum is found by taking the derivative with respect to $A$ : thus $F^{\prime}(A)=\mathbf{I}-2\left(\frac{\mathbf{I}}{A}\right) A$. We get the usual result that at the maximum $F^{\prime}(A)=0$, and $A=\frac{\bar{A}}{2}$. In other words, the standard logistic diffusion pattern is symmetric around the midpoint $\frac{\bar{A}}{2}$. But, in the context of our analysis, this point is delayed for $\delta>0, \varphi>0$ and $0<v \leq 1$.

\subsubsection{The role of government}

We consider a explicit role for the government in promoting the production of innovation. In particular, we assume that the government sets taxes and uses the tax revenue to grant transfers in order to boost innovation in the private sector. ${ }^{50}$ The government budget position $\left(G_{D}\right)$ is made of taxes minus government expenditures $\left(G_{C}\right)$ minus transfers $(T R)$

$$
G_{D}=T-G_{C}-T R
$$

\footnotetext{
${ }^{48}$ The effect of obsolescence seems to be particularly important in analyzing the economics of innovation due to issues like competition pressures, changes in consumer preferences, and changes in the relative price of inputs or factors of production. For instance, among a much larger assortment of IT technologies, cell phones and PCs are usually discarded by the millions as new varieties are introduced into the market and consumers make the switch to improved versions (See Baily 1981, Fraumeni 1997, Howitt 1998, Slade 2009.) It is worth noting also that technology obsolescence plays an important role to explain economic differences across countries (See Comin and Hobijn 2010).

${ }^{49}$ Stokey 2012, Benhabib et al., 2014. In general terms, we may set any rule governing growth at the frontier's technology, e.g., a exponential rule: $\dot{\bar{A}}=\bar{g} \bar{A}$, or a logistic rule: $\dot{\bar{A}}=\overline{\mathbf{I}} \bar{y}\left(1-\frac{\bar{A}}{\bar{A}^{*}}\right)$ (where $\bar{A}^{*}$ represent the limit of human knowledge). While including a rule of this kind seems more realistic, it would take us through a more complex dynamics.

${ }^{50}$ Alternatively, the promotion of innovation may be based on innovation subsidies, as we explain later in Subsection (4.5.5).
} 
To collect tax revenues the government sets a flat tax rate $(\bar{\tau})$ on income but allows for the exemption of (effective) investments. Thus, the tax bill is ${ }^{51}$

$$
T=\bar{\tau}(Y-I), \quad 0<\bar{\tau}<1
$$

A simple case, consistent with our analysis below, is that the government balances transfer payments with tax revenues, $T R=T$ and government consumption is zero, $G_{C}=0$. Thus, a budget balance prevails

$$
0=T-T R
$$

From the point of view of the private sector, the government influences consumption and investment decisions in the following manner. First, it reduces the value of consumption as the private agent now has to pay taxes

$$
C=Y-S-T
$$

Using Equation (4.7) in Equation (4.3') and rearranging terms, we get

$$
\begin{aligned}
C & =Y-S-\bar{\tau}(Y-I) \\
& =Y-I-\kappa I^{2}-\bar{\tau}(Y-I) \\
& =(1-\bar{\tau})(Y-I)-\kappa I^{2}
\end{aligned}
$$

which in per worker terms writes as follows

$$
c=(1-\bar{\tau})(f\{A\}-b\{\mathbf{I}\})-\bar{\tau} \kappa \mathbf{I}^{2}
$$

where, once again, we use the definition $S / L=s$ jointly with Equations (4.1) and (4.4) in getting to the latter expression. Clearly, introducing a tax rate as we have done in Equation (4.5') redefines the problem of the agent. Now it is related to the maximization of the utility of what is left for consumption after the cost of investment and taxes are subtracted (note that setting $\bar{\tau}=0$, Equations (4.5) and (4.5') are the same).

The second way the government influences private decisions is by increasing the investment in innovation. To this end, the government grants innovation transfers which are aimed exclusively to enlarge the resources of the agent to invest in innovation. In so doing, it expects to influence the performance of the economy leading, over the long-run, to higher levels of productivity and consumption. In the next section we analyze the likely consequences and difficulties of this policy approach.

\footnotetext{
${ }^{51}$ Setting the tax bill this way implies that the tax rate, $\bar{\tau}$, will show up somewhere in the solution of the optimization problem. Notice that, alternatively, the tax bill might be set as $T=\bar{\tau}(Y-S)=\bar{\tau}\left(Y-I-\kappa I^{2}\right)$. While doing so simplifies the presentation and leads to a neat solution of the optimization problem, it is inconsistent with the assumption that the cost of adjustment is not under the control of the investor, hence, non-deductible from taxation.
} 


\subsection{The Sponsorship Mechanism}

In Equation (4.6) effective investment by the private agent (without transfers from the government) is given, in per worker terms, by I. We assume that while they pay taxes, the agent is unaware of the government's policy, which implies that the use of taxes to grant transfers as a further source of investment resources works only indirectly through government intervention.

We also assume that the government's policy is to fully transfer the collected taxes in order to support investment in innovation in the private sector (this equivalence to be explained shortly). This way, after the intervention by the government, private investments are enlarged by an amount equal to $\mathbf{I} \tau_{Z}$ where $\tau_{Z}$ denotes the transfers ratio as a proportion of effective investments by the agent. A key aspect of this transfers mechanism is that, from the viewpoint of the agent, $\tau_{Z}$ is a fixed value, e.g., the government announces its policy to the agent based on some historical average that guarantees the budget balance.

Thus, after transfers, total investments become

$$
\mathbf{I}\left(1+\tau_{Z}\right)=\mathbf{I} \tilde{z}, \quad 0 \leq \tau_{Z}, \quad 1 \leq \tilde{z}
$$

where $\tilde{z}=1+\tau_{Z}$ amounts to an "sponsorship mechanism" whereby transfers increase the resources to invest in innovation. Using Equation (4.9) to modify Equation (4.6) we get (assuming, for simplicity, $v=1, \varphi=0$ )

$$
\dot{A} / A=\mathbf{I} \tilde{z}(1-A / \bar{A})-\delta, \quad 0<\delta<1, \quad 1 \leq \tilde{z}
$$

where, from the point of view of the agent, $\tilde{z}$ is exogenously given. Notice that with $v=1$ and $\varphi=0$, Equation (4.6) and Equation $\left(4.6^{\prime}\right)$ are the same when $\tilde{z}=1$, which would be the case when there are no transfers (and therefore no taxes).

In order to analyze the macroeconomic consequences of the "sponsorship mechanism", notice that, while per worker transfers amount to $\mathbf{I} \tau_{Z}$, at the aggregate level, total transfer are given by

$$
T R=(\mathbf{I} L) \tau_{Z}=I \tau_{Z}
$$

where $\tau_{Z}$ denotes the transfers rate.

Using Equations (4.7) and (4.10) in Equation (4.8), we obtain

$$
\begin{aligned}
T & =T R \\
\bar{\tau}(Y-I) & =I \tau_{Z} \\
\bar{\tau}\left(\left(\frac{I}{Y}\right)^{-1}-1\right) & =\tau_{Z}
\end{aligned}
$$

this equation may be alternatively written, as we prefer, in per worker terms as follows

$$
\bar{\tau}\left(\left(\frac{\mathbf{I}}{y}\right)^{-1}-1\right)=\tau_{Z}
$$


where $(\mathbf{I} / y)^{-1}$ denotes the inverse of the investment ratio: the ratio of investment to output. Equation (4.11) implies that, depending on this ratio, the transfers rate is larger than the tax rate which is a key aspect of our model. For instance, if $\bar{\tau}=10 \%$ and $\mathbf{I} / y=20 \%$ we get, from Equation (4.11), that $\tau_{Z}=40 \%$. However, as the investment ratio increases, the transfers rate decreases. For instance, with $\bar{\tau}=10 \%$ and $\mathbf{I} / y=30 \%$ we get $\tau_{Z}=23 \%$. And for an investment ratio (implausibly) larger than $50 \%$, the transfer rate is less than the tax rate for any value of the latter. This is explained because, as we see from Equations (4.4) and $\left(4.5^{\prime}\right)$, the increase in the investment ratio leads to a proportional increase of the savings ratio which narrows the tax base and, therefore, reduces the transfers fund.

There are further issues to be considered in analyzing the implications of Equation (4.11). Firstly, as we have noticed above, from the point of view of the agent, the sponsorship mechanism is exogenously given. This is a strong assumption to be maintained throughout. Notice that if investors know that they are entitled to obtain transfers according to Equation (4.11), the sponsorship mechanism would become neutral. e.g., the agent would adjust their consumption/savings behavior in the same proportion of the received transfers, therefore, leaving the actual amount of investments and innovation where they were. Keeping Equation (4.11) exogenous to the agent's decision making precludes this kind of arbitrage.

Secondly, it seems necessary to emphasize that the tax and transfers mechanism that we have obtained in Equation (4.11) implicitly reflects the normative idea that the government is interested to boost a process of innovation-based growth. ${ }^{52}$ This is in contrast to a case where distortionary increases in taxation lead to reduce consumption without a compensating increase in investment promotion mechanisms - as we explain below.

Finally, given Equations (4.7)-(4.11) above, we also assume that the government is able to keep a balanced budget. In this context-from the point of view of government - a desirable economic goal is to preserve the tax base, influencing decision making in order to achieve an increase in consumption that is at least proportional to the tax rate. Formally, the aim of the sponsorship mechanism is to influence the agent to achieve the following result

$$
\frac{\int_{0}^{T} e^{-r t}\left[(1-\bar{\tau})(f\{A\}-b\{\mathbf{I}\})-\left.\bar{\tau} \kappa \mathbf{I}^{2}\right|_{\tilde{z}>1}\right] d t}{\int_{0}^{T} e^{-r t}\left[f\{A\}-\left.b\{\mathbf{I}\}\right|_{\tilde{z}=1}\right] d t}-1 \geq \bar{\tau}
$$

It is easy to verify, using Equations (4.9)-(4.11), that the condition $\tilde{z}=1$ implies $\bar{\tau}=\tau_{Z}=0$ and in this case Equation (4.12) equals zero, whereas $\tilde{z}>1$ implies

\footnotetext{
${ }^{52}$ We have elaborated previously (Chapter 3 ) on a large body of literature that brings supports to the sponsorship mechanism: Nelson 1993, Dosi, Marengo and Pascuali 2006, Lundvall 2007, Hall and Lerner 2010, Mazzucato 2013. Certainly the government support to innovation involves more than financial support, including overall macroeconomic conditions (price stability, fiscal sustainability, sound financial systems). The relative merit of these practices and the merit of the innovation policy highlighted in more recent strands of the literature is a wide and still open area of academic debate (see Page 1994, Wade 1996, Mazzucato and Penna 2015, Breznitz, Ornston and Samford 2018).
} 
$0<\bar{\tau}<\tau_{Z}$ which, at least potentially, leads to increase consumption over the long run. We elaborate further on this condition after solving the optimization problem of the representative agent in the next section.

\subsection{Solving the optimization problem}

In this section we develop the optimization problem of the private agent which differs from the social optimum because taxes and transfers are exogenous to the private agent. Notice that the rationale of the difference between private, or competitive, and socially efficient solutions of the optimization problem that we establish here are similar in spirit to Lucas (1988).

In particular, if the agent knows in advance what the taxes they pay will be used for, e.g, financing investments, the social efficient solution would be equivalent to a situation without taxes and without transfers. This is because if the agent knows transfers are granted under the rule in Equation (4.11), they realize that their investment resources, per worker, are just $(1-\bar{\tau}) \mathbf{I}+\bar{\tau} y=\tilde{\mathbf{I}}$ and, with the agent in control of $\tilde{\mathbf{I}}$, Equation (4.11) is redundant in the first place as $\mathbf{I} \tilde{z}=(1-\bar{\tau}) \mathbf{I}+\bar{\tau} y$ too. Additionally, the social efficient solution, where the agent is in control of the tax and transfers mechanism, is similar to set a condition that $\tilde{z}=1$ and $\tau_{Z}=\bar{\tau}=0$ as we show in Appendix 4.A.

On the contrary, if the agent is unaware of what the taxes they pay will be used for, they take the sponsorship mechanism, $\tilde{z}$, as given. Technically, the agent is not concerned with the fact that their investment behavior affects the transfers mechanism established through Equation (4.11) and arbitrage behavior is not possible either, otherwise we would be back to the social efficient scenario $\tilde{z}=1$ introduced above.

Under the competitive solution of the optimization problem there are two possibilities, either $\tilde{z}>1$ or $\tilde{z}<1$. Below, we show that only the first of these scenarios is consistent with a sponsorship mechanism that enhances innovation and growth; we discuss that the second scenario, namely $\tilde{z}<1$, amounts to a case of confiscatory taxation.

Let us solve the overall optimization problem under the competitive scenario, e.g., taking $\tilde{z}$ as given, before explaining in more detail the social efficient scenario, and the sponsorship mechanism and confiscatory taxation scenarios.

As we noted earlier, the objective of the representative agent is to maximize the discounted value of consumption given by Equation (4.5') that we reproduce here as

$$
c=(1-\bar{\tau})(f\{A\}-b\{\mathbf{I}\})-\bar{\tau} \kappa \mathbf{I}^{2}
$$

and given that innovation changes over time according to the logistic law of 
motion in Equation $\left(4.6^{\prime}\right)$, which is also reproduced here as $^{53}$

$$
\dot{A} / A=\mathbf{I} \tilde{z}(1-A / \bar{A})-\delta, \quad 0<\delta<1, \quad 1 \leq \tilde{z}
$$

To be more explicit, let us specify the production function as it was presented earlier in Equation(4.2), namely

$$
y=f\{A\}=A^{\alpha}, \quad 0<\alpha \leq 1
$$

Also, let us specify the convex adjustment investment cost function from Equation (4.4) assuming $\kappa=1 / 2$

$$
b\{\mathbf{I}\}=\mathbf{I}+\frac{\mathbf{I}^{2}}{2}
$$

The optimization problem, in per worker terms and with future values discounted at rate $r$, is ${ }^{54}$

$$
\begin{aligned}
& \max \int_{0}^{T} e^{-r t}\left[(1-\bar{\tau})(f\{A\}-b\{\mathbf{I}\})-\bar{\tau} \kappa \mathbf{I}^{2}\right] d t \\
& \text { s.t. } f\{A\}=A^{\alpha} \\
& b\{\mathbf{I}\}=\mathbf{I}+\frac{\mathbf{I}^{2}}{2} \\
& \dot{A}=\mathbf{I} \tilde{z} A(1-A / \bar{A})-\delta A
\end{aligned}
$$

$A\{0\}=A_{0}>0, \quad \mathbf{I}\{0\}=\mathbf{I}_{0}>0, \quad 0<\alpha \leq 1, \quad 0<\delta<1, \quad \tilde{z} \geq 1, \quad \kappa=1 / 2$

The current value Hamiltonian $H_{c}$ is

$$
H_{c}(\mathbf{I}, A, \lambda)=(1-\bar{\tau})\left(A^{\alpha}-\mathbf{I}\right)-\frac{\mathbf{I}^{2}}{2}+\lambda\left(\mathbf{I} \tilde{z} A\left(1-\frac{A}{\bar{A}}\right)-\delta A\right)
$$

This is a prototypical problem of optimal control, we see that investment "I" (the control) influences the objective function twice, directly, through its own value

\footnotetext{
${ }^{53}$ In the specification of our optimization problem we follow the conventional practice in the literature of investment theory with cost of adjustment (Summers 1981, Abel 1982, Turnovsky 1996, Heijdra 2009, pp. 40 ff., Romer 2019, pp. 420 ff). Setting up the problem the other way round, e.g., with the objective given as

$$
c=(1-\bar{\tau})(f\{A\}-\mathbf{I})
$$

and innovation evolving according to

$$
\dot{A} / A=b\{\mathbf{I}\} \tilde{z}(1-A / \bar{A})-\delta, \quad 0<\delta<1, \quad 1 \leq \tilde{z}
$$

is technically plausible (See Hayashi 1982), buy it leads to a different analytical problem as it changes the economic intuition and equilibrium solutions-further explanation follows after solving the optimization program.

${ }^{54}$ Our model is based on the Stigler-Ozga model of diffusion in advertising theory (see Gould 1976 and Kamien and Schwartz 1991 Section II.9). A similar line of reasoning as ours, namely, a model that builds on the dynamics of diffusion and local learning capabilities on catching up and falling behind, is found in Verspagen 1991.
} 
in the objective function, and, indirectly, through its impact on the evolution of the state equation. The state variable $(A)$ evolves according to the logistic diffusion mechanism. The technology of the frontier, $\bar{A}$, is exogenously given and influences the objective only indirectly through the state equation. Finally, from the point of view of the optimizing agent, the sponsorship mechanism, $\tilde{z}$, is exogenously given, e.g., Equations (4.8)-(4.11) are not part of the agent's intertemporal optimization process.

We are aimed to find an expression that reflects the dynamics of investments in innovation, which is determined by the control. The first order conditions (FOC) for optimization satisfy Equation $\left(4.6^{\prime}\right)$ and

$$
\begin{array}{ccc}
\frac{\partial H_{c}}{\partial \mathbf{I}}= & \lambda \tilde{z} A\left(1-\frac{A}{\bar{A}}\right)-(1-\bar{\tau})-\mathbf{I}=0 \\
\dot{\lambda}-r \lambda=-\frac{\partial H_{c}}{\partial A}= & \lambda\left[-\mathbf{I} \tilde{z}\left(1-\frac{A}{\bar{A}}\right)+\mathbf{I} \tilde{z} \frac{A}{\bar{A}}+\delta\right]-\alpha A^{\alpha-1}(1-\bar{\tau})
\end{array}
$$

plus the usual transversality conditions

$$
\operatorname{Lim}_{t \rightarrow+\infty} e^{-r t} \lambda(t) \geq 0, \quad \operatorname{Lim}_{t \rightarrow+\infty} e^{-r t} \lambda(t) A(t)=0
$$

Equation (4.13) characterizes the solution for optimal investments in innovation: it equates the future increase in innovation with the current increase in the cost of the investment. Equation (4.14) determines the motion of the co-state variable (the shadow value of innovation). The latter is analogous to the problem of equalizing the marginal product of innovation to the opportunity cost of the investment in innovation (given by the discount rate $r$ and taking into account the rate of obsolescence). ${ }^{55}$

By log-transforming Equation (4.13) we have

$$
\ln (1-\bar{\tau}+\mathbf{I})=\ln (\lambda)+\ln (\tilde{z})+\ln (A)+\ln \left(1-\frac{A}{\bar{A}}\right)
$$

Since $\bar{\tau}$ and $\tilde{z}$ are time-invariant, differencing this equation with respect to time yields

$$
\frac{1}{1-\bar{\tau}+\mathbf{I}} \dot{\mathbf{I}}=\frac{\dot{\lambda}}{\lambda}+\frac{\dot{A}}{A}-\frac{\dot{A}}{\bar{A}-A}
$$

Note, from Equation (4.14), that

$$
\frac{\dot{\lambda}}{\lambda}=r-\mathbf{I} \tilde{z}\left(1-\frac{A}{\bar{A}}\right)+\mathbf{I} \tilde{z} \frac{A}{\bar{A}}+\delta-\frac{\alpha A^{\alpha-1}(1-\bar{\tau})}{\lambda}
$$

\footnotetext{
${ }^{55}$ Second order conditions for optimality are satisfied also; sufficiency is established by checking that the conditions of the Mangasarian's theorem are fulfilled (Kamien and Schwartz 1991 pp. $221 \mathrm{ff})$. Notice that the production function has properties $f^{\prime}>0, f^{\prime \prime} \leq 0$ and, from Equation (4.13),

$$
\frac{\partial^{2} H_{c}}{\partial \mathbf{I}^{2}}=-1
$$

and, also from Equation (4.13), $\lambda>0$. Hence, the Hamiltonian is concave in $A$ and $\mathbf{I}$.
} 
this expression can be written more concisely as

$$
\begin{aligned}
\frac{\dot{\lambda}}{\lambda} & =r-\frac{A}{A}\left(\mathbf{I} \tilde{z}\left(1-\frac{A}{\bar{A}}\right)-\delta\right)+\mathbf{I} \tilde{z} \frac{A}{\bar{A}}-\frac{\alpha A^{\alpha-1}(1-\bar{\tau})}{\lambda} \\
& =r-\frac{\dot{A}}{A}+\mathbf{I} \tilde{z} \frac{A}{\bar{A}}-\frac{\alpha A^{\alpha-1}(1-\bar{\tau})}{\lambda}
\end{aligned}
$$

inserting the latter expression for $\frac{\dot{\lambda}}{\lambda}$ into Equation (4.15) yields (after suppressing redundant terms)

$$
\frac{1}{1-\bar{\tau}+\mathbf{I}} \dot{\mathbf{I}}=r+\mathbf{I} \tilde{z} \frac{A}{\bar{A}}-\frac{\alpha A^{\alpha-1}(1-\bar{\tau})}{\lambda}-\frac{\dot{A}}{\bar{A}-A}
$$

Note, from Equations $\left(4.6^{\prime}\right)$ that

$$
\frac{\dot{A}}{\bar{A}-A}=\mathbf{I} \tilde{z} \frac{A}{\bar{A}}-\delta \frac{A}{\bar{A}-A}
$$

using this expression into Equation $\left(4.15^{\prime}\right)$ and suppressing redundant terms, yields

$$
\frac{1}{1-\bar{\tau}+\mathbf{I}} \dot{\mathbf{I}}=r-\frac{\alpha A^{\alpha-1}(1-\bar{\tau})}{\lambda}+\delta \frac{A}{\bar{A}-A}
$$

From Equation (4.13) we obtain the following expression for $\lambda$

$$
\lambda=\frac{1-\bar{\tau}+\mathbf{I}}{\tilde{z} A\left(1-\frac{A}{A}\right)}
$$

using this expression in Equations $\left(4.15^{\prime \prime}\right)$ and collecting terms yields

$$
\frac{1}{1-\bar{\tau}+\mathbf{I}} \dot{\mathbf{I}}=r+\frac{\delta A}{\bar{A}-A}-\frac{\alpha A^{\alpha} \tilde{z}(1-A / \bar{A})}{1-\bar{\tau}+\mathbf{I}}
$$

Equation (4.16) may be rewritten as

$$
\dot{\mathbf{I}}=\left[r+\frac{\delta A}{\bar{A}-A}\right](1-\bar{\tau}+\mathbf{I})-\alpha A^{\alpha} \tilde{z}(1-A / \bar{A})
$$

where Equation $\left(4.16^{\prime}\right)$ provides a suitable specification of the differential equation that describes the dynamics of investments in innovation.

From the state Equation $\left(4.6^{\prime}\right)$, an equilibrium path satisfying $\dot{A}=0$ implies

$$
A=\bar{A}\left[1-\frac{\delta}{\mathbf{I} \tilde{z}}\right]
$$

From Equation $\left(4.16^{\prime}\right)$, the equilibrium path satisfying $\dot{\mathbf{I}}=0$ yields $^{56}$

$$
\mathbf{I}=\frac{\alpha A^{\alpha} \tilde{z}(1-A / \bar{A})}{r+\frac{\delta A}{A-A}}-(1-\bar{\tau})
$$

\footnotetext{
${ }^{56}$ As noted earlier, setting up the optimization problem the other way round, e.g., with the
} 
Note that, everything else constant, an increase (decrease) of $\tilde{z}$ increases (decreases) the amount of investments and, therefore, the size of innovation both in Equation (4.17) and in Equation (4.18).

Remember, from the discussion throughout Equations (4.9)-(4.12), that we have defined $\tilde{z}=1+\tau_{Z}$, and we have found that $\bar{\tau}<\tau_{Z}$ which implies that, by construction, the transfers rate is higher than the tax rate. While we have presented our case under the assumption that $\tilde{z} \geq 1$, the discussion following Equation (4.11) suggests that, in general terms, there are three distinct possibilities regarding the influence of the sponsorship mechanism on the equilibrium possibilities of our model, which are determined by $\tilde{z}=1, \tilde{z}>1$ and $\tilde{z}<1$.

\subsubsection{Equilibria without transfers $(\tilde{z}=1)$}

As we discussed at the introduction of Section 4.5, this scenario is equivalent to a social efficient solution, which would be the case when the agent knows transfers are granted under the rule in Equation (4.11). This is because in such a case the agent realizes that their investment resources, per worker, are $(1-\bar{\tau}) \mathbf{I}+\bar{\tau} y=\tilde{\mathbf{I}}$ and that means Equation (4.11) becomes unnecessary as part of the optimization program. Technically $\tilde{\mathbf{I}}$ and $\mathbf{I} \tilde{z}$ are the same, hence, knowledge of $\tilde{\mathbf{I}}$ by the agent, is like assuming that they can control $\tilde{z}$ and leads to a social optimum where $\tilde{z}=1$, which implies $\bar{\tau}=0$ and $\tau_{Z}=0$ (for illustrative properties we still leave $\tilde{z}$ and $\bar{\tau}$ as indicated in Equations (4.17)-(4.18) ). ${ }^{57}$

In order to analyze the equilibrium properties of the model under this scenario, let us portray the vector field determined by Equations (4.17) and (4.18)

objective given as

$$
c=(1-\bar{\tau})(f\{A\}-\mathbf{I})
$$

and innovation evolving according to

$$
\dot{A} / A=b\{\mathbf{I}\} \tilde{z}(1-A / \bar{A})-\delta, \quad 0<\delta<1, \quad 1 \leq \tilde{z}
$$

leads to a different analytical problem. The alternative system leads to the following steady state solution of the differential equation governing the movement of investment

$$
\mathbf{I}=1-\frac{r+\frac{\delta A}{A-A}}{\alpha A^{\alpha} \tilde{z}(1-A / \bar{A})}
$$

which is the "reciprocal" of Equation (4.18). More important, the system formed by Equations (I) and (II) has no equilibrium solutions.

${ }^{57}$ Notice that with the agent in control of $\tilde{\mathbf{I}}=(1-\bar{\tau}) \mathbf{I}+\bar{\tau} y$ the objective function will become $f\{A\}-\tilde{\mathbf{I}}-\kappa \mathbf{I}^{2}$ and the state equation will become $\dot{A}=\tilde{\mathbf{I}} A(1-A / \bar{A})-\delta A$, where the term $\mathbf{I} \tilde{z}$ has being replaced with the knowledge of the agent of $\tilde{\mathbf{I}}$. Under these conditions, the optimal solutions in Equation (4.17) and (4.18) change to

$$
A=\bar{A}\left[1-\frac{\delta}{\mathbf{I}}\right]
$$

and,

$$
\mathbf{I}=\frac{\alpha A^{\alpha}(1-A / \bar{A})}{r+\frac{\delta A}{A-A}}-1
$$

where both $\tilde{z}$ and $\bar{\tau}$ have vanished from the social optimum solution - a detailed proof of this results is in Appendix 4.A. 
in the I-A plane in Figure 4.1 (the parameter values used are: $\delta=10 \%, r=1 \%$, $\alpha=0.7, \bar{A}=10$, the plot is edited for illustrative purposes). ${ }^{58}$

From Equation (4.17), the $\dot{A}=0$ curve is an increasing function that grows (asymptotically) as $A$ approaches $\bar{A}$. This curve has an intercept on the vertical axis when $A \stackrel{a}{\rightarrow} 0$ at $\mathbf{I}=\delta / \tilde{z}$. To characterize the dynamics of the function, notice that, as innovation investments increase, the change in the $\dot{A}=0$ is positive, and $\mathrm{A}$ is increasing (decreasing) above (below) the $\dot{A}=0$ locus. This behavior is represented by the horizontal arrows of motion.

From Equation (4.18), the $\dot{\mathbf{i}}=0$ locus determines a bell-shape curve. This function gets close to zero both as $A \stackrel{a}{\rightarrow} 0$ and as $A \stackrel{a}{\rightarrow} \bar{A} \cdot{ }^{59}$ The curve is increasing for small values of $A$ and decreasing for large values of $A$. Therefore, we observe that innovation investments rise for points above the $\dot{\mathbf{i}}=0$ line, and they fall for points below it. The vertical arrows of motion illustrate this behavior.

There are two equilibria in Figure 4.1. To characterize each, we follow Kamien and Schwartz 1991, Section II.9. We linearize the model around the steady state $\left(A_{s s}, \mathbf{I}_{s s}\right)$ getting

$$
\left[\begin{array}{l}
\dot{A} \\
\dot{\mathbf{I}}
\end{array}\right]=\left[\begin{array}{ll}
j_{11} & j_{12} \\
j_{21} & j_{22}
\end{array}\right]\left[\begin{array}{c}
A-A_{s s} \\
\mathbf{I}-\mathbf{I}_{s s}
\end{array}\right]
$$

where the first entry in the righthand side of the equation is the two-by-two Jacobian matrix ( " $\Delta$ ") whose elements are the partial derivatives of the system around an equilibrium, which are obtained as follows ${ }^{60}$

\footnotetext{
${ }^{58}$ Parameter values for $\delta$ and $r$ are established with respect to $\bar{A}$. First, we use the parameter values to obtain the plot from Equation (4.17), and use this result as an input to obtain the plot from Equation (4.18). Appendix 4.B provides the algorithm in Python used to obtain the actual plot.

${ }^{59}$ Technically the first expression on the right hand side of Equation (4.18) should be zero at both ends $A=0$ and $A=\bar{A}$. But this implies negative investments as then $\mathbf{I}=-(1-\bar{\tau})$ where $0<\bar{\tau}<1$. Likewise, as $\delta>\mathbf{I} \stackrel{a}{\rightarrow} 0$ in Equation (4.17) implies $A<0$. To ensure non negativity we need to impose conditions as $\delta \leq \mathbf{I} \tilde{z}$ in Equation (4.17), and $\frac{\alpha A^{\alpha} \tilde{z}(1-A / \bar{A})}{r+\frac{\delta A}{A-A}} \geq(1-\bar{\tau})$ in Equation (4.18). Also, as was discussed earlier, the catching up process implies $A<<\bar{A}$ as backward countries get to the frontier only asymptotically. Finally, notice that we assume that the initial levels of innovation and investment are strictly larger than zero.

${ }^{60}$ Obtaining the element $j_{21}$ is a bit trickier than in the other cases; we use the fact that, at the steady state, the following expressions are equivalent
}

$$
A^{\alpha-1} \tilde{z}(1-A / \bar{A})=\left[\frac{r}{A}+\frac{\delta}{\bar{A}-A}\right](1-\bar{\tau}+\mathbf{I})
$$

and,

$$
\frac{A^{\alpha} \tilde{z}}{\bar{A}}=\left[\frac{r}{\bar{A}-A}+\frac{\delta A}{(\bar{A}-A)^{2}}\right](1-\bar{\tau}+\mathbf{I})
$$

These expressions are used to simplify the partial derivative $j_{21}$. 


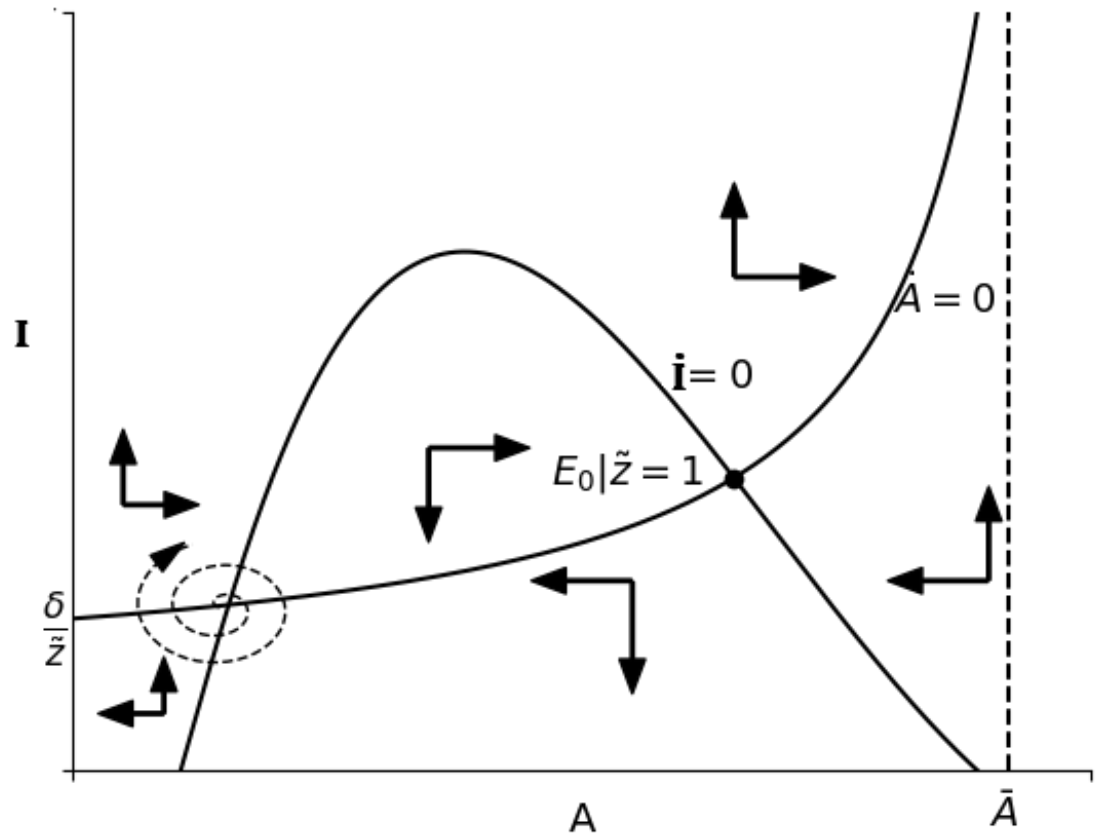

Figure 4.1: Phase diagram under scenario $\tilde{z}=1$. The arrows of motion show that the leftmost side equilibrium is unstable and that on the rightmost side is saddlepoint stable. Note that here $\bar{\tau}=0, \tau_{Z}=0$ and $\tilde{z}=1$, other parameter values are: $\delta=10 \%$, $r=1 \%, \alpha=0.7, \bar{A}=10$, the plot is edited for illustrative purposes, e.g., the origin has been moved to the right for better depiction of the arrows of motion (values for $\delta$ and $r$ are established with respect to $\bar{A}$. First, we use the parameter values to obtain the plot from Equation (4.17), then we use this result an an input in Equation (4.18). Appendix 4.B provides the algorithm in Python used to obtain the actual plot).

$$
\begin{aligned}
& j_{11}=\left.\frac{\partial \dot{A}}{\partial A}\right|_{\dot{A}=0}=-\frac{A_{s s} \mathbf{I}_{s s} \tilde{z}}{\bar{A}} \\
& j_{12}=\left.\frac{\partial \dot{A}}{\partial \mathbf{I}}\right|_{\dot{A}=0}=A_{s s} \tilde{z}\left[1-\frac{A_{s s}}{\bar{A}}\right] \\
& j_{21}=\left.\frac{\partial \dot{\mathbf{i}}}{\partial A}\right|_{\dot{\mathbf{I}}=0}=\left(\frac{2 \delta A_{s s}}{\left(\bar{A}-A_{s s}\right)^{2}}+\frac{2 r A_{s s}-r \bar{A}}{A_{s s}\left(\bar{A}-A_{s s}\right)}-\frac{\alpha-1}{A_{s s}}\left(r+\frac{\delta A_{s s}}{\bar{A}-A_{s s}}\right)\right)\left(1-\bar{\tau}+\mathbf{I}_{s s}\right. \\
& j_{22}=\left.\frac{\partial \dot{\mathbf{i}}}{\partial \mathbf{I}}\right|_{\dot{\mathbf{I}}=0}=r+\frac{\delta A_{s s}}{\bar{A}-A_{s s}} \quad 102
\end{aligned}
$$


The characteristic roots of the matrix $\Delta, \varepsilon_{1}$ and $\varepsilon_{2}$, are obtained as usual

$$
\varepsilon_{1,2}=\frac{\operatorname{tr}(\Delta) \pm \sqrt{[\operatorname{tr}(\Delta)]^{2}-4|\Delta|}}{2}
$$

where $\operatorname{tr}(\Delta)$ and $|\Delta|$ are, respectively, the trace and the determinant of $\Delta$. In order to characterize the equilibrium behavior we need to assume suitable parameter values, namely $r=\delta>0$ and $\mathbf{I}>0 .{ }^{61}$ We find, for high values of $\mathrm{A}$, that $\operatorname{tr}(\Delta)=j_{11}+j_{22}>0$ and $|\Delta|=j_{11} \times j_{22}-j_{21} \times j_{12}<0$, hence if follows that the system is saddlepoint stable for the intersection of the loci $\dot{A}$ and $\dot{\mathrm{i}}$ in the rightmost part of Figure 4.1. Since, from the information provided in the Jacobian matrix, $j_{11}<0$ and $j_{22}>0$, we deduce that the innovation process is stable while the investment dynamics is unstable.

The leftmost equilibrium, on the other hand, is featured by low values of $A$ which implies that $j_{21}<0, \operatorname{tr}(\Delta)>0$ and $|\Delta|>0$. Also, we note that this equilibrium features $\operatorname{tr}(\Delta)<|\Delta|$ which implies that the roots are complex conjugates. The (imaginary) roots may be written as $^{62}$

$$
\varepsilon_{1,2}=\frac{\operatorname{tr}(\Delta)}{2} \pm \frac{\sqrt{4|\Delta|-[\operatorname{tr}(\Delta)]^{2}}}{2}
$$

Thus, on the lefthand region we have two complex roots with positive real parts, $\operatorname{tr}(\Delta)>0$ and $|\Delta|>0$. The solution is characterized as an unstable focus that oscillates and moves away from the equilibrium unless $A(0)=A_{s s}$ and $\mathbf{I}(0)=\mathbf{I}_{s s} \cdot{ }^{63}$ Graphically, from Figure 4.1 we see that the instability of the system on the lefthand region is characterized because the linearized locus $\dot{A}$ is flatter than the linearized locus $\dot{\mathbf{i}}^{64}$

In economic terms, the qualitative properties of the system described in Figure 4.1 imply that only when the initial level of innovation is sufficiently

\footnotetext{
${ }^{61}$ Note that $r=\delta=\mathbf{I}=0$, or sufficiently close to zero, implies $\varepsilon_{1,2}=0$; and, on the other hand, $r=\delta=0$ and $\mathbf{I}>0$ implies $\varepsilon_{1}=0>\varepsilon_{2}$. In these cases, Equations (4.17)-(4.18) are either inconsistent or redundant: in the first case there are no equilibria; in the later, with a root equal to zero, any point may be an (knife-edge) equilibrium. Also, note that when $r=0<\delta$ and $\mathbf{I}>0$, the roots are real and distinct with $\varepsilon_{1}>0>\varepsilon_{2}$. In this case, the solution hinges on the value of $\delta$ : a large $\delta$ leads the solution to be dominated by the positive root and both A and I grow without bound; if $\delta$ is small, on the other hand, the solution converge to a saddlepoint equilibrium. Finally, when $\delta=0<r$ and $\mathbf{I}>0$ there is also a saddlepoint equilibrium. But, in the latter case there are roots that are complex conjugates - as explained in the main text.

${ }^{62}$ We may write the two complex roots as
}

$$
\varepsilon_{1,2}=a \pm d i
$$

where $a=\operatorname{tr}(\Delta) / 2$ and $d=\frac{\sqrt{[\operatorname{tr}(\Delta)]^{2}-4|\Delta|}}{2}$. Then, to obtain the expression on the text, we use the property of imaginary numbers $i^{2}=-1$.

${ }^{63}$ Note that a stable focus, one oscillating inwards instead, would have been characterized by two complex roots with a negative real part, $\operatorname{tr}(\Delta)<0$ (Kamien and Schwartz 1991 Section B5). In our approach, a negative value for the trace only arises for very small parameter values and $r<\delta$, namely $\delta=0.1$ and $r=1,0 E-0.5$.

${ }^{64}$ Compare this equilibrium on the lefthand region with the saddlepoint equilibrium on the righthand region, so characterized because the linearized locus $\dot{A}$ stepper than the linearized locus í. 
large, the economy gets on the path to the equilibrium on the rightmost side. As it stands, under the scenario $\tilde{z}=1$ the equilibrium on the right hand side is unique and unaffected by the sponsorship mechanism.

\subsubsection{Equilibria with positive transfers $(\tilde{z}>1)$}

We have established that when the government has an interest in promoting innovation and, in more general terms, economic growth, it can do so by setting a flat tax rate on consumption in order to fund further investment in innovation (see Equation $\left(4.5^{\prime}\right)$ ). More specifically, from Equation (4.11), we see that, by setting a flat tax rate on consumption $(\bar{\tau}>0)$, the government raises funds to grant innovation transfers in a way such that, by construction, the transfers rate is higher than the flat tax rate, e.g., $\bar{\tau}<\tau_{Z}$ (given a suitable value for the investment ratio $\mathbf{I} / y$ ) and the sponsorship mechanism is larger than $1, \tilde{z}>1$.

For instance, we have seen, assuming $\mathbf{I} / y=20 \%$, that setting $\bar{\tau}=10 \%$ leads to a transfers rate of $\tau_{Z}=40 \%$ and a sponsorship mechanism of $\tilde{z}=1.4$. To illustrate the impact of this kind of change, in Figure 4.2 we plot together the equilibria found under the conditions $\bar{\tau}=\tau_{Z}=0$ (scenario $\tilde{z}=1$ ) and the equilibria found under the new conditions, namely, $\bar{\tau}=10 \%$ and $\tau_{Z}=40 \%$ (scenario $\tilde{z}=1.4$ ). To simplify the presentation, we focus on the right hand region saddlepoint equilibria for both these scenarios (we do not repeat the arrows of motion and we do not discuss anymore the unstable equilibria on the left hand region as in this regard the analysis remains unchanged).

Note, furthermore, that all parameter values that we have established above remain, namely, $\delta=10 \%, r=1 \%, \alpha=0.7$ and $\bar{A}=10$. Since, consistent with Equation (4.11), we need to ensure that the investment ratio is I/ $y=20 \%$ (for the scenario $\tilde{z}=1.4$ to hold), this ratio is obtained from the fact that in $E_{0}$, $\mathbf{I}=0.7$ and $A=5.57$, hence $y=A^{\alpha}=3.36$ and $\mathbf{~} / y \approx 20 \%$ (note that the plot is enlarged in the I-axis direction to ease the illustration).

Thus, we imagine a situation where, starting from the equilibrium point $E_{0}$, a $\operatorname{tax} \bar{\tau}=10 \%$ is levied on consumption that supports a sponsorship mechanism of $\tilde{z}=1.4$ which, in turn, leads to a new balanced growth path and a new saddlepoint equilibrium at $E_{1}$, therefore increasing the steady state level of innovation even with the same value of investment.

Clearly, a policy shock of this kind would impact first the investment dynamics at point $E_{0}$ (remember that investment is the unstable variable) leading it to jump onto the stable trajectory whereas A remains constant in the first instance. This would eventually raise the ratio $\mathbf{I} / y$ affecting the transfers rate through the condition in Equation (4.11). For the sake of simplicity, we assume that such a change is not very large and the investment ratio remains circa $\mathbf{I} / y=20 \%$ in getting from the equilibrium $E_{0}$ to $E_{1}$. Notice that this is a safe assumption for infinitesimal changes from $E_{0}$ to $E_{1}$ led by the increase in $\tilde{z}$. Yet, by way of illustration, we use sufficiently large changes of numbers for plotting and still keep I $/ y=20 \%$ constant.

The positive influence of the sponsorship mechanism has two components. The first, as may be seen from Equation (4.17), is that the value of $\tilde{z}>1$ 
shifts the innovation locus downwards to the right with a lower intercept at $\frac{\delta}{\tilde{z} \mid \tilde{z}>1}<\frac{\delta}{\tilde{z} \mid \tilde{z}=1}$. More formally, from Equation $\left(4.6^{\prime}\right)$ and using the rules of the Implicit Function Theorem, we may see that along the $\dot{A}=0$ line the derivative of $A$ with respect to $\tilde{z}$ is negative, which implies that an increase in the sponsorship mechanism shifts the $\dot{A}$ line down to the right

$$
\left.\frac{\partial A}{\partial \tilde{z}}\right|_{\dot{A}=0}=-\frac{\mathbf{I} A\left(1-\frac{A}{\bar{A}}\right)}{\mathbf{I} \tilde{z}\left(1-2 \frac{A}{A}\right)-\delta}<0
$$

The second component in the movement from the point $E_{0}$ to the point $E_{1}$ is that the increase in the sponsorship mechanism drives an expansion of the $\dot{\mathbf{I}}=0$ bell-shape line. This can be seen, more formally, using Equation $\left(4.16^{\prime}\right)$ since, along the $\dot{\mathbf{I}}=0$ line, the implicit derivative of $\mathbf{I}$ with respect to $\tilde{z}$ is positive

$$
\left.\frac{\partial \mathbf{I}}{\partial \tilde{z}}\right|_{\dot{\mathbf{I}}=0}=\frac{\alpha A^{\alpha}\left(1-\frac{A}{A}\right)}{r+\frac{\delta}{A-A}}>0
$$

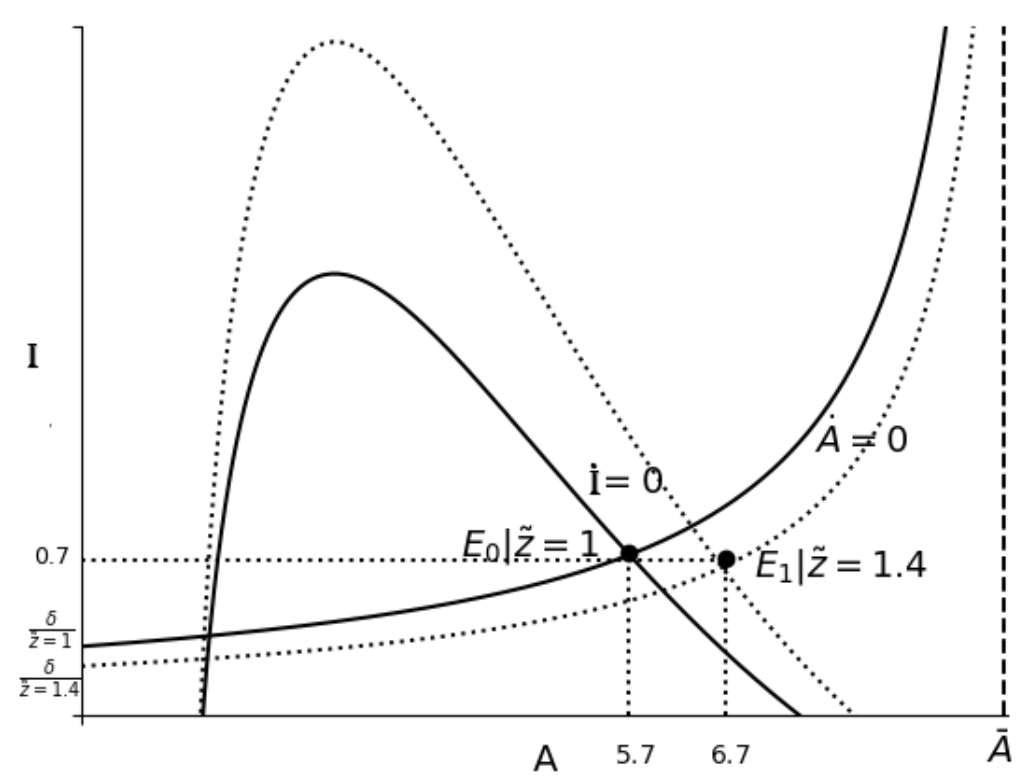

Figure 4.2: The sponsorship mechanism scenario with $\tilde{z}>1$. Here $E_{0}$ relies on $\bar{\tau}=0, \tau_{Z}=0$ and $\tilde{z}=1 ; E_{1}$ relies on $\bar{\tau}=10 \%, \tau_{Z}=40 \%$ and $\tilde{z}=1.4$, other parameter values that we have established earlier remain, namely, $\delta=10 \%, r=1 \%$, $\alpha=0.7, \bar{A}=10$. The plot is edited for illustrative purposes, e.g., the I-axis enlarged.

As it stands from Figure 4.2, and following from our discussion at the end of Section (4.4), an innovation policy based on the sponsorship mechanism is 
adequate to boost the production of innovation and spur a virtuous cycle of growth and development provided the government is interested in the promotion of innovation and is able to regulate the sponsorship mechanism without incurring in either unsustainable fiscal deficits or negative consumption effects.

Graphically, the equilibrium with transfers needs to lie to the right of the equilibrium without transfers; and the steady state value of innovation in the equilibrium with transfers has to be large enough to lead a large increase in productivity, and therefore consumption, at present value terms - remember that we have defined productivity (output per worker) as an increasing function of innovation.

For instance, in the context of our example, the transition from the equilibrium point at $E_{0}$, where $\tau_{Z}=0 \%$ (and $\tilde{z}=1$ ), to the new equilibrium $E_{1}$, where $\tau_{Z}=40 \%$ (and $\tilde{z}=1.4$ ), the increase in transfers that has been supported by an increase of $10 \%$ in taxation, needs to ensure an increase of at least $10 \%$ in productivity if the sponsorship mechanism is to be considered a successful policy (below we show a numerical example in this direction). Clearly that is a difficult task for policy makers given the many uncertainties involved in the production of innovation, which however have not been a reason for the policy not to be adopted in practice. ${ }^{65}$

\subsubsection{Equilibria with confiscatory taxation $(\tilde{z}<1)$}

If the government is unable, or unwilling, to promote innovation, which as we have pointed out earlier amounts to a situation where taxation is positive $(\bar{\tau}>0)$ and transfers are zero or negative $\left(\tau_{Z} \leq 0\right)$, we observe $\tilde{z} \leq 1$.

In strict sense, positive taxation with zero transfers still leaves $\tilde{z}=1$. But, from Equation (4.18), we see that an increase in the tax rate still has a positive impact on investment, which is explained because, as we established in Equation $\left(4.5^{\prime}\right)$, effective investment is tax-deducible and the cost of adjustment, by its very nature, can not be taxed either.

It is when taxes are levied on investment that we get to a situation analytically equivalent to $\tilde{z}<1$, therefore, we refer to this as a case of confiscatory taxation.

In particular, notice that, if taxes are levied on investment (a tax on gross output rather than on consumption), Equation (4.7) would modify to

$$
T=\bar{\tau} Y
$$

and the equilibrium solution, Equation (4.18), would modify to

$$
\mathbf{I}=\frac{\alpha A^{\alpha}(1-\bar{\tau})(1-A / \bar{A})}{r+\frac{\delta A}{A-A}}-1, \quad 0<\bar{\tau}<1
$$

where the term $(1-\bar{\tau})$ in the numerator of this equation implies that in the steady state investment is reduced in a proportion equal to the size of the tax.

\footnotetext{
${ }^{65}$ Mazzucato 2013, Mazzucato and Penna 2015, Breznitz 2007, Breznitz 2018.
} 
Graphically, and qualitatively, the economy would be in a situation equivalent to $\tilde{z}<1$.

As we observe from Figure 4.3, in this scenario the saddlepoint shifts inwards in comparison with the scenario where $\tilde{z}=1$ analyzed above. Notice that we obtain the new figure using the same parameter values as established earlier, namely, $\delta=10 \%, r=1 \%, \alpha=0.7, \bar{A}=10$ (the plot is enlarged in the I-axis direction to ease the illustration).

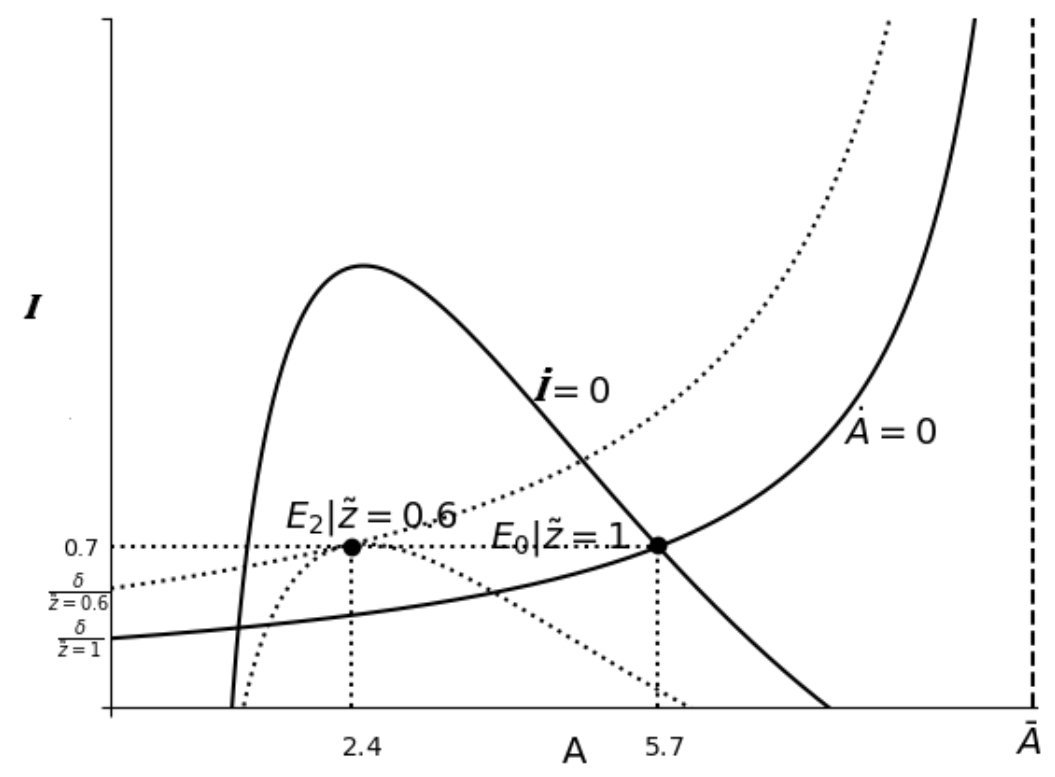

Figure 4.3: The sponsorship mechanism scenario with $\tilde{z}<1$. Here $E_{0}$ relies on $\bar{\tau}=0, \tau_{Z}=0$ and $\tilde{z}=1 ; E_{2}$ relies on the assumption of an investment tax equivalent to $\tilde{z}=0.6$, other parameter values that we have established earlier remain, namely, $\delta=10 \%, r=1 \%, \alpha=0.7, \bar{A}=10$. Again the plot is edited for illustrative purposes, e.g., the I-axis enlarged.

From Figure 4.3, the transition of the the equilibrium point from $E_{0}$ to $E_{2}$ led by an increase in taxation on gross output, has two components. First, from Equation (4.17), we see that there is a reduction in the value of innovation which shifts the $\dot{A}=0$ locus upwards to the left with an intercept at $\frac{\delta}{\tilde{z} \mid \tilde{z}<1}>\frac{\delta}{\tilde{z} \mid \tilde{z}=1}$. Second, from Equation $\left(4.18^{\prime}\right)$, we see a reduction in the size of investment, which shrinks the $\dot{\mathbf{I}}=0$ locus.

Figure 4.3 suggests that inappropriate government interventions that lead to reduce the steady state value of innovation, also have negative welfare effects as such interventions lead to a reduction of output (per worker), therefore reducing 
consumption.

Furthermore, as the equilibrium shifts to the left from $E_{0}$ to $E_{2}$, the dash lines describing the innovation and investment loci under intervention suggest here the possibility of poverty traps induced by the government: the economy gets trapped in a low saddlepoint equilibrium. We notice that those possibilities have been researched in numerous studies. ${ }^{66}$

Finally, if follows also from the analysis of Figure 4.3, that the system might even be devoid of equilibria when and if $\tilde{z} \stackrel{a}{\rightarrow} 0$. This technical possibility of the model arises because, in more general terms, the sponsorship mechanism influences the qualitative structure of the dynamics of the system, therefore leading to scenarios with two, one or no equilibria. While it is tempting to relate the possibility of non existence of equilibria to actual economic situations, we refrain to do so leaving it as a subject for future research instead.

Summing up, there are three distinct scenarios with regard to the role of government in easing the financing needs of the private sector innovation activity:

(i) $\tilde{z}<1$, consistent with the political barriers to technology adoption highlighted in some strands of the development literature;

(ii) $\tilde{z}=1$, which is a scenario without intervention;

(iii) $\tilde{z}>1$, consistent with the NIS perspective that public funds stimulate innovation investments and therefore lead to increasing stocks of innovation in present value terms.

The setting just outlined illustrates a critical feature distinguishing the NIS framework. From the conventional viewpoint, the best government can do is setting up institutions and policies to get the economy from scenario i) to ii); under the NIS view, the crucial point is to guarantee the financial sponsorship needed to get from scenario ii) to iii) and this has been the theoretical foundation of the innovation policy followed by both countries at the frontier and successful catching up countries.

\subsubsection{A numerical application}

As we established earlier, Section 4.4, from the point of view of government, a desirable economic goal is to influence the optimizing agent in order to achieve an increase in consumption that is at least proportional to the tax rate, which formally was written above in Equation (4.12) as

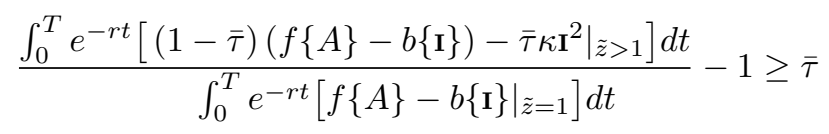

Notice that this condition may be easily verified using Equations (4.9)-(4.11) to determine a value for $\tilde{z}$. Also, we can use Equation (4.17) to determine a value

\footnotetext{
${ }^{66}$ Parente and Prescott 1994, 2002; Damsgaard and Krusell 2010; Stokey 2012.
} 
for A given the sponsorship mechanism and a (constant) value of investment. In general, $\tilde{z}>1$ implies $0<\bar{\tau}<\tau_{Z}$ which, at least potentially, leads to increase consumption over the long run in an scenario with taxes and transfers.

In this section, we estimate the impact of the sponsorship mechanism on the steady state value of A using Equation (4.17). As it turns out, with a constant value of investment it is unnecessary to use Equation (4.18) to determine the steady state value of $\mathrm{A}$, therefore, note that the numerical exercises below are unrelated to the graphical analysis in Subsections 4.5.1-4.5.3.

Under suitable parameter values, namely, assuming initial values $A=1$, $\alpha=0.7$ and $\mathbf{I}=0.2$ such that, at the origin, $A=y=1$ and $\mathbf{I} / y=20 \%$; and assuming that $\bar{\tau}=0$ at the origin, we find from Equation (4.11) that $\tau_{Z}=0$ and, hence, $\tilde{z}=1$. Furthermore, we may assume $\delta=0.1$ and $\bar{A}=2$, such that we implicitly establish that the rate of obsolescence is half the investment ratio and that, at the origin, the economy is around halfway of the frontier (with $\mathrm{A}=1$ and $\bar{A}=2$ ). Plugging these parameter values into Equation (4.17) yields

$$
A=\bar{A}\left[1-\left.\frac{\delta}{\mathbf{I} \tilde{z}}\right|_{\tilde{z}=1}\right]=2\left[1-\frac{0.1}{0.2 \times 1}\right]=1.0
$$

Next, in an scenario with taxes and transfers, which leads taxes from $\bar{\tau}=0$ to $\bar{\tau}=10 \%$, and keeping other parameter values constant, we find from Equation (4.11) that $\tau_{Z}=40 \%$, hence, $\tilde{z}=1.4$. Plugging again these values into Equation (4.17) yields

$$
A=\bar{A}\left[1-\left.\frac{\delta}{\mathbf{I} \tilde{z}}\right|_{\tilde{z}=1.4}\right]=2\left[1-\frac{0.1}{0.2 \times 1.4}\right] \approx 1.3
$$

where comparison of scenarios (a) and (b) show that, starting from the same initial conditions for other variables, the change in the sponsorship mechanism from $\tilde{z}=1$ to $\tilde{z}=1.4$ leads to an increase of approximately $30 \%$ in innovation.

Now, given that, as we have pointed out above, the value of output is determined by $A^{\alpha}$ with $\alpha=0.7$, we obtain $1^{0.7}=1.0$ when $\tilde{z}=1$; and $1.3^{0.7}=1.2$ when $\tilde{z}=1.4$. Furthermore, as we have assumed a constant value of investment, $\mathbf{I}=0.2$ and the cost of investment is given by Equation $\left(4.4^{\prime}\right)$ as $b\{\mathbf{I}\}=\mathbf{I}+\frac{\mathbf{I}^{2}}{2}$, we obtain that the net value of consumption (after taxes) is $c=1-0.2-\frac{0.2^{2}}{2}=0.78$ when $\tilde{z}=1$; and $c=0.9 *(1.2-0.2)-\frac{0.2^{2}}{2} \approx 0.88$ when $\tilde{z}=1.4$, where multiplying for 0.9 in the latter expression is because the agent now pays a fix tax rate on consumption $(\bar{\tau}=10 \%)$.

Assuming, for simplicity, that $\mathrm{T}=1$ and there is no discount $(r=0)$, plugging the above calculations into Equation (4.12) yields, under the parameter configuration of this example,

$$
\frac{\left.\left[(1-0.1)(1.2-0.2)-\frac{0.2^{2}}{2}\right]\right|_{\tilde{z}=1.4}}{\left.\left[1-0.2-\frac{0.2^{2}}{2}\right]\right|_{\tilde{z}=1}}-1 \approx 13 \% \geq \bar{\tau}=10 \%
$$

hence, consisting with the desirable economic goal, the change in the sponsorship mechanism from $\tilde{z}=1$ to $\tilde{z}=1.4$ drives a net increase in consumption of 
approximately $13 \%$ which compares favorably with the change in taxation from $\bar{\tau}=0$ to $\bar{\tau}=10 \%$ at the origin - starting from similar initial conditions for other variables.

Let us recall that the positive change in welfare is achieved here under the assumption that there is no opportunity for arbitrage by the agent leading to offset the power of the mechanism.

Notice that, under perfect arbitrage, the change from $\bar{\tau}=0$ to $\bar{\tau}=10 \%$ with $\mathbf{I} / y=20 \%$ still leads to a change from $\tilde{z}=1$ to $\tilde{z}=1.4$ in the initial conditions. But, after taxes, the agent would adjust the investment ratio from $\mathbf{I} / y=20 \%$ to $\mathbf{I} / y \approx 15 \%$ yielding

$$
\frac{\left.\left[(1-0.1)(1.2-0.15)-\frac{0.15^{2}}{2}\right]\right|_{\tilde{z}=1.4}}{\left.\left[1-0.2-\frac{0.2^{2}}{2}\right]\right|_{\tilde{z}=1}}-1 \approx 0 \%
$$

which, of course, entails a failure of the sponsorship mechanism.

On the other side, if, as a consequence of the sponsorship mechanism the agent increases the after tax investment ratio over $\mathbf{I} / y=20 \%$ the increase in welfare is even higher. But, clearly, since the increase in investment entails a reduction in consumption the increase in investments cannot be without bound.

In particular, under the conditions we have established above, under the sponsorship mechanism of $\tilde{z}=1.4$ consumption increases when the after tax investment ratio increases from $\mathbf{I} / y=20 \%$ to $\mathbf{I} / y=28 \%$ and decreases thereafter for higher ratios; and for an investment ratio larger than $\mathbf{I} / y=40 \%$ the net increase in consumption is smaller than the initial change in the tax rate from $\bar{\tau}=0$ to $\bar{\tau}=10 \%$.

\subsubsection{The change of transfers into subsidies}

With a promotion of innovation strategy based on innovation subsidies rather than on transfers the analysis throughout Subsection (4.3.2) and Section (4.4) remains essentially unchanged (save for the correspondent relabeling of transfers and the term $\tau_{z}$ as a subsidy rate instead, say $\left.\tau_{\overline{\bar{z}}}\right)$. Also, the term $\tilde{z}$ would vanish for Equation (4.6') as the state equation would be unaffected by the subsidy while that is not the case for the objective function. Similar to our reasoning in the equilibrium with transfers, from the point of view of the agent, subsidies are exogenously given, e.g., Equations (4.8)-(4.11) - after the correspondent relabeling of the transfers rate into the subsidies rate - are not part of the intertemporal optimization process of the agent.

One straightforward possibility to include the subsidy and still assuming taxation is on gross consumption, leads to the following modification of the objective function (alternative possibilities to be explained below)

$$
\begin{aligned}
c & =(1-\bar{\tau})\left(A^{\alpha}-\left(1-\tau_{\overline{\bar{z}}}\right)\left(\mathbf{I}-\frac{\mathbf{I}^{2}}{2}\right)\right) \\
& =(1-\bar{\tau}) A^{\alpha}-(1-\bar{\tau})\left(1-\tau_{\overline{\bar{z}}}\right)\left(\mathbf{I}-\frac{\mathbf{I}^{2}}{2}\right)
\end{aligned}
$$


where we have included already in this equation the explicit forms of the production and investment functions and, for simplicity, we maintain the assumption that both the tax-deduction ad the subsidy are inclusive of adjustment cost.

The current value Hamiltonian of this new problem is

$$
H_{c}(\mathbf{I}, A, \lambda)=(1-\bar{\tau}) A^{\alpha}-(1-\bar{\tau})\left(1-\tau_{\bar{z}}\right)\left(\mathbf{I}-\frac{\mathbf{I}^{2}}{2}\right)+\lambda\left(\mathbf{I} A\left(1-\frac{A}{\bar{A}}\right)-\delta A\right)
$$

where we notice that the sponsorship mechanism, $\tilde{z}$, has vanished from the constraint and, instead, the subsidy rate, $\tau_{\overline{\bar{z}}}$, appears now in the objective function.

The first order conditions (FOC) for optimization of the innovation subsidies mechanism satisfy

$$
\begin{array}{rlrl}
\frac{\partial H_{c}}{\partial \mathbf{I}} & = & \lambda A\left(1-\frac{A}{\bar{A}}\right)-(1-\bar{\tau})\left(1-\tau_{\overline{\bar{z}}}\right)(1+\mathbf{I})=\quad 0 \\
\dot{\lambda}-r \lambda=-\frac{\partial H_{c}}{\partial A}= & \lambda\left[-\mathbf{I}\left(1-\frac{A}{A}\right)+\mathbf{I} \frac{A}{\bar{A}}+\delta\right]-\alpha A^{\alpha-1}(1-\bar{\tau}) \\
\frac{\partial H_{c}}{\partial \lambda}= & \mathbf{I} A\left(1-\frac{A}{\bar{A}}\right)-\delta A=\dot{A}
\end{array}
$$

plus the usual transversality conditions. Note that Equation (4.22) reproduces the relevant state equation for the present problem (without the sponsorship mechanism $\tilde{z}$ in it).

We follow a similar procedure as was explained (step-by-step) in the optimization approach of the problem with transfers, namely, we take logs and difference Equation (4.20) with respect to time, which yields

$$
\frac{1}{1+\mathbf{I}} \mathbf{i}=\frac{\dot{\lambda}}{\lambda}+\frac{\dot{A}}{A}-\frac{\dot{A}}{\bar{A}-A}
$$

using Equations (4.20), (4.21) and (4.22) into (4.23) and collecting terms yields

$$
\frac{1}{1+\mathbf{I}} \dot{\mathbf{I}}=r+\frac{\delta A}{\bar{A}-A}-\frac{\alpha A^{\alpha}(1-A / \bar{A})}{\left(1-\tau_{\overline{\bar{z}}}\right)(1+\mathbf{I})}
$$

The crucial point to note from Equation (4.24), is that the tax rate, $\bar{\tau}$, does not show up anymore in the optimization problem, but the subsidy rate, $\tau_{\bar{z}}$, does. This is explained because a time-invariant tax on consumption does not affect the relative price of investment and, therefore, does not affect the intertemporal consumption decision of the agent. ${ }^{67}$ The subsidy rate only affects investment and, as a result of this treatment, this rate shows up in the optimization problem of the agent. Equation (4.24) may be rewritten as

$$
\dot{\mathbf{I}}=\left[r+\frac{\delta A}{\bar{A}-A}\right](1+\mathbf{I})-\frac{\alpha A^{\alpha}(1-A / \bar{A})}{1-\tau_{\overline{\bar{z}}}}
$$

\footnotetext{
${ }^{67}$ Heijdra 2009, pp. 455 ff.
} 
Finally, from the state equation, Equation (4.22), an equilibrium path satisfying $\dot{A}=0$ in the optimization problem with the innovation subsidies mechanism implies

$$
A=\bar{A}\left[1-\frac{\delta}{\mathbf{I}}\right]
$$

which compares with Equation (4.17) because the sponsorship mechanism is not in Equation (4.25).

From Equation $\left(4.24^{\prime}\right)$, the equilibrium path satisfying $\dot{\mathbf{I}}=0$ yields

$$
\mathbf{I}=\frac{\frac{\alpha A^{\alpha}(1-A / \bar{A})}{1-\tau_{\bar{z}}}}{r+\frac{\delta A}{A-A}}-1
$$

which compares with Equation (4.18) because the sponsorship mechanism is not in Equation (4.26) and instead there is the new innovation subsidies mechanism $\left(1-\tau_{\overline{\bar{z}}}\right)$ dividing the numerator of this equation. As it stands we may calculate

$$
\frac{1}{1-\tau_{\overline{\bar{z}}}}=\overline{\bar{z}}
$$

and rewrite Equation (4.26)

$$
\mathbf{I}=\frac{\alpha A^{\alpha} \overline{\bar{z}}(1-A / \bar{A})}{r+\frac{\delta A}{A-A}}-1
$$

where comparison of Equation (4.26') and Equation (4.18) shows that, qualitatively, the dynamic effects of the innovation subsidies mechanism, $\overline{\bar{z}}$, and the sponsorship mechanism, $\tilde{z}$, that we developed earlier are essentially the same, namely,

(i) $\overline{\bar{z}} \leq 1 \mid \tau_{\overline{\bar{z}}}>0$ in the case of confiscatory taxation;

(ii) $\overline{\bar{z}}=\left.1\right|_{\overline{\bar{z}}}=0$ in a scenario without government intervention;

(iii) $\overline{\bar{z}}>1 \mid \tau_{\overline{\bar{z}}}>0$, consistent with a policy based on the innovation subsidies mechanism.

Therefore, the dynamics of the system with subsidies may be studied using the same phase diagrams presented above.

Notice, however, that numerically the results change. Using the examples following Equation (4.11), we see that, for a given investment ratio $(\mathrm{I} / y=20 \%)$, a transfers rate of $40 \%$ that is financed with a tax rate of $10 \%$ on consumption, implies a sponsorship mechanism of $\tilde{z}=1+\tau_{Z}=1.4$, whilst a subsidy mechanism of the same size (40\%) implies a innovation subsidies mechanism of

$$
\frac{1}{1-0.4}=1.67
$$

Notice, finally, that there are further alternatives to the specification of the innovation mechanism through subsidies rather than through transfers. For 
instance one may specify that taxation is on gross output (investment is not excluded), which leads to modify the objective function, Equation (4.19), as follows

$$
c=(1-\bar{\tau}) A^{\alpha}-\left(1-\tau_{\bar{z}}\right)\left(\mathbf{I}-\frac{\mathbf{I}^{2}}{2}\right)
$$

Note that, through the optimization procedure along the lines already described, the relevant state equation for this problem is still given by Equation (4.22) and its solution in Equation (4.25). Instead, the new tax and subsidy arrangement leads to modify Equation $\left(4.26^{\prime}\right)$ into

$$
\mathbf{I}=\frac{\frac{\alpha A^{\alpha}(1-\bar{\tau})(1-A / \bar{A})}{1-\tau_{\overline{\bar{z}}}}}{r+\frac{\delta A}{A-A}}-1
$$

the crucial point to note here is that now the tax rate $(\bar{\tau})$ shows up in the numerator of Equation $\left(4.26^{\prime \prime}\right)$, e.g., the tax rate is not neutral anymore in the intertemporal consumption decisions of the agent. The impact of the subsidy policy is now captured by the term

$$
\frac{1-\bar{\tau}}{1-\tau_{\bar{z}}}
$$

that appears in the numerator of Equation $\left(4.26^{\prime \prime}\right)$. Noticeably, with a policy of taxes on gross output to subsidy investment, the numerical impact is higher as it implies that each period more resources are subtracted from output to put them on investment. This is a new aspect of the model that leads to modify the reasoning in Equation (4.11). Specifically, in the new scenario of noneutrality of taxation we find that

$$
\bar{\tau} y=\mathbf{I} \tau_{\bar{z}}
$$

after rearranging terms implies that

$$
\bar{\tau}(\mathbf{I} / y)^{-1}=\tau_{\bar{z}}
$$

where, with the tax on gross output, the subsidy rate is equal to the tax rate times the inverse of the investment ratio $(\mathbf{I} / y)$. As it stands, here again the success of the innovation subsidies mechanism depends on the agent ignoring the policy such that arbitrage decision making based on the mechanism is not possible, e.g., while both taxes and subsidies show up in the optimization problem of the agent, they ignore how subsidy decisions are made by the government, therefore, Equation (4.28) is not part of the optimization process of the agent.

From Equation (4.28) we have that, given a investment ratio $(\mathbf{I} / y=20 \%)$, nonneutrality of taxation and no arbitrage decision-making, a tax rate of $10 \%$ implies now a subsidy rate of $50 \%$. Using these tax and subsidy rates in Equation (4.27) implies an impact of

$$
\frac{1-\bar{\tau}}{1-\tau_{\overline{\bar{z}}}}=\frac{1-0.1}{1-0.5}=1.8
$$


which is higher than the effects we found earlier for a similar tax $(\bar{\tau}=10 \%)$ and investment ratio $(\mathbf{I} / y=20 \%)$ in the sponsorship mechanism $(\tilde{z}=1.4)$; and it is also higher than the innovation subsidies mechanism when the tax is on consumption, Equation (4.19), where we saw that the impact is $\frac{1}{1-0.4}=1.67$.

To sum up, while there are obvious changes in terms of the numerical results, under a scenario where the tax is on gross output and the whole amount of taxation is used to subsidy investment, the qualitative dynamics of the subsidies mechanism remains unchanged and can still be analyzed from the phase diagrams provided above in Subsection (4.5.1)-(4.5.3).

\subsection{Concluding Remarks}

We have presented a model here that builds on the interaction between the adoption of foreign technology and the process of local innovation, and identify this interaction as a crucial feature to understand the ability of backward countries to catching up. More in particular, we set up an environment where innovation, along technology trajectories that are associated with state-of-theart inventions and working practices that are common to all countries, leads to speed the rate of economic growth and thus determines the catching up process.

We have also described a formal framework where the government financial sponsorship mechanism help to overcome the financial constraints that limit the ability of entrepreneurs in the private sector to innovate. The case for sponsorship mechanism, which depends here on a more extended NIS framework, provides a theoretical basis to better understand the crucial relationship between the production of innovation and the process of catching up; also, it provides a technical basis for the modern discussion on the appropriate role of government in the promotion of innovation.

Let us briefly mention what we think are other key takeaways from the model:

First, the sponsorship mechanism provides a richer characterization of the role of the government in the economy. In earlier advances of the endogenous growth literature the most influential arguments are in line with conventional neo-classical prescriptions - more savings, more schooling, and proper institutions. ${ }^{68}$

Second, the model creates an enriched framework in which to consider the interaction between the diffusion of new technology, its adoption and the need to foster innovation along common working practices, technological inventions and modes of production. That approach seems warranted to inform the innovation policy in developing countries along the policy practice in countries at the frontier. ${ }^{69}$

Third, the model provides an input to better the academic understanding on the determinants/limits of the advantage of backwardness. Unlike the usual

\footnotetext{
${ }^{68}$ Romer 1994 and Parente and Prescott 2002.

${ }^{69}$ World Bank 2010, OECD 2013.
} 
tenet that backward countries benefit automatically from the technology advance at the frontier, the model presented here has stressed that the benefits of foreign technology are mostly indirect and occur through the local innovation effort. In this context, the model integrates the role of the indigenous innovation policy as a means to realize the benefits of technology diffusion.

It is worth stressing that in the systemic approach the production of innovations, and not just the adoption of output-augmenting and cost-reducing technologies, is the key determinant of a country's long-run competitive advantage; and therefore the true engine of economic growth over the long-run. ${ }^{70}$

All in all, our aim in this chapter has been to capture the widespread fact of reality that innovation is the true engine of growth, if alongside the contributions of technology diffusion. The government - through its own innovation effort and the institutional/policy framework - has a great deal of influence both upon the transitional dynamics, and the final state of the economy.

\footnotetext{
${ }^{70}$ Lundvall 2007.
} 


\section{Appendix 4A: The Social Optimum}

With the agent in control of $(1-\bar{\tau}) \mathbf{I}+\bar{\tau} y=\tilde{\mathbf{I}}$ the current value Hamiltonian $H_{c}$ becomes

$$
H_{c}(\mathbf{I}, A, \lambda)=A^{\alpha}-\tilde{\mathbf{I}}-\frac{\mathbf{I}^{2}}{2}+\lambda\left(\tilde{\mathbf{I}} A\left(1-\frac{A}{\bar{A}}\right)-\delta A\right)
$$

or, written in extensive form

$$
H_{c}(\mathbf{I}, A, \lambda)=A^{\alpha}-\left[(1-\bar{\tau}) \mathbf{I}+\bar{\tau} A^{\alpha}\right]-\frac{\mathbf{I}^{2}}{2}+\lambda\left(\left[(1-\bar{\tau}) \mathbf{I}+\bar{\tau} A^{\alpha}\right] A\left(1-\frac{A}{\bar{A}}\right)-\delta A\right)
$$

The first order conditions (FOC) for optimization satisfy Equation $\left(4.6^{\prime} \mathrm{A}\right)$, $(4.13 \mathrm{~A})$ and $(4.14 \mathrm{~A})$ where the labels are intended to ease comparison with the corresponding equations in the main text

$$
\begin{gathered}
\dot{A}=\left[(1-\bar{\tau}) \mathbf{I}+\bar{\tau} A^{\alpha}\right] A\left(1-\frac{A}{\bar{A}}\right)-\delta A \\
\frac{\partial H_{c}}{\partial \mathbf{I}}=\quad \lambda(1-\bar{\tau}) A\left(1-\frac{A}{\bar{A}}\right)-(1-\bar{\tau})-\mathbf{I}=0 \\
\dot{\lambda}-r \lambda=-\frac{\partial H_{c}}{\partial A}=-\lambda\left[\left[(1-\bar{\tau}) \mathbf{I}+\bar{\tau} A^{\alpha}\right]\left(1-\frac{A}{\bar{A}}\right)-\delta\right] \\
+\lambda\left[\left[(1-\bar{\tau}) \mathbf{I}+\bar{\tau} A^{\alpha}\right] \frac{A}{\bar{A}}-\bar{\tau} \alpha A^{\alpha-1} A\left(1-\frac{A}{\bar{A}}\right)\right] \\
-\alpha A^{\alpha-1}(1-\bar{\tau})
\end{gathered}
$$

plus transversality conditions.

Log-transformation of Equation (4.13A) and differencing with respect to time yields

$$
\frac{1}{1-\bar{\tau}+\mathbf{I}} \dot{\mathbf{I}}=\frac{\dot{\lambda}}{\lambda}+\frac{\dot{A}}{A}-\frac{\dot{A}}{\bar{A}-A}
$$

From Equation (4.14A) we obtain

$$
\frac{\dot{\lambda}}{\lambda}=r-\frac{\dot{A}}{A}+\left[(1-\bar{\tau}) \mathbf{I}+\bar{\tau} A^{\alpha}\right] \frac{A}{\bar{A}}-\bar{\tau} \alpha A^{\alpha}\left(1-\frac{A}{\bar{A}}\right)-\frac{(1-\bar{\tau}) \alpha A^{\alpha-1}}{\lambda}
$$

and, from Equation $\left(4.6^{\prime} \mathrm{A}\right)$ we obtain

$$
\frac{\dot{A}}{\bar{A}-A}=\left[(1-\bar{\tau}) \mathbf{I}+\bar{\tau} A^{\alpha}\right] \frac{A}{\bar{A}}-\delta \frac{A}{\bar{A}-A}
$$

using these two expressions into Equation (4.15A), suppressing redundant terms and rearranging, we obtain

$$
\frac{1}{1-\bar{\tau}+\mathbf{I}} \dot{\mathbf{i}}=r-\bar{\tau} \alpha A^{\alpha}\left(1-\frac{A}{\bar{A}}\right)-\frac{(1-\bar{\tau}) \alpha A^{\alpha-1}}{\lambda}+\delta \frac{A}{\bar{A}-A}
$$


Finally, using Equation (4.13A) into (4.15"A), we obtain

$$
\frac{1}{1-\bar{\tau}+\mathbf{I}} \dot{\mathbf{I}}=r+\delta \frac{A}{\bar{A}-A}-\bar{\tau} \alpha A^{\alpha}\left(1-\frac{A}{\bar{A}}\right)-\frac{(1-\bar{\tau})^{2} \alpha A^{\alpha}\left(1-\frac{A}{A}\right)}{1-\bar{\tau}+\mathbf{I}}
$$

which may be written equivalently as

$$
\frac{1}{1-\bar{\tau}+\mathbf{I}} \dot{\mathbf{i}}=r+\delta \frac{A}{\bar{A}-A}-\frac{\left(\bar{\tau}(1-\bar{\tau}+\mathbf{I})+(1-\bar{\tau})^{2}\right) \alpha A^{\alpha}\left(1-\frac{A}{\bar{A}}\right)}{1-\bar{\tau}+\mathbf{I}}
$$

we may simplify further the latter expression to obtain

$$
\frac{1}{1-\bar{\tau}+\mathbf{I}} \dot{\mathbf{I}}=r+\delta \frac{A}{\bar{A}-A}-\frac{\left(\bar{\tau}-\bar{\tau}^{2}+\bar{\tau} \mathbf{I}+1^{2}-2 \bar{\tau}+\bar{\tau}^{2}\right) \alpha A^{\alpha}\left(1-\frac{A}{A}\right)}{1-\bar{\tau}+\mathbf{I}}
$$

which reduces to

$$
\frac{1}{1-\bar{\tau}+\mathbf{I}} \dot{\mathbf{I}}=r+\delta \frac{A}{\bar{A}-A}-\frac{(1-\bar{\tau}+\bar{\tau} \mathbf{I}) \alpha A^{\alpha}\left(1-\frac{A}{A}\right)}{1-\bar{\tau}+\mathbf{I}}
$$

from which we obtain

$$
\dot{\mathbf{I}}=\left(r+\delta \frac{A}{\bar{A}-A}\right)(1-\bar{\tau}+\mathbf{I})-(1-\bar{\tau}+\bar{\tau} \mathbf{I}) \alpha A^{\alpha}\left(1-\frac{A}{\bar{A}}\right)
$$

Where Equations $\left(4.6^{\prime} \mathrm{A}\right)$ and $\left(4.16^{\prime} \mathrm{A}\right)$ provide the dynamic equations of interest to the maximizing agent. From the state Equation $\left(4.6^{\prime} \mathrm{A}\right)$, an equilibrium path satisfying $\dot{A}=0$ implies

$$
A=\bar{A}\left[1-\frac{\delta}{\tilde{\mathbf{I}}}\right]=\bar{A}\left[1-\frac{\delta}{(1-\bar{\tau}) \mathbf{I}+\bar{\tau} A^{\alpha}}\right]
$$

From Equation $\left(4.16^{\prime} \mathrm{A}\right)$, the equilibrium path satisfying $\mathbf{i}=0$ yields

$$
\frac{1-\bar{\tau}+\mathbf{I}}{1-\bar{\tau}+\bar{\tau} \mathbf{I}}=\frac{\alpha A^{\alpha}\left(1-\frac{A}{A}\right)}{r+\delta \frac{A}{A-A}}
$$

Notice that we may write the left hand side of the latter equation as

$$
\frac{1-\bar{\tau}+\bar{\tau} \mathbf{I}-\bar{\tau}_{\mathbf{I}}+\mathbf{I}}{1-\bar{\tau}+\bar{\tau} \mathbf{I}}=1+\frac{(1-\bar{\tau}) \mathbf{I}}{1-\bar{\tau}+\bar{\tau}_{\mathbf{I}}}
$$

Thus, we can write Equation $\left(4.16^{\prime} \mathrm{A}-\mathrm{a}\right)$ as

$$
\frac{(1-\bar{\tau}) \mathbf{I}}{1-\bar{\tau}+\bar{\tau} \mathbf{I}}=\frac{\alpha A^{\alpha}\left(1-\frac{A}{A}\right)}{r+\delta \frac{A}{A-A}}-1
$$

the latter expression may be alternatively written as

$$
\mathbf{I}=\left(\frac{\alpha A^{\alpha}\left(1-\frac{A}{A}\right)}{r+\delta \frac{A}{A-A}}-1\right) \frac{1-\bar{\tau}+\bar{\tau} \mathbf{I}}{1-\bar{\tau}}
$$


which also leads to

$$
\mathbf{I}=\left(\frac{\alpha A^{\alpha}\left(1-\frac{A}{A}\right)}{r+\delta \frac{A}{\bar{A}-A}}-1\right)+\left(\frac{\alpha A^{\alpha}\left(1-\frac{A}{A}\right)}{r+\delta \frac{A}{A-A}}-1\right) \frac{\bar{\tau}_{\mathbf{I}}}{1-\bar{\tau}}
$$

Taking the second component from the right hand side to the left hand side, and solving for $\mathbf{I}$ we obtain

$$
\mathbf{I}\left(1-\left(\frac{\alpha A^{\alpha}\left(1-\frac{A}{A}\right)}{r+\delta \frac{A}{A-A}}-1\right) \frac{\bar{\tau}}{1-\bar{\tau}}\right)=\frac{\alpha A^{\alpha}\left(1-\frac{A}{A}\right)}{r+\delta \frac{A}{A-A}}-1
$$

which, finally, leads to a suitable expression of the dynamic equation governing innovation investments under the social optimum scenario

$$
\mathbf{I}=\frac{\frac{\alpha A^{\alpha}\left(1-\frac{A}{A}\right)}{r+\delta \frac{A}{A-A}}-1}{1-\left(\frac{\alpha A^{\alpha}\left(1-\frac{A}{A}\right)}{r+\delta \frac{A}{A-A}}-1\right) \frac{\bar{\tau}}{1-\bar{\tau}}}
$$

Is is easy to verify, from Equation (4.18A), that the only maximizing option is found when $\bar{\tau} \stackrel{a}{\rightarrow} 0$ in which case Equation (4.17A) becomes

$$
A=\bar{A}\left[1-\frac{\delta}{\mathbf{I}}\right]
$$

and Equation (4.18A) becomes simply

$$
\mathbf{I}=\frac{\alpha A^{\alpha}\left(1-\frac{A}{A}\right)}{r+\delta \frac{A}{A-A}}-1
$$

From which we may conclude that, when the agent is aware that taxation would be fully used to finance investment, the social optimal solution is equivalent to have $\bar{\tau}=0$ and no sponsorship mechanism. 


\section{Appendix 4B: The algorithm in Python}

import numpy as np

from scipy.optimize import minimize

import matplotlib.pyplot as plt

from matplotlib.patches import Polygon



Abar $=10$

delta $=.5$

$\mathrm{A}=$ np.arange $(0.0,10.0,0.01)$

$\mathrm{s} 1=($ Abar*delta $/($ Abar-A $))$

$\mathrm{s} 2=\left((\right.$ alpha*A**alpha* $(1-\mathrm{A} / \mathrm{Abar})) /\left(\mathrm{r}+\operatorname{delta}^{*} \mathrm{~A} /(\right.$ Abar-A $\left.\left.)\right)-1\right)$

\# Equilibria without the sponsorship mechanism $\mathrm{z}=1$

line, $=$ plt.plot $\left(\mathrm{A}, \mathrm{s} 1,{ }^{\prime} \mathrm{k}-{ }^{\prime}\right)$

line, $=$ plt.plot $\left(\mathrm{A}+1.2, \mathrm{~s} 2,{ }^{\prime} \mathrm{k}^{-}{ }^{\prime}\right)$

\# Equilibria with the sponsorship mechanism $z>1$

$\mathrm{z}=1.4$

$\mathrm{s} 1 \mathrm{z}=\left(\right.$ Abar*delta $/\left(\mathrm{z}^{*}(\right.$ Abar-A $\left.\left.)\right)\right)$

$\mathrm{s} 2 \mathrm{z}=\left(\left(\right.\right.$ alpha*A**alpha* $\left.\mathrm{z}^{*}(1-\mathrm{A} / \mathrm{Abar})\right) /\left(\mathrm{r}+\right.$ delta*$^{*} \mathrm{~A} /($ Abar-A $\left.\left.)\right)-1\right)$

line, $=$ plt.plot $\left(\mathrm{A}+1.2, \mathrm{~s} 1 \mathrm{z},{ }^{\prime} \mathrm{k}: '\right)$

line, $=$ plt.plot $\left(\mathrm{A}+1.2, \mathrm{~s} 2 \mathrm{z},{ }^{\prime} \mathrm{k}: '\right)$

\# Editing section (the algorithm still runs if this block is dropped out )

plt.plot $(5.7,1.18, ' k o ')$

plt.text(-.46, 2, r'I',fontsize=10, weight='bold')

plt.text $\left(9,-0.1, \mathrm{r}^{\prime} \bar{A}^{\prime}\right.$, fontsize $=14$, weight='bold')

plt.text $\left(-.4,0.34, \mathrm{r}^{\prime} \frac{\delta}{\tilde{z}}\right.$, fontsize $=18$, weight='bold')

plt.text $\left(7.61,1.9, \mathrm{r}^{\prime} \dot{A}=0\right.$ ',fontsize=14, weight='bold')

plt.text $\left(5.15,1.6, \mathrm{r}^{\prime} \mathbf{i}=0\right.$ ',fontsize $=14$, weight='bold')

plt.text $\left(3.94,1.15, \mathrm{r}^{\prime} E_{0} \mid \tilde{z}=1\right.$ ',fontsize=14, weight='bold')

plt.axis $([0,9,0,3.5])$

plt.xlabel('A',fontsize $=14$ )

frameon $=$ False

plt.show () 


\section{Chapter 5}

\section{Econometrics of Adoption and Innovation}

\subsection{Introduction.}

Whether the ability of less developed countries to catch up hinges primarily on technology diffusion or on domestic technology is an intriguing question at the heart of growth economics. It is, moreover, a question that raises huge policy implications which, however, stem from what researchers hold as a feasible theoretical explanation upon the ultimate determinants of growth and catching up. Therefore, in this chapter we endeavor to assess whether, and to what extent, the contesting explanations of the relationship between technology and long-run growth underlined in the mainstream economics, and in the evolutionary and NIS frameworks, are empirically relevant. ${ }^{1}$

In particular, we endeavor to assess to what extent long-run growth hinges on foreign technology - as most mainstream studies hold - and to what extent it hinges on indigenous technology, or the interaction of foreign and local technology — as the evolutionary framework holds. We also assess to what extent local technology, or innovation for that matter, hinges on government coordination which is a means to capture the influence of a country's national innovation system in this regard - as we explain below.

The widespread belief that long-run growth and catching-up are closely related to worker's productivity, which in turn relates to the available technology,

\footnotetext{
${ }^{1}$ Let us recall the reader that the mainstream view in our discussion relates to the logic spread in the neoclassical and endogenous model according to which technology is produced exclusively in countries at the frontier, whereas adoption/imitation are the alternatives left to countries falling behind (Solow 1956, Lucas 1988, Romer 1994, Jones 2005). The evolutionary and NIS theories make the case for a broader view of innovation and a concern about the whole system of innovation, which in turn commands active government intervention beyond the market failures fixing paradigm. See Nelson and Winter 1982, 2002, Nelson et al., 2018 on the evolutionary approach. See Freeman 1987, Nelson 1993, Lundvall 1992, 1993, 2007 and Soete et al., 2010 on the NIS perspective. For a trace to earlier literature see Chapter 1.
} 
is beyond question. ${ }^{2}$ With regard to the debate on the productivity contributions accrued to foreign technology and (local) innovation, this is yet an open question relating to the causes of the observed disparity in growth and levels of income across countries. ${ }^{3}$ Below, we refer to these two sources of productivity simply as adoption (of foreign technology) and (local) innovation.

We present below a workable version of the theoretical model developed in the previous chapter. In the model of this chapter, each country's growth and catching-up performance hinges on the interplay between adoption and innovation. Then, we formulate a set of hypotheses upon the long-run relationships between productivity, the interaction of foreign technology and local innovation, and government coordination. We test our hypotheses by means of well established cointegration techniques.

A key feature of our analysis is the distinction between countries that over long periods of time have succeeded to catch-up and countries that have not. More specifically, we distinguish between countries at the frontier of technology (FRCs), successful cases of catching-up (CUCs), countries in stagnation (STCs), and countries that have kept lagging further and further behind (LGCs). This classification is based on the dynamics of each country's income per capita relative to the average of the FRCs. ${ }^{4}$

The variables that we deem relevant to capture the effects of interests are drawn from the innovation literature and the received theory of economic growth. We use the conventional index of multifactor productivity, MFP; an index of foreign technology that is based on R\&D expenditures in FRCs countries; ${ }^{5}$ and an index of innovation capacity that is based on the share of labor in cognitive non-routine activities. ${ }^{6}$ To measure government coordination we use an index that is a simple average of labor productivity, financial development, human capital and governance, each of these components is in turn made up of other sub-indicators - as explained below.

\footnotetext{
${ }^{2}$ One of the key claims in the growth literature is that technology differences, measured as a residual, account for up to $90 \%$ or more of growth differences across countries, and more than $90 \%$ of the gap in income levels (e.g., Easterly and Levine 2001). Some contributions (i.e., Keller 2004), state that diffusion accounts for the lion's share of domestic improvements in MFP-asserted to be more than $90 \%$ in many cases. The preeminence of technology is not safely established though: while some authors hold the technology view, others hold that capital accumulation is the subject of interest, e.g., Jorgenson et al., 1987, Jorgenson and Vu 2005, 2010. And even among the former, lots of controversy arises on the proper concept/aspect of technology to focus on (see Bernard and Jones 1996a and 1996b for discussions).

${ }^{3}$ Previous contributions on the foreign/domestic sources of technology include Amable 1993, Coe and Helpman 1995, Verspagen 1997, and Keller 2002, 2004, among others.

${ }^{4}$ Our basic sample consists of 133 countries. The number of countries in the econometric analysis is determined by data availability, as explained below. One purpose for future research is the expansion and refinement of the database we have initiated in this regard.

${ }^{5}$ This is the same strategy used earlier by Coe and Helpman 1995, Coe, Helpman and Hoffmaister 1995, Keller 2002.

${ }^{6}$ According to recent advances in the labor-segmentation literature, workers in this category are characterized by mental rather than manual/physical skills, and are employed on tasks that require problem-solving rather than following well-defined instructions/procedures, thus they are most probably involved with the innovative aspect of production, for example, Autor, Levy, and Murnane 2003, and Autor and Dorn 2013.
} 
The remainder of this chapter proceeds as follows. In Section 5.2, we elaborate on the model and theoretical justifications that motivate the hypotheses to be tested in a later section. In Section 5.3, we discuss the criteria for the classification of countries in the groups mentioned earlier; and we explain also the measurement, computation and assumptions made for the different variables entering the model. In Section 5.4, we discuss the econometric framework underlying the analysis. In Section 5.5, we conduct the cointegration analysis, fit the vector error correction models and explain the estimated results for each country in the CUCs classification; we also present and discuss the average results for every country classification. Finally, Section 5.6 provides the usual concluding remarks.

\subsection{Theoretical Framework}

As we have argued in earlier chapters, mainstream economics, on one side, and the evolutionary and NIS frameworks, on the other, command different perspectives on the aspects of technology that matter to explain long-run growth and catching-up. Let us recap on some key aspects of the dissent that result purposeful for the objectives in this chapter.

In the mainstream's perspective growth and catching-up hinge more or less automatically on technology diffusion: a setting where backward countries thrive through the mechanical application of technologies produced at the frontier. ${ }^{7}$ Although this view builds on earlier contributions that became widespread under the notion of advantage of backwardness, ${ }^{8}$ they generally rely on more limited intervention by the State in the economy. ${ }^{9}$

The models of distance to the frontier pertain to the latter type. ${ }^{10}$ The key to this approach is that adoption and innovation follow sequential stages: at low development levels countries rely heavily on the adoption of technologies developed at the frontier; and, at high development levels, innovation becomes the fundamental engine of growth. The benefits of being backward are realized whenever the right conditions hold, namely, market institutions are in place and market transactions are conducted with limited intervention by the government.

Further models attempting to provide explanations about the difference in achievements between countries at the frontier and backward countries that do not rely on explicit forms of government intervention relate to the so-called issue of appropriate technology. ${ }^{11}$ The line of reasoning is that the adoption of new

\footnotetext{
${ }^{7}$ De Long and Summers 1991, Romer 1993, Lee 1995, Mankiw et al., 1995, Keller 2002, Caselli and Wilson 2004, Caselli 2005, Acemoglu et al., 2006, Caselli and Coleman 2006, Comin and Hobijn 2010.

${ }^{8}$ Gerschenkron 1962.

${ }^{9}$ Gerschenkron's argument of advantage of backwardness was exactly the opposite of "limited" State intervention, namely that although "backwardness" provided opportunities, extensive government intervention is necessary to escape it. The author acknowledges J. Fagerberg for helpful suggestions that made this point clear.

${ }^{10}$ Acemoglu et al., 2006, Zilibotti 2008.

${ }^{11}$ Atkinson and Stiglitz 1969, Acemoglu 2014.
} 
technologies is specific to particular production techniques so that investors in backward countries would only learn and bring in technologies that are closely related with the factors' endowment of the economy and their own production activities. ${ }^{12}$ A similar perspective, namely an upgrading of a country's technological background that does not rely on explicit forms of government intervention, can be found in recent approaches to this research that concentrate on the complexity of the type of products a country is able to produce which, in turn, determines its growth and development possibilities. ${ }^{13}$ The fact that remains here is that countries benefit more or less automatically from the adoption of inventions that reduce the cost and/or increase the efficient scale of production.

Noteworthy, in contrast to the above literature, an explicit focus on the role of government to impact the technology background, hence the development possibilities of backward countries, is found in the case where policy intervention is deemed necessary to conduct the indigenous construction of absorptive capacities, e.g., infrastructure, institutions, human and social capital. ${ }^{14}$ In this approach, the debate that remains is whether intervention creates more havoc than opportunity given the probability of "market failures" to be replaced by "government failures".

Evolutionary economics and the NIS framework are closer in spirit to the latter view. But they set a different view of technology and the role of government. In the first place, evolutionay economists emphasize on issues of learning and assimilation over, but not instead of, technology transfer; secondly, it relies on a broad view of innovation, which we have suggested amount to distinguish between high-tech and low-tech dimensions of technology. ${ }^{15}$ Thus, even though evolutionary economists do not deny the importance of technology diffusion/adoption, they are more likely to stress the importance of indigenous innovation as an engine of growth. ${ }^{16}$ From this perspective, the most salient feature of innovation is the ability to produce "something new" that has a commercial value (as there are buyers willing to pay for it). ${ }^{17}$

The NIS literature, on the other hand, associates the success of innovation with the ability of countries to thread the whole system of innovation at the country-wide level. ${ }^{18}$ The argument is that the relationships and interactions between innovations generated in different parts of the economic system involve,

\footnotetext{
${ }^{12}$ Basu and Weil 1998, Basu and Fernald 2002.

${ }^{13}$ Hidalgo et al., 2007, Hausmann et al., 2011

${ }^{14}$ Nelson and Phelps 1966, Abramovitz 1986, Hall and Jones 1999, Lin, Monga et al., 2011.

${ }^{15}$ Nelson and Winter 1982, 2002, Nelson 2008, Fagerberg, Srholec, and Verspagen 2010. The contrast is raised between high-tech innovation-aimed at pushing forward the technology frontier-and low-tech innovations, which even if negligible in terms of fostering changes at the world frontier, still may involve new products and processes enhancing growth in any type of businesses and in multiple areas of activity, namely, management, design, logistics, distribution, and marketing.

${ }^{16}$ Fagerberg 2003, Nelson 2008.

${ }^{17}$ Nelson and Winter 1982, 2002, Fagerberg et al., 2010. Noticeably, this view is supported by development in the business literature, see Gatignon et al., 2015.

${ }^{18}$ Freeman 1987, Nelson 1993, Lundvall 1992, 1993, 2007, Fagerberg 2003, Soete et al., 2010, Lee and Malerba 2018.
} 
to a large extent, non-price relationships, and commands active government intervention beyond the fixing of market failures. ${ }^{19}$ In addition, this perspective holds that rather than through cost reductions (low wages) or economies of scale, the most important competitive advantage of countries over the long-run is their innovation capacity. ${ }^{20}$

Let us formalize the differences between the mainstream and the evolutionary and NIS approaches in the context of the relationship between a country's technology and its ability to grow and catch-up. To this end, consider a framework where differences in levels of (per capita) income across countries are proportional to the ratio between (local) innovation, $Z$, and (the adoption of) foreign technology, $\bar{A}$.

$$
Y^{*} / \bar{Y}^{*} \approx Z / \bar{A}
$$

Let $\omega>1$ be the factor by which innovation depends on past innovations: $Z_{t}=\omega Z_{t-1}$. Thus, the current state of innovation that is associated with technology adoption and past innovativeness at the local level is given by ${ }^{21}$

$$
Z_{t}=a \omega Z_{t-1}+b\left(\bar{A}-Z_{t-1}\right)+c Z_{t-1}\left(\bar{A}-Z_{t-1}\right)
$$

where $a, b$, and $c$ are parameters that, respectively, denote the weights of past innovations, the adoption of frontier technology, and the interaction between both of them. Subtracting $Z_{t-1}$ on both sides and dividing throughout by $Z_{t-1}$ we find, after some algebra, an expression that relates the rate of growth of the economy, $\left(g_{t}^{*}\right)$, with the rate of growth of innovation,

$$
g_{t}^{*}=\frac{Z_{t}-Z_{t-1}}{Z_{t-1}}=(a \omega-1)+b\left(F_{t}-1\right)+c Z_{t-1}\left(F_{t}-1\right)
$$

where $F_{t}=\bar{A} / Z_{t-1}$ captures the conventional notion of distance to the frontier. $^{22}$ Notice that the farther a country falls behind (the smaller $Z_{t-1}$ is with respect to $\bar{A}$ ) the larger the value of $F$. In this case, the major source of growth is through adoption. Conversely, when $Z_{t}=\bar{A}$, the adoption effect fades away and the only source of growth is innovation.

This equation encapsulates the three distinct sources of technology progress and economic growth introduced earlier: if backward countries benefit mostly from adoption, the parameter $b$ should be large (relative to the other two parameters) and more so the further a country lags behind; if the economic performance depends mostly on the interaction between (local) innovation and foreign

\footnotetext{
${ }^{19} \mathrm{~A}$ fundamental tenet of the NIS approach is that innovation is, overall, a process of interactive learning across the distinct parts of the system. Interactive learning defines a process where the distinct parts of the innovation system communicate and even cooperate in the creation and utilization of new economically useful knowledge. This entails interaction between firms, firms and university labs, and firms and government labs, for example, and between the parts of the local system with foreign system (Nelson et al., 2018).

${ }^{20}$ Lundvall 2007.

${ }^{21}$ See Acemoglu et al., 2006 for a similar approach. The inclusion of the last term in our approach emphasizes the view that local innovations occur through the interaction between local "creativeness" and foreign technology.

${ }^{22}$ Acemoglu et al., 2006, Aghion and Howitt 2006.
} 
technology, the parameter $c$ should be larger instead; finally, the parameter $a$ is of major relevance only for countries that have already reached the frontier. The econometric assessment of these sources of technology and growth is our first aim in this paper.

Let us now assume that the contextual conditions needed to promote business innovation are summarized in a function $\theta(h)$ as follows

$$
g_{t}^{*}=\theta(h)\left[(a \omega-1)+b\left(F_{t}-1\right)+c Z_{t-1}\left(F_{t}-1\right)\right]
$$

Our second aim is to empirically evaluate whether, and to what extent, public actions aimed to coordinate these contextual conditions in $\theta(h)$ are important to promote innovation and, hence, economic growth and catching-up.

Mainstream economics characterizes the set of conditions in $\theta(h)$ as pure market conditions and market conforming policies. Under this framework it is generally meant that the intervention of government in the economy should be limited to compensate for economic inefficiencies accrued to market distortions, or doing things for which markets are not good enough. For example, to create macroeconomic stability, distributional equity and sustainability, and to correct for resource misallocation due to misleading price signals, externalities, and information asymmetries. The construction of absorption capabilities is considered to be important, but to a lesser extent than in the alternative literature we will discuss shortly. Basically, in the mainstream, those capabilities are related to human capital and free market institutions: property rights, international economic integration, financial development. ${ }^{23}$

In contrast, under the NIS approach, contextual conditions relate to a more complex institutional/policy framework. In Chapter 3, we have identified - on the basis of specialized literature - three key roles of the government in this regard, namely sponsorship, leadership, and coordination. ${ }^{24}$ A serious setback for the empirical assessment of these three aspects, however, is that they involve elements that are either poorly or not systematically measured, if at all, and more so in countries off the frontier. For instance, records of public expenditures on $\mathrm{R} \& \mathrm{D}$ conducted in government labs, which relates to our definition of leadership; and records of direct/indirect financing of business $\mathrm{R} \& \mathrm{D}$ with public sources or other government schemes of finance to boost business innovation, which relates to our definition of sponsorship, are generally unavailable or reported un-systematically for most of the developing countries in our database.

Likewise, a strong version of government coordination would need to account with indicators of the active government intervention that figures prominently in the discussion in the specialized literature. ${ }^{25}$ Alternatively, one would need to account for some metrics upon the coordination of economic decisions between

\footnotetext{
${ }^{23}$ Barro 1997, Rodrik 2005, 2006, Lucas 2009, Spence 2011, Acemoglu et al., 2012, Stokey 2012 .

${ }^{24}$ Nelson 1993, Freeman 1995, Lundvall 2007, Soete et al., 2010, Lee and Malerba 2018, among others.

${ }^{25}$ Breznitz 2007, Mazzucato 2013, Mazzucato and Penna 2015, Breznitz, Ornston and Samford 2018 .
} 
government and firms as has been documented in empirical literature (e.g., the deliberation councils between government and the business sector in Japan, Korea, Taiwan and other Asian countries). ${ }^{26}$

Unfortunately, to the best of our knowledge, none of the desirable indicators of coordination that we have mentioned exists. Therefore, to measure the coordination aspect we need to rely on more conventional indicators that are normally counted elsewhere in the literature as "absorptive capacities", namely macroeconomic stability, financial stability, provision of human capital, infrastructure, governance which, in general terms, allow us to capture the ability of government to enforce a regulatory framework favorable to private-sector economic activities. This, however, means that our approach below relies on just a mild version of the government coordination aspects that are emphasized in the NIS approach. A clear implication is that our test of coordination cannot be neatly distinguished from the analysis of the impact of absorptive capacities/ technological capabilities elsewhere in the literature. ${ }^{27}$

Summing up, our goal below is to evaluate the following three hypotheses: i) that there is a structural long-run relationship between foreign technology and productivity; ii) that there is a structural long-run relationship between the interaction of foreign technology with (local) innovation and productivity; and iii) that there is a structural long-run relationship between (government) coordination and productivity. Moreover, we predict that the structural associations of interest are more meaningful for the countries at the frontier (FRCs) and countries that have succeeded to catching-up (CUCs) than for countries that remain stagnant (STCs) and laggard countries (LGCs).

\subsection{The Data}

\section{Cross-Country Classifications}

Our classification relies on the sample of 133 countries introduced earlier in Chapter 2. Thus, there are 24 high-income countries that make up the frontier of technology and income (FRCs), 27 countries deemed successful cases of catchingup (CUCs), 24 countries deemed in stagnation (STCs), and 58 countries deemed as laggard (LGCs). This classifications rely on whether the relative differences in income per-capita of each group with the FRCs has reduced, remained the same, or increased over time. ${ }^{28}$

\footnotetext{
${ }^{26}$ Page 1994, Wade 1996, 2009.

${ }^{27}$ The author gratefully acknowledges this point to insightful comments by J. Fagerberg. Clearly, the construction of a more appropriate dataset to take into account the distinct aspects of coordination, alongside the issues of sponsorship and leadership that are mentioned in the text, is a huge endeavor beyond the ambitions of this thesis. Therefore, we let the construction of a consistent database as an issue for future research.

${ }^{28}$ Recall that the data is obtained from the PWT V.8. It includes 167 countries. 10 countries are excluded as they had a relative income per capita larger than $75 \%$ of the frontier at the outset (these are rich oil-producing and other high-income countries). The frontier is made of the OECD countries that became members before 1990. We use the rgdpna variable, which reports real GDP at constant 2005 national prices (in millions of 2005 US\$). 10-year averages
} 
Income per-capita is calculated as 10-year averages - provided sufficient available information. Thus, for countries with full data availability, there are six decades with information between the 1950s (1950-1959), and the 2000s (20002009); the six decades are 1950s, 1960s, 1970s, 1980s, 1990s, and 2000s. ${ }^{29}$ By relative income we mean the ratio between each country's 10-year average and the corresponding 10-year average of countries at the frontier, which is itself an average (of the 10-year averages) across FRCs countries.

The classification of countries as CUCs, STCs, or LGCs is based on the ratio of the relative income between the last and first decades. For instance, the relative income of Brazil in the 1950s was $21.6 \%$ (of the average at the frontier), and increased to $22.6 \%$ in the 2000s. The ratio between the latter and former numbers yields $22.6 \% / 21.6 \% \cong 1.0$, which means that no meaningful change occurred in the relative position of Brazil vis $-\grave{a}-v i s$ the FRCs countries. By contrast, the same ratio calculated for Taiwan yields 4.2, for Thailand (2.8), Costa Rica (0.78), and Djibouti (0.23). Thus, we set the following ad hoc 0.751.25 threshold: CUCs are determined as countries where the aforementioned ratio is larger than 1.25 ; LGCs are countries where the ratio is smaller than 0.75; and STCs are countries falling in between the cases $0.75 \leq$ STCs $\leq 1.25 .{ }^{30}$

As we pointed out earlier, the number of countries in the cointegration analysis below depends on data availability for other variables in the system (foreign technology, innovation and coordination). After matching the data for each of these variables, our econometrics relies on a sample of 62 countries $(23 \mathrm{FRCs}$, 12 CUCs, 13 STCs and 14 LGCs) spanning over a 30-year period between 19802010 .

\section{Productivity}

We obtain measures of MFP for each country using conventional growth accounting. Consider the standard production function (measured in per-worker terms), $Y=A K^{\alpha}$, where $Y$ and $K$ are output and capital per-worker, $\alpha=1 / 3$ is the share of capital in total income, and $A$ is the conventional productivity term. Using lowercase to denote the loglinear transform and expressing the equation in growth rates yields $\Delta y / y-\alpha \Delta k / k=\Delta a / a .^{31}$

are calculated in all cases (as long as a country has information at least over 8 years). A detailed account of the classification and relative levels of income is provided in Appendix Tables 2A.1-2A.4 (Chapter 2).

${ }^{29}$ Some countries do not have enough observations back to the 1950s. In fact, in the six decades between the 1950s and 2000s, there are only 35 countries with information. Another group of 46 countries have data only for five decades (between 1960s-2000s), and 28 countries only for four decades (between 1970-2000).

${ }^{30}$ Of course, changes in this ad hoc threshold lead to changes in the classification, though it is dubious that doing so within reasonable boundaries will bring substantial alteration in the main conclusions to be reached throughout.

${ }^{31}$ The data is obtained from PWT V.8. (rgdpna and comparisons to rtfpna) 


\section{Foreign technology}

We use as indicator of foreign technology the expenditures on R\&D carried out by FRCs. ${ }^{32}$ The standard practice - after Coe and Helpman 1995 - consists in calculating import weighted foreign $\mathrm{R} \& \mathrm{D}$ capital stocks according to the following rule 33

$$
w_{r d}=\operatorname{wrd}_{i, t-1}(1-\delta)+\sum_{j} \omega_{i, j, t} \operatorname{erd}_{j, t}
$$

In particular, for country " $i$ ", the import weighted foreign R\&D capital stock that is locally available at time "t", $w r d_{i}$, is equal to the stock that was available at time t-1 net of depreciation, plus a weighted sum of the current expenditures on $\mathrm{R} \& \mathrm{D}$ in countries at the frontier " $\operatorname{erd}_{j}$ ". The weights are given by the bilateral share of imports between country " $i$ " and country " $j$ ", $\left(\omega_{i, j}\right)$.

The rationale for this methodology is that there are spillovers in the process of international technology diffusion and trade is an important channel of diffusion. Backward countries benefit from R\&D expenditures at the frontier to the extent that the research outcomes end up embodied in the goods imported from those countries (machines and equipment, intermediate goods). ${ }^{34}$

Clearly, international trade is not the only channel of technology diffusion, researchers (or even producers) in backward countries may benefit from research conducted in advanced countries that gives them the possibility to know from new technology and ideas without incurring further opportunity costs; they may benefit of direct contact with original inventors through seminars and conferences or as the knowledge on those ideas and technologies becomes available in libraries and the internet; finally, foreign direct investment and licensing are other important sources of international technology spillovers frequently studied in the literature.

Noticeably, whereas the latter forms involve the need for incentives, i.e., in order to attract foreign investment, and market transaction (patents, copyrights), the former forms of diffusion, namely through international trade, are relatively "automatic", i.e., they take the form of pure technology spillovers. Certainly, the relative importance of each channel is an empirical question, but as Keller points out in its extensive investigation: "many economist believe, though, that most international technology diffusion occurs not through market transactions but instead through technology (spillovers)" ${ }^{35}$

\footnotetext{
${ }^{32}$ Coe and Hepman 1995, Keller 2004.

${ }^{33}$ Equation (5.2) resembles the capital accumulation equation, $K_{t}=K_{t-1}(1-\delta)+I$, with stock $\mathrm{K}=w r d$ and investments flows $\mathrm{I}=\sum_{j} \omega_{i, j} e r d_{j}$. Here, the initial stock is calculated as $\operatorname{wrd}_{i, 0}=\sum_{j} \omega_{i, j, t} \operatorname{erd} d_{j, t} /(g+\delta)$ where $g$ is the average of early growth rates of the R\&D stocks at the frontier (theoretically, $g$ needs to be calculated from early growth rates up to the initial period, yet in practice data availability prevents that kind of calculation and $g$ is replaced with the average growth rate through the period of study). See the appendix in Coe and Hepman 1995.

${ }^{34}$ Coe and Hepman 1995, Keller 2004.

${ }^{35}$ Keller 2004, pp 758 ff.
} 
Coe and Helpman (1995) show that - for a group of OECD countries - there is a sound relationship between the long-run productivity growth of backward countries and foreign R\&D expenditures. They point out that higher bilateral import shares allow for larger technology transfers from the frontier. In their analysis this relationship holds and is both economically and statistically significant. Keller (2002), on the other hand, suggests that unweighted foreign R\&D capital stocks - hence constructed without using the share of importsyield similar results as those originally obtained by Coe and Helpman (1995). The unweighted version of Equation (5.2) is

$$
r d_{i, t}=r d_{i, t-1}(1-\delta)+\sum_{j} e r d_{j, t}
$$

Based on the above findings by Coe and Helpman (1995) and Keller (2002), both the weighted and unweighted versions of foreign $R \& D$ capital stocks seem relevant channels of diffusion of technology from the frontier. We, therefore, use both these approaches in our analysis. In particular, we introduce the unweighted version as a weakly exogenous variable in the cointegration analysis below, and we use the weighted version to construct the following interaction term between foreign technology and local innovations $(\mathrm{z})$ for each country.

$$
z r d_{i, t}=w_{r d} \times z_{i, t}
$$

This treatment of variables is in fact appropriate, namely, the weighted version of foreign technology, used to construct the interaction term, is based on the assumption that countries in the receiving end profit on the technology that is embodied in imported goods used as inputs/factors in the production of local innovation. By construction, the unweighted version of foreign technology is a different variable. It builds on the assumption that backward countries benefit from research conducted in advanced countries by other than the trade channel, e.g., knowing from new technology and ideas without incurring further opportunity costs (direct contact, seminars, conferences, the internet). Noticeably, in our econometric analysis the use of the weighted version to construct the interaction term through Equation (5.4) and then the unweighted version as a further exogenous variable is an appropriate treatment to address eventual collinearity problems.

To construct the foreign $R \& D$ capital stocks, we first calculate annual R\&D expenditures for each country in the FRCs classification. To this end, we use the share of expenditures on R\&D (as \% of GDP) and total GDP values. The annual R\&D expenditures calculated in this manner are then used to calculate the stocks indicated by Equations (5.2) and (5.3). ${ }^{36}$ The bilateral import shares are obtained from the IMF historical statistics on trade - this information is available for the period 1981-2010. ${ }^{37,38}$

\footnotetext{
${ }^{36}$ See https://data.oecd.org/rd/gross-domestic-spending-on-r-d.htm. FRCs' GDP figures are obtained from PWT V.8, as noted earlier in the text.

${ }^{37}$ IMF, Database, Direction of Trade Statistics.

${ }^{38}$ In the construction of our indicators we are constrained by data availability/quality for
} 


\section{Local innovation}

A country's potential for local innovation $(z)$ is captured by the share of workers employed in cognitive non-routine activities (h). We generate an index of innovation for each country $i$ and year $t$ in the following manner

$$
z_{i, t}=I_{b}\left(\frac{h_{i, t}}{L_{i, t}}\right)
$$

where $\mathrm{L}$ denotes the total workforce, and $I_{b}$ denotes that innovation is itself an index with base year $b$. This index of innovation is inspired by two recent developments in the literature. First, research findings on the determinants of job segmentation that point to a process of transition/polarization in the job market toward innovation related activities. ${ }^{39}$ In particular, machine automation and digital technology lead to the shrinkage of routine occupations - those that are performed by following a pre-established, well-defined set of instructions - and to the increase of non-routine occupations - those involving decision-making, problem-solving, and human interaction skills. ${ }^{40}$

The second development that justifies our argument points to findings that lots of the innovations that spur economic growth - even in developed countriesare generated by specialized workers in operative processes rather than through R\&D activities. ${ }^{41}$ That is, while innovation is conventionally assumed to be a product of "high-tech" sectors (nanotechnology, biotechnology, ICT, machines and equipment) where specialized R\&D workers are endeavored to develop new breakthroughs, in practice lots of innovations occur in "low-tech" sectors (food production, metal products, paper and printing) and are often initiated by the staff responsible for ongoing functions: managers, engineers, technicians, master craftsmen, and other qualified workers; or by specialized departments (management and quality control). Of course, low-tech innovations refer to more simple developments (e.g., organizational and marketing innovation, logistics innovations, new products design and development, new business models) which however are able to boost productivity.

Our contention that the share of workers in cognitive non-routine activities is suitable to capture the notion of innovation drawn from the NIS literature seems well justified. Notably, measuring innovation in this manner could improve earlier attempts to understand whether and how local innovativeness contributes to a country's productivity performance. For instance, whereas the focus of

some years. To get a database that is consistent we rely on data with no more than five blanks between years with information. Missing data between years are interpolated arithmetically. See Tables 5A.2, 5A.3 and 5B.2 for details on data availability constraints.

${ }^{39}$ Autor Levy and Murnane 2003 and Autor and Dorn 2013.

${ }^{40}$ In fact, the literature on job segmentation has established four classifications to distinguish between working occupations characterized by mental and physical activities: i) cognitive nonroutine, ii) cognitive routine iii) manual non-routine, and iv) manual routine. The first of these classifications is deemed to capture the extent to which occupations are characterized by mental rather than manual/physical skills, and the extent to which workers are employed on tasks that require problem-solving capacities rather than following a well-defined set of instructions/procedures (Autor Levy and Murnane 2003, Levy and Murnane 2007).

${ }^{41}$ Herstatt and von Hippel 1992, Hirsch-Kreinsen 2008, Som and Kirner 2016. 
analysis in many empirical studies is on educational attainment, which measures, at best, the potential capabilities of a country's workforce, ${ }^{42}$ our index of innovation focuses on what those capabilities are actually used for in practice. Moreover, our index allows for a realistic split of worker occupations into adoption and innovation activities as long as the focus on the types of tasks workers are actually devoted to, allows an educated guess of how those workers do interact with technology. ${ }^{43}$

While we are aware of alternative indicators that have been built to measure the economic contributions of technology, ${ }^{44}$ we do not see that they match our purposes: firstly, because the focus of those indicators is on general aspects of technology, technological capabilities, or absorptive capacities, which makes it hard to decouple the contributions of adoption from those of innovation; ${ }^{45}$ secondly, because those alternative indicators are generally available for a smaller number of countries or a shorter period of time than is the case with our index of innovation, e.g., the Global Innovation Index (GII) - now 12 years long but only 4 years (from 2007 to 2010) compatible with other indicators in our sample - makes it unsuitable for the scope of our analysis in this thesis. ${ }^{46}$

To the best of our knowledge, this is the first contribution to use occupational working categories to trace a relationship with the ability of countries to undergo adoption and innovation activities, and to do so for a relatively large sample, including developing countries. Previous failure to do this may be due to the fact that the corresponding theoretical background is relatively recent and the required statistical information too sparse.

To operationalize the index of innovation, we draw the cognitive non-routine share of workers for countries for the period 1980-2010 using information from the International Labor Organization. This source provides information on employment based on the ISCO and correspondence tables. ${ }^{47}$ We include within the cognitive non-routine category three major groups: i) legislators, senior

\footnotetext{
${ }^{42}$ Coe, Helpman, and Hoffmaister 1997, Vandenbussche, Aghion, and Meghir 2006, Madsen et al., 2010, Messinis and Ahmed 2013, and Islam et al., 2014.

${ }^{43}$ Levy and Murnane 2007.

${ }^{44}$ for instance Archibugi, Denni and Filippetti 2009.

${ }^{45}$ The innovation surveys conducted in many countries capture well the kind of innovation activities we are concerned with. Unfortunately, those surveys are not yet well established in countries off the frontier in the classification standards for the countries in this thesis. See, for instance, Mairesse and Mohnen 2010, ECLAC 2011.

${ }^{46}$ Archibuggi et al., 2009. Some of the most important indicators on technology and innovation that are available are: the Summary Innovation Index (34 countries, since 2000); the Global Summary Innovation Index (25 countries, since 2006); the Technology Index produced by the World Economic Forum (TI-WEF, 75 countries since 2002 and 125 since 2007); the Knowledge Index (World Bank, 132 countries, since 2006); the Technological Activity Index (UNCTAD, available since 1995) and, lastly, the Global Innovation Index (GII) released by Cornell University, INSEAD and WIPO since 2007. The GII index cover 129 and 80 indicators on innovation inputs and outputs, which makes it highly complete and a source of reference for future research on this front (The author gratefully acknowledges Carolina Castaldi for bringing the GII index into this discussion).

${ }^{47}$ The ISCO classification has gone through four rounds of change, namely, ISCO-58, ISCO68, ISCO-88, and ISCO-08. The correspondence tables and statistics are provided on the International Labor Organization website: http://laborsta.ilo.org
} 
officials, and managers; ii) professionals; and iii) technicians and associate professionals. ${ }^{48}$

\section{Government coordination}

As we have mentioned above, measuring coordination the way it is described in our theoretical account of the innovation systems literature is a difficult task. ${ }^{49}$ The concept involves elusive elements of government goodwill that are hard to be captured in any single indicator. Therefore, following a similar approach as the mostly ad hoc practice to develop composite synthetic indicators of technology, ${ }^{50}$ we develop an indicator of coordination intended to capture the most salient features of this concept. In doing so, we indicate the economic intuition to proxy the different aspects of coordination that we have derived in the theoretical approach. Also, we use data from commonly used datasets. ${ }^{51}$

Our mild index of government coordination is a simple average of four components: labor productivity, financial development, human capital and governance. These components are deemed to reflect the ability of government to offset market failures and increase productivity gains across different manufacturing sectors, to ease the allocation of finance to productive activities, to ensure the connection between education and the production sector, and to enforce a business-friendly policy environment.

In other words, our coordination index relates industry-specific productivity achievements with the availability of financial and human capital resources, and overall government policy practices. Noticeably, the possibility that some country is high on one aspect and low on another cannot be ruled out. This is a common weakness in the construction of synthetic indicators and implies that at least some of the various factors in our index of coordination may be substitutes rather than complements. ${ }^{52}$

Each components in the overall index of coordination is made up of other sub-indicators. Let us start with labor productivity. The NIS framework emphasizes on networking and collaboration practices that bring together innovations

\footnotetext{
${ }^{48}$ The details with regard construction of this indicator are provided in Appendix $5 \mathrm{~A}$ at the end of this chapter.

${ }^{49}$ See Chapter 3.

${ }^{50}$ Archibugi et al., 2009.

${ }^{51}$ There are other technical alternatives to generate composite indicators like the one of interest here, namely, Exploratory Factor Analysis(EFA), Principal Components Analysis (PCA) and k-mean clustering (Forgy 1965, Wansbeek and Meijer 2000). The general approach is to use the correlation and variance structure of the data to derive the information that is common to the indicator(s) of interest. Some approaches (PCA, k-mean clustering) are a-theoretical, while others (EFA) are based on a modeling approach prior to the extraction of information from the source variables (but the researcher still needs to guarantee the model is correctly specified). As it stands, these different approaches do not excuse the researcher from the definition and operationalization of the concepts and the construction of the different variables to capture the effects of interest. While interesting, the exploration of those alternatives are involving and beyond our scope here. Therefore, we leave this possibility as a subject for future research.

${ }^{52}$ This, again, is a point that we owe to insightful comments to the author by J. Fagerberg.
} 
produced in different parts of the system, which presumably allows both lowtech and high-tech sectors of production to thrive together. To capture the gains in productivity across economic sectors we generate an overall index of labor productivity that is a geometric average of the constant-price value added perworker in each country $i$, sector of activity $j$, and year $t: P_{i j t}=V A_{i j t} / L_{i j t} \cdot{ }^{53}$

$$
O L P_{i, t}=\left(\prod_{j} I_{b}\left(P_{i, j, t}\right)\right)^{1 / N} ; j=1,2, \ldots N
$$

where $I_{b}$ is again used to denote an index: in this case that means that labor productivity is itself an index with base year $b$.

We follow a similar procedure to generate an indicator of financial development, which is made up of three distinct elements: domestic credit granted by the bank sector (public and private) to private sector enterprises (\% of GDP), stock market total value traded (\% of GDP) and number of publicly listed companies on a country's stock market. ${ }^{54}$ Formally, the index of financial development for each country $i$ is given by

$$
F D_{i, t}=\left(I_{b}\left(B C_{i, t}\right) \times I_{b}\left(S M V T_{i, t}\right) \times I_{b}\left(C L S M_{i, t}\right)\right)^{1 / 3}
$$

where BC denotes bank credit, SMVT the stock market value traded, and CLSM the number of companies listed in the stock market.

In turn, we construct an index of human capital as a geometric average of two elements: the average years of total schooling for the population over the age of $15(\mathrm{AS} 15+)$, and the government total expenditures on education as a $\%$ of GDP (GEE). ${ }^{55}$

$$
H C_{i, t}=\left(I_{b}\left(A S 15+_{i, t}\right) \times I_{b}\left(G E E_{i, t}\right)\right)^{1 / 2}
$$

Finally, we measure government policy as the arithmetic average of three components: government effectiveness (Geff), regulatory quality (RQ) and rule of law $(\mathrm{RoL}) .^{56}$

$$
G P_{i, t}=\left(G e f f_{i, t}+R Q_{i, t}+R o L_{i, t}\right) / 3
$$

Government effectiveness captures perceptions of the quality of public services, and policy formulation and implementation, and the credibility about the government's commitment to such policies. Regulatory quality captures perceptions

\footnotetext{
${ }^{53}$ The data about labor productivity is drawn from the United Nations Industrial Development Organization (UNIDO-INDSTAT4 ISIC-Rev3). To construct our index, we use measures of labor productivity for all manufacturing sectors according to the ISIC-Rev3 (excluding recycling activities). Table 5B.1 in the appendix section at the end of this chapter presents a glimpse of how so-called low- and medium-tech sectors/activities (LMT), and high-tech sectors/activities (HT) are distributed across industries.

${ }^{54}$ See Cihak, Demirguc-Kunt, Feyen and Levine 2012. The data for these indicators has been obtained from the World Bank Global Financial Development Database.

${ }^{55}$ See Barro and Lee 2013. The data for these calculations has been obtained from the World Development Indicators.

${ }^{56}$ The choice of an arithmetic, instead of a geometric mean, in this case is because all the components in the index range between negative and positive numbers.
} 
of the ability of the government to formulate and implement policies/regulations consistent with private sector development. Lastly, rule of law captures the extent to which agents have confidence in and abide by the law, the quality of contract enforcement, property rights, the police, and the courts, as well as the likelihood of crime and violence. Each indicator is is reported in units of a standard normal distribution ranging between -2.5 (poor performance) to 2.5 (high performance). ${ }^{57}$

Given these components the government coordination is given by the arithmetic mean of the four sub-indicators:

$$
G C_{i, t}=\left(O L P_{i, t}+F D_{i, t}+H C_{i, t}+G P_{i, t}\right) / 4
$$

Figure 5.1 portrays the relationship between countries' productivity and each of the stocks of foreign technology (Figure 5.1a), local innovation (Figure 5.1b), and the interaction between foreign technology and local innovation (Figure 5.1c). Graphical inspection seems to support our claim that the association between countries' productivity (measured in the vertical axis) and each of the other variables is stronger for countries that have successfully managed to catchup. That is, in all cases the slope of the CUCs classification is steeper than for countries deemed in stagnation (STCs), and indeed the slope of countries considered laggards (LGCs) is flatter in every case. Note that, in all three cases (Figures 5.1a-5.1c), the lines for FRCs are closer to those of STCs that the CUCs. This seems consistent with the characterization of stagnant countries: the productivity levels of STCs are just enough to maintain a tight match with the FRCs countries, whereas CUCs (LGCs) exhibit higher (lower) levels of productivity.

Figure 5.2 portrays the relationship between countries' innovation (measured in the vertical axis), and government coordination. Again, we see that the association between the two variables is stronger (the slope is steeper) for CUCs than for the other country classifications. The lower levels of coordination in LGCs cause these countries to group toward the left of the figure. The lower levels of innovation in these same group is apparent from the flatter slope of the regression line (relative to other country groups).

\subsection{Analytical Framework}

There are five variables in our model: $x_{t}=\left(a_{t}, z r d_{t}, z_{t}, g c_{t}, r d_{t}\right)^{\prime}$, namely the productivity term $\left(a_{t}\right)$, the interaction between foreign and local technology $\left(z r d_{t}\right)$, local innovation $\left(z_{t}\right)$, government coordination $\left(g c_{t}\right)$ and foreign R\&D

\footnotetext{
${ }^{57}$ The data for this indicator is based on the Worldwide Governance Indicators released by the World Bank (Kaufmann, Kraay and Mastruzzi 2010). The three indicators used in the arithmetic average are available from 1996 onward (with blanks in 1997, 1999 and 2001), we filled in the blanks with the same values of the previous year and assume that back to 1980 the indicator values are the same as those of 1996. Even though this procedure implies little dynamics over time for the indicator of government policy, it adequately reflects the hindrance put up by governance constraints on the development outcomes of the countries in our sample.
} 
(a)

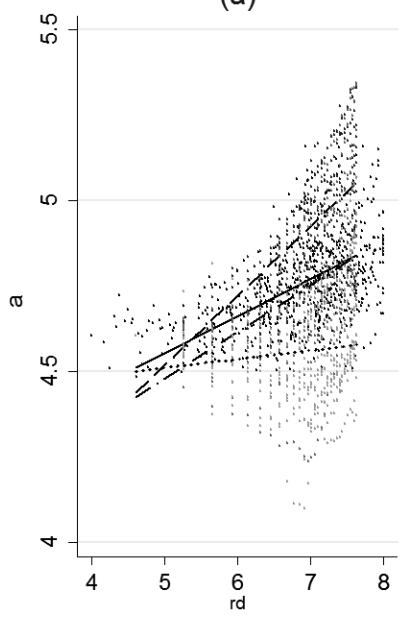

(b)

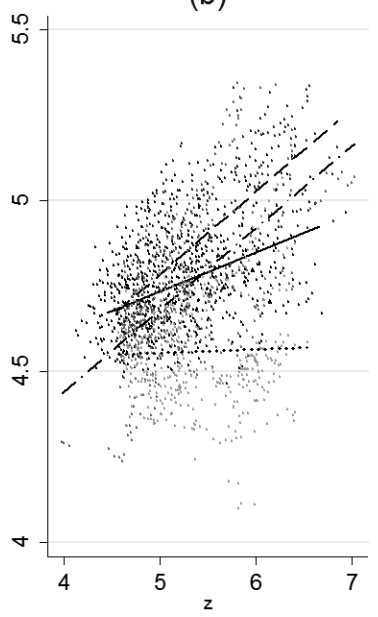

(c)



Figure 5.1: Productivity vis - ̀̀-vis foreign REBD, innovation and their interaction in FRCs, CUCs, STCs and LGCs. Relationship between countries' productivity (a)in the vertical axis - and stocks of foreign $R \xi \mathcal{G}(\mathrm{rd})$, innovation $(z)$, and interaction between foreign technology and local innovation (zrd) - in the horizontal axis. All variables are index numbers $(1981=100)$ expressed in logarithms. The line segments show the predictions from linear regressions of " $a$ " on each of the other variables across countries. In all cases the solid line portrays the prediction for FRCs, the dashed line the CUCs, the dotted-dashed line the STCs, and the dotted line the LGCs. Each country is observed yearly between 1981-2010.

$\left(r d_{t}\right)$. The cointegration analysis of this system is based on the Johansen approach as we assume the presence of multiple cointegrating vectors which leads to the need to impose identifying restrictions in order to estimate the structural relations among the variables. ${ }^{58}$ An additional advantage of using this approach is that it allows to decompose the structural shocks to the variables in the system into transitory (short-run) and permanent (long-run) effects. Even though we are mostly concerned with the long-run impact of permanent shocks, a meaningful cointegration relations requires that both short-run and long-run parameters are well-signed and statistically significant.

\footnotetext{
${ }^{58}$ Johansen 1988, 1995. The Johansen methodology allows for testing the presence of several, say $\mathrm{K}-1$, cointegration vectors in a set of $\mathrm{K} \mathrm{I}(1)$ variables. Further, this approach allows for a complete specification of the long-run and short-run dynamics, and for testing relevant restrictions on the cointegrating space aimed to the identification of structural relationships between the variables in the system.
} 


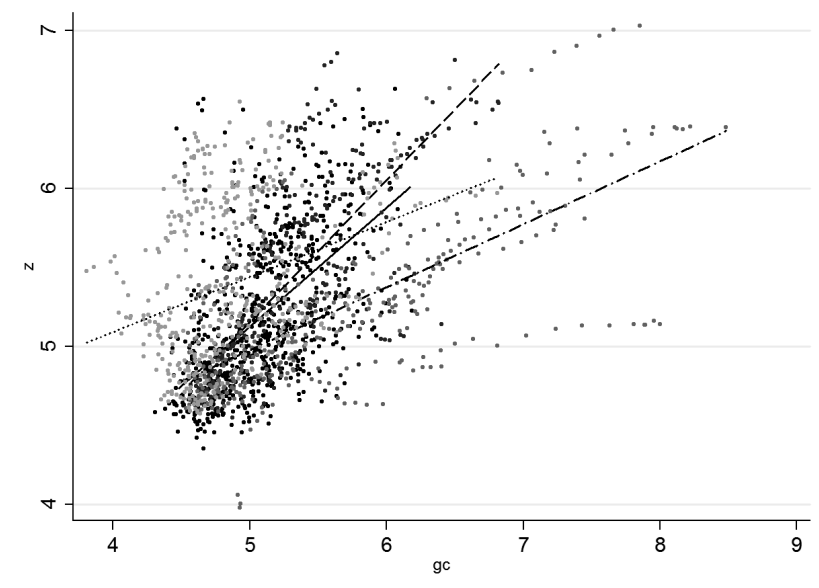

Figure 5.2: Innovation vis - à - vis government coordination in FRCS, CUCs, STCs and LGCs. Relationship between countries' innovation ( $z$ in the vertical axis), and government coordination ( $g c$ in the horizontal axis). All variables are index numbers (1981=100) expressed in logarithms. The line segments show the predictions from linear regressions of " $z$ " on "gc" across countries. In all cases, the solid line portrays FRCs, the dashed line the CUCs, the dotted-dashed line the STCs, and the dotted line the LGCs. Each country is observed yearly between 1981-2010.

We test the unit-root properties for each individual time-series country per country, and examine the cointegration properties of the five variables system for each of the 62 countries in the sample. To report the empirical results we present an extended discussion for the individual countries in the CUCs classification and the average results for each of the FRCs, CUCS, STCs, and LGCs classifications. ${ }^{59}$

The vector error correction model (VEC) is defined by the following equation

$$
\Delta x_{t}=\gamma+\tau t+\alpha\left[\beta x_{t-1}+\mu+\rho t\right]+\sum_{j=1}^{p-1} \Gamma_{j} \Delta x_{t-j}+\epsilon_{t}
$$

where $x_{t}$ is a $\mathrm{K} \times 1$ vector that includes the five variables in our system $(\mathrm{K}$

\footnotetext{
${ }^{59}$ As we deal with a large number of countries, an alternative analytical approach is panel data cointegration (for a review, see Baltagi 2014). Clearly the cointegration test on a single time series is different from the test on panel data. But panel data cointegration tests that are based on the average of the test computed for each individual are indeed comparable at the country level. The problem is that the panel data approach does not allow to test for more than one cointegration vector among the variables in the system, does not allow to impose identifying restrictions and produces estimates that are very different from the estimates based on the Johansen technique, e.g., the inference of cointegration found with the Johansen approach is not always confirmed - as expected-by the cointegration test on the time series of the same country in the panel data approach.
} 
denotes the number of variables), $\gamma_{t}$ and $\tau$ are each $\mathrm{K} \times 1$ vectors of parameters (short-run constants and time trends); $t$ is a linear time trend; $\alpha$ and $\beta$ are $\mathrm{K} \times \mathrm{r}$ vectors of parameters ( $\beta$ is called the cointegrating vector and $\alpha$ the short-run adjustment coefficient sometimes also called a loading-vector), $\mu$ and $\rho$ are each $\mathrm{K} \times \mathrm{r}$ vectors of parameters (long-run constants and time trends); and $\Gamma_{j} \ldots \Gamma_{p-1}$ are $\mathrm{K} \times \mathrm{K}$ vectors of parameters. In our analysis below, we consider in all cases a restricted trend in the cointegration relation, and a constant in the short and long-run relations. Thus, we assume $\tau=0$.

To determine the number of cointegration relationships we report the results of the trace test. ${ }^{60}$ Among $\mathrm{K}$ variables which are unit roots there are at most $\mathrm{K}-1$ cointegrating vectors. The trace test is used to determine how many $\mathrm{r} \leq$ $(\mathrm{K}-1)$ distinct eigenvalues $(\lambda)$ exist that are significant, and hence how many cointegrating relationships are in the system. The test proceeds by testing the following set of null hypotheses ${ }^{61}$

$$
H_{0}: r=0, H_{0}: r=1, \ldots, H_{0}: r=K-1
$$

The trace statistics is given by

$$
\lambda_{\text {trace }}=-T \sum_{i=r+1}^{K} \ln \left(1-\hat{\lambda}_{i}\right)
$$

where $\mathrm{T}$ is the number of observations and $\hat{\lambda}_{i}$ denotes the $i$-th estimated eigenvalue. For any given value of $r$, large values of the trace statistic are evidence against the null hypothesis that there are $\mathrm{r}$ or fewer cointegrating relations in the system.

In setting up the cointegration rank we checked also the maximum-eigenvalue statistics (MES) and information criteria: namely Schwarz Bayesian information criterion (SBIC) and the Hannan and Quinn information criterion (HQIC). ${ }^{62}$ We also checked that the rank condition is consistent with stable processes. This property implies that if the rank condition is adequately chosen it should lead to no more that K-r unit moduli if the system is to be stable. For reasons of space, below we report only the results of the trace statistics.

\subsection{Results}

As it was anticipated in the previous section, we run our econometrics countryper-country for each of the FRCs, CUCs, STCs, and LGCs classifications. Yet,

\footnotetext{
${ }^{60}$ Johansen 1994, 1995.

${ }^{61}$ For example, if $\mathrm{K}=2$ and $H_{0}: \quad \mathrm{r}=0$ cannot be rejected a model in first differences is considered. Otherwise, $H_{0}: \mathrm{r}=1$ is tested and a cointegrating rank of 1 is considered if the null cannot be rejected. If $H_{0}: \mathrm{r}=1$ is rejected, $H_{0}: \mathrm{r}=\mathrm{K}$ and a model in levels (a stationary VAR) is considered (Lutkepohl 2005, pp. 328-330).

${ }^{62}$ Under the null hypothesis the MES assumes a given $r$ against the alternative that there are $r+1$ cointegrating equations. In turn, choosing the number of cointegration equations that minimizes the SBIC and HQIC provides a consistent estimation in this regard.
} 
to conserve space, below we report and discuss in detail the results for the CUCs and the average of the main results for this and every other classification. The analysis of the dynamic multipliers is also presented for each classification of countries.

\section{$C U C s$}

To carry out the unit root test we use the Augmented Dickey Fuller test (ADF) modified by Elliott, Rothenberg and Stock $1996{ }^{63}$ We also use the Kwiatkowski-Phillips-Schmidt-Shin test (KPSS), which in contrast to the ADF test is used to test the null hypothesis of stationarity.

Table 5.1 shows that under the ADF test in levels the null hypothesis is not rejected. However, for the first differenced variables the test is not rejected in some cases either, which reduces the statistical support to conclude that some variables are I(1) processes, namely productivity (a) in Cyprus, Egypt, Hong Kong and Korea; innovation $(z)$ in China, Egypt, Hong Kong, Indonesia, Israel, Korea, Singapore and Thailand; and government coordination $(g c)$ in China, Hong Kong, Korea and Singapore. Under the KPSS test, the null hypothesis that the variables are stationary in levels is rejected in all cases with higher levels of confidence than for the first differenced series. Therefore, in all these cases we render the series $\mathrm{I}(1) .{ }^{64}$

Testing for the cointegrating rank and the parameters of the VEC models requires some care in choosing the appropriate lag structure. Our analysis below seems too restrictive in this regard as with $5 \mathrm{I}(1)$ series and 30-yearly observations per country, the system allows just for a limited analysis of the lagged effects before running out of degrees of freedom. ${ }^{65}$ This data limitation is not easy to address which prevent us from using a larger sample. Therefore we conduct our analysis below allowing for at most 3 lags and using conventional information criteria and stability conditions to determine the proper lag order

\footnotetext{
${ }^{63}$ The modified ADF test is based on a transformation of the original time series using generalized least squares (GLS) methods which improve the asymptotic power of the standard test in the presence of nuisance parameters affecting the deterministic and unobserved components, and the distribution properties of the data (Elliott et al., 1996).

${ }^{64}$ We find out that many variables generally show increasing trends, which are dealt with by including a trend at the levels of the series. But there might be still cases of structural breaks: sudden shifts and cases where the series tend to oscillate or stagnate over time. Perron 1989 and Zivot and Andrews 1992 provide insights in this regard. Note, however, that the large number of countries we are dealing with prevents us from a close inspection on specific cases.

${ }^{65}$ For instance, with a lag length of 2 there are 28 usable observations in the system. With $r=3$ and $K=5$, there are $n_{s r}=9$ parameters to be estimated per equation in the differenced part, namely 3 adjustment coefficients, 5 lags (1 lag less than in the corresponding VAR) and a constant. In turn, in the long-run cointegration vectors there are $n_{l r}=3$ parameters to be estimated per equation, namely 2 parameter coefficients plus a trend (the constant term is not directly estimated). Taking the short and long run together, the number of parameters per equation is calculated as
}

$$
n_{\text {parms }}=\frac{\left(n_{s r}+n_{l r}\right) K-r^{2}}{K} \approx 10
$$

which clearly is high for 28 observations (it leaves $28-10=18$ degrees of freedom). 


\begin{tabular}{|c|c|c|c|c|c|c|c|c|c|c|}
\hline \multirow{3}{*}{ Group } & \multirow{3}{*}{$\begin{array}{l}\text { Country } \\
\text { All/1 }\end{array}$} & \multirow{3}{*}{$\begin{array}{l}\text { Variable } \\
\text { rd }\end{array}$} & \multicolumn{4}{|c|}{ ADF test } & \multicolumn{4}{|c|}{ KPSS test } \\
\hline & & & \multicolumn{2}{|l|}{ Levels } & \multicolumn{2}{|c|}{ Differences } & \multicolumn{2}{|l|}{ Levels } & \multicolumn{2}{|c|}{ Differences } \\
\hline & & & 0.595 & (6) & 0.391 & $(5)$ & $0.149^{* *}$ & $(8)$ & $0.405^{*}$ & $(8)$ \\
\hline \multirow[t]{44}{*}{ CUCs } & \multirow[t]{4}{*}{ China } & $\mathrm{a}$ & -2.29 & (1) & $-3.72 * * *$ & (1) & $0.15^{* *}$ & $(8)$ & 0.17 & $(8)$ \\
\hline & & $\mathrm{z}$ & -1.85 & (1) & -1.38 & (1) & $0.12^{*}$ & (8) & 0.26 & (8) \\
\hline & & zrd & -2.47 & (1) & -0.38 & (1) & $0.14^{*}$ & (8) & 0.33 & $(8)$ \\
\hline & & gc & -0.82 & (1) & -0.01 & (2) & $0.39 * * *$ & (1) & $0.44^{*}$ & $(8)$ \\
\hline & \multirow[t]{4}{*}{ Cyprus } & ac & $\begin{array}{l}-0.02 \\
-0.48\end{array}$ & (1) & $\begin{array}{l}-0.01 \\
-0.23\end{array}$ & (4) & $0.15 * *$ & (8) & $0.42^{*}$ & (8) \\
\hline & & $\mathrm{z}$ & -2.27 & (1) & $-3.75^{* * *}$ & (1) & 0.12 & (1) & 0.15 & (8) \\
\hline & & zrd & -1.26 & (1) & 1.48 & (1) & $0.16^{* *}$ & (8) & $0.42^{*}$ & (8) \\
\hline & & $\mathrm{gc}$ & -2.02 & (1) & $-2.43^{*}$ & (1) & 0.10 & (8) & 0.12 & (8) \\
\hline & \multirow[t]{4}{*}{ Egypt } & $\mathrm{a}$ & -0.90 & (1) & -0.15 & (7) & $0.15^{* *}$ & (7) & $0.42^{*}$ & (7) \\
\hline & & $\mathrm{z}$ & -1.56 & (1) & -1.21 & (3) & $0.19^{* *}$ & (1) & 0.19 & (1) \\
\hline & & zrd & -1.20 & (1) & 1.19 & (1) & $0.16^{* *}$ & (8) & $0.43^{*}$ & (8) \\
\hline & & gc & -2.88 & (1) & $-2.56^{* *}$ & (2) & $0.13^{*}$ & (8) & 0.14 & (8) \\
\hline & \multirow[t]{4}{*}{ Hong Kong } & $\mathrm{a}$ & -1.58 & (1) & -1.86 & (2) & $0.20^{* *}$ & (1) & 0.13 & (1) \\
\hline & & $\mathrm{z}$ & -1.49 & (1) & -1.99 & (1) & $0.20^{* *}$ & (1) & 0.25 & (1) \\
\hline & & $\mathrm{zrd}$ & 0.18 & (8) & 1.45 & (1) & $0.15^{* *}$ & $(8)$ & $0.41^{*}$ & (8) \\
\hline & & $\mathrm{gc}$ & -0.77 & (1) & -1.58 & (1) & $0.38^{* * * *}$ & (1) & $0.67^{* *}$ & (1) \\
\hline & \multirow[t]{4}{*}{ Indonesia } & $\mathrm{a}$ & -2.18 & (1) & $-2.14^{*}$ & (1) & $0.12 *$ & (1) & 0.12 & $(8)$ \\
\hline & & $\mathrm{z}$ & -2.31 & (1) & -1.02 & (1) & $0.16^{* *}$ & (1) & $0.39^{*}$ & (1) \\
\hline & & zrd & -0.36 & (8) & 1.39 & (1) & $0.15^{* *}$ & (8) & $0.42^{*}$ & (8) \\
\hline & & $\mathrm{gc}$ & -1.84 & (1) & $-2.71 * * *$ & (1) & $0.14^{*}$ & (1) & 0.13 & (8) \\
\hline & \multirow{4}{*}{ Malaysia } & $\mathrm{a}$ & -2.37 & (1) & $-2.77 * * *$ & (1) & 0.08 & (1) & 0.08 & (1) \\
\hline & & $\mathrm{z}$ & -2.12 & (1) & $-3.34^{* * *}$ & (1) & $0.16^{* *}$ & (1) & 0.14 & (8) \\
\hline & & zrd & -2.39 & (1) & 1.81 & (1) & $0.33^{* * *}$ & (1) & $0.43^{*}$ & (8) \\
\hline & & $\mathrm{gc}$ & -1.36 & (1) & $-2.62^{* *}$ & (1) & $0.32^{* * * *}$ & (1) & 0.13 & (8) \\
\hline & \multirow{4}{*}{ Malta } & $\mathrm{a}$ & -0.52 & (1) & $-2.19^{*}$ & (3) & $0.32 * * *$ & (1) & 0.24 & (3) \\
\hline & & $\mathrm{z}$ & -1.57 & (1) & $-2.83 * * *$ & (1) & $0.17 * *$ & (1) & 0.27 & (8) \\
\hline & & zrd & -1.35 & (1) & 0.52 & (1) & $0.15^{* *}$ & (8) & $0.40^{*}$ & (8) \\
\hline & & $\mathrm{gc}$ & -1.15 & (3) & $-3.12 * * *$ & (1) & $0.14^{*}$ & (1) & 0.10 & (3) \\
\hline & \multirow[t]{4}{*}{ Israel } & $\mathrm{a}$ & -0.98 & (4) & $-4.03 * * *$ & (1) & $0.14^{* *}$ & (8) & 0.25 & (8) \\
\hline & & $\mathrm{z}$ & -1.82 & (1) & -2.15 & (1) & $0.14^{*}$ & (1) & 0.10 & (1) \\
\hline & & zrd & -0.83 & (2) & 0.56 & (1) & $0.16^{* *}$ & (8) & $0.45^{*}$ & (8) \\
\hline & & $\mathrm{gc}$ & -1.91 & (1) & $-2.52 *$ & (1) & $0.18^{* *}$ & (0) & 0.13 & (1) \\
\hline & \multirow[t]{4}{*}{ Korea } & $\mathrm{a}$ & -1.05 & (2) & -0.06 & (6) & $0.15^{* *}$ & (8) & $0.36^{*}$ & $(8)$ \\
\hline & & $\mathrm{a}$ & -1.00 & (1) & $\begin{array}{l}-0.00 \\
-2.01\end{array}$ & (2) & $0.13^{*}$ & (8) & 0.26 & (8) \\
\hline & & zrd & -0.66 & (2) & 0.15 & (2) & $0.15^{* *}$ & (8) & $0.46^{*}$ & (8) \\
\hline & & $\mathrm{gc}$ & -1.50 & (2) & -1.94 & (1) & $0.22 * * *$ & (1) & 0.26 & (1) \\
\hline & \multirow[t]{4}{*}{ Singapore } & $\mathrm{a}$ & -2.32 & (1) & $-3.39 * * *$ & (1) & $0.14^{*}$ & (8) & 0.17 & (8) \\
\hline & & $\mathrm{z}$ & -1.49 & (1) & -1.19 & (4) & $0.29^{* * *} *$ & (1) & 0.14 & (4) \\
\hline & & zrd & -0.54 & (1) & -0.12 & (1) & $0.15^{* *}$ & (8) & $0.45^{*}$ & (8) \\
\hline & & $\mathrm{gc}$ & -1.68 & (3) & -1.79 & (1) & $0.16^{* *}$ & (3) & 0.22 & (1) \\
\hline & Thailand & $\mathrm{a}$ & -1.53 & (1) & $-2.71 * * *$ & (1) & $0.13^{*}$ & (8) & 0.18 & (8) \\
\hline & & $\mathrm{z}$ & -1.42 & (1) & -2.12 & (1) & $0.15^{* *}$ & (1) & 0.18 & (1) \\
\hline & & zrd & -0.72 & (2) & -0.27 & (1) & $0.22 * * *$ & (2) & $0.67^{* *}$ & (2) \\
\hline & & $\mathrm{gc}$ & $\begin{array}{l}-0.12 \\
-1.42\end{array}$ & (1) & $-2.29 *$ & (1) & $0.28 * * *$ & (1) & 0.26 & (1) \\
\hline
\end{tabular}

Table 5.1: Unit Root Tests CUCs countries. All variables are index numbers (1981=100) expressed in logarithms. The lag lengths (in parentheses) are chosen using the Schwert 1989 method: lag $_{\max }=\left[12\left\{\frac{T}{100}\right\}^{\frac{1}{4}}\right]$. The null hypothesis in the ADF (KPSS) test is unit root (stationary). The test in levels include a trend and a constant. The test in first differences include a constant (no trend). *, **, and ***, denote significance at the 10\%, 5\%, and 1\% levels, respectively. Results are obtained using Stata's dfgls and kpss.

$1 /$ Notice that the test for "rd" in the first row stands for the unweighted version of foreign RED obtained through Equation (5.2). This variable is the same for all countries off the frontier.

Critical V. for the KPSS tests with a trend are 10\%: 0.12, 5\%:0.15, and 1\%:0.22.

Critical V. for the KPSS tests without a trend are 10\%: 0.35, 5\%:0.46, and 1\%:0.74. 
of the system for each country. In all the reported cases we are able to check that there are no autocorrelation problems. ${ }^{66}$

Table 5.2 reports the results of the trace test for the 5 variables system $x_{t}=\left(a_{t}, z r d_{t}, z_{t}, g c_{t}, r d_{t}\right)^{\prime}$. For most countries we cannot reject that there are between two and three cointegrating equations (the exceptions are Cyprus and Malaysia with up to two cointegration vectors each). Therefore, we do settle for specifying $r=3$ - except for Cyprus and Malaysia, for which we consider $r=2$ instead. Our choice is generally supported by the MES statistics; the SBIC and HQIC criteria suggest 4 cointegrating equations in all cases, but that alternative is not supported by the stability analysis. in all cases, the analysis of the VEC systems below is based on stable processes.

\begin{tabular}{lcccll}
\hline Country & $H_{0}: r=0$ & $H_{0}: r=1$ & $H_{0}: r=2$ & $H_{0}: r=3$ & $H_{0}: r=4$ \\
\hline China(2) & 222.99 & 95.15 & 53.33 & $23.51^{*} 5$ & 8.03 \\
Cyprus(2) & 212.87 & 72.99 & $41.49^{*} 5$ & 21.64 & 7.74 \\
Egypt(2) & 195.17 & 93.95 & 49.50 & $25.22^{*} 5$ & 9.67 \\
Hong Kong(1) & 237.22 & 90.42 & 50.48 & $19.29^{*} 5$ & 6.25 \\
Indonesia(1) & 276.36 & 116.94 & 61.31 & $20.12^{*} 5$ & 4.66 \\
Malaysia(2) & 173.74 & $66.19^{*} 1$ & $36.82^{*} 5$ & 22.23 & 10.47 \\
Malta(2) & 189.31 & 72.93 & $43.05^{*} 1$ & $23.37^{*} 5$ & 9.63 \\
Israel(2) & 189.92 & 80.50 & 49.51 & $24.04^{*} 5$ & 7.06 \\
Korea(2) & 191.18 & 85.05 & $48.15^{*} 1$ & $24.89^{*} 5$ & 9.58 \\
Singapore(3) & 183.35 & 98.55 & 51.87 & $24.21^{*} 5$ & 9.71 \\
Thailand(1) & 248.67 & 109.98 & 60.88 & $23.56^{*} 5$ & 5.89 \\
& & & & & \\
5\% C. Value & 87.31 & 62.99 & 42.44 & 25.32 & 12.25 \\
1\% C. Value & 96.58 & 70.05 & 48.45 & 30.45 & 16.26 \\
\hline
\end{tabular}

Table 5.2: Cointegration tests CUCs countries. The table reports the results of the $\lambda_{\text {trace }}$ tests for the null hypotheses that there are $r=0, \ldots, r=4$ cointegration vectors among the five variables in the system $x_{t}=\left(a_{t}, z r d_{t}, z_{t}, g c_{t}, r d_{t}\right)^{\prime}$. The test includes a restricted trend in all cases. Lag lengths (in parentheses) chosen according to the conventional information criteria, including up to three lags. ${ }^{*} 1$ and ${ }^{*} 5$ denotes significance at the $1 \%$ and $5 \%$ respectively. Critical values are reported at the bottom of the table.

Finding the proper order of the variables is important for estimation purposes of the parameters in the VEC model. The hierarchical ordering of the variables in the system $x_{t}=\left(a_{t}, z r d_{t}, z_{t}, g c_{t}, r d_{t}\right)^{\prime}$ is based on the causal structure suggested by our theoretical model. This ordering is uniquely determined and implies that productivity, " $a$ ", is the most endogenous variable; in turn, the interaction term, " $z r d$ ", is endogenous to (local) innovation, " $z$ ", and R\&D investments in countries at the frontier, " $r d$ "; (local) innovation is endogenous to government coordination, " $g c$ " and " $r d "$ " and " $g c$ " and " $r d$ " are weakly exogenous.

The estimation of the coefficients of interest, namely the short-run adjust-

\footnotetext{
${ }^{66}$ We need to keep in mind that our sample size, namely 30 observations per country, is not large enough to provide safe statistics on model adequacy. In general, we exclude countries with unstable processes, autocorrelation and overall nonnormality problems, but keep in the sample a few of cases where the normality of the residuals is rejected for specific series (Hong Kong, Malaysia), which of course still may affect the corresponding tests of significance.
} 
ment coefficients $(\alpha)$ and the long-run coefficients $(\beta)$, requires $r^{2}$ restrictions (where $r$ is the number of cointegrating vectors). The cointegration results determined by imposing the Johansen normalization restrictions are shown in Table 5.3. With $r=3$ for China, Egypt, Hong Kong, Indonesia, Malta, Israel, Korea, Singapore, and Thailand, the cointegration vectors are defined for the triplets ("a", "gc", "rd"), ("zrd", "gc", "rd") and ("z", "gc", "rd"). The default normalization implies that " $a$ " $=1$ in the first cointegrating vector (first row for each country); "zrd" = 1 in the second cointegrating vector (second row); and " $z$ " $=1$ in the third cointegrating vector (third row). With $r=2$ for Cyprus and Malaysia, the cointegration vectors are defined for the 4 variables in the set ("a", "z", "gc", "rd") and the 4 variables in the set ("zrd", "z", "gc", "rd") with " $a "=1$ in the first cointegrating vector and " $z r d "=1$, in the second.

From Table 5.3, the Johansen normalization restrictions allow us to analyze the cointegration properties between productivity, government coordination and foreign technology (the first cointegrating vector). They also allow us to analyze cointegration between the interaction term, government coordination and foreign technology (the second cointegrating vector). Finally, they allow us to analyze cointegration between (local) innovation, government coordination and foreign technology. We cannot, however, directly infer the relationship between productivity and the interaction term which is one of our key targets - to account for this kind of relationship we would need to rely on the analysis of impulse response functions. As we mentioned above, rearranging the variables to find a parameter estimate in this regard makes little sense given the unique hierarchical order of the variables in the system. And imposing over-identifying restriction does not solve the problem either.

As we mentioned, the correlation between productivity and the interaction term may still be analyzed through impulse response functions. After all, if the pairs ("a", "rd") and ("zrd", "rd") are cointegrated, it must hold that the pair ("a", "zrd") is also cointegrated. The difficulty that arises for analyzing the structural shocks in this system is that the coefficient estimates in Table 5.3 do not show reliable cointegrating vectors neither among the variables in the triplets ("a", "gc", "rd"), ("zrd", "gc", "rd") and ("z", "gc", "rd") nor among the 4 variables systems of Cyprus and Malaysia. The long-run effects of foreign technology are statistically significant in most cases, but the size impacts are too large to allow for a meaningful economic interpretation: namely, Hong Kong (-11.64, -7.78), Indonesia (-7.73, -5.63), Thailand (-8.65, -109.76, -93.94). And a similar difficulty arises for the analysis of the long-run impacts of government coordination, and for the estimates of the short-run adjustment coefficients, which are not always significant and in some cases also quite large.

Of course, the results obtained from the VEC methodology are affected by individual idiosyncratic country effects not all of which are adequately captured by our data (war, social riots, policy changes and so on). ${ }^{67}$ Yet, the investigation of country specific events is not in our scope in this exploratory analysis.

To handle other difficulties that were mentioned earlier, a renormalization

${ }^{67}$ See, for instance, Juselius, Møller and Tarp 2014. 


\begin{tabular}{|c|c|c|c|c|c|c|c|c|c|}
\hline \multirow[b]{2}{*}{$a_{t}$} & \multirow[b]{2}{*}{$z r d_{t}$} & \multicolumn{2}{|c|}{ Cointegration } & vector ( $\beta$ coeff.) & \multicolumn{4}{|c|}{ SR-Adj ( $\alpha$ coeff. $)$} & \multirow[b]{2}{*}{$\Delta r d_{t}$} \\
\hline & & $z_{t}$ & $g c_{t}$ & $r d_{t}$ & $\Delta a_{t}$ & $\Delta z r d_{t}$ & $\Delta z_{t}$ & $\Delta g c_{t}$ & \\
\hline 1.00 & 0 & 0 & -0.06 & $0.82^{* * *}$ & $-0.94^{* * * *}$ & 0.33 & $0.37^{*}$ & $0.70 * * *$ & $-0.04^{* * *}$ \\
\hline 0 & 1.00 & 0 & $2.43^{* * *}$ & $6.6^{* * *}$ & $-1.34 * * *$ & 0.09 & 0.02 & $0.33^{*}$ & $0.17^{* * *}$ \\
\hline 0 & 0 & 1.00 & $2.90^{* * *}$ & $8.95 * * *$ & $1.22^{* * *}$ & -0.17 & -0.10 & $-0.38^{* *}$ & $-0.16^{* * *}$ \\
\hline 1.00 & 0 & $-0.07^{* * *}$ & $0.11^{* * *}$ & $-1.31 * * *$ & -0.48 & -2.14 & -3.00 & $-1.33^{*}$ & $0.06^{* *}$ \\
\hline 0 & 1.00 & $-1.57^{* * *}$ & $0.55^{* * *}$ & $-5.38 * * *$ & 0.14 & 0.62 & 0.80 & $0.37^{* *}$ & $0.02^{* * *}$ \\
\hline 1.00 & 0 & 0 & $-0.11^{*}$ & $-0.21^{*}$ & $-0.60^{* * *}$ & -0.18 & 0.40 & 0.75 & -0.02 \\
\hline 0 & 1.00 & 0 & 0.59 & $-11.64 * * *$ & -0.25 & 1.04 & $1.67^{*}$ & -0.35 & 0.05 \\
\hline 0 & 0 & 1.00 & 0.24 & $-7.78^{* * *}$ & 0.32 & -1.49 & $-2.38^{*}$ & 0.52 & -0.05 \\
\hline 1.00 & 0 & 0 & -0.62 & $5.29 * * *$ & $-0.38 * * *$ & $0.92^{* * *}$ & $0.71 * * *$ & 0.09 & $0.21^{* * *} *$ \\
\hline 0 & 1.00 & 0 & 2.40 & $-18.97^{* * *} *$ & $-1.14^{* * *}$ & $2.14^{* * *}$ & $1.80 * * *$ & $-1.25^{* * *}$ & $0.62^{* * *}$ \\
\hline 0 & 0 & 1.00 & 2.21 & $-16.83^{* * *}$ & $1.09^{* *}$ & $-1.96 * * *$ & $-1.68^{* * *}$ & $1.36^{* * *}$ & $-0.57 * * *$ \\
\hline 1.00 & 0 & 0 & $-3.02^{* * *}$ & $-7.73 * * *$ & -0.17 & 0.41 & 0.30 & $0.42^{* * *}$ & -0.02 \\
\hline 0 & 1.00 & 0 & $6.58 * * *$ & $-5.63 * * *$ & 0.38 & -0.89 & -0.68 & $-1.17^{* * *}$ & $0.10^{* * *}$ \\
\hline 0 & 0 & 1.00 & $7.45^{* * *}$ & -1.01 & -0.41 & 0.94 & 0.72 & $1.12^{* * *}$ & $-0.10^{* * *}$ \\
\hline 1.00 & 0 & 0.09 & $-0.86^{* * *}$ & $-1.55^{* * *}$ & -0.14 & $-0.93^{* * *}$ & $-0.96 * * *$ & $0.18^{*}$ & $0.02^{*}$ \\
\hline 0 & 1.00 & $-1.19^{* * *}$ & $-0.55^{* * *}$ & $-2.04^{* * *}$ & 0.27 & $2.15^{* * *}$ & $2.03^{* * *}$ & -0.32 & $0.16^{* * *}$ \\
\hline 1.00 & 0 & 0 & $-0.28^{*}$ & $-0.54^{* * *}$ & $0.18^{*}$ & $0.52^{* * *}$ & $0.39^{*}$ & -0.19 & $0.13^{* * *} *$ \\
\hline 0 & 1.00 & 0 & $1.02 * * *$ & $-1.88 * * *$ & -0.06 & 0.21 & 0.06 & 0.44 & $0.16 * * *$ \\
\hline 0 & 0 & 1.00 & $0.47^{* * *}$ & 0.07 & 0.61 & $-2.21^{* * *}$ & $-1.83^{*}$ & $-2.45^{*}$ & $-0.17^{* * *}$ \\
\hline 1.00 & 0 & 0 & $-0.33^{* * *}$ & $-0.81^{* * *}$ & $-1.45^{* * *} *$ & 0.60 & 0.93 & -0.28 & -0.04 \\
\hline 0 & 1.00 & 0 & $9.56 * * *$ & $16.51^{* *}$ & $-0.05 * * *$ & 0.02 & 0.03 & $-0.04^{*}$ & $-0.005 * *$ \\
\hline 0 & 0 & 1.00 & $0.40^{* * *}$ & $-1.33^{* * *}$ & 0.06 & 0.01 & -0.12 & $-0.48^{* * *}$ & $0.06^{* * *}$ \\
\hline 1.00 & 0 & 0 & $0.14^{*}$ & $-0.70 * * *$ & $-1.22^{* *}$ & -1.14 & -1.43 & -0.77 & 0.03 \\
\hline 0 & 1.00 & 0 & $3.45^{* *}$ & $-9.94^{* *}$ & 0.23 & $2.41^{* * *}$ & $2.50 * * *$ & 0.37 & 0.01 \\
\hline 0 & 0 & 1.00 & $2.34^{*}$ & -5.04 & -0.36 & $-3.09 * * *$ & $-3.20 * * *$ & -0.54 & -0.004 \\
\hline 1.00 & 0 & 0 & $-0.61^{* * *}$ & $-1.91^{* * *}$ & $-1.37^{* * *} *$ & $1.57^{* * *}$ & $1.52^{* * *}$ & 0.57 & 0.01 \\
\hline 0 & 1.00 & 0 & $-2.03 * * *$ & $-6.08 * * *$ & $1.46^{* * *}$ & $-1.20^{*}$ & $-1.17^{*}$ & $-0.83^{*}$ & 0.05 \\
\hline 0 & 0 & 1.00 & $-1.53^{* * *}$ & $-2.34^{* * *}$ & $-1.82^{* * *}$ & 1.20 & 1.12 & $1.21^{* *}$ & -0.05 \\
\hline 1.00 & 0 & 0 & $-2.04^{* * * *}$ & $-8.65^{* * *} *$ & $-1.51^{* * *}$ & 0.08 & 0.05 & $-1.17^{*}$ & 0.02 \\
\hline 0 & 1.00 & 0 & $-21.73^{* * *}$ & $-109.76^{* * *}$ & -0.24 & $4.36^{* * *}$ & $4.34^{* * *}$ & $-1.39 * *$ & 0.01 \\
\hline 0 & 0 & 1.00 & $-18.79^{* * *}$ & $-93.94 * * *$ & $0.42^{*}$ & $-5.05 * * *$ & $-5.03 * * *$ & $1.72^{* *}$ & -0.01 \\
\hline
\end{tabular}

5.3: Estimated cointegration vectors with Johansen normalization restrictions (CUCs). We condition on 3 rating equations among the 5 variables system-normalized by " $a_{t}$ ", " $z r d_{t}$ " and " $z_{t}$ " respectively (Cyprus and sia with 2 vectors). A constant and a trend included (not shown) in the cointegrating vector. We report the l estimates $\left(1,-\beta_{x_{j}}\right)$. ***, and *** denote significance for $P>|z|$ at the $10 \%, 5 \%$, and 1\%. The short-run nent coefficients (SR-Adj) are shown in the last block of columns for each of $\Delta a_{t} \ldots \Delta r d_{t}$ : there are 3 adjustment ents which correspond to the vector normalized by " $a_{t}$ " (first row in each country); the vector normalized by "zrd $d_{t}$ " d row); and the vector normalized by " $z_{t}$ " (third row). 
of the 5-variable system is in order. We consider a set of restrictions that is consistent with the rationale of our hypotheses, which is informed by the theory introduced in Section 5.2. ${ }^{68}$

So, we first test whether there is a structural cointegration relationship between productivity, the interaction term and government coordination; then we test if the interaction term cointegrates with (local) innovation and foreign technology - recall that the interaction term is made of (local) innovation and the import's share weighted average of foreign technology; and in the third cointegrating vector we test whether (local) innovation cointegrates with government coordination and foreign technology - for Cyprus, Malaysia and Korea the last vector is omitted (a stable VEC in Korea is found for $r=2$ ). In the case of Malta a stable VEC can be obtained for $r=1$.

In other words, we test whether the structural cointegration relationships of interest are supported by the data for the triplets ("a", "zrd", "gc"), ("zrd", "z", "rd") and ("z", "gc", "rd"). The first vector is normalized by "a" and has zero long-run restrictions on "z" and "rd" - (local) innovation and foreign technology affect productivity through the interaction term. The second vector is normalized by "zrd" and has zero long-run restrictions on "a" and "gc," and the third vector is normalized by "z" and has zero long-run restrictions on "a" and "zrd" - by construction, the interaction term is endogenous to (local) innovation but not the other way around.

The results are shown in Table 5.4. Regarding the first cointegration vector (the first row for each country), we find that the long-run effect of the interaction term ("zrd") is significant but in four cases, namely Egypt (-0.02), Malaysia (0.07), Israel (0.002) and Korea (-0.01). In turn, the long-run effect of government coordination is insignificant for Korea (0.06).

Regarding the second cointegration vector (the second row for each country), we find that the long-run effect of (local) innovation is significant but in Egypt (0.03), Indonesia (0.01) and Singapore (-0.07). In turn, the long-run effect of foreign technology is generally significant though the size impact is still quite large in some cases (e.g., -13.65 for Indonesia).

In the third cointegrating vector (the third row for countries other than Cyprus, Malaysia, Malta and Korea), the long-run effect of government coordination is statistically significant but for Indonesia (0.0002), Singapore (-0.03) and Thailand (-0.02) - for Cyprus, Malaysia and Korea the effect of government coordination in the second cointegration vector is significant and it is also significant in the vector for Malta. In turn, the effect of foreign technology is generally significant but for Thailand (-6.73), though we see again that the size impact is quite large for Indonesia (16.85).

We also observe, from the sign of the estimates in the distinct cointegration vectors, that for some countries the series in the system seem to move in opposite directions over the long-run. That is, from the theoretical association between productivity and other variables, it would be expected $\beta_{z r d}$ and $\beta_{g c}$ to have a

\footnotetext{
${ }^{68}$ On identification of structural relations in VEC models see Johansen 1995, Davidson 1998, Fisher, Huh and Summers 2001.
} 


\begin{tabular}{|c|c|c|c|c|c|c|c|c|c|}
\hline \multirow[b]{2}{*}{$a_{t}$} & \multirow[b]{2}{*}{$z r d_{t}$} & \multicolumn{3}{|c|}{ Cointegration } & \multicolumn{4}{|c|}{ SR-Adj ( $\alpha$ coeff. $)$} & \multirow[b]{2}{*}{$\Delta r d_{t}$} \\
\hline & & $z_{t}$ & $g c_{t}$ & $r d_{t}$ & $\Delta a_{t}$ & $\Delta z r d_{t}$ & $\Delta z_{t}$ & $\Delta g c_{t}$ & \\
\hline 1.00 & $-0.16^{* * *}$ & 0 & $-0.28^{* * *} *$ & 0 & $-0.81^{* * *} *$ & $0.43^{* *}$ & $0.46^{* *}$ & $0.69 * * *$ & $-0.04 * *$ \\
\hline 0 & 1.00 & $-0.38 * * *$ & 0 & $1.30 * * *$ & -1.67 & -0.33 & -0.26 & $0.62^{* *}$ & $0.14^{* * *}$ \\
\hline 0 & 0 & 1.00 & $0.63^{* * *}$ & $5.69 * * *$ & $0.71^{* * *}$ & 0.06 & 0.06 & $-0.29 * *$ & $-0.09 * * *$ \\
\hline 1.00 & $-0.05 * * *$ & 0 & $0.08^{* * *}$ & $-1.06 * * *$ & -0.48 & -2.14 & -3.00 & $-1.33^{*}$ & $0.06^{* *}$ \\
\hline 0 & 1.00 & $-1.57^{* * *}$ & $0.55^{* * *}$ & $-5.38 * * *$ & 0.12 & 0.52 & 0.66 & $0.31^{* *}$ & $0.03^{* * *}$ \\
\hline 1.00 & -0.02 & 0 & $-0.13^{*}$ & 0 & $-0.53^{* *}$ & -0.10 & 0.48 & 0.69 & -0.04 \\
\hline 0 & 1.00 & 0.03 & 0 & $-10.59 * * *$ & -0.27 & 1.02 & $1.66^{*}$ & -0.34 & 0.05 \\
\hline 0 & 0 & 1.00 & $-0.19 * * *$ & $-6.86^{* * *}$ & 0.35 & -1.51 & $-2.41^{*}$ & 0.54 & -0.05 \\
\hline 1.00 & $3.14^{* * *}$ & 0 & $-0.46^{* * *}$ & 0 & $-0.33^{* *}$ & $0.49^{* * *}$ & $0.48 * * *$ & $-0.25 * * *$ & $0.06^{* * *}$ \\
\hline 0 & 1.00 & $-3.74 * * *$ & 0 & $-8.28^{* * *}$ & $-0.29^{* *}$ & $0.46^{* * *}$ & $0.45 * * *$ & $-0.22^{* * *}$ & $0.06^{* * *}$ \\
\hline 0 & 0 & 1.00 & $-1.66^{* * *}$ & $-3.38 * * *$ & $0.19^{*}$ & $-0.34^{* * *}$ & $-0.37^{* * *}$ & $0.12^{* *}$ & 0.00 \\
\hline 1.00 & $0.09 * * *$ & 0 & $-0.84^{* * *}$ & 0 & -0.03 & $-0.99 * * *$ & $-0.90^{* * *}$ & -0.03 & $-0.14 * * *$ \\
\hline 0 & 1.00 & 0.01 & 0 & $-13.65^{* * *}$ & -0.20 & -0.25 & $-0.66^{* * *}$ & -0.02 & $0.55 * * *$ \\
\hline 0 & 0 & 1.00 & 0.00 & $-12.49 * * *$ & 0.20 & 0.28 & $0.67^{* * *} *$ & 0.02 & $-0.52 * * *$ \\
\hline 1.00 & 0.07 & 0 & $-0.90^{* * *} *$ & $-1.71^{* * *}$ & -0.14 & $-0.93^{* * *} *$ & $-0.96^{* * *}$ & $0.18^{*}$ & $0.02^{*}$ \\
\hline 0 & 1.00 & $-1.19 * * *$ & $-0.55^{* * *}$ & $-2.04^{* * *}$ & 0.28 & $2.22^{* * *}$ & $2.10^{* * *}$ & -0.33 & $0.16^{* * *}$ \\
\hline 1.00 & $1.04^{* * *}$ & $-1.52^{* * *}$ & $0.30 * * *$ & $-2.01 * * *$ & -0.02 & $0.34^{* * *}$ & 0.01 & 0.01 & $0.34^{* * *}$ \\
\hline 1.00 & 0.00 & 0 & $-0.04^{* * *} *$ & 0 & $-2.62^{* * *}$ & 0.75 & 0.95 & -1.30 & -0.05 \\
\hline 0 & 1.00 & $-1.85 * * *$ & 0 & $-1.00^{* *}$ & 0.03 & 0.30 & $0.41^{*}$ & -0.14 & 0.00 \\
\hline 0 & 0 & 1.00 & $3.24^{* * *}$ & $3.94 * * *$ & 0.01 & 0.00 & -0.03 & $-0.19^{* *}$ & -0.01 \\
\hline 1.00 & -0.01 & 0 & 0.06 & $-0.47^{* * *} *$ & $-1.49^{* * *} *$ & -0.83 & -0.93 & -0.33 & 0.02 \\
\hline 0 & 1.00 & $-1.28 * * *$ & $0.29^{* *}$ & $-3.60^{* * *}$ & $0.20^{* * *}$ & $0.26^{*}$ & 0.20 & $0.22^{* * *}$ & $0.07^{* * *}$ \\
\hline 1.00 & $-0.06^{*}$ & 0 & $-0.51^{* * *}$ & 0 & $-1.06^{* * *}$ & 0.44 & 0.53 & -0.03 & -0.05 \\
\hline 0 & 1.00 & -0.07 & 0 & $-4.03^{* * *}$ & $0.87 * * *$ & -0.35 & $-0.58^{*}$ & -0.04 & $0.28 * * *$ \\
\hline 0 & 0 & 1.00 & -0.03 & $-1.94^{* * *}$ & $-1.27^{* * *}$ & 0.64 & $0.83^{*}$ & 0.05 & $-0.26^{* *}$ \\
\hline 1.00 & $-0.11^{* * *}$ & 0 & $-0.37^{* * * *}$ & 0 & $-2.71^{* * * *}$ & 2.26 & 2.39 & 0.46 & 0.06 \\
\hline 0 & 1.00 & $0.17 * * *$ & 0 & $-10.22^{*}$ & $-0.80^{* *}$ & $5.85 * *$ & $5.95 * *$ & $-2.81 * *$ & 0.10 \\
\hline 0 & 0 & 1.00 & -0.02 & -6.73 & $1.05^{* *}$ & $-7.86^{* *}$ & $-7.98 * *$ & $3.72^{* *}$ & -0.13 \\
\hline
\end{tabular}

5.4: Estimated cointegration vectors (CUCs). We report the original estimates $\left(1,-\beta_{x_{j}}\right)$ computed with Johansen's um likelihood method. A constant and a trend included (not shown) in the cointegrating vector. ***, and *** significance for $P>|z|$ at the 10\%, 5\%, and 1\% levels respectively. For each country, the first row shows the ration results for the triplet $\left(a_{t}, z r d_{t}, g c_{t}\right)$; the second row the cointegration results for the triplet $\left(z r d_{t}, z_{t}, r d_{t}\right)$; e third the cointegration results for the triplet $\left(z_{t}, g c_{t}, r d_{t}\right)$. The short-run adjustment coefficients (SR-Adj) are in the last block of columns for each equation from $\Delta a_{t} \ldots \Delta r d_{t}$. 
negative sign in the the triplet ("a", "zrd", "gc")— note that we are normalizing for "a" and reporting the estimates as a vector of the form $\left(1,-\beta_{x_{j}}\right)$. We see the expected results for some countries in Table 5.4, namely China $(1,-0.16$, -0.28), but many other coefficients in the table show opposite patterns with productivity. Although indicative, these results should not be problematic. A better picture of the long-run association between any two series in VEC models depends on the systematic relationship between them and all the other variables in the system.

On the other hand, we see that the adjustment coefficients - " $\alpha$ " in the equation for $\Delta a_{t}$-are nonsignificant for productivity in Cyprus (-0.48, 0.12), Egypt $(-0.27,0.35)$, Indonesia $(-0.03,-0.20,0.20)$, Malaysia $(-0.14,0.28)$, Malta $(-0.02)$ and Israel $(0.03,0.01)$. Likewise, in the equations from $\Delta z r d_{t}$ to $\Delta r d_{t}$, we see that many adjustment coefficients are not significantly different from zero. Nonsignificant coefficients may follow from the true short-run exogeneity of the affected variables. For instance, we observe that government coordination seems to be independent of any long-run disequilibria in Egypt and Indonesia, which is consistent with the weak exogeneity we attribute to this variable. However, nonsignificant parameters may reveal also correlation patterns and measurement problems that affect specific variables. This may be the case for the nonsignificant coefficients under the equation for $\Delta a_{t}$ that we see in some countries.

In summary, a critical scrutiny of the results presented in Table 5.4 reveals various troubles in setting up cointegration vectors that are well behaved in all cases. Still, so far these partial results also support our hypotheses that the variables in the system are cointegrated. In particular, we have found that productivity is generally related with other variables in the long-run, either directly (with "zrd" and "gc") or indirectly (through the impact of "z" and "rd" on "zrd", and the impact of "gc" and "rd" on "z"). Furthermore, for countries other than Cyprus, Indonesia, Malaysia and Malta, productivity is significantly affected at least by some long-run disequilibria (in the sense that at least one $\alpha \neq 0$ under the equation for $\Delta a_{t}$ ). Likewise, we find that (local) innovation is generally related with "gc" and "rd" in the long-run. And with few exceptions it seems to be significantly affected by at least some long-run disequilibria $\left(\alpha \neq 0\right.$ under the equation for $\left.\Delta z_{t}\right)$.

In order to improve the subsequent analysis (e.g., the dynamic multipliers analysis), we impose exclusion (zero) restrictions on the parameter estimates that turn out to be statistically insignificant in the cointegration equationsthe $\beta_{x}$ coefficients in Table 5.4. ${ }^{69}$ Using c1, c2 and c3 to denote the first, second and third cointegration vectors respectively, those restrictions amount to test the null hypotheses that $H o: \beta_{c 1, z r d}=\beta_{c 2, z}=0$ in Egypt; Ho: $\beta_{c 2, z}=0$ in

\footnotetext{
${ }^{69}$ Exclusion restrictions on short-run adjustment coefficients are not tested in our analysis. These restrictions are not difficult to test, but unlike the case of long-run restrictions, the relatively larger number of restrictions to be imposed on short-run coefficients implies a substantial cost from the computational viewpoint: extensive iterations are needed before convergence is achieved country-by-country. Notice, moreover, that the possible existence of near-linear dependencies among the variables in the system implies that one needs to learn more about the feasibility of distinct types of restrictions rather than setting zero restrictions outright.
} 
Indonesia; Ho: $\beta_{c 1, z r d}=0$ in Malaysia; Ho: $\beta_{c 1, z r d}=\beta_{c 1, g c}=0$ in Korea; Ho: $\beta_{c 2, z}=\beta_{c 3, g c}=0$ in Singapore; and $H o: \beta_{c 3, g c}=\beta_{c 3, r d}=0$ in Thailand. In general, these over-identifying restrictions cannot be rejected (the results of these tests are omitted).

One remarkable feature of impulse-response functions that are drawn from VEC models is the fact that they do not die out to zero after the initial shock. This property that usually holds for stationary, stable VAR processes does not necessarily hold in VEC models where the one-time initial impulse can have permanent non-zero effects. ${ }^{70}$

In Figure 5.3 the impulse-response functions based on the constrained results (after the exclusion restrictions) for each country are depicted. We focus here on the point estimates of the response of productivity to a one-time orthogonalized shock in each of the other variables. ${ }^{71}$ Total accumulated responses, which seem more logical to analyze the long-run productivity effects of those shocks, are discussed later in this chapter.

The response to an impulse on the interaction term ("zrd" $\rightarrow$ "a") is seen to vary largely across countries. For China, Israel and Korea there is a permanent decline of productivity; for Egypt, Indonesia, Malta and Thailand there is a permanent positive effect; and for Cyprus, Hong Kong, Malaysia and Singapore, a decline shortly after impact is followed by a recovery and a permanent positive effect. Also, we observe that for Singapore and Thailand the size of the response is relatively large, more than 0.02 units in comparison with less than 0.01 in every other country.

The response induced by a shock on (local) innovation (" $\mathrm{z}$ " $\rightarrow$ "a") is positive for China, Egypt, Hong Kong, Malta, Israel and Thailand (after an instantaneous decline in the last case); and the induced response is negative for Cyprus, Indonesia, Malaysia and Korea. More specifically, in the case of Korea the initial shock leads to a transitory increase of productivity which is followed by a permanent decline in subsequent periods. In the case of Israel there is a transitory positive effect that declines rapidly and exhibits some variation before it converges to some positive value. And in Singapore, the decline at impact is followed by a permanent recovery and a relatively large positive effect thereafter, in comparison with the size of the response for any other country.

The response of productivity to an impulse on government coordination ("gc" $\rightarrow$ "a") is mostly positive. Only Hong Kong and Malta show a permanent decline after the initial shock. Israel and Thailand exhibit substantial variation before the response function stabilizes for some positive value. And the estimated response is relatively large in the cases of Singapore, Thailand and Indonesia.

Finally, the response to an impulse on foreign technology ("rd" $\rightarrow$ "a") is

\footnotetext{
${ }^{70}$ Lutkepohl 2005, Ch. 6.

${ }^{71}$ Notice that confidence intervals based on impulse-response functions after VEC models are not available from the routine in the software-package used for this estimation (Stata). Of course, the confidence intervals may be obtained through bootstrapping methods. But that procedure is computationally expensive as it involves extensive replications of the underlined VEC model country-per-country.
} 

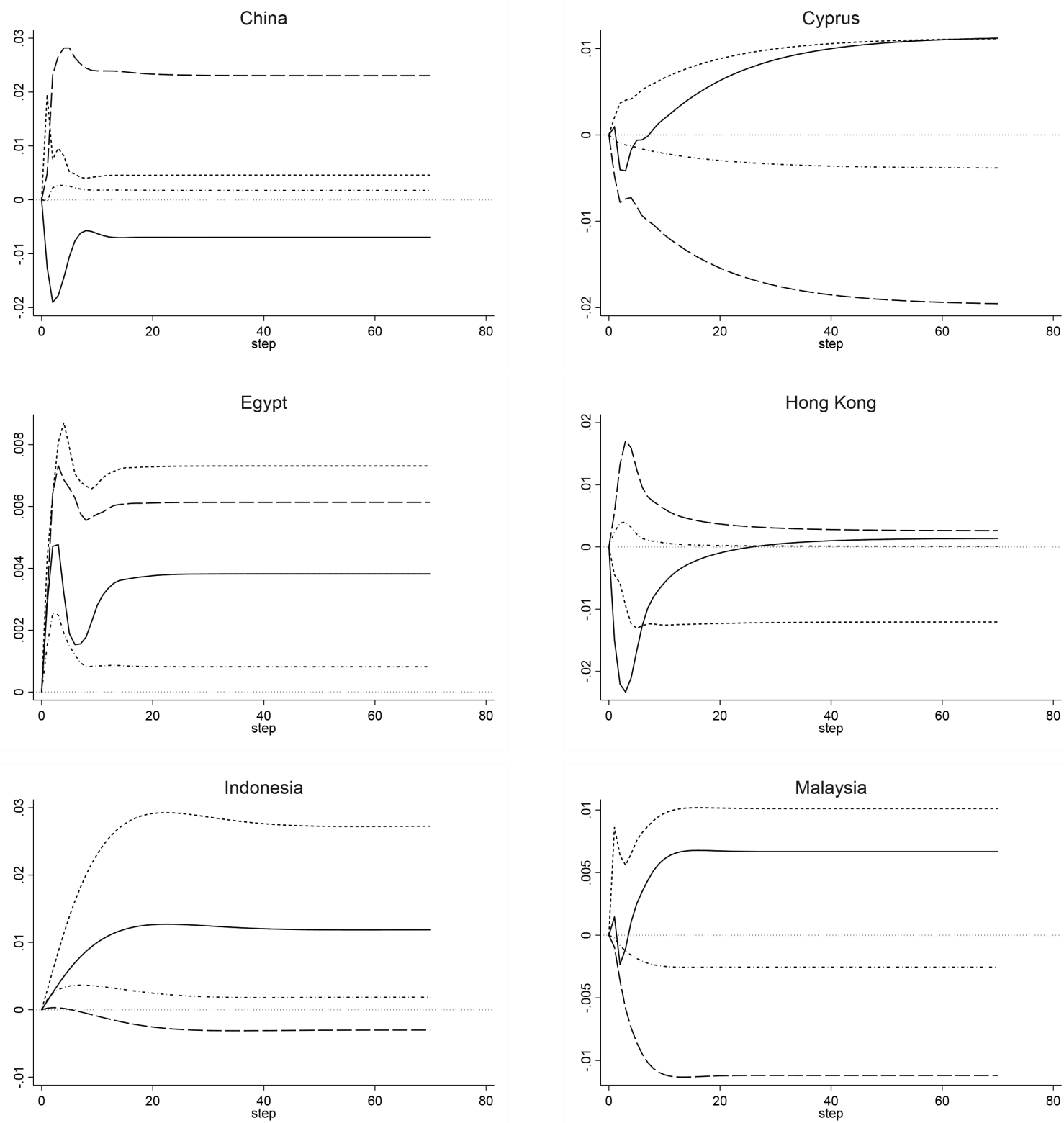
positive for China, Egypt, Indonesia, Malta, Hong Kong, Singapore and Thailand. And it is negative for Cyprus, Malaysia, Israel and Korea. In Singapore the decline at impact is followed by a permanent recovery and a positive effect thereafter, while in Korea there is an instantaneous increase in productivity which is followed by a permanent decline thereafter, and in Israel there is mostly a negative effect with large variation at the initial periods.

All in all, the impulse-response analysis depicted in Figure 5.3 shows no systematic pattern in the relation between productivity and each of the other variables in the system. Again, we note that from our theoretical considerations it was expected a positive impact on productivity from a shock on each of the other variables. For instance, we would have expected a high positive effect from a shock on the interaction term as, by construction, it captures the twin benefits of foreign technology and local innovation; and also a positive effect from a shock on government coordination, which would follow from our discussion about the role of government in the NIS framework.

The fact that the expected results do not show up systematically in a country-by-country approach should, however, not be surprising. As we already mentioned above, our ability to find the desired results is limited by a variety of reasons, namely the small size of our sample, the unavailability of better data to measure accurately the theoretical concepts we deal with (e.g., we rely on a mild version of "gc"), and the omission of country idiosyncratic effects. While these reasons prevent us from a precise estimation of the parameters of interest and the corresponding impulse-response functions, which may seriously mislead our conclusions on a country-per-country analysis, we would expect that, by analyzing the entire range or distribution of the response functions across a classification of countries, the results shall make more economic sense (in terms of our hypotheses at the outset).

To illustrate our point we compute overall average response functions, namely the period-by-period unweighted average response functions over all countries with information in the CUCs classification. There are four average functions corresponding to the response of productivity to impulses originated in each of the other variables. These average functions are classified according to the impulse variable and shown in Figure 5.4, where the country-by-country response functions are displayed as well (these are the same shown previously in Figure $5.3)$.

In calculating the average impulse-response functions we need to pay attention to the unfluence of extreme values. For instance, the large responses that we already noted in Singapore and Thailand are now much more evident when we look at the impulses running from "zrd" to "a" in Figure 5.4. Similarly, in the case of the impulses running from " $\mathrm{z}$ " to "a" we see a large positive response (corresponding to China); and in the case of the impulses running from "gc" to "a" there are two large positive responses (Indonesia and Thailand); finally, in the case of the impulses running from "rd" to "a" there is a large response (Thailand). We see that in some cases the influence of extreme positive values is offset by responses in the opposite direction in other countries, but in many other cases they are not. For instance, in the impulses running from "zrd" and 
"gc" to "a".

To deal with the difficulty that the averages may be skewed by the extreme responses found in some countries, we compute also the overall median response functions, namely the midpoint in the distribution of the responses across countries. We compute these midpoints period-by-period. Clearly, by dividing the range of values into two halves, the overall median response functions offer a more accurate representation of the empirical distribution of the responses across countries. Notice that there is a wide variance in these empirical distributions, which is a consequence of the fact that in many cases the country specific response functions are either largely negative or largely positive rather than clustered around the center.

In Figure 5.4 the overall average response functions are depicted using thick solid white lines; in turn, the overall median response functions are depicted using thick solid black lines. To gain some insight into the empirical distribution of these functions, and the leverage exerted by the "extreme" response values in some countries, one standard deviation intervals are established around the median. How we do this is explained next.

First we calculate the sample standard deviation over all countries and use it to generate an interval that is plotted as a light grey shaded area with respect to the median; then we drop the country with the most extreme response values on the right and also on the left of the distribution (the sample median is unaffected by this procedure); we recalculate the standard deviation over the remaining countries and generate a new interval that is plotted as a slightly darker grey shaded area than before. We repeat this procedure twice, dropping each time one more country on the right and left of the distribution and plotting the new intervals as slightly darker grey shaded areas.

In summary, in Figure 5.4 there are four grey bands around the sample median, corresponding to the one-standard-deviation intervals that are computed for the overall sample (the lightest grey shaded area), and for the sample after sequentially dropping the first, second and third most extreme responses on both sides of the distribution. As a result, the innermost and darkest band lies close to the median, though it represents also the dispersion for a lesser number of countries ( 5 in the case of the CUCs).

The large dispersion and lack of systematic patterns in the impulse-response functions are clearly problematic in the attempt to determine the suitability of our theory. However, it is interesting to observe that in spite of the limitations of the empirical distribution, the response functions portrayed in Figure 5.4 still reveal some evidence in favor of our hypotheses.

We see that the average response is skewed upwards in the functions for $(z r d \rightarrow a)$ and $(g c \rightarrow a)$. Clearly, in both these cases the overall median offers a more suitable alternative to make sense of the distribution of the response functions across individual countries. For the cases of the functions $(z \rightarrow a)$ and $(r d \rightarrow a)$ the empirical distribution is more symmetric around the mean, thus it makes little difference whether we focus on the average or the median of the distribution.

A shock on the interaction term $(z r d \rightarrow a)$ has an instantaneous negative 



Figure 5.4: Average and median impulse-response functions for the CUCs over a horizon of 70-years. The orthogonalized impulse response functions measure the response of productivity to a one-time unit standard deviation shock on each of the other variables. Dashed-thin lines depict the functions obtained for individual countries (see Figure 5.3); the thick solid white lines depict the overall average; and the thick solid black lines depict the overall median. One standard deviation bands are plotted around the median by taking into account the overall sample (the lightest grey shaded area) and the sample after sequentially subtracting one, two and three countries with the most extreme responses on both sides of the empirical distribution (the darkest inner band indicating the latter case). 
effect at impact - which is heavily influenced by China, Hong Kong, and Singapore, as can be verified by referring to Figure 5.3 ; but the negative effect at impact is followed by a permanent positive effect over time. The same dynamic pattern remains regardless of whether we look at the average or the median of the distribution - though, as we have already noted, the average is skewed upwards, influenced by the response function of Singapore.

In other remarkable result, we observe strong positive responses to a shock hitting government coordination $(g c \rightarrow a)$. This result holds regardless of whether we look at the average or the median of the distribution. But, again, the average is evidently skewed upwards influenced by the highly positive response functions of Thailand and Indonesia.

In the case of the response to a shock on innovation $(z \rightarrow a)$, both the overall average and the overall median slightly overlie the zero line; and similar, though not identical, effects are observed in the corresponding average and median responses to a shock hitting foreign technology $(r d \rightarrow a)$. Notice that the responses are slightly higher for the scenario $(r d \rightarrow a)$ than for the scenario $(z \rightarrow a)$.

In summary, by focusing on either the overall average or the overall median response functions we obtain more sensible results as to the impact of the interaction term, (local) innovation, government coordination and foreign technology on productivity. Under these particular scenarios we may argue that there is evidence in support of our hypotheses that the interaction of foreign and local technology and government coordination have both positive impacts on productivity. In addition, we observe that the interaction term has a larger impact than each of its individual elements.

Recall, from the discussion in Section 5.2, that we would expect that the interaction term and government coordination have larger productivity impacts in countries that have been successful in catching up and those that are already at the frontier, namely the CUCs and the FRCs, than in countries that remain in stagnation or those lagging over time, namely the STCs and th LGCs. The procedure just discussed, by which a reasonable interpretation of the impulseresponse functions relies on the patterns of the distribution rather than on the outcomes for individual countries, is replicated below to investigate whether, as we posited earlier, the CUCs and FRCs countries outperform the STCs and the LGCs.

\section{Summary over country classifications}

We focus on the analysis of so-called mean group estimates of the long-run and short-run coefficients in the VEC models for each country classification. ${ }^{72}$ Our methodology to estimating the mean group estimates follows and, we do think, improves the standard practice, namely, we first determine the cointegrating rank and run the cointegration analysis for each individual country;

\footnotetext{
${ }^{72}$ The unit root properties of the variables for each country show that they may be considered I(1) along the same lines of the analysis for the CUCs classification shown in Table 5.1. Detailed results from our calculations are available from the author.
} 
then, we calculate the unweighted average of the individual estimates over the countries in each classification; finally, we calculate the standard deviation over the coefficient estimates. ${ }^{73}$

Formally, the mean group estimate of the coefficients $\beta_{j, c, x_{i}}$ for the variable " $x_{i}$ " of the cointegration vector " $c$ " in country " $j$ " is

$$
\bar{\beta}_{c, x_{i}}=N^{-1} \sum_{j=1}^{N} \beta_{j, c, x_{i}}
$$

and its standard deviation is

$$
s . d \cdot \bar{\beta}_{c, x_{i}}=\left((N(N-1))^{-1} \sum_{j=1}^{N}\left(\beta_{j, c, x_{i}}-\bar{\beta}_{c, x_{i}}\right)^{2}\right)^{1 / 2}
$$

We restrict the computation of the mean group estimates to the country systems that show the same cointegrating rank. For most countries we cannot reject $r=3$, therefore, we report the computed results for the triplets ("a", "zrd", "gc"), ("zrd", "z", "rd") and ("z", "gc", "rd") with the same normalization restrictions discussed earlier.

From the upper block in Table 5.5 we see that the average coefficients are reasonably high in most cases for both long and short run effects. The larger average estimates are found for the long-run effect of "rd" in the CUCs (-6.64, -3.11) and STCs (-3.05); and for the long-run effect of "gc" in STCs (5.24). It is clear, on the other side, that there are wide differences in the estimates across and within the various country classifications: the standard deviations, reported in the parentheses below the coefficients, indicate that the estimates differ largely on a country-by-country basis. ${ }^{74}$

As we pointed out earlier, though the dynamics in a VEC process depends on the systematic relationship between all variables, the sign of the long-run coefficients is still of interest. We have argued why we expect a positive longrun association among all variables in the system. Yet, we see that this is the actual case in just a few of cases, namely the series in the vector ("a", "zrd", "gc") for the FRCs and the CUCs (the first row in each classification), and

\footnotetext{
${ }^{73}$ As we have pointed out before, conventional mean group estimators (Pesaran and Smith 1995, Blackburne and Frank 2007.) are not adequate for our estimation purposes. Available (panel data) procedures do not allow to test for more than one cointegration equation among the series in the system; in addition, those procedures do not allow to impose identifying restrictions, which clearly is a limitation as we have found evidence of more than one cointegrating relationship in the 5 variables system. Another problem is the lack of consistency between individual-by-individual and panel estimates, namely, using standard procedures, conflicting findings may be found between the aggregate test for more than two countries (say evidence of no cointegration) and the test for individual countries (evidence of cointegration).

${ }^{74}$ Note that the standard deviation of the averaged coefficient estimates indicates the dispersion of the country-by-country coefficients around the mean group estimate. One can also calculate these quantities taking into account parameter heterogeneity using the so-called random-coefficients-regression, RCR (Swamy 1970, Pesaran and Smith 1995); though attractive, this alternative is computationally demanding and it is not available in conventional statistical packages.
} 


\begin{tabular}{|c|c|c|c|c|c|c|c|c|c|}
\hline \multirow[b]{2}{*}{$a_{t}$} & \multirow[b]{2}{*}{$z r d_{t}$} & \multicolumn{3}{|c|}{ Cointegration } & \multicolumn{5}{|c|}{ SR-Adj ( $\alpha$ coeff. $)$} \\
\hline & & $z_{t}$ & $g c_{t}$ & $r d_{t}$ & $\Delta a_{t}$ & $\Delta z r d_{t}$ & $\Delta z_{t}$ & $\Delta g c_{t}$ & $\Delta r d_{t}$ \\
\hline 1.00 & $\begin{array}{l}-0.18 \\
(0.52)\end{array}$ & 0 & $\begin{array}{l}-0.23 \\
(1.14)\end{array}$ & 0 & $\begin{array}{l}-0.58 \\
(0.71)\end{array}$ & $\begin{array}{l}0.63 \\
(1.34)\end{array}$ & $\begin{array}{l}0.56 \\
(1.36)\end{array}$ & $\begin{array}{l}0.22 \\
(1.33)\end{array}$ & $\begin{array}{l}0.10 \\
(0.20)\end{array}$ \\
\hline 0 & 1.00 & $\begin{array}{l}0.28 \\
(2.10)\end{array}$ & 0 & $\begin{array}{l}-1.31 \\
(6.80)\end{array}$ & $\begin{array}{l}0.22 \\
(0.42)\end{array}$ & $\begin{array}{l}0.76 \\
(0.96)\end{array}$ & $\begin{array}{l}0.49 \\
(1.07)\end{array}$ & $\begin{array}{l}-0.26 \\
(1.03)\end{array}$ & $\begin{array}{l}0.37 \\
(0.46)\end{array}$ \\
\hline 0 & 0 & 1.00 & $\begin{array}{l}0.05 \\
(1.27)\end{array}$ & $\begin{array}{l}-1.59 \\
(5.29)\end{array}$ & $\begin{array}{l}-0.62 \\
(2.15)\end{array}$ & $\begin{array}{l}-0.79 \\
(1.43)\end{array}$ & $\begin{array}{l}-0.46 \\
(1.25)\end{array}$ & $\begin{array}{l}-0.52 \\
(5.29)\end{array}$ & $\begin{array}{l}-0.45 \\
(1.14)\end{array}$ \\
\hline 1.00 & $\begin{array}{l}-0.41 \\
(1.12)\end{array}$ & 0 & $\begin{array}{l}-0.38 \\
(0.25)\end{array}$ & 0 & $\begin{array}{l}-1.16 \\
(1.00)\end{array}$ & $\begin{array}{l}0.47 \\
(0.91)\end{array}$ & $\begin{array}{l}0.63 \\
(0.90)\end{array}$ & $\begin{array}{l}0.03 \\
(0.64)\end{array}$ & $\begin{array}{c}-0.03 \\
(0.06)\end{array}$ \\
\hline 0 & 1.00 & $\begin{array}{l}-0.83 \\
(1.35)\end{array}$ & 0 & $\begin{array}{l}-6.64 \\
(5.10)\end{array}$ & $\begin{array}{l}-0.33 \\
(0.72)\end{array}$ & $\begin{array}{l}0.96 \\
(2.05)\end{array}$ & $\begin{array}{l}1.00 \\
(2.15)\end{array}$ & $\begin{array}{l}-0.42 \\
(1.02)\end{array}$ & $\begin{array}{l}0.17 \\
(0.18)\end{array}$ \\
\hline 0 & 0 & 1.00 & $\begin{array}{l}0.28 \\
(1.37)\end{array}$ & $\begin{array}{l}-3.11 \\
(5.90)\end{array}$ & $\begin{array}{l}0.18 \\
(0.68)\end{array}$ & $\begin{array}{l}-1.25 \\
(2.77)\end{array}$ & $\begin{array}{l}-1.32 \\
(2.89)\end{array}$ & $\begin{array}{l}0.57 \\
(1.31)\end{array}$ & $\begin{array}{c}-0.15 \\
(0.17)\end{array}$ \\
\hline 1.00 & $\begin{array}{l}0.31 \\
(0.68)\end{array}$ & 0 & $\begin{array}{l}-1.54 \\
(5.48)\end{array}$ & 0 & $\begin{array}{c}-0.44 \\
(0.37)\end{array}$ & $\begin{array}{c}-0.01 \\
(0.87)\end{array}$ & $\begin{array}{l}-0.13 \\
(0.82)\end{array}$ & $\begin{array}{l}-0.05 \\
(0.34)\end{array}$ & $\begin{array}{l}0.11 \\
(0.15)\end{array}$ \\
\hline 0 & 1.00 & $\begin{array}{l}0.43 \\
(2.29)\end{array}$ & 0 & $\begin{array}{l}-3.05 \\
(3.68)\end{array}$ & $\begin{array}{l}-0.01 \\
(0.16)\end{array}$ & $\begin{array}{l}-0.36 \\
(1.04)\end{array}$ & $\begin{array}{l}-0.44 \\
(1.05)\end{array}$ & $\begin{array}{l}-0.08 \\
(0.49)\end{array}$ & $\begin{array}{l}0.16 \\
(0.15)\end{array}$ \\
\hline 0 & 0 & 1.00 & $\begin{array}{l}5.24 \\
(17.22)\end{array}$ & $\begin{array}{l}-0.53 \\
(3.49)\end{array}$ & $\begin{array}{l}-0.27 \\
(0.74)\end{array}$ & $\begin{array}{l}-0.11 \\
(1.51)\end{array}$ & $\begin{array}{l}0.20 \\
(0.89)\end{array}$ & $\begin{array}{l}0.19 \\
(0.54)\end{array}$ & $\begin{array}{l}-0.42 \\
(1.20)\end{array}$ \\
\hline 1.00 & $\begin{array}{l}-0.19 \\
(1.74)\end{array}$ & 0 & $\begin{array}{l}0.67 \\
(2.87)\end{array}$ & 0 & $\begin{array}{l}-0.26 \\
(0.27)\end{array}$ & $\begin{array}{l}0.37 \\
(1.09)\end{array}$ & $\begin{array}{l}0.44 \\
(1.10)\end{array}$ & $\begin{array}{l}0.31 \\
(0.47)\end{array}$ & $\begin{array}{l}0.02 \\
(0.19)\end{array}$ \\
\hline 0 & 1.00 & $\begin{array}{l}0.36 \\
(0.98)\end{array}$ & 0 & $\begin{array}{l}-1.63 \\
(5.39)\end{array}$ & $\begin{array}{l}-0.36 \\
(0.63)\end{array}$ & $\begin{array}{l}0.16 \\
(1.44)\end{array}$ & $\begin{array}{l}0.06 \\
(1.56)\end{array}$ & $\begin{array}{l}0.15 \\
(1.20)\end{array}$ & $\begin{array}{l}0.22 \\
(0.32)\end{array}$ \\
\hline 0 & 0 & 1.00 & $\begin{array}{l}-0.28 \\
(2.00)\end{array}$ & $\begin{array}{l}0.08 \\
(5.67)\end{array}$ & $\begin{array}{l}0.55 \\
(1.23)\end{array}$ & $\begin{array}{l}-0.63 \\
(1.28)\end{array}$ & $\begin{array}{l}-0.64 \\
(1.41)\end{array}$ & $\begin{array}{l}-0.53 \\
(1.61)\end{array}$ & $\begin{array}{l}-0.14 \\
(0.30)\end{array}$ \\
\hline & $20(-)$ & & $16(-)$ & & $14(-)$ & $9(+)$ & $13(+)$ & $8(+)$ & $13(+)$ \\
\hline & & $18(+)$ & & $22(-)$ & $12(+)$ & $13(+)$ & $10(+)$ & $9(-)$ & $16(+)$ \\
\hline & & & $20(+)$ & $22(-)$ & $11(-)$ & $11(-)$ & $12(-)$ & $10(-)$ & $15(-)$ \\
\hline & $5(-)$ & & $7(-)$ & & $6(-)$ & $3(-)$ & $3(-)$ & $2(+)$ & $3(-)$ \\
\hline & & $4(-)$ & & $7(-)$ & $3(-)$ & $2(+)$ & $6(+)$ & $3(-)$ & $4(+)$ \\
\hline & & & $4(+)$ & $5(-)$ & $4(+)$ & $2(-)$ & $5(-)$ & $4(+)$ & $3(-)$ \\
\hline & $8(+)$ & & $9(-)$ & & $7(-)$ & $5(-)$ & $5(-)$ & $4(-)$ & $7(+)$ \\
\hline & & $6(+)$ & & $10(-)$ & $5(-)$ & $7(-)$ & $6(-)$ & $4(-)$ & $10(+)$ \\
\hline & & & $9(+)$ & $10(-)$ & $6(-)$ & $6(-)$ & $5(+)$ & $5(+)$ & $10(-)$ \\
\hline & $13(-)$ & & $14(+)$ & & $4(-)$ & $9(+)$ & $8(+)$ & $6(+)$ & $11(+)$ \\
\hline & & $11(+)$ & & $13(-)$ & $6(-)$ & $8(+)$ & $9(+)$ & $6(+)$ & $9(+)$ \\
\hline & & & $12(+)$ & $13(+)$ & $7(+)$ & $4(-)$ & $10(-)$ & $5(-)$ & $12(-)$ \\
\hline
\end{tabular}

Mean group estimated cointegration vectors. For each country classification, the first row is the vector for the triplet $\left.{ }_{t}\right)$; the second for the triplet $\left(z r d_{t}, z_{t}, r d_{t}\right)$; and the third for the triplet $\left(z_{t}, g c_{t}, r d_{t}\right)$. The upper block reports the $\left.-\beta_{x_{j}}\right)$; quantities in parentheses below the coefficient are standard deviations. A constant and a trend included (not the cointegrating vector. The lower block reports the number of countries with significant coefficients; in parentheses is $n$ of the effect of the average $-\beta_{x_{j}}$. 
the series in the vector ("zrd", "z", "rd") for the CUCs - the negative sign of the $\beta$-coefficients suggests that the series in the corresponding vectors tend to move in the same direction with the normalized variable over the long-run, as expected.

This positive long-run relation does not hold anymore in other cointegration vectors. We see that the average effects of $\beta_{r d_{t}}$ are adequately signed in most cases, but those of $\beta_{g c_{t}}$ are rather ambiguous. For instance, it bears a negative sign in the first cointegration vector and a positive sign in the third cointegration vector for each of the FRCs, CUCs and STCs, respectively. While in the first case it is consistent with our theory, suggesting a positive long-run association between productivity and government coordination, in the second case it leads to the conclusion that innovation and government coordination move in opposite directions which, in light of our discussion, makes no economic sense. Likewise, the (positive) signs of $\beta_{z_{t}}$ in the second cointegrating vector for FRCs, STCs and LGCs suggest that over the long-run the interaction term and innovation move in opposite directions, which conflicts with the definition of, and the theoretical association between these variables.

Another obvious concern is about the significance of the individual estimates that make up the average. Obviously, the mean group estimates are based on coefficients differing from country to country. Unless one is prepared to make stronger assumptions, this implies that the disturbances, and therefore the variance-covariance matrices in the regressions across individual countries are heterogeneous. Ignoring this heterogeneity generates inconsistent estimates of the coefficient means and their corresponding standard errors. ${ }^{75}$ Of course, heteroscedastic disturbances across individuals implies that the mean group estimates under the Johansen cointegration approach need to be corrected. But the procedure would take us into burdensome issues of matrix algebra that are beyond the scope of this research. ${ }^{76}$

The immediate implication of the problem above is that even though all the coefficients of the individual cointegration vectors are statistically significant, the mean group estimates appear statistically insignificant. In other words, based on the statistics reported in the upper block of Table 5.5 we may be forced to conclude that there are no cointegrating vectors in the aggregate even though the country-by-country regressions show valid cointegrating vectors in all cases. Therefore, instead of relying on the statistical significance of the mean group estimates, we provide a checklist to help the verification of the significance of the individual coefficients across all regressions.

Thus, the lower block of Table 5.5 reports the number of countries that show statistically significant coefficients; additionally, it reports in parentheses

\footnotetext{
${ }^{75}$ Pesaran and Smith 1995, Swamy 1970.

${ }^{76}$ Adequate solutions are not available from standard panel cointegration packages either. Under conventional panel data regression models the solution has been discussed by Swamy 1970; and in the context of panel data cointegration by Pesaran and Smith 1995. Yet, to the best of our knowledge, the panel data cointegration packages on offer are based on the strong assumption of constant variances, zero covariances and the absence of any serial or auto correlation of the disturbances which leads to produce inconsistent estimates.
} 
the direction of the average effect. For instance, we observe that from the 22 countries in the FRCs classification, 20 report significant parameters for the average effect of $\beta_{z r d_{t}} ; 16$ report significant coefficients for the average effect of $\beta_{g c_{t}}$; and 18 report a significant effect for the average trend term. A similar analysis follows for the coefficients in other cointegrating vectors and country classifications.

Based on this information, we can conjecture, not surprisingly, that the estimates in the distinct cointegration vectors turn out to be statistically significant, albeit not systematically nor for all countries. To give a glimpse into this feature of our results, note from Table 5.4 that for Hong Kong $\beta_{z r d_{t}}$ is significant and the trend-coefficient is nonsignificant in the first cointegration vector, whilst for Israel the results for the same coefficients are the other way about. This, however, is not necessarily a problem for evaluating the 'creditworthiness' of the mean group estimates. Back to the information reported in the lower block of Table 5.5, notice that the most meaningful cointegration vectors, in terms of their sign and statistical significance, still arise in the first cointegration vector for the FRCs and the CUCs, and the second cointegration vector for the CUCs.

The same reasoning applies in assessing the impact of the short-run adjustment coefficients. We see that only 14 out of 22 FRCs report significant coefficients in the first cointegrating vector (with an average negative impact); and the numbers are 12 and 11 for the second and third vectors, respectively. As we discussed earlier, nonsignificant coefficients may reveal evidence of true short-run exogeneity, but they may also be an indication of near-linear dependencies and/or measurement errors.

For instance, though the results are not shown in the table, we have found that for 12 out of the 22 FRCs government coordination seems to be fully unrelated with long-run disequilibria (i.e., the $\alpha$-coefficients are insignificant in the equation for $\Delta_{g c_{t}}$ ), which is consistent with our expectations of $g c_{t}$ being weakly exogenous. However, 6 countries show that productivity is fully unrelated with long-run disequilibria; and 7 countries show that that is the case for innovation which, at least partly, conflicts with our expectations that these variables are endogenous in the system; though, of course, we know that they still may be affected by $\beta$-coefficients and other than the $\alpha$-coefficients in the short-run.

All in all, it is worth noting that despite having the same kind of estimation problems that were discussed earlier, the mean group estimates in Table 5.5 support our hypotheses according to which the most meaningful cointegration relationships do hold for the triplets ("a", "zrd", "gc") and ("zrd", "z", "rd") for the FRCs and the CUCs, and not necessarily for the STCs and the LGCs. Before turning to more general conclusions, next we present a comparison of the average impulse-response functions over each country classification. To this end, we rely on restricted estimates (imposing exclusion restrictions on non significant long-run coefficients in the regressions country-by-country) and focus on the overall median response functions, which seems reasonable to deal with the difficulties posed by extreme positive or negative values.

Before proceeding, notice that one of the implications of the wide variance in the empirical distribution of the impulse-response functions is that we cannot 
point to the statistical significance of the differences in the comparison of the median values across the distinct country classifications. Hence, our comparison applies only to the magnitude and direction of these differences.

In Figure 5.5. We use again solid lines to depict the values obtained previously for the CUCs (except for the scaling these are the same as in Figure 5.4). The response functions for other country classifications are portrayed as follows: we use dotted lines for the FRCs, long-dashed lines for the STCs and dash-dotted lines for the LGCs.

From Figure 5.5, we observe that the median response functions are generally quite small. Yet, the responses computed for the CUCs are typically higher than for other classifications. The notable exception is the high positive median response to a shock hitting innovation $(z \rightarrow a)$ in the LGCs countries which, in line with our definition of innovation in Section 5.3, may be plausible as many LGCs countries may have adopted strategies that gradually changed labor from routine to cognitive non-routine working occupations.

The lower level of the LGCs' responses to shocks hitting other variables may explain why these countries have been mostly lagging over time. For instance, the negative pattern in the response to shocks hitting the interaction term suggests a limitation of the LGCs to combine (local) innovation capacities with existing technology trajectories. Such an argument is consistent with the comparatively negligible value of the median response function in these countries to shocks hitting foreign technology $(r d \rightarrow a)$.

Although seemingly puzzling, the mostly negative - but virtually zeroresponses obtained for the FRCs are not (completely) implausible. First, we observe that the median response of the FRCs to shocks hitting the interaction term is positive, which provides supporting evidence for our hypothesis in this regard. The result that the FRCs' function lies here below the CUCs' is also consistent with the expectation that, by combining (local) innovation capacities and foreign technology, the CUCs would have drawn higher benefits than other countries in the catching up process. In turn, the slightly negative patterns observed for the response of the FRCs to shocks hitting other variables may be taken as an indication that many (narrowly more than half of) countries at the frontier technology can gradually derive less and less benefits of their already high levels of technology, innovation capacity and government coordination. In fact, it is possible that for FRCs countries a shock hitting foreign technology represents more of a strategic risk than an opportunity (e.g., more intense market competition). Finally, the median values corresponding to the responses obtained for the STCs seem also reasonable. The negative pattern observed in the case of impulses hitting the interaction term suggests that these countries have mostly failed to combine (local) innovation capacities with the diffusion of foreign technology. And this would have been the case even if STCs countries could achieve benefits at first impact from shocks hitting foreign technology, as we can infer from the response pattern in the scenario $(r d \rightarrow a)$.

The negative response to a shock hitting innovation $(z \rightarrow a)$, and the fact that a shock hitting government coordination $(g c \rightarrow a)$ has only a mild positive effect at impact may altogether explain, at least partially, why the STCs 

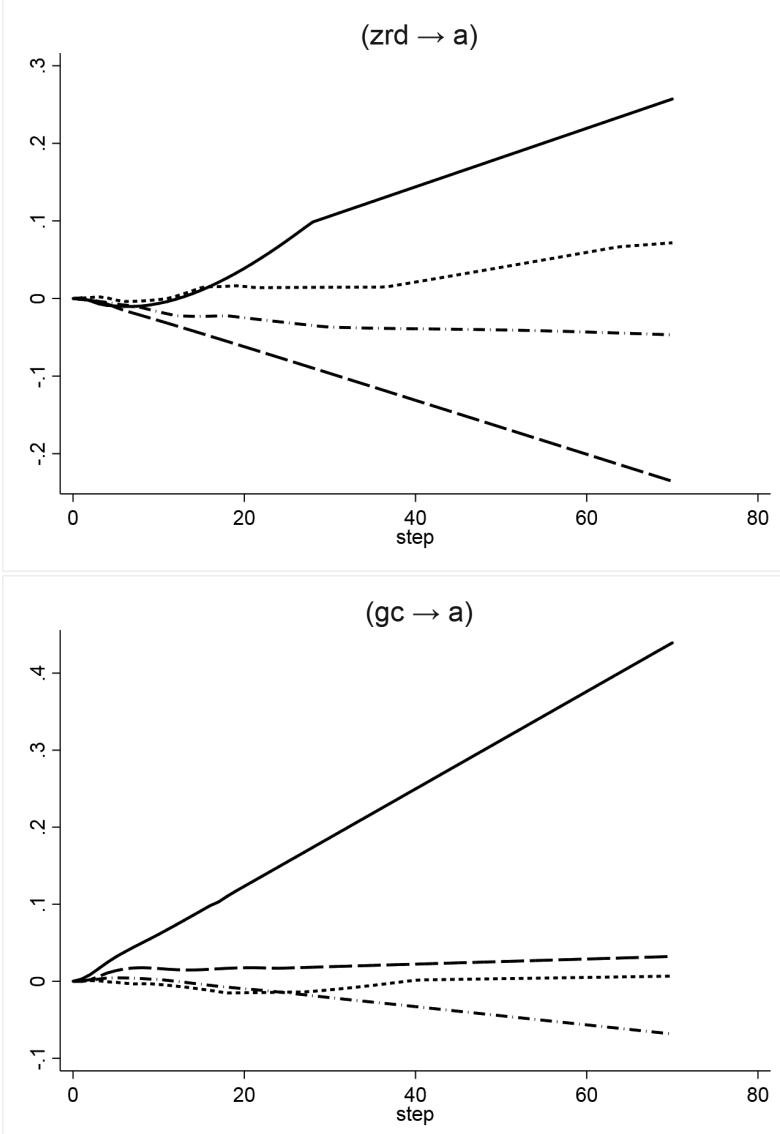
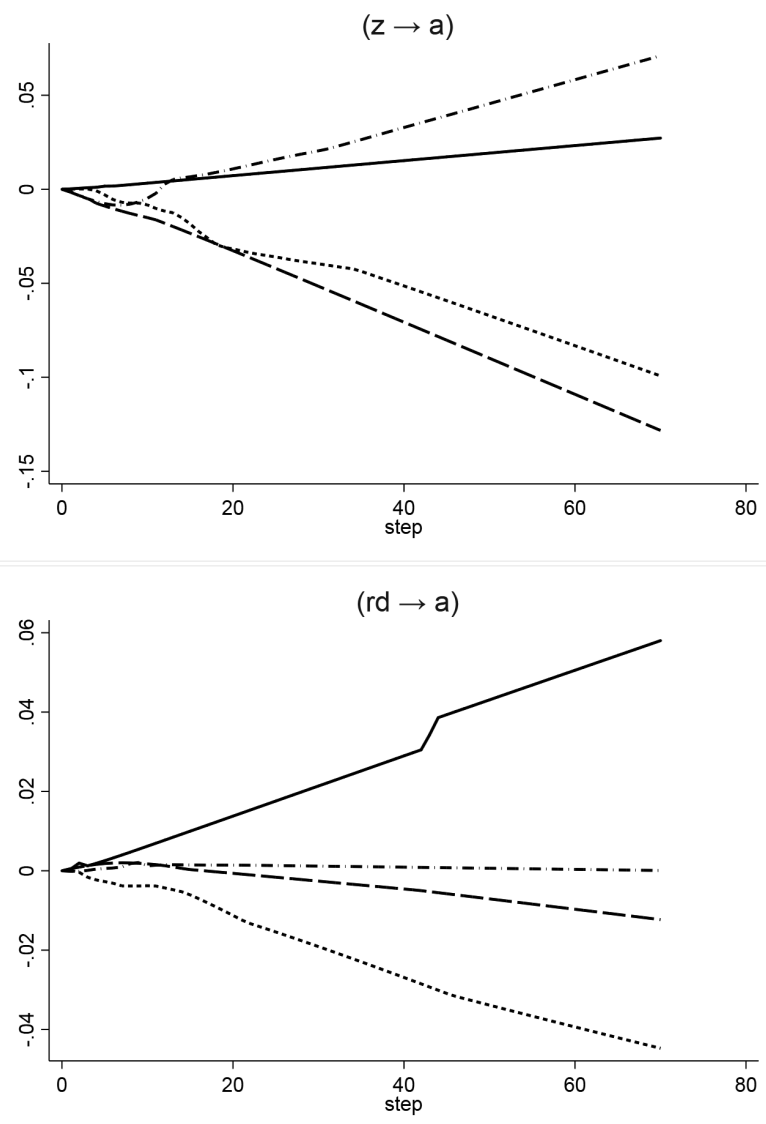

Figure 5.6: Long-run multipliers: overall median response values of the long-run productivity effects (over a horizon of 70-years). The response functions measure the accumulated orthogonalized impulseresponse of productivity to a unit standard deviation shock on each of the other variables. The median of the distribution is computed period-by-period. In each case, the solid lines represent the CUCs, the dotted lines the FRCs, the long-dashed lines the STCs and the dashed-dotted lines the LGCs. 
countries have been less successful in catching up. In line with our definition of innovation, STCs, like other countries in our analysis, are characterized by an increasing transition from routine to cognitive non-routine working occupations. But though well-educated workers are expected to contribute more to productivity growth, a necessary condition in this context is that the workers' qualifications correspond to the needs of the economy. A problem faced by many both backward and frontier countries is the mismatch between workers' preparation and the needs of the economy. ${ }^{77}$ Hence, it may be that even with some changes in the right direction (e.g., government coordination) this mismatch is a major problem featured by STCs.

The so-called long-run multiplier effects or accumulated impulse-response functions for the system are shown in Figure 5.6. ${ }^{78}$ Again, we concentrate on the median of the distribution of the responses of productivity to one standard deviation shocks on each other variable, but these responses are now accumulated over a period of 70 years.

From Figure 5.6, we observe that the accumulated effects are consistent with the patterns depicted earlier (see Figure 5.5), namely the responses of the CUCs are generally larger than in any other country classification; the exception to this general pattern is still related to the high response values to the impulse running from innovation in LGCs countries.

Also, we observe that the impact of the impulse hitting the interaction term $(z r d \rightarrow a)$ is higher than the impacts of impulses hitting individually either innovation $(z \rightarrow a)$ or foreign technology $(r \rightarrow a)$; and this result is particularly strong in the cases of the CUCs and FRCs classifications. Once again, this supports our view that for these two groups the interaction term has a larger impact than each of its individual elements.

Other results that were discussed earlier become visible in Figure 5.6 as well. For instance, the (accumulated) response of the FRCs to a shock hitting government coordination $(g c \rightarrow a)$ is slightly negative and then tapers off to zero suggesting that over the long-run the FRCs countries apparently derive less and less benefits of their already high levels of government coordination. In turn, the negative trend in the response of the FRCs to a shock on foreign technology reinforces our interpretation that for these countries a shock on foreign technology may represent mostly a stronger competition risk by technological advances from other advanced economies.

In the case of the LGCs countries, we see high response values to the impact running from innovation $(z \rightarrow a)$, but the response to the impact running from foreign technology $(r d \rightarrow a)$ is practically negligible. Together, these effects explain the slightly negative response in LGCs countries to shocks hitting the interaction term $(z r d \rightarrow a)$. Moreover, in light of the negative response to impulses on government coordination $(g c \rightarrow a)$, these results lead us to infer that the main limitation of the LGCs countries to catching up has been the lack

\footnotetext{
${ }^{77}$ Cedefop 2012, Inter-American Development Bank 2012.

${ }^{78}$ The long-run effects or accumulated impulse-response functions are obtained by summing up the effects over the period of analysis (here 70 years) of a shock in one variable (Lutkepohl 2005).
} 
of a coherent innovation system.

A similar conclusion holds, though for different reasons and to somewhat larger extent, for the STCs countries. In this case we observe slight (accumulated) positive responses to shocks hitting government coordination and foreign technology (at impact); but large negative responses to innovation and the interaction term. This lead us to conclude that unlike the CUCs and the FRCs, and mostly in line with the results of the LGCs, the main problem of the STCs countries to catching up is that they lack a coherent innovation system.

In summary, it seems fair to reckon that in spite of data and technical limitations that we have duly acknowledged, we have found empirical evidence to support our propositions at the outset, namely that there is a structural positive long-run relationship between the interaction term and productivity; and a structural positive long-run relationship between government coordination and productivity. In addition, it is worth pointing that the results that we have found seem to confirm our expectation that these structural associations are more likely to emerge in the case of the CUCs and FRCs than in the case of the STCs and LGCs countries.

These findings seem also to support the idea found in numerous studies that government discrete interventions in order to coordinate the whole system of innovation has been widespread in many frontier countries and countries that have been catching up with them - noticeably, by combining local (innovation) and foreign technology. ${ }^{79}$ Of course, one would not expect to observe a high degree of intervention in all cases, nor would a meaningful long-run relationship necessarily show up systematically in every country.

Consider, for instance, that most of the literature just referenced has concentrated on the experiences of a number of South East Asian countries with strong interventionist governments, namely China, Japan, South Korea and Singapore; or they have pointed on what is seen as considerable government involvement in promoting innovation in, namely, Denmark, Finland, Sweden and other Nordic countries. While the computed results of the long-run impacts in our analysis are strongly confirmatory of those views, there are many other cases where the expected association does not show up, namely Hong Kong, Ireland, the Netherlands, Norway. Also, we do not observe, as would be expected, a strong role for government coordination in the innovation and productivity achievements of many frontier countries: the USA, and the UK, are key examples where such interventions have been documented, ${ }^{80}$ yet they failed to show up in the data.

Likewise, we do not observe that in all cases the interaction term has a more substantial impact than any of its individual components. For some catching up countries that does seem to be the case, namely Indonesia, Malaysia, Singapore and Thailand, but for many others it does not. For instance, for China, Hong Kong and Israel, innovation alone appears to be much more important than

\footnotetext{
${ }^{79}$ Kim 1980, 1993, Freeman 1987, Nelson 1993, Page 1994, Wade 1996, 2009, Hall and Soskice 2003, Rodrik 2005, Mohnen et al., 2006, Breznitz 2007, Lin et al., 2011, Lee 2013. See Acemoglu et al., 2012, Stiglitz 2014 for a debate. See also Prashad 2013 for a provoking discussion.

${ }^{80}$ Cohen 2010, Mazzucato 2013.
} 
foreign technology - alone or combined with innovation. Similarly, for some frontier countries, namely Australia, Austria, Belgium, Finland, the Netherlands, Norway, Spain, the UK, the interaction term has the most influence; but for the USA, Japan, and Italy, it is innovation.

However, as we have discussed, the fact that the expected structural cointegration relationships fail to show up systematically does not invalidate the statistical support for the hypotheses that we set out to test. While considerable attention is needed to improve the quality of the data before we can resort to valid generalizations, our focus on the entire distribution rather than on individual country-by-country cases provides useful empirical evidence that supports the relevance of our theory. In other words, our approach provides a valuable indication that the main propositions in regard with the NIS framework that we put forward in our theoretical discussion, hold for a number of countries that include both those already at the frontier and those that have been catching up.

\subsection{Concluding Remarks}

In order to investigate the relationship between technology diffusion, innovation and the ability of countries to catch-up; and also to assess econometrically the contrasting claims between the mainstream and the evolutionary and NIS theories in this regard, we set our research to determine whether over the long-run the economic performance of countries, measured by the rate of growth of productivity, hinges mostly on foreign technology, as the mainstream holds, or on the interaction between (local) innovation and foreign technology, as evolutionary economists hold. Further, we also set our research to assess whether the structural relationship between these variables (productivity, foreign technology and innovation) is influenced positively, as expected, by the government through the enforcement of the NIS system.

We have found two main results that support our theoretical reasoning and the predictions of the hypotheses raised at the outset. The first is the evidence of a structural long-run association between productivity and the interaction of (local) innovation with foreign technology, which we have found is more feasible in the case of successful cases of catching-up.

This result confirms the hypothesis that the interaction between (local) innovation and foreign technology should have a larger long-run growth impact than when each of these components is taken in isolation. More noticeable, it is consistent with our theoretical discussion and implies that, instead of "automatic", the growth effects of foreign technology are realized only when they are combined with the learning and assimilation aspects that feature prominently in the evolutionary view of innovation. In the context of our measurement of this complex concept, using the share of workers devoted to cognitive non-routine activities as a proxy for innovation, this means that the growth effects of technology inflows are realized only when there is a substantial amount of workers able to convey the information, commercial opportunities, new directions and 
combinations, and areas of improvement related to the new technology.

Our result is therefore in stark contrast with earlier evidence that productivity in countries off the frontier hinges overall on foreign technology; ${ }^{81}$ and, in more general terms, our result contradicts the mainstream tenet that it is primarily the ability to adopt/imitate the technology of the most advanced countries which appears to increase the potential of less developed countries to catch-up. ${ }^{82}$

The second important result is the evidence of a positive long-run relationship between government coordination and (local) innovation, which again we have found is more likely to show up in the case of successful cases of catching up. In the context of our research, using a synthetic indicator to capture a variety of market and non market contextual conditions, this result confirms our hypothesis that there is an structural association between the ability of the government to coordinate the innovation system and the long-run growth performance of the economy.

This means that, if governments want to enhance the process of economic growth, conventional market institutions (property rights), stabilization policies (fiscal and monetary), and price incentives (taxes, subsidies) would be more probably insufficient to provide the right environment and boost innovation activities. Therefore, governments should pursue innovation strategies and policies that place more emphasis on the organization of the whole innovation system, including all market and non market mechanisms that influence the structure and functioning of business innovation activities.

The policy relevance of the evidence we have been able to glean seems obvious. As we have seen, taken together the impact of government coordination and the impact of the interaction of (local) innovation with foreign technology on productivity, these are mostly associated with countries that stand as successful cases of catching-up, and also with countries that are already at the frontier. This implies that there are substantial areas of improvement in this regard for countries that remain stagnant and those that have kept lagging behind. Of course, choosing the appropriate strategies and policy instruments in order to boost innovation, increase growth and achieve higher levels of income shall depend on a detail analysis of the economic and other contextual conditions that are specific to each country.

We have already noted in our methodological discussion why considerable attention is needed to improve the quality of the data before we can resort to valid generalizations. However, it is worth emphasizing that our empirical approach and our results provide suggestive evidence to support our theory according to which innovation, broadly defined, is the true engine of long-run growth and the whole process hinges critically and positively on the ability of the government to lead the national system of innovation.

\footnotetext{
${ }^{81}$ Coe and Helpman 1995, Coe, Helpman and Hoffmaister 1995, Keller 2002, 2004.

${ }^{82}$ Romer 1993, Spence 2011.
} 


\section{Appendix 5A: Local innovation}

The basic statistics with regard the International Standard Classification of Occupations (ISCO) is provided by the International labor Organization (ILO). The aim of this classification is to organize jobs into a defined set of groups according to the tasks and duties undertaken by workers. There are four versions of the classification: ISCO-58 (released 1958), ISCO-68 (1968), ISCO-88 (1988), and ISCO-08 (2008). Classification changes are addressed in correspondence tables that are released with each subsequent version.

The following table shows the standard classification of working activities under the ISCO methodology. The last column shows the classification of working categories in this chapter. Non-routine activities are considered to be the source of innovation. We construct our database with information from var-

\begin{tabular}{lll}
\hline & ISCO Working activities & Category \\
\hline 1 & Legislators, senior officials and managers & Non-routine \\
2 & Professionals & Non-routine \\
3 & Technicians and associate professionals & Non-routine \\
\hline 4 & Clerks & Routine \\
5 & Service workers and shop and market sales workers & Routine \\
6 & Skilled agricultural and fishery workers & Routine \\
7 & Craft and related trade workers & Routine \\
8 & Plant and machine operators and assemblers & Routine \\
9 & Elementary occupations & \\
\hline
\end{tabular}

Table 5A.1: Classification of ISCO working activities. The first two columns show the classification of working activities according to the International Standard Classification of Occupations. The last columns shows the classification in this thesis.

Source: International Labor Organization, Author.

ious sources. In particular, the ILO database provides the required data for many countries. This has been supplemented with further sources, namely, the United Nations Organization (UNO), the Economic Commission for Latin America and the Caribbean (ECLAC), the Asian Productivity Organization databases (APO), and several country specific databases. ${ }^{83}$

Our database is constructed by taking the share of each working category with respect to the total. We obtain a consolidated data set by filling in the missing data with linear interpolation provided there are not more that 5 blanks in between non-missing data points. We also projected some values provided the extrapolation involves less than 4 points. The list of countries, first/last years with observations, and total data points (excluding interpolated values), are shown below for each of the FRCs, CUCs, STCs, and LGCs classifications.

\footnotetext{
${ }^{83} \mathrm{http}$ ///aborsta.ilo.org/ Total and economically active population and employment by occupation; http://unstats.un.org/unsd/demographic/products/dyb/dyb_Eco/dyb_eco.htm Table 5 - Employed population by occupation (ISCO), age and sex: 1995 - 2014; http://interwp.cepal.org/anuario_estadistico/anuario_2014/en/index.asp Structure of the urban employed population by occupational group In accordance with the International Standard Classification of Occupations (ISCO, 1988) of ILO. http://www.apotokyo.org/wedo/measurement APO Productivity Database 2014 Version 2 (xlsx) [Updated 31 January 2015]
} 


\begin{tabular}{|c|c|c|c|c|}
\hline & country & $\begin{array}{l}\text { First } \\
\text { Obs. }\end{array}$ & $\begin{array}{l}\text { Last } \\
\text { Obs. }\end{array}$ & Total Obs. \\
\hline & FRCs Countries & & & \\
\hline 1 & France & 1962 & 2008 & 47 \\
\hline 2 & Belgium & 1961 & 2008 & 48 \\
\hline 3 & Germany & 1961 & 2008 & 48 \\
\hline 4 & Greece & 1961 & 2008 & 48 \\
\hline 5 & Switzerland & 1961 & 2008 & 48 \\
\hline 6 & United Kingdom & 1961 & 2008 & 48 \\
\hline 7 & Denmark & 1960 & 2008 & 49 \\
\hline 8 & Netherlands & 1960 & 2008 & 49 \\
\hline 9 & Norway & 1960 & 2008 & 49 \\
\hline 10 & Sweden & 1960 & 2008 & 49 \\
\hline 11 & United States & 1960 & 2008 & 49 \\
\hline 12 & Australia & 1961 & 2011 & 51 \\
\hline 13 & Finland & 1960 & 2010 & 51 \\
\hline 14 & Ireland & 1961 & 2011 & 51 \\
\hline 15 & Luxembourg & 1960 & 2010 & 51 \\
\hline 16 & Portugal & 1960 & 2011 & 52 \\
\hline 17 & Spain & 1960 & 2011 & 52 \\
\hline 18 & Turkey & 1960 & 2011 & 52 \\
\hline 19 & Austria & 1951 & 2008 & 58 \\
\hline 20 & Italy & 1951 & 2008 & 58 \\
\hline 21 & New Zealand & 1951 & 2008 & 58 \\
\hline 22 & Iceland & 1950 & 2008 & 59 \\
\hline 23 & Canada & 1951 & 2011 & 61 \\
\hline \multirow[t]{2}{*}{24} & Japan & 1950 & 2010 & 61 \\
\hline & CUCs Countries & & & \\
\hline 1 & China & 1982 & 2010 & 29 \\
\hline 2 & Antigua and Barbuda & 1970 & 2001 & 32 \\
\hline 3 & Maldives & 1977 & 2008 & 32 \\
\hline 4 & St.Vincent \& Grenadines & 1960 & 1991 & 32 \\
\hline 5 & Tunisia & 1966 & 1997 & 32 \\
\hline 6 & Malaysia & 1975 & 2008 & 34 \\
\hline 7 & Indonesia & 1976 & 2010 & 35 \\
\hline 8 & Hong Kong & 1976 & 2011 & 36 \\
\hline 9 & Egypt & 1971 & 2007 & 37 \\
\hline 10 & Singapore & 1974 & 2010 & 37 \\
\hline 11 & Grenada & 1960 & 1998 & 39 \\
\hline 12 & Israel & 1970 & 2008 & 39 \\
\hline 13 & Thailand & 1971 & 2010 & 40 \\
\hline 14 & Dominica & 1960 & 2001 & 42 \\
\hline 15 & Romania & 1966 & 2008 & 43 \\
\hline 16 & Botswana & 1964 & 2008 & 45 \\
\hline 17 & Cyprus & 1960 & 2011 & 52 \\
\hline 18 & Macao & 1960 & 2011 & 52 \\
\hline 19 & Malta & 1957 & 2008 & 52 \\
\hline 20 & Korea, Republic of & 1955 & 2007 & 53 \\
\hline
\end{tabular}

Table 5A.2: Local Innovation Data Availability. We show the first and last year with data. The last column shows the number of years with non-missing values. Source: Author based on UNIDOINDSTAT4 - 2014 edition. 


\begin{tabular}{|c|c|c|c|c|}
\hline & country & $\begin{array}{l}\text { First } \\
\text { Obs. }\end{array}$ & $\begin{array}{l}\text { Last } \\
\text { Obs. }\end{array}$ & Total Obs. \\
\hline & STCs Countries & & & \\
\hline 1 & Lesotho & 1976 & 2006 & 31 \\
\hline 2 & Pakistan & 1972 & 2008 & 37 \\
\hline 3 & Syria & 1970 & 2007 & 38 \\
\hline 4 & Poland & 1970 & 2008 & 39 \\
\hline 5 & Panama & 1974 & 2013 & 40 \\
\hline 6 & Brazil & 1970 & 2010 & 41 \\
\hline 7 & Chile & 1970 & 2011 & 42 \\
\hline 8 & Fiji & 1956 & 2007 & 44 \\
\hline 9 & St. Lucia & 1960 & 2004 & 45 \\
\hline 10 & Belize & 1960 & 2005 & 46 \\
\hline 11 & Bulgaria & 1965 & 2011 & 47 \\
\hline 12 & Cambodia & 1962 & 2008 & 47 \\
\hline 13 & Morocco & 1960 & 2008 & 49 \\
\hline 14 & Trinidad \& Tobago & 1960 & 2008 & 49 \\
\hline 15 & Mauritius & 1962 & 2011 & 50 \\
\hline 16 & Costa Rica & 1963 & 2013 & 51 \\
\hline 17 & India & 1961 & 2011 & 51 \\
\hline 18 & Hungary & 1960 & 2011 & 52 \\
\hline 19 & Sri Lanka & 1953 & 2008 & 56 \\
\hline \multirow[t]{2}{*}{20} & Dominican Republic & 1950 & 2013 & 64 \\
\hline & LGCs Countries & & & \\
\hline 1 & Cote d'Ivoire & 1978 & 2008 & 11 \\
\hline 2 & Namibia & 1981 & 2006 & 11 \\
\hline 3 & Burundi & 1979 & 2006 & 12 \\
\hline 4 & Uganda & 1981 & 2007 & 12 \\
\hline 5 & Central African Republic & 1975 & 2007 & 14 \\
\hline 6 & Jordan & 1961 & 2006 & 19 \\
\hline 7 & Rwanda & 1978 & 2006 & 19 \\
\hline 8 & Iraq & 1977 & 2007 & 21 \\
\hline 9 & Zimbabwe & 1982 & 2006 & 21 \\
\hline 10 & Liberia & 1962 & 2006 & 23 \\
\hline 11 & Ethiopia & 1981 & 2006 & 26 \\
\hline 12 & Bolivia & 1976 & 2011 & 36 \\
\hline 13 & Malawi & 1977 & 2013 & 37 \\
\hline 14 & Lebanon & 1970 & 2007 & 38 \\
\hline 15 & Philippines & 1971 & 2008 & 38 \\
\hline 16 & Suriname & 1964 & 2007 & 41 \\
\hline 17 & Sierra Leone & 1963 & 2007 & 42 \\
\hline 18 & Zambia & 1969 & 2010 & 42 \\
\hline 19 & Bangladesh & 1961 & 2006 & 45 \\
\hline 20 & Honduras & 1961 & 2006 & 45 \\
\hline 21 & Argentina & 1960 & 2006 & 47 \\
\hline 22 & Nigeria & 1963 & 2009 & 47 \\
\hline 23 & Mexico & 1960 & 2008 & 49 \\
\hline 24 & South Africa & 1960 & 2008 & 49 \\
\hline 25 & Ghana & 1960 & 2010 & 51 \\
\hline 26 & Nepal & 1961 & 2011 & 51 \\
\hline 27 & Uruguay & 1963 & 2013 & 51 \\
\hline 28 & Ecuador & 1962 & 2013 & 52 \\
\hline 29 & Jamaica & 1960 & 2011 & 52 \\
\hline 30 & Paraguay & 1962 & 2013 & 52 \\
\hline 31 & El Salvador & 1961 & 2013 & 53 \\
\hline 32 & Peru & 1961 & 2013 & 53 \\
\hline 33 & Iran & 1956 & 2011 & 56 \\
\hline 34 & Guatemala & 1950 & 2006 & 57 \\
\hline 35 & Colombia & 1951 & 2008 & 58 \\
\hline
\end{tabular}

Table 5A.3: Local Innovation Data Availability. We show the first and last year with data. The last column shows the number of years with non-missing values 16 Source: Author based on UNIDOINDSTAT4 - 2014 edition. 


\section{Appendix 5B: Government Coordination}

To construct our index, we use measures of labor productivity through all manufacturing sectors according to the ISIC-Rev3 (Excluding recycling activities). The following table presents a glimpse on how so-called Low and Medium Tech sectors/activities (LMT), and High-tech sectors/activities (HT) are distributed across industries.

\begin{tabular}{llll}
\hline & Industry name (ISIC-Rev3) & Classification & High-Tech activities \\
\hline 15 & Food and beverages & LMT & \\
16 & Tobacco products & LMT & \\
17 & Textiles & LMT & \\
18 & Wearing apparel, fur & LMT & \\
19 & Leather, leather products and footwear & LMT & \\
20 & Wood products (excluding furniture) & LMT & \\
21 & Paper and paper products & LMT & \\
22 & Printing and publishing & LMT & \\
23 & Coke, ref. petroleum prod. nuclear fuel & LMT & Pharma/cals, Biotech, nanotech \\
24 & Chemicals and chemical products & HT & \\
25 & Rubber and plastics products & LMT & \\
26 & Non-metallic mineral products & LMT & \\
27 & Basic metals & LMT & \\
28 & Fabricated metal products & LMT & \\
29 & Machinery and equipment n.e.c. & HT & nanoelectronics \\
30 & Office, accounting and computing mach. & HT & ICT \\
31 & Electrical machinery and apparatus & HT & nanomedicine \\
32 & Radio, television and communication eq. & HT & \\
33 & Medical, precision and optical inst. & HT & Aircraft \& spacecraft \\
34 & Motor vehicles, trailers, semi-trailers & HT & \\
35 & Other transport equipment & HT & LMT \\
36 & Furniture; manufacturing n.e.c. & & \\
\hline
\end{tabular}

Table 5B.1: Technology classifications for the manufacturing sector. Classification based on the OECD standards. HT stands for High-Tech sectors and activities. LMT stands for Low and Medium Technology activities.

The United Nations Industrial Development Organization dataset (UNIDOINDSTAT4 ISIC-Rev3), provides the basic statistics for our calculations. These are figures of value added and number of employees which allow us to calculate the productivity per worker for each industrial sector in each country with information. Value added figures are adjusted using the bilateral PPP convertion ratios of each country with the USA that are calculated in the PWT V.8.0 ${ }^{84}$

The INDSTAT4 database presents availability and accuracy problems that affect the reliability of productivity figures across sectors and countries, namely missing data and/or sudden and extreme changes in the reported value added and number of employees that form the basis of the calculation.

Our approach to address these difficulties in systematic. ${ }^{85}$ First, we smooth each sector series by calculating 5 years centered moving averages using non-

\footnotetext{
${ }^{84}$ We use the variable "pl_gdpo" which gives the price level of each country's current GDP (output-side) relative to the price of the same variable in the USA, with base year $2005=1$ (See Feenstra et al., 2015)

${ }^{85}$ The large number of countries and economic sectors in the database prevents us from a specific analysis of the series for individual countries.
} 
missing values; second, we fill in the missing values using linear interpolation between non-missing data points. We also projected some values provided the extrapolation involves less than 4 years. Unfortunately, our approach affects the statistical properties of the data. In particular it may lead to underestimate some statistics (standard errors) and overestimate others (p-values). Whilst we warn the reader upon the accuracy/reliability of our dataset, and the need for further research in this regard, we do think that our productivity calculations are still useful to study the long-run dynamics we deal with in our regression approach. We actually think that this information is good enough for determining the overall direction of productivity in each sector and country under analysis.

The list of countries, first/last years with observations, and total data points (excluding interpolated values), are shown below for each of the FRCs, CUCs, STCs, and LGCs classifications. 


\begin{tabular}{|c|c|c|c|c|c|}
\hline & country & $\begin{array}{l}\text { First } \\
\text { Obs. }\end{array}$ & $\begin{array}{l}\text { Last } \\
\text { Obs. }\end{array}$ & Total Obs. & Sectors \\
\hline & FRCs Countries & & & & \\
\hline 1 & New Zealand & 1963 & 2010 & 37 & 18 \\
\hline 2 & Germany & 1963 & 2010 & 41 & 18 \\
\hline 3 & Greece & 1963 & 2007 & 41 & 18 \\
\hline 4 & Australia & 1963 & 2011 & 42 & 22 \\
\hline 5 & United Kingdom & 1963 & 2010 & 43 & 18 \\
\hline 6 & Italy & 1967 & 2010 & 44 & 18 \\
\hline 7 & United States & 1963 & 2008 & 44 & 18 \\
\hline 8 & Belgium & 1963 & 2010 & 45 & 18 \\
\hline 9 & Denmark & 1963 & 2010 & 45 & 18 \\
\hline 10 & Portugal & 1963 & 2010 & 46 & 17 \\
\hline 11 & France & 1963 & 2010 & 47 & 18 \\
\hline 12 & Netherlands & 1963 & 2010 & 47 & 18 \\
\hline 13 & Turkey & 1963 & 2009 & 47 & 18 \\
\hline 14 & Japan & 1963 & 2010 & 48 & 17 \\
\hline 15 & Finland & 1963 & 2010 & 48 & 18 \\
\hline 16 & Norway & 1963 & 2010 & 48 & 18 \\
\hline 17 & Spain & 1963 & 2010 & 48 & 18 \\
\hline 18 & Sweden & 1963 & 2010 & 48 & 18 \\
\hline 19 & Austria & 1963 & 2010 & 48 & 21 \\
\hline 20 & Ireland & 1963 & 2010 & 48 & 22 \\
\hline \multirow[t]{2}{*}{21} & Canada & 1963 & 2011 & 49 & 18 \\
\hline & CUCs Countries & & & & \\
\hline 1 & Thailand & 1968 & 2006 & 22 & 18 \\
\hline 2 & Botswana & 1981 & 2011 & 25 & 2 \\
\hline 3 & Taiwan & 1973 & 2006 & 26 & 18 \\
\hline 4 & China & 1980 & 2007 & 28 & 18 \\
\hline 5 & Tunisia & 1963 & 2007 & 30 & 18 \\
\hline 6 & Macao & 1978 & 2011 & 34 & 16 \\
\hline 7 & Hong Kong & 1973 & 2011 & 39 & 17 \\
\hline 8 & Egypt & 1964 & 2010 & 40 & 18 \\
\hline 9 & Indonesia & 1970 & 2011 & 41 & 17 \\
\hline 10 & Malaysia & 1968 & 2010 & 42 & 18 \\
\hline 11 & Malta & 1963 & 2009 & 45 & 16 \\
\hline 12 & Israel & 1963 & 2010 & 47 & 16 \\
\hline 13 & Korea, Republic of & 1963 & 2010 & 48 & 18 \\
\hline 14 & Cyprus & 1963 & 2011 & 49 & 17 \\
\hline \multirow[t]{2}{*}{15} & Singapore & 1963 & 2011 & 49 & 18 \\
\hline & STCs Countries & & & & \\
\hline 1 & Morocco & 1976 & 2011 & 31 & 18 \\
\hline 2 & Pakistan & 1963 & 2006 & 32 & 18 \\
\hline 3 & Sri Lanka & 1966 & 2010 & 34 & 18 \\
\hline 4 & Fiji & 1968 & 2011 & 36 & 14 \\
\hline 5 & Syria & 1963 & 2005 & 37 & 9 \\
\hline 6 & Hungary & 1970 & 2010 & 39 & 18 \\
\hline 7 & Poland & 1970 & 2011 & 41 & 18 \\
\hline 8 & Mauritius & 1968 & 2011 & 44 & 17 \\
\hline 9 & Chile & 1963 & 2008 & 46 & 18 \\
\hline \multirow[t]{2}{*}{10} & India & 1963 & 2010 & 48 & 18 \\
\hline & LGCs Countries & & & & \\
\hline 1 & Iraq & 1970 & 2011 & 19 & 18 \\
\hline 2 & Burundi & 1971 & 2010 & 21 & 7 \\
\hline 3 & Madagascar & 1967 & 2006 & 26 & 12 \\
\hline 4 & Bangladesh & 1967 & 2006 & 29 & 18 \\
\hline 5 & Ecuador & 1963 & 2008 & 46 & 18 \\
\hline 6 & Jordan & 1963 & 2011 & 46 & 18 \\
\hline 7 & Iran & 1963 & 2010 & 47 & 18 \\
\hline 8 & Colombia & 1963 & 2011 & 49 & 18 \\
\hline
\end{tabular}

\section{0}

Table 5B.2: Government Coordination Data Availability. We show the first and last year with data. "Total Obs." shows the number of years with non-missing data. The last column shows the number of sectors. Source UNIDO-INDSTAT4-2014 edition. 


\section{Chapter 6}

\section{Conclusion.}

\subsection{Contributions.}

This thesis has built upon the premise that the contesting views upon the economics of technology diffusion and innovation that are underlined by the mainstream growth economics, on one side, and the evolutionary and NIS frameworks, on the other, makes it difficult to think seriously upon what are the true determinants of growth and catching-up in backward countries. That is because having equally feasible yet incompatible conceptual frameworks makes it hard to clearly distinguish the substantive factors that really matter, or to reconcile the theory with the stylized facts of reality. And the uncertainty, in turn, makes harder the design an implementation of sound economic policies in order to influence long-run objectives.

Therefore, our main endeavor throughout was to provide a bridge between these theoretical approaches. We engaged in the development of an alternative analytical framework better able to account for the empirical evidence and to explain in a more consistent fashion both the technology aspects that matter the most with a focus on the long-run and the proper role of government in this regard.

To reach this core objective, we revisited in Chapter 2 the observed major trends in economic growth and catching-up patterns across-countries since the mid-twentieth century. Based on these empirical observations, we proposed a classification of countries between those that are already at the frontier of income and technology (FRCs); those that might be considered successful cases of catching-up (CUCs); those that have evidently remained stagnant over long periods of time (STCs); and, finally, those that might be referred to as laggard in the sense that they have kept falling further and further behind over time (LGCs). We proposed also a simple mathematical formula to show that only the CUCs exhibit feasible time frames to close the income gap with the frontier (between 9 and 54 years). By contrast, countries in the STCs classification are between 38-191 years short of the frontier; and countries in the LGCs 
classification between $227-302$ years. ${ }^{1}$

Then, we provided, in Chapter 3, an assessment of the key aspects that raise much of the controversy and disagreement between the mainstream and the evolutionary and NIS theories. In line with our objectives, our assessment was focused on such aspects as learning and assimilation, and the Schumpeterian notions of entrepreneurship that feature prominently in the evolutionary view of innovation; we stressed the distinction and interaction between the concepts of innovation and the diffusion/adoption of foreign technology; and, finally, we discussed the underlying differences between the mainstream and NIS approaches about the proper role of government intervention in order to boost the (local) innovation system. An important aspect of our assessment is the proposition that ideological considerations play an important role to understand the methodological approach in each of the above mentioned theories, specifically in terms of their ability to capture the stylized facts of reality and in terms of their policy implications.

Based on an extensive body or research within the field, in Chapter 3 we also associated the NIS framework with three core aspects of government action to boost innovation: i) leadership, which refers to the production of innovations by the government itself; ii) sponsorship, which refers to the public funding of innovations initiated by the private sector; and iii) coordination, which places stress on the role of government to ease the spread of innovations produced in different parts of the economy (universities, industries, government labs). We argued extensively why and how these aspects of the NIS system suggest a more active and complex role for the government in order to influence the production of innovation and promote long-run growth. Noteworthy, we stressed also why these arguments warrant an institutional/policy framework that falls beyond mere market failures fixing interventions.

In Chapter 4, we formulated a mathematical model that brings together the core ideas of each of the aforementioned theories. We have argued that, on technical grounds, it is perfectly feasible to develop analytically tractable models to investigate, in the mainstream tradition, the long-run effects of government intervention along the insights of the evolutionary and the NIS theories. Hence, our model sought to put together the conventional intertemporal optimization approach-proper of mainstream economics - the evolutionary perspective of innovation and the long-run impacts of the interaction between foreign technology and local innovation underlined by the distinct aspects of concern in the NIS framework, with a focus on the financial sponsorship mechanism that has become widespread in this approach. Further, the proposed model was set to provide an accurate description of the observed dynamics between the classification of countries drawn in Chapter 2. In our view, the proposed mathematical model mimics well the stylized facts and is able to show why and how a focus on the whole innovation system led by the government is warranted in the research of substantive questions about economic growth in the long-run, and the

\footnotetext{
${ }^{1}$ These results are based on the median of the distribution for each country classification. See Section 2.4 .
} 
catching-up prospects of backward countries.

Consistent with the core research question at the outset-whether catchingup hinges on the ability of backward countries to enforce the adoption of foreign technology or, instead, on their ability to set an institutional environment that promotes (local) innovation - in Chapter 5, we endeavored to provide an econometric test of our theoretical model. We ran cointegration tests country-bycountry in order to assess whether a number of structural long-run relationships of interest are supported by the data, namely, i) a structural long-run relationship between foreign technology and productivity; ii) a structural long-run relationship between the interaction of foreign technology with (local) innovation and productivity; and iii) a structural long-run relationship between (government) coordination and productivity. Noteworthy, data limitations prevented us from a complete assessment of the economic relevance of the NIS framework in the long-run (i.e., including leadership and sponsorship issues). The fact that most aspects related to this framework are still poorly understood and measured, and more so in countries off the frontier, has led us to place them as a subject for future research.

The key indicators used to capture the long-run relationships of interest were constructed based on earlier insights in the literature. We followed the practice of using $\mathrm{R} \& \mathrm{D}$ expenditures in frontier countries as a proxy for foreign technology, which spreads to countries falling behind through the imports channel. In turn, to measure innovation and coordination, we relied on two pieces of earlier research in the context of technology change and innovation: first, the distinction in numerous studies of labor market segmentation between workers devoted to cognitive non-routine tasks, and workers devoted to routine tasks; second, the distinction drawn in many innovation studies between high-tech and low-tech economic activities.

Our basic argument goes that high-tech sectors (nanotechnology, biotechnology, ICT, machines and equipment) determine technology trajectories that certainly are important to understand the contributions of foreign technology to the economic achievements of backward countries. Those trajectories, however, are similar for all countries, and along them lots of the innovations that in the end affect the path of long-run growth and catching-up take place. This basic argument is supported by empirical evidence that suggest that, even in the most advanced countries, innovation and long-term growth are to a large extent related to low-tech activities (e.g., food production, metal products, paper and printing); that is, these are innovations that arise in the context of operative processes - rather than a result of R\&D activities - and are mostly initiated by the staff responsible for the ongoing functions.

We have argued largely throughout our discussion of innovation in this thesis that the above distinctions within working categories and technology activities fit well the notion of innovation documented in evolutionary economics. And on the basis of those arguments, we have associated a country's innovation capacity with the share of workers in cognitive non-routine activities.

In turn, as a proxy for government coordination we set an index based on the simple average of four components: labor productivity (across high and low 
tech activities), financial development, human capital and governance. While we have widely recognized that our approach to this subject accounts just for a mild version of the aspects of government coordination that are emphasized in the NIS framework, it is true that the indicators in our approach provide quite a simple and straightforward manner to capture issues of government coordination that are of little debate. That is, the proposed coordination index relates industryspecific productivity achievements with the availability of financial resources, human capital and overall government policy practices, which are all aspects about which mainstream, evolutionary and NIS economists hardly disagree. ${ }^{2}$

We have argued that a reasonable interpretation of the findings in our econometric approach relies on the patterns of the distribution of the impulse-response functions that follow from the cointegration analysis, rather than on the outcomes obtained for individual countries.

By focusing on the median-statistics of the overall distribution of these impacts, the econometric results provide suggestive evidence in support of the propositions advanced earlier in Chapter 5. That is, they suggest that the interaction of (local) innovation and foreign technology is a major engine of growth and catching-up. In particular, for the group of countries at the frontier (FRCs), and for the group of countries that have been successfully catching-up with them (CUCs), we found that the impact of the interaction term is higher than the impact of any of its individual components, namely the individual impact of either (local) innovation or foreign technology. By contrast, countries that we classified as stagnant (STCs) or laggard (LGCs) show a lower response to this interaction even if any of the impacts on (local) innovation (for the LGCs) or foreign technology (for the STCs) spurs a positive productivity response. In addition, we found that the impact of government coordination is particularly large in the group of catching-up countries.

While we have widely acknowledged that due to data limitations and other technical difficulties found in our statistical approach we cannot generalize these relationships, we also find it fair to reckon that the econometric evidence supports the validity of our theory. Our findings provide a clear indication that, unlike the STCs and the LGCs, the catching-up patterns of the CUCs countries are characterized by their ability to efficiently combine the benefits of technology diffusion with the benefits of (local) innovation along a process featured by the increase of cognitive non-routine occupational categories, and also by substantial government coordination. In light of our discussion of the mainstream, evolutionary and NIS theories, these econometric results are in strong contrast with the mainstream emphasis that the potential of backward countries to catch-up hinges on their ability to adopt the technology of the most

\footnotetext{
${ }^{2}$ We have discussed in Chapter 5, Section 5.2, that a strong version of government coordination would need to meet most of the disagreement on the coordination role of government between mainstream and evolutionary economics: discretionary interventions to favor specific sectors through government procurement, directed and subsidized credit facilities, and the explicit coordination of economic targets between the government and private sector, for instance through deliberation councils (see also Page 1994, Wade 1996, 2009). Unfortunately, systematic indicators about these aspects are not available.
} 
advanced countries. Instead, they provide evidence in support of the evolutionary emphasis on learning and assimilation. Additionally, the results favor the NIS view that catching-up depends largely on the ability of countries to enforce the (local) innovation system.

All in all, our attempt in this thesis has been to provide a new rationale to study many features associated with the field of international development. The main theme in our discussion is that much progress can be done in these areas, namely the study of economic growth, economic development and catching up issues, by linking the insights of the evolutionary theory and the NIS framework - which are much richer and policy oriented-and the mainstream methodological and analytical framework - which is more adequate to study the technical and mathematical issues that are of importance when the focus is on the economy as a planning problem over the long-run.

Of course, we do not pretend-and indeed we were not aimed to do so from the beginning - to offer a definitive answer to the problems of growth and catching-up discussed throughout. Not only because the limitations mentioned above still prevent us from providing more definitive answers, but because the issues of technology diffusion, innovation and government intervention that are at the heart of our discussion are inevitably highly controversial. Again, further theoretical research, better quality data and convincing empirical support would be necessary before we can provide a suitable generalization of the theoretical framework that we have proposed in this regard.

\subsection{Limitations.}

The weaknesses in our approach are both theoretical and empirical. At the theoretical level, the main limitation is the treatment of the government as exogenous to the economic system. That is, in spite of the fact that its role in fostering innovation, long-run growth and catching-up is explicitly modelled, in the theoretical model of Chapter 3 we have highly simplified the public sector and the problems created by fiscal and monetary affairs. Clearly, a better assessment of the ability of government to coordinate, fund and lead the overall system of innovation would need to take care of these affairs - and thus the conduct of fiscal and monetary policies.

Another limitation regards to the implicit assumption in our approach of a virtuous interaction between political and economic interests. Certainly, the NIS framework relies mostly on examples drawn from country specific cases, but the whole approach is highly normative, namely heavily shaped by the view that policymakers are benevolent and do their best to boost innovation and long-run growth.

In practice, however, the choice and implementation of adequate economic policies are frequently shown to be hampered by conflicting interests that reflect the preferences of competing groups in society. In Chapter 4, we mentioned 
some strands of the literature that seeks to explain the failure, observed in some countries, to profit from technology diffusion due to political elites that explicitly block the adoption of new technologies. However, the mathematical model that we proposed in the same chapter do not account for such political constraints in the implementation/workings of the NIS system. In that sense, the proposed model still has to overcome the political naiveness implicit in the modelling approach.

On the empirical side, the key limitations of our approach have been related to aspects of data availability and data quality. Indeed, the main reason why we focused on a mild, instead of a strong, version on issues of government coordination; and also the reason why we did not pursue an assessment of other aspects of the NIS framework, namely leadership and sponsorship, was due to data availability. As we largely discussed in Chapter 5, the empirical assessment of these three roles of government involves aspects that are poorly or not systematically measured anywhere, and less so in backward countries. While the refinement of our dataset in this regard is an important limitation to address in order to improve the reliability of our empirical results, certainly it is not an issue easy to solve in the near future.

Besides data availability, there are various reasons why the economic and statistical significance of the econometric results we found need to be taken with caution. For one thing, the data on our variables of interest (foreign technology, local innovation, government coordination) are not directly observable, thus we had relied here on "synthetic" indicators, which - as is usually the case - raise many issues.

In our view, some of the chosen indicators are better, or more convincing, than others. For instance, the use of cognitive and non-routine working categories seems to us a plaussible manner to capture the innovation capacity of a country's workforce, and more so than the use of indicators of education that has been customary in other studies in this context. As we have discussed above, our index focuses on what the workers' capabilities are used for in practice rather than the potential capabilities of the people still in the education system. Yet, other indicators in our approach, say the index of government coordination, might raise much controversy upon the adequacy of our variable definitions and the way the concepts are actually captured by the data. These limitations come in addition to the classical problem of measurement errors, which in turn affects the consistent estimation of the parameters of interest.

Another problem related with the dataset in our empirical approach is data quality. Even in cases where there is a fair deal of information for especific indicators in our study, we have found problems related with the accuracy, coherence (over time), and international comparability of the reported data. For instance, methodological changes over time or across countries are many times evident but not explicitly reported/explained at the country level, which is an issue that may seriously have hampered our ability to find systematic support for our predictions in the econometric approach.

Yet, while we have to acknowledge that our database is in need of further expansion and quality betterment. In our approach above, whenever posible 
we have corrected the conflicting data to make it consistent across countries and over time. The adjustments to the original dataset have been done in a systematic way and we have reported the changes in the methodological notes accompannying statistical tables. But, certainty, quality adjustment is a continuos process, and thus further reviews and eventual improvements are possible in our future research.

In closing this section, it is worth mentioning that the data limitations just mentioned are not exclusive to our investigation in this thesis. The extended practice of constructing synthetic indicators aimed to compare technology capabilities across countries is faced with similar limitations. ${ }^{3}$ And other authors in this context have come to the same conclusion as we did: to rely on workable simplifications that allow focus on comparable standards for a large number of countries and over long periods of time.

\subsection{Future Research.}

Of course, we do not render any of the theoretical and empirical limitations in the previous sections as reasons to think that our approach is ill founded or off the mark, but rather as issues to be addressed in future research.

For instance, the theoretical model that we have developed in Chapter 3 may be extended into a number of areas, namely to consider a coherent foundation with respect to the role of public policy, taking account of fiscal and monetary affairs; or it may be provided with rigorous microeconomic foundations in relation with the production of sectoral innovations.

Also from the theoretical standpoint, our model may be extended to study the role of politics in influencing the role of government within the NIS system; and thus the influence of the political process in the policymaking and institutions that affect the funding and spread of innovations conducted by universities, government labs, the private sector, and so on.

Likewise, aside of the issues related to the refinement and extension of the dataset on innovation that we have initiated here, further research in the empirical front may be conducted to deal with adequate modifications of some standard software packages for analyzing time series in the context of panel data-like it is the case in our empirical investigation above. For instance, a research focus here may be on the problems that we have identified of lack of robustness and consistency between the estimation results drawn from standard panel data cointegration procedures and the results drawn from a country-by-country cointegration approach that is based on standard times-series procedures.

To sum up, we do think of the present thesis as bringing in new ideas for the academic research of economic growth and development. Those ideas however, will need to be perfected through further research. Looking ahead, the task is

\footnotetext{
${ }^{3}$ Archibugi et al., 2009
} 
to develop better models to explore feasible circumstances for efficient coordination, sponsorship, and leadership of a country's national innovation system. As Blanchard once pointed out:

...the good news for policymakers is that there is indeed a core of usable macroeconomics; the good news for macroeconomic researchers is that there is a lot of work still to be done. ${ }^{4}$

\footnotetext{
${ }^{4}$ Blanchard, 1997
} 


\section{Bibliography}

Abel, A. (1982). Dynamic effects of permanent and temporary tax policies in a q model of investment. Journal of Monetary Economics, 9(3), 353-373.

Abramovitz, M. (1986). Catching up, forging ahead and falling behind. Journal of Economic History, June.

Abramovitz, M., and Stegun, I. (1964). Handbook of mathematical functions, US Govt. Printing Office, Washington, DC.

Acemoglu, D. (2009). Introduction to Modern Economic Growth. The MIT Press.

Acemoglu, D. (2014). Localized and biased technologies: Atkinson and Stiglitz's new view, induced innovations, and directed technological change. National Bureau of Economic Research working paper No. w20060.

Acemoglu, D., Akcigit, U., Alp, H., Bloom, N., and Kerr, W. (2013). Innovation, reallocation and growth (No. w18993). National Bureau of Economic Research.

Acemoglu, D., and Cao, D. (2015). Innovation by entrants and incumbents. Journal of Economic Theory, 157, 255-294.

Acemoglu, D., and Robinson, J. (2000). Political losers as a barrier to development. American Economic Review. May.

Acemoglu, D., and Robinson, J. (2003). Economic backwardness in political perspective. National Bureau of Economic Research working paper no. 8831.

Acemoglu, D., Robinson, J., and Verdier, T. (2012). Can't we all be more like Scandinavians? Asymmetric growth and institutions in an interdependent world. National Bureau of Economic Research WP w18441.

Acemoglu, D., Zilibotti, F., and Aghion, P. (2006). Distance to frontier, selection and economic growth. Journal of the European Economic Association, $4(1), 37-74$. 
Achdou, Y., Buera, F., Lasry, J., Lions, P., and Moll, B. (2014). Partial differential equation models in macroeconomics. Philosophical Transactions of the Royal Society of London A: Mathematical, Physical and Engineering Sciences, 372(2028), 20130397.

Aghion, P., Akcigit, U., and Howitt, P. (2013). What do we learn from Schumpeterian growth theory? National Bureau of Economic Research working paper no. w18824.

Aghion, P., and Howitt, P. (2006). Joseph Schumpeter lecture appropriate growth policy: A unifying framework. Journal of the European Economic Association, 4(2-3), 269-314.

Aghion, P., Howitt, P., and Mayer-Foulkes, D. (2005). The effect of financial development on convergence: Theory and evidence. The Quarterly Journal of Economics, 120(1), 173-222.

Akcigit, U., Hanley, D., and Stantcheva, S. (2016). Optimal taxation and r\&d policies (No. w22908). National Bureau of Economic Research.

Almus, M., and Czarnitzki, D. (2003). The effects of public R\&D subsidies on firms' innovation activities: The case of East Germany. Journal of Business and Economic Statistics 21 (2), 226-236.

Alvarez, F., Buera, F., and Lucas, R. (2014). Idea flows, economic growth, and trade. National Bureau of Economic Research working paper no. 19667.

Amable, B. (1993). Catch up and convergence: A model of cumulative growth. International Review of Applied Economics, 7(1), 1-25.

Anderson, P., Arrow, K., and Pines, D. (1988). The economy as an evolving complex system I.

Ang, J., and Madsen, J. (2011). Can second-generation endogenous growth models explain the productivity trends and knowledge production in the Asian miracle economies? Review of Economics and Statistics, 93(4), 1360-1373.

Archibugi, D., and Coco, A. (2004). A new indicator of technological capabilities for developed and developing countries (ArCo). World development, 32(4), 629-654.

Archibugi, D., Denni, M., and Filippetti, A. (2009). The technological capabilities of nations: The state of the art of synthetic indicators. Technological Forecasting \& Social Change.

Arrow, K. (1962). Economic welfare and the allocation of resources for invention. In The rate and direction of inventive activity: Economic and social factors (pp. 609-626). Princeton University Press.

Arthur, W. (1994), Increasing returns and path dependence in the economy, Ann Arbor, Michigan: University of Michigan Press. 
Arthur, W., Durlauf, S., and Lane, D. (1997) The Economy as an Evolving Complex System II.

Atkinson, A., and Stiglitz, J. (1969). A new view of technological change. The Economic Journal, 573-578.

Autor, D., and Dorn, D. (2013). How technology wrecks the middle class. The New York Times, August-24.

Autor, D., Levy, F., and Murnane, R. (2003). The skill content of recent technological change: An empirical exploration. Quarterly Journal of Economics, $118,1279-1333$.

Baily, M., (1981). Productivity and the services of capital and labor." In Brookings Papers on Economic Activity, vol. 1: 1-50.

Baldwin, R. (1971). Determinants of the commodity structure of U.S. trade. The American Economic Review, 61(1), 126-146.

Ball, L., and Romer, D. (1991). Sticky prices as coordination failure. The American Economic Review, 539-552.

Banks, R. (2013). Growth and diffusion phenomena: Mathematical frameworks and applications (Vol. 14). Springer Science \& Business Media.

Baltagi, B. (2014). The Oxford Handbook of Panel Data. Oxford University Press, USA.

Barro, R. (1990). Government spending in a simple model of endogenous growth. Journal of Political Economy, 98(5 pt 2).

Barro, R. (1991). Economic growth in a cross-section of countries. The Quarterly Journal of Economics, 106(2), 407-443.

Barro, R. (1997). Determinants of economic growth, Cambridge, MA: MIT Press.

Barro, R., and Lee, J. (2013). A new data set of educational attainment in the world, 1950-2010. Journal of Development Economics, vol 104, pp.184-198.

Barro, R., and Sala-i-Martin, X. (1997). Technological diffusion and convergence. Journal of Economic Growth, March.

Basu, S., and Fernald, J. (2002). Aggregate productivity and aggregate technology. European Economic Review, 46(6), 963-991.

Basu, S., and Weil, D. (1998). Appropriate technology and growth. The Quarterly Journal of Economics, 113(4), 1025-1054.

Baumol, W. (1986). Productivity Growth, Convergence and Welfare: What the Long-Run Data Show, American Economic Review, December. 
Baumol, W. (2002). The Free-market innovation machine: Analyzing the growth miracle of capitalism. Princenton, Princeton University Press.

Becker, B., and Hall, S. (2013). Do R\&D strategies in high-tech sectors differ from those in low-tech sectors? An alternative approach to testing the pooling assumption. Economic Change and Restructuring, 46(2), 183-202.

Bell, M., and Pavitt, K. (1997). Technological accumulation and industrial growth: Contrasts between developed and developing countries. Technology, globalisation and economic performance, 83-137.

Benhabib, J., and Spiegel, M. M. (2005). Human capital and technology diffusion. Handbook of Economic Growth, 1, 935-966.

Benhabib, J., Perla, J., and Tonetti, C. (2014). Catch up and fall-back through innovation and imitation. Journal of Economic Growth, 19(1), 1-35.

Benhabib, J., Perla, J., and Tonetti, C. (2017). Reconciling models of diffusion and innovation: A theory of the productivity distribution and technology frontier (No. w23095). National Bureau of Economic Research.

Benhabib, J., and Perli, R. (1994). Uniqueness and indeterminacy: On the dynamics of endogenous growth. Journal of economic theory, 63(1), 113-142.

Bernard, A., and Jones, C. (1996a). Comparing apples to oranges: Productivity convergence and measurement across industries and countries. The American Economic Review, 1216-1238.

Bernard, A., and Jones, C. (1996b). Technology and convergence. The Economic Journal, 106(437), 1037-1044.

Beyer, A., Haug, A., and Dewald, W. (2009). Structural breaks, cointegration and the Fisher effect. European Central Bank, WP 1013.

Blackburne, E., and Frank, M. (2007). Estimation of nonstationary heterogeneous panels. The Stata Journal, 7(2), 197-208.

Blanchard, O. (1997). Is there a core of usable macroeconomics? American Economic Review, May.

Blanchard, O., and Fischer, S. (1989). Lectures on macroeconomics. Cambridge, MA: MIT Press.

Blume, L. E., and Durlauf, S. N. (Eds.). (2005). The economy as an evolving complex system, III: current perspectives and future directions. Oxford University Press.

Bohn, H., and Gorton, G. (1993). Coordination failure, multiple equilibria and economic institutions. Economica, 257-280. 
Boldrin, M., and Levine, D. (2002). The case against intellectual property. American Economic Review, 92(2), 209-212.

Bosworth, B., and Collins, S. (2003). The empirics of growth: An update. Brooking Papers on Economic Activity 2003(2), 113-79.

Brezis, E., Krugman, P., and Tsiddon, D. (1993). Leapfrogging in international competition: A theory of cycles in national technological leadership. The American Economic Review 83(5), 1211-19.

Breznitz, D. (2007). Innovation and the state: Political choice and strategies for growth in Israel, Taiwan, and Ireland. Yale University Press.

Breznitz, D., Ornston, D., and Samford, S. (2018). Mission critical: the ends, means, and design of innovation agencies. Industrial and Corporate Change, $27(5), 883-896$.

Bullard, J., and Butler, A. (1993). Nonlinearity and chaos in economic models: Implications for policy decisions. The Economic Journal, 849-867.

Carrion-i-Sylvestre, J., and Sans'o, A. (2006). Testing the null of cointegration with structural breaks. Oxford Bulletin of Economics and Statistics, 68, 623646.

Caselli, F. (2005). The missing input, accounting for cross-country income differences. In Aghion, P., and Durlauf, S. (eds.) Handbook of Economic Growth, Ch. 9, 679-741.

Caselli, F., and Coleman, W. (2006). The world technology frontier. The American Economic Review, 96(3), 499-522.

Caselli, F., and Wilson, D. (2004). Importing technology. Journal of Monetary Economics, 51, 1-32.

Castellaci, F. (2008). Technology clubs, technology gaps, and growth trajectories. MPRA Paper 27595.

Castellion, G., and Markham, S. (2013). Perspective: new product failure rates: influence of argumentum ad populum and selfinterest. Journal of Product Innovation Management, 30(5), 976-979.

Cedefop (2012). The Skill Mismatch Challenge in Europe, Employment and Social Developments in Europe, European Commission, Luxembourg.

Cihak, M., Demirguc-Kunt, A., Feyen, E., and Levine, R. (2012). Benchmarking financial systems around the world. World Bank Policy Research Working Paper 6175, World Bank, Washington, D.C.

Cimoli, M., Hofman, A., and Mulder, N. (2010). Innovation and economic development: The impact of information and communication technologies in Latin America. Edward Elgar Pub. 
Cimoli, M., and Soete, L. (1992). A generalized technology gap trade model. Maastricht University working paper no. 27-6485.

Clark, G., and Feenstra, R. (2003). Technology in the great divergence. National Bureau of Economic Research, 277-322.

Coe, D., and Helpman, E. (1995). International R\&D spillovers. European Economic Review, 39(5), 859-87.

Coe, D., Helpman, E., and Hoffmaister, A. (1995). North-south R\&D spillovers. National Bureau of Economic Research working paper no. 5048.

Coelli, T., Rao, D., O'Donnell, C., and Battese, G. (2005). An introduction to efficiency and productivity analysis. Springer Science and Business Media.

Cohen, W. (2010). Fifty years of empirical studies of innovative activity and performance. Handbook of the Economics of Innovation, 1, 129-198.

Cohen, W., and Levinthal, D. (1989). Innovation and learning: The two faces of R\&D. The Economic Journal, 99(397), 569-596.

Collins, S., and Bosworth, B. (1996). Economic growth in East Asia: Accumulation versus assimilation. Brookings Papers on Economic Activity, 1996(2), 135-203.

Comin, D., and Hobijn, B. (2010). An exploration of technology diffusion. American Economic Review: 100(December), 2031-2059.

Comin, D., and Mestieri, M. (2014). Technology diffusion: measurement, causes, and consequences. Handbook of Economic Growth, 2, 565-622.

Damsgaard, E., and Krusell, P. (2010). The world distribution of productivity: Country TFP choice in a Nelson-Phelps economy. National Bureau of Economic Research working paper no. w16375.

Danguy, J., Rassenfosse, G., and van Pottelsberghe, B. (2013). On the origins of the worldwide surge in patenting: An industry perspective on the R\&Dpatent relationship. Melbourne Institute WP. 15/13.

De Long, J., and Summers, L. (1991). Equipment investment and economic growth. The Quarterly Journal of Economics, 106(2), 445-502.

De Vries, G., Mulder, N., Dal Borgo, M., and Hofman, A. (2010). ICT investment in Latin America: Does it matter for economic growth? In Cimoli et al., Innovation and Economic Development: The Impact of Information and Communication Technologies in Latin America. Edward Elgar Pub. 96-117.

Dinopoulos, E., and Syropoulos, C. (2007). Rent protection as a barrier to innovation and growth. Economic Theory, 32(2), 309-332. 
Dixit, A., and Stiglitz, J. (1977). Monopolistic competition and optimum product diversity. The American Economic Review, 297-308.

Dosi, G. (2013). The third industrial revolution in global business. Cambridge University Press.

Dosi, G., and Nelson, R. (1994). An introduction to evolutionary theories in economics. Journal of evolutionary economics, 4(3), 153-172.

Dosi, G., and Nelson, R. (2010). Technical Change and Industrial Dynamics as Evolutionary Processes. Handbook of the Economics of Innovation, 1, 52-114.

Dosi, G., Fabiani, S., Aversi, R., and Meacci, M. (1994). The dynamics of international differentiation: A multi-country evolutionary model. Industrial and corporate change, 3(1), 225-242.

Dosi, G., Marengo, L., and Pasquali, C. (2006). How much should society fuel the greed of innovators? On the relations between appropriability, opportunities and rates of innovation. Research Policy, 35(8), 1110-1121.

Dougherty, C., and Jorgenson, J. (1996). international comparison of sources of growth. American Economic Review, 86, 25-29.

Durlauf, S., Johnson, P., and Temple, J. (2005). Growth econometrics. Handbook of Economic Growth, 1, 555-677.

Durlauf, S, and Quah, D. (1999). The new empirics of economic growth. Handbook of Macroeconomics, 1, 235-308.

Eaton, J., and Kortum, S. (2001). Trade in capital goods. European Economic Review. 45(7), 1195-235.

Easterly, W., Kremer, M., Pritchett, L., and Summers, L. (1993). Good policy or good luck? Country growth performance and temporary shocks. Journal of Monetary Economics, 32(3), 459-483.

Easterly, W., and Levine, R. (2001). What have we learned from a decade of empirical research on growth? It's not factor accumulation: Stylized facts and growth models. The World Bank Economic Review, 15(2), 177-219.

ECLAC. (2011). National innovation surveys in Latin America: empirical evidence and policy implications. United Nation-ECLAC Publishing.

Edwards, S. (1998). Openness, Productivity and Growth: What Do We Really Know?, Economic Journal, March.

Elliott, G., Rothenberg, T., and Stock, J. (1996). Efficient tests for an autoregressive unit root. Econometrica 64:813-836.

ElMaraghy, H., Schuh, G., ElMaraghy, W., Piller, F., Schönsleben, P., Tseng, M., \& Bernard, A. (2013). Product variety management. CIRP AnnalsManufacturing Technology, 62(2), 629-652. 
Elmslie, B. (1995). Retrospectives: the convergence debate between David Hume and Josiah Tucker. Journal of Economic Perspectives, 9(4), 207-216.

Ertur, C., and Koch, W. (2011). A contribution to the theory and empirics of Schumpeterian growth with worldwide interactions. Journal of Economic Growth, 16(3), 215-255.

Fagerberg, J. (1994). Technology and international differences in growth rates. Journal of Economic Literature.

Fagerberg, J. (1995). Convergence or Divergence? The Impact of Technology on Why Growth Rates Differ, Journal of Evolutionary Economics, Spring.

Fagerberg, J. (2003). Schumpeter and the revival of evolutionary economics: an appraisal of the literature. Journal of evolutionary economics, 13(2), 125-159.

Fagerberg, J., Feldman, M., and Srholec, M. (2013). Technological dynamics and social capability. US states and European nations. TIK working paper on Innovation Studies No. 20130819.

Fagerberg, J., and Srholec, M. (2007). The competitiveness of nations: Why some countries prosper while others fall behind. World Development, 35(10), $1595-620$.

Fagerberg, J., Srholec, M., and Verspagen, B. (2010). Innovation and economic development. Handbook of the Economics of Innovation, 2, 833-872.

Fagerberg, J., and Verspagen, B. (2002). Technology-gaps, innovation-diffusion and transformation: An evolutionary interpretation. Research Policy, 31, 12911304.

Fare, R., Grosskopf, S., Norris, M., and Zhang, Z. (1994). Productivity growth, technical progress, and efficiency change in industrialized countries. The American economic review, 66-83.

Fei, J. and Ranis, G. (1997), Growth and Development From an Evolutionary Perspective, Oxford: Basil Blackwell.

Fisher, L., Huh, H., and Summers, P. (2001). Structural identification of permanent shocks in VEC models: a generalization. Journal of Macroeconomics, $22(1), 53-68$.

Foray, D., and Lissoni, F. (2010). University research and public-private interaction. Handbook of the Economics of Innovation, 1, 276-308.

Forgy, E. (1965) Cluster analysis of multivariate data: efficiency vs. interpretability of classification, Biometrics, 21, 768.

Fraumeni, B. (1997). The measurement of depreciation in the US national income and product accounts. Survey of current business-United States Department of Commerce, 77, 7-23. 
Freeman, C. (1987). Technology policy and economic performance: Lessons from Japan (pp. 11-17). London: Pinter Publishers.

Freeman, C. (1994). The economics of technical change. Cambridge Journal of economics, 18(5), 463-514.

Freeman, C. (1995). The "National System of Innovation" in historical perspective. Cambridge Journal of economics, 19(1), 5-24.

Freeman, C. (2004) Technological infrastructure and international competitiveness, Industrial and Corporate Change, 13(3).

Feenstra, R., Inklaar, R., and Timmer, M. (2015). The Next Generation of the Penn World Table. American Economic Review, 105(10), 3150-3182,

Gatignon, H., Gotteland, D., Haon, C., and Zimmer, J. (2015). Making innovation last: Volume 2: Sustainable strategies for long term growth (Vol. 2). Springer.

Gault., F. (2014). Where are innovation indicators, and their applications, going? UNU-MERIT working paper series 2014-055.

Gerschenkron, A. (1962). Economic backwardness in historical perspective. Harvard University Press.

Gollin, D. (2002). Getting income shares right. Journal of Political Economy, $110(2), 458-74$.

Gong, G., Greiner, A., and Semmler, W. (2004). The Uzawa-Lucas model without scale effects: theory and empirical evidence, Structural Change and Economic Dynamics, 15(4), 401-420.

Gomulka, S. (1990). The theory of technological change and economic growth. Routledge.

Gordon, R. (2014). The demise of U.S. economic growth: Restatement, rebuttal, and reflections. National Bureau of Economic Research working paper no. 19895 .

Gorodnichenko, Y., and Schnitzer, M. (2013). Financial constraints and innovation: Why poor countries don't catch up. Journal of the European Economic Association, 11(5), 1115-1152.

Gould, J. (1976). Diffusion processes and optimal advertising policy. In Mathematical Models in Marketing (pp. 169-174). Springer Berlin Heidelberg.

Griffith, R., Redding, S., and van Reenen, J. (2004). Mapping the two faces of R\&D: Productivity growth in a panel of OECD industries. Review of Economics and Statistics, 86(4), 883-895. 
Griliches, Z., and Mairesse, J. (1995). Production functions: The search for identification. National Bureau of Economic Research working paper no. w5067.

Grossman, G., and Helpman, E. (2001). Innovation and growth in the global economy, 7th Ed. Cambridge, MA: MIT Press.

Gush, J., Jaffe, A., Larsen, V., and Laws, A. (2017). The effect of public funding on research output: the New Zealand Marsden Fund. New Zealand Economic Papers, 1-22.

Ha, J., and Howitt, P. (2007). Accounting for trends in productivity and R\&D: A Schumpeterian critique of semi-endogenous growth theory. Journal of Money, Credit and Banking, 39(4), 733-774.

Hall, B., and Lerner, K. (2010). The Financing of R\&D and innovation. Handbook of the Economics of Innovation, 1, 610-635.

Hall, B. and Rosenberg, N. (Eds.). (2010). Handbook of the Economics of Innovation, 1. 4-8, Elsevier.

Hall, P. (2001). Varieties of Capitalism. John Wiley and Sons, Inc.

Hall, P., and Soskice, D. (2003). Varieties of Capitalism: The Institutional Foundation of Comparative Advantage. Oxford University Press, Oxford.

Hall, R., and Jones, C. (1999). Why do some countries produce so much more output than others? Quarterly Journal of Economics, 114, 83-116.

Hauk, W., and Wacziarg, R. (2009). A Monte Carlo study of growth regressions. Journal of Economic Growth, 14(2), 103-147.

Hausmann, R., Hidalgo, C., Bustos, S., Coscia, M., Chung, S., Jimenez, J., Simoes, A., and Yildirim, M. (2011). The Atlas of Economic Complexity. Boston, MA.

Hausmann, R., Pritchett, L., and Rodrik, D. (2005). Growth accelerations. Journal of economic growth, 10(4), 303-329.

Hayashi, F. (1982). Tobin's marginal $q$ and average $q$ : A neoclassical interpretation. Econometrica 50(1), 213-224.

Heijdra, B. (2009). Foundations of Modern Macroeconomics. Second Ed. Oxford University Press.

Herstatt, C., von Hippel, E. (1992). From experience: Developing new product concepts via the lead user method: A case study in a "low-tech" field. Journal of Product Innovation Management 9 (3), 213-222.

Hidalgo, C., Klinger, B., Barabási, A. L., and Hausmann, R. (2007). The product space conditions the development of nations. Science, 317(5837), 482487. 
Hirsch-Kreinsen, H. (2008). "Low-tech" innovations. Industry and Innovation, 15(1), 19-43.

Hobday, M. (1995). East Asian latecomer firms: Learning the technology of electronics. World Development, 23(7), 1171-1193.

Howitt, P. (1998). Measurement, obsolescence and general purpose technologies: in Helpman (eds.), General Purpose Technology and Economic Growth, MIT Press.

Huang, C., Arundel, A., Hollanders, H. (2010). How firms innovate: R\&D, non-R\&D, and technology adoption. UNU-MERIT WP. 2010-027

Hume, D. (1742). Writings on Economics. Republished by Rotwein, E. (ed.) Madison: University of Wisconsin Press, 1955

Inter-American Development Bank (2012). Disconnected: Skills, Education and Employment in Latin America, IDB Education.

Islam, R., Ang, J., and Madsen, J. (2014). Quality-adjusted human capital and productivity growth. Economic Inquiry, 52(2), 757-777.

Johansen, S. (1995). Likelihood-based inference in cointegrated vector autoregressive models. Oxford: Oxford University Press.

Johansen, S. (1988). Statistical analysis of cointegrating vectors. Journal of Economic Dynamics and Control, 12(2/3), 231-254.

Johansen, S., Mosconi, R., and Nielsen, B. (2000). Cointegration analysis in the presence of structural breaks in the deterministic trend. Econometrics Journal, $3(2), 216-249$.

Jones, C. (1995). Times series tests of endogenous growth models. The Quarterly Journal of Economics, 110, 495-525.

Jones, C. (2005). Growth and ideas. Handbook of Economic Growth, 1, 10631111.

Jorgenson, D., Gollop, F., and Fraumeni, B. (1987). Productivity and US Economic Growth.

Jorgenson, D., and Vu, K. (2005). Information technology and the world economy. Scandinavian Journal of Economics, 107(4), 631-50.

Jorgenson, D., and Vu, K. (2010). Latin America and the world economy. In Cimoli et al., Innovation and Economic Development: The Impact of Information and Communication Technologies in Latin America. Edward Elgar Pub. $19-42$.

Jovanovic, B., and Nyarko, Y. (1996). Learning by doing and the choice of technology. Econometrica: Journal of the Econometric Society, 1299-1310. 
Juselius, K., Møller, N. \& Tarp, F. (2014). The Long-Run Impact of Foreign Aid in 36 African Countries: Insights from Multivariate Time Series Analysis. Oxford Bulletin of Economics and Statistics, 76(2), 153-184.

Kaufmann, D., Kraay, A., and Mastruzzi, M. (2010). The Worldwide Governance Indicators: Methodology and Analytical Issues. World Bank Policy Research Working Paper No. 5430.

Kaldor, N., and Mirless, J. (1962). A new model of economic growth. The Review of Economic Studies, 29(3), 174-192.

Kamien, M., and Schwartz, N. (1991). Dynamic Optimization. The Calculus of Variations and Optimal Control in Economics and Management. Second Edition. Advanced Textbooks in Economics, 31. North Holland.

Kandori, M., Mailath, G., and Rob, R. (1993). Learning, mutation, and longrun equilibria in games. Econometrica: Journal of the Econometric Society, 29-56.

Kasahara, S. (2004). The Flying Geese Paradigm: A critical study of its application to East Asian regional development.

Katz, J. (1984). Domestic technological innovations and dynamic comparative advantage: further reflections on a comparative case-study program. Journal of Development Economics, 16(1-2), 13-37.

Kelly, L. (2002). Pursuing problems in growth. Journal of Economic Growth, $7(3), 283-308$.

Kehoe, T., and Ruhl, K. (2008). Are shocks to the terms of trade shocks to productivity? Review of Economic Dynamics, 11(4), 804-819.

Keller, W. (2002). Geographic localization of international technology diffusion. American Economic Review, 92, 120-142.

Keller, W. (2004). International technology diffusion. Journal of Economic Literature, 17 (Sep), 752-782.

Kerr, W., and Nanda, R. (2015). Financing innovation. Annual Review of Financial Economics, 7, 445-462.

Khan, B. (2015). Inventing Prizes: A Historical Perspective on Innovation Awards and Technology Policy. Business History Review, 89(4), 631-660.

Kim, L. (1980). Stages of development of industrial technology in a developing country: A model. Research Policy, 9(3), 254-277.

Kim, L. (1993). National systems of industrial innovation: dynamics of capability building in Korea. In Nelson, R. National innovation systems: A comparative analysis, 357-383. 
King, R., and Levine, R. (1994). Capital fundamentalism, economic development, and economic growth. In Carnegie-Rochester Conference Series on Public Policy (Vol. 40, pp. 259-292). North-Holland.

Khan, M. (2012). Estimating the level of investment in knowledge across the OECD countries. Intellectual capital for communities.

Kohli, U. (2004). Real GDP, Real Domestic Income, and Terms-of-Trade Changes, Journal of International Economics, 62, 83-106.

Kongsamut, P., Rebelo, S., and Xie, D. (2001). Beyond balanced growth. The Review of Economic Studies, 68(4), 869-882.

Kortum, S. (1997). Research, patenting, and technological change. Econometrica: Journal of the Econometric Society, 1389-1419.

Kremer, M. (1998), Patent buyouts: a mechanism for encouraging innovation, Quarterly Journal of Economics, November.

Kumar, S., and Russell, R. (2002). Technological change, technological catch up, and capital deepening: Relative contributions to growth and convergence. American Economic Review, 527-548.

Lahiri, A. (2001). Growth and equilibrium indeterminacy: the role of capital mobility. Economic Theory, 17(1), 197-208.

Lall, S. (1987). Learning to industrialize: the acquisition of technological capability by India. Springer.

Lall, S. (2000). The technological structure and performance of developing country manufactured exports, 1985-98. Oxford Development Studies, 28(3), 337-369.

Lee, J. (1995). Capital goods imports and long-run growth. Journal of Development Economics, 48(1), 91-110.

Lee, K. (2013) Schumpeterian analysis of economic catch-up: Knowledge pathcreation, and the middle income trap. Cambridge.

Lee, K., and Malerba, F. (2018). Economic catch-up by latecomers as an evolutionary process. In Nelson, R., Dosi, G., Helfat, C., Pyka, A., Saviotti, P., Lee, K., and Malerba, F. Modern evolutionary economics: an overview. Ch. 6. Cambridge University Press.

Le Grand, J. (1991). The theory of government failure. British journal of political science, 21(4), 423-442.

Lerner, J., and Stern, S. (2019). Innovation Policy and the Economy: Introduction to Volume 19. Innovation Policy and the Economy, 19(1), xi-xiv. 
Levine, R., and Renelt, D. (1991). Cross-country studies of growth and policy: methodological, conceptual, and statistical problems. Vol. 608. World Bank Publications.

Levine, R., and Renelt, D. (1992). A sensitivity analysis of cross-country growth regressions. American Economic Review, 82(4), 942-63.

Levy, F., and Murnane, R. (2007). How computerized work and globalization shape human skill demands. Learning in the Global Era: International Perspectives on Globalization and Education, 158-174.

Lin, J., Monga, C., te Velde, D., Tendulkar, S., Amsden, A., Amoako, K., and Lim, W. (2011). DPR debate: Growth identification and facilitation: The role of the state in the dynamics of structural change. Development Policy Review, $29(3), 259-310$.

List, F. (1841). The National System of Political Economy.(Das Nationale System der Politischen Ökonomie: Basel: Kyklos)

Los, B., and Timmer, M. (2005). The "appropriate technology" explanation of productivity growth differentials: An empirical approach. Journal of Development Economics, 77, 517-31.

Lucas, R. (1988). On the mechanics of economic development. Journal of Monetary Economics, 22, 3-42.

Lucas, R. (2000). Some macroeconomics for the 21st century. The Journal of Economic Perspectives, 159-168.

Lucas, R. (2009). Trade and the diffusion of the industrial revolution. American Economic Journal: Macroeconomics, 1(1), 1-25.

Lucas, R., and Moll, B. (2014). Knowledge growth and the allocation of time. Journal of Political Economy, 122(1).

Lundvall, B. (1992). National systems of innovation: Toward a theory of innovation and interactive learning, London: Frances Pinter.

Lundvall, B. (1993). User-producer relationships, national systems of innovation and internationalisation, in D. Foray and C. Freeman (eds.), Technology and the wealth of nations: the dynamics of constructed advantage Pinter Publishers, New York: 277300.

Lundvall, B. (2007). National innovation systems - analytical concept and development tool. Industry and Innovation, 14(1), 95-119.

Lutkepohl, H. (2005). New introduction to multiple time series analysis. Springer Science \& Business Media.

Luttmer, E. (2015). Four models of knowledge diffusion and growth. Working paper no. 724 . 
Madsen, J., Islam, M., and Ang, J. (2010). Catching up to the technology frontier: the dichotomy between innovation and imitation. Canadian Journal of Economics, 43(4), 1389-1411.

Mairesse, J., and Mohnen, P. (2010). Using innovation surveys for econometric analysis. Handbook of the Economics of Innovation, 2, 1129-1155.

Mankiw, G., Phelps, E., and Romer, P. (1995). The growth of nations. Brookings papers on economic activity, 275-326.

Mankiw, G., and Romer, P. (Eds.) (1997). New Keynesian Economics: Coordination failures and real rigidities, V. 2. The MIT Press. Cambridge, Massachusetts. London, England.

Mazzucato, M. (2013). The entrepreneurial state: Debunking public vs. private sector myths (Vol. 1). Anthem Press.

Mazzucato, M., and Penna, C. (2015). Mission-oriented finance for innovation: New ideas for investment-led growth. Policy Network and Rowman \& Littlefield International.

McMillan, M., and Rodrik, D. (2012). Globalization, structural change, and productivity growth. International Food Policy Research Institute, working paper 01160 .

Medio, A., and Negroni, G. (1996). Chaotic dynamics in overlapping generations models with production. In: Barnett, W., Kirman, A., and Salmon M. (Eds.), Non Linear Dynamics and Economics, Cambridge University Press.

Messinis, G., and Ahmed, A. (2013). Cognitive skills, innovation and technology diffusion. Economic Modelling, 30, 565-578.

Mohnen, P., Mairesse, J., and Dagenais, M. (2006). Innovativity: A comparison across seven European countries. Economics of Innovation and New Technology, 15(4-5), 391-413.

Mokyr, J. (2010). The Contribution of Economic History to the Study of Innovation and Technical Change: 1750-1914. In Handbook of the Economics of Innovation, 1, 11-47.

Mokyr, J. (2014). Secular stagnation? Not in your life. Secular Stagnation: Facts, Causes and Cures, 83.

Moreau, F. (2004). The role of the state in evolutionary economics. Cambridge Journal of Economics, 28(6), 847-874.

Mowery, D., and Rosenberg, N. (1993) The U.S. National Innovation System. In Nelson, R. National innovation systems: A comparative analysis, 29-75. 
Murphy, K., Shleifer, A., and Vishny, R. (1989). Income distribution, market size, and industrialization. The Quarterly Journal of Economics, 104(3), 537564 .

Nelson, R. (1993). National innovation systems: a comparative analysis. University of Illinois at Urbana-Champaign's Academy for Entrepreneurial Leadership Historical Research Reference in Entrepreneurship.

Nelson, R. (2008). Economic development from the perspective of evolutionary economic theory. Oxford development studies, 36(1), 9-21.

Nelson, R., and Phelps, E. (1966). Investment in humans, technological diffusion, and economic growth. The American Economic Review, 56(1/2), 69-75.

Nelson, R., and Rosenberg, N. (1993). Technical innovation and national systems. In Nelson, R. National innovation systems: A comparative analysis, 3-21.

Nelson, R., and Winter, S. (1982). An evolutionary theory of economic change. Cambridge: Belknap.

Nelson, R., and Winter, S. (2002). Evolutionary theorizing in economics. The Journal of Economic Perspectives, 16(2), 23-46.

Nelson, R., Dosi, G., Helfat, C., Pyka, A., Saviotti, P., Lee, K., and Malerba, F. (2018). Modern evolutionary economics: an overview. Cambridge University Press.

Nishioka, S. (2013). R\&D, trade in intermediate inputs, and the comparative advantage of advanced countries. Journal of the Japanese and International Economies, 30, 96-110.

Nordhaus, W. (1997). Traditional Productivity Estimates are asleep at the (Technological) Switch. The Economic Journal, 107(444), 1548-1559.

Nuxoll, D. (1994). Differences in relative prices and international differences in growth rates. The American Economic Review, 84(5), 1423-1436.

OECD. (2005). The Oslo Manual: The measurement of scientific and technological activities. Guidelines for Collecting and Interpreting Innovation Data. 3rd edition. Paris, France: OECD/Eurostat.

OECD. (2009). Policy responses to the economic crisis: investing in innovation for long-term growth. OECD Publishing.

OECD. (2013). Supporting Investment in Knowledge Capital, Growth and Innovation. OECD Publishing.

Pack, H., and Nelson, R. (1999). The Asian miracle and modern growth theory. The World Bank. 
Page, J. (1994). The East Asian miracle: an introduction. World Development, 22(4), 615-625.

Pages, C. (2010). The Age of Productivity. Transforming Economies from the Bottom Up. Inter-American Development Bank.

Parente, S., and Prescott, E. (2002). Barriers to Riches (Vol. 3). The MIT Press.

Parente, S., and Prescott, E. (1994). Barriers to technology adoption and development. The Journal of Political Economy, 102(2), 298-321.

Perla, J., and Tonetti, C. (2014). Equilibrium imitation and growth. Journal of Political Economy, 122(1), 52-76.

Perla, J., Tonetti, C., and Waugh, M. (2015). Equilibrium technology diffusion, trade, and growth. National Bureau of Economic Research working paper no. w20881.

Perron, P. (1989). The great crash, the oil price shock and the unit root hypothesis. Econometrica, 57(6), 1361-1401.

Pesaran, M., and Smith, R. (1995). Estimating long-run relationships from dynamic heterogeneous panels. Journal of econometrics, 68(1), 79-113.

Phelps, E. (1966). Models of technical progress and the golden rule of research. The Review of Economic Studies, 33(2), 133-145.

Phelps, E. (2016). What Is Wrong with the West's Economies?. Homo Oeconomicus, 33(1-2), 3-10.

Pomeranz, K. (2009). The great divergence: China, Europe, and the making of the modern world economy. Princeton University Press.

Prashad, V. (2013). The poorer nations: A possible history of the global south. Verso Books.

Prettner, K., and Trimborn, T. (2016). Demographic change and R\&D-based economic growth. Economica.

Pritchett, L. (1997). Divergence, big time. Journal of Economic Perspectives, Summer.

Pritchett, L. (2000). The tyranny of concepts: CUDIE (cumulated depreciated investment effort) is not capital. Journal of Economic Growth, 5, 361-84.

Radelet, S. (2016). Africa's Rise-Interrupted? Finance and Development, $53(2)$.

RICYT. (2005). El estado de la ciencia. Principales indicadores de ciencia y tecnología iberoamericanos-interamericanos. Buenos Aires, Argentina: RICYT/OAS/CYTED. 
Rodrik, D. (2005). Growth strategies. Handbook of economic growth, 1, 9671014.

Rodrik, D. (2006). Goodbye Washington Consensus, Hello Washington Confusion?. Journal of Economic Literature. December, (4), 973-987.

Rodrik, D. (2011). The future of economic convergence. National Bureau of Economic Research working paper no. w17400.

Romer, D. (2019). Advanced Macroeconomics, Mcgraw-hill

Romer, P. (1986). Increasing returns and long-run growth. Journal of political Economy: 94(5), 1002-37.

Romer, P. (1990). Endogenous technological change. Journal of Political Economy: $98(5), 71-102$.

Romer, P. (1993). Idea gaps and object gaps in economic development. Journal of Monetary Economics, 32(3), 543-573.

Romer, P. (1994). The origins of endogenous growth. The Journal of Economic Perspectives, 3-22.

Romer, P. (2000). Should the government subsidize supply or demand in the market for scientists and engineers?, NBER Working Papers 7723, National Bureau of Economic Research, Inc.

Sachs, J., and McArthur, W. (2002). Technological advancement and long-run economic growth in Asia. In Bai, C., and Yuen, C. (eds.), Technology and the New Economy. Ch. 4. 157-85. MIT Press.

Sachs, J., and Warner, A. (1995). Economic Reform and the Process of Global Integration, Brookings Papers on Economic Activity.

Safarzyńska, K., and van den Bergh, J. (2010). Evolutionary models in economics: A survey of methods and building blocks. Journal of Evolutionary Economics, 20(3), 329-373.

Saikkonen, P., and Lutkepohl, H. (2002). Testing for a unit root in a time series with a level shift at unknown time. Econometric Theory, 18(2), 313-348.

Schmookler, J. (1966). Invention and Economic Growth (Vol. 26). Cambridge, MA: Harvard University Press.

Schneider, J., and Ziesemer, T. (1995). What's new and what's old in new growth theory: Endogenous technology, microfoundation and growth rate predictions. Zeitschrift fur Wirtschafts-u Sozialwissenschaften (ZWS) 115, 429472 .

Schumpeter, J. (1934). The Theory of Economic Development. Cambridge, Mass.: Harvard University Press. 
Schumpeter, J. (1950). Capitalism, Socialism, and Democracy. 3rd Ed. New York.

Schwert, G. (1989). Tests for unit roots: A Monte Carlo investigation. Journal of Business and Economic Statistics 2: 147-159.

Scott, A. (2006). The changing global geography of low-technology, laborintensive industry: Clothing, footwear, and furniture. World Development 34 (9), 1517-1536.

Semmel, B. (1965). The Hume-Tucker Debate and Pitt's Trade Proposals. Economic Journal, December, 75, 759-70. Sharif, M. \& Ramanathan, K. (1981). Binomial innovation diffusion models with dynamic potential adopter population. Technological forecasting and social change, 20(1), 63-87.

Shell, K. (1966). Toward a theory of inventive activity and capital accumulation, American Economic Review, 56(2), 62-68.

Shionoya, Y. (Ed.). (2002). The German historical school: the historical and ethical approach to economics (Vol. 40). Routledge.

Silverberg, G. (1997). Evolutionary modelling in economics: recent history and immediate prospects. MERIT.

Silverberg, G., and Lehnert, D. (1993). Long waves and 'evolutionary chaos' in a simple Schumpeterian model of embodied technical change. Structural Change and Economic Dynamics 4(1), 9-37.

Silverberg, G., and Lehnert, D. (1996). Evolutionary chaos: growth fluctuations in a schumpeterian model of creative destruction. In: Barnett, W., Kirman, A., and Salmon M. (Eds.), Non Linear Dynamics and Economics, Cambridge University Press.

Silverberg, G. and Verspagen, B. (1995). Evolutionary theorizing on economic growth. In Dopfer, K. (ed.), The Evolutionary Principles of Economics, Cambridge, IIASA, MERIT. WP-95-76 and 2/95-017).

Simon, H. (1979) Rational decision making in business organizations [Nobel Memorial Lecture], American Economic Review, 69(4), September: 493-513.

Simon, J. (1998). The ultimate resource 2. Princeton University Press.

Slade, G. (2009). Made to break: Technology and obsolescence in America. Harvard University Press.

Smith, A. (1776). An inquiry into the wealth of nations. Strahan and Cadell, London.

Snowdon, B., and H., Vane. (2005). Modern macroeconomics: its origins, development and current state. Edward Elgar Publishing. 
Soete, L., Verspagen, B., and ter Weel, B. (2010). Systems of innovation. Handbook of the Economics of Innovation, 2, 1159-1180.

Solow, R. (1956). A contribution to the theory of economic growth. The quarterly journal of economics, 70(1), 65-94.

Som, O., and Kirner, E. (2016). Low-tech Innovation. Springer International $\mathrm{Pu}$.

Spence, M. (2011). The next Convergence: The Future of Economic Growth in a Multispeed World. Macmillan.

Steinmuller, E. (2010). Economics of technology policy. In Handbook of the Economics of Innovation, 28, Vol. 2, 1181-1218.

Stephan, P. (2002). Using human resource data to illuminate innovation and research utilization. In: Merrill, S., McGeary, M. (Eds.), Using Human Resource Data to Track Innovation. National Academy Press, Washington, DC.

Stephan, P. (2010). The economics of science. In Handbook of the Economics of Innovation, 1, 218-273.

Stiglitz, J. (2008). Government failure vs. market failure: Principles of regulation.

Stiglitz, J. (2014). Leaders and followers: Perspectives on the Nordic model and the economics of innovation. Journal of Public Economics.

Stiglitz, J., and Heertje, A. (Eds). (1989). The Economic Role of the State. Wiley-Blackwell.

Stokey, N. (2012). Catching up and falling behind. Journal of Economic Growth, 20(1), 1-36.

Summers, L., Bosworth, B., Tobin, J., \& White, P. (1981). Taxation and corporate investment: A q-theory approach. Brookings Papers on Economic Activity, 1981(1), 67-140.

Summers, L. (2014). US economic prospects: Secular stagnation, hysteresis, and the zero lower bound. Business Economics, 49(2), 65-73.

Temple, J., and Johnson, P. (1998). Social capability and economic growth. Quarterly Journal of Economics, 113, 965-90.

Swamy, P. (1970). Efficient inference in a random coefficient regression model. Econometrica: Journal of the Econometric Society, 311-323.

Thaler, R. 2015. Misbehaving: The Making of Behavioral Economics. New York: W. W. Norton \& Company

Teuling, C., and Baldwin, R. (Eds). (2014). Secular Stagnation: Facts, Causes, and Cures - a New Vox eBook. VoxEU.org 
Timmer, M. (2012). The World Input-Output Database (WIOD): Contents, Sources, and Methods. WIOD-WP-10.

Timmer, M., Inklaar, R., O’Mahony, M., and van Ark, B. (2010). Economic Growth in Europe: A Comparative Industry Perspective. Cambridge University Press.

Tobin, J. (1969). A general equilibrium approach to monetary theory. Journal of money, credit and banking, 1(1), 15-29.

Trajtenberg, M. (2002). Government support for commercial R\&D: Lessons from the Israeli experience. In: Jaffe, A., Lerner, J., Stern, S. (Eds.), Innovation Policy and the Economy, 2, Cambridge, MA, pp. 79-134.

Tucker, J. (1776). Four Tracts on Political and Commercial Subjects. 3rd ed. Reprint, Clifton, N.J.: Augustus M. Kelley Publishers, 1974.

Turnovsky, S. (1996). Fiscal policy, adjustment costs, and endogenous growth. Oxford Economic Papers, 48(3), 361-381.

UNCTAD. (2013). Global value chains and development. Investment and Value Added Trade in the Global Economy.

Urban, G., Weinberg, B., Hauser, J. (1996). Premarket forecasting of reallynew products. Journal of Marketing 60, 47-60.

Uzawa, H. (1965). Optimum technical change in an aggregative model of economic growth. International Economic Review, 6(1), 18-31.

Van Ark, B., Hao, J. X., Corrado, C., and Hulten, C. (2009). Measuring intangible capital and its contribution to economic growth in Europe. EIB papers, 14(1), 62-93.

Vandenbussche, J., Aghion, P., and Meghir, C. (2006). Growth, distance to frontier and composition of human capital. Journal of Economic Growth, 11(2), $97-127$.

Veblen, T. (1898). Why is economics not an evolutionary science?. The quarterly journal of economics, 12(4), 373-397.

Veblen, T. (1915). Imperial Germany and the industrial revolution, NY, McMillan.

Verspagen, B. (1991). A new empirical approach to catching up or falling behind. Structural Change and Economic Dynamics, 2(2), 359-80.

Verspagen, B. (1992). Endogenous innovation in neoclassical growth models: A survey. Journal of Macroeconomics, 14(4), 631-62.

Verspagen, B. (1993). Uneven growth between interdependent economies: evolutionary view on technology-gaps, trade and growth. Aldershot, Avebury. 
Verspagen, B. (1997). Estimating international technology spillovers using technology flow matrices. Weltwirtschaftliches Archiv, 133, 226-248.

Verspagen, B., \& Werker, C. (2003). The invisible college of the economics of innovation and technological change. Estudios de Economía Aplicada, 21(3), 393-419.

Viotti, E. (2002). National learning systems: a new approach on technological change in late industrializing economies and evidences from the cases of Brazil and South Korea. Technological Forecasting and Social Change, 69(7), 653-680.

Wade, R. (1996). Japan, the World Bank, and the Art of Paradigm Maintenance: "The East Asian Miracle" in Political Perspective. New Left Review, (217), 3 .

Wade, R. (2009). Rethinking industrial policy for low income countries. African development review, 21(2), 352-366.

Wansbeek, T. and Meijer, E. (2000). Measurement Error and Latent Variables in Econometrics. Amsterdam: North Holland.

Wirkierman, A., Ciarli, T., and Savona, M. (2018). Varieties of European National Innovation Systems, unpublished

World Bank. (2010). Innovation Policy: A Guide for Developing Countries. World Bank. https://openknowledge.worldbank.org/handle/10986/2460

World Bank, Commission on Growth. (2008). The growth report: strategies for sustained growth and inclusive development. World Bank Publications.

Xie, D. (1994). Divergence in economic performance: transitional dynamics with multiple equilibria. Journal of Economic Theory, 63(1), 97-112.

Zivot, E., and Andrews, D. (1992). Further evidence on the great crash, the oil-price shock, and the unit-root hypothesis. Journal of Business \& Economic Statistics, 20(1), 25-44.

Ziesemer, T. (1990). Public factors and democracy in poverty analysis. Oxford Economic Papers, New Series, 42(1), Special Issue on Public Economics, 268280.

Ziesemer, T. (1991). Human capital, market structure and taxation in a growth model with endogenous technical progress. Journal of Macroeconomics, 13(1), 47-68.

Ziesemer, T. (1995a). Endogenous growth with public factors and heterogeneous human capital producers. Finanz Archiv, 52(1), 1-20.

Ziesemer, T. (1995b). Economic development and endogenous terms of trade determination: review and reinterpretation of the Prebisch-Singer thesis. Unctad Review. 
Zilibotti, F. (2008). Economic growth through the development process. CESifo Economic Studies, 54(3), 325-357. 


\section{PROPOSITIONS}

accompanying the thesis

"Endogenous Growth with National Innovation Systems: The Ultimate Route to Catching Up in the World Economy." Juan Ricardo Perilla Jiménez

1. The popularity of new products is a decreasing function of the time they have been in the marketplace. By its very nature, the success of innovation is inevitably temporary and very short-lived. New products that survive competition would work wonders for the first generation, but they do it less well for the second generation, and still less for the third (This thesis).

2. The crux of innovation is that, at length, the pressures of market selection and competition and, hence, consumers' craze for the "new" compel producers to permanently seek for newer market strategies and novel products (This thesis).

3. The process of economic growth is overall a reflection of the dynamics of innovation. The discovery/invention of major technologies helps to resolve the productivity problem, beyond that the problem that remains is what to produce, e.g., how to take advantage of the commercial opportunities opened up by the newest technology breakthroughs (This thesis).

4. It is certainly the case that controversy rather than consensus is the underlying feature that ultimately leads to the creation of new and valuable knowledge (This thesis).

5. Truth matters less than the talent with which some economists mistake.

6. Physicians bury their mistakes, lawyers put them in jail, economists publish them (MEC).

7. Those who do not understand that two explanations that oppose each other can be perfectly possible and defensible should not be an economist.

8. The relative merits of rules versus discretion in economic policy making is more complicated than is commonly understood. The great risk theoretical economists run is the possibility of searching for permanent solutions to transitory problems.

9. Nothing too regretful as reading, simply because they write about interesting things, the talent-less writer.

10. Admiring something that is not amusing is halfway between admiring just what is amusing and being amused just but what is admirable. Yet, admiring just what is admirable denotes suspicious taste.

11. Nothing too complicated as pretending understanding. 


\section{VALORISATION ADDENDUM}

This thesis explores on ideas that connect the innovation capabilities of countries with their chances to expand income, economic growth and prosperity opportunities for all. On these grounds, the research that has been conducted here turns out to be relevant for society at large, even if only potentially and indirectly, and most probably in the distant future.

On reflection, it is fair to say that looking for immediate recognition and implementation of the fruits of academic research is complicated. Quite the contrary, particularly when it comes to the kind of fundamental research that is conducted in the field of economics, it may take a considerable length of time and transformation before new ideas are accepted and implemented in a way so that they have practical impact, and - no wonder - lots of new ideas never make it to this final stage.

Even when the results of scientific research withstand the test of time, which happens when and if they are recognized of some value, their usefulness to the profession, the economy and the society are constantly verified against the facts of reality. New theories and models are always a subject of controversy in every field of science. New ideas can and often are modified in part, or fully reformulated until nothing remains from the original, or they can be rejected after a while of popularity. But, to be sure, by no means being a subject of controversy is a minor success. After all, many of the more modest findings never make it to the controversial territory at all. It is certainly the case that controversy rather than consensus is the underlying feature that ultimately leads to the creation of new and valuable knowledge.

In brief, whether the ultimate ambition of this research to improve social prosperity is going to be reached or not, will depend on whether these ideas are found worth of controversy and dialogue by the scientific community, and whether they will be able to influence political decision at some point in the distant future. Therefore, this research is firstly intended for researchers, academics and policymakers who are interested in innovation policy, economic growth and development economics.

Since the questions related to the relationship between technology diffusion, the production of innovation, innovation policy, economic growth and development economics, have been explored in the literature from different theoretical perspectives. And those perspectives involve different justifications for the role of government in setting up the right conditions to promote an environment for innovation which, in turn, is expected to determine the ability of less developed countries to catch up, in this thesis we have proposed an organizing framework to understand how the innovation system operates in the first place.

One key lesson obtained from this framework is the need to rectify the theoretical structure from which logical policy recommendations are derived regarding the promotion of innovation as the fundamental engine of economic growth. 
Specifically, we explain why it is needed to introduce within such a framework the explicit role of government alongside other features of the innovation system that we have identified and discussed within this thesis. Innovation has some of those special characteristics that K. Arrow attributed to health services, where private interest is not well defined, which let him to famously declare that even though (free) enterprise is desirable as much as possible, it would have to be supplemented with as much intervention as necessary. By its very nature, innovation does not fit in the conventional economics' rationale of perfectly foresighted maximizing individuals mainly - but not only - because innovation involves lots of uncertainty. This special characteristic implies that markets let alone would much probably produce too little innovation.

Actually, we provide a strong claim that the policy relevance of academic research on this front, namely the relationship between the promotion of innovation and long-run economic growth and catching up, is better informed by the evolutionary and NIS approaches to the study of development in backwards economies, and that these approaches contrast with the mainstream theory of economic growth, the distance from frontier and advantages of backwardness approaches. The point that conventional economics has failed to convincingly incorporate the economics of innovation is widely recognized by other academic economists. For instance, Edmund Phelps, a leading economist, has pointed out that, despite their sophistication in other respects, what is wrong with conventional approaches to explain economic growth is that those approaches make no room for the possibilities created by indigenous innovation, which is in open contrast with the fact of reality that everywhere people are constantly imagining new products and using their creativity to build them.

The novelty of our approach is not the introduction of the evolutionary theory. This theoretical perspective has been around since the very foundations of economics as a social science. Marshall, one of the founders of what we know as the neoclassical approach, and also various other classical economists are known to have declared in not few occasions that the advance of economics is closely related to the evolution of biological systems where both the inner and outer forms of the system are constantly changing. The famous Marshallian quote according to which "The Mecca of the economist lies in economic biology rather than in economic dynamics" is often presented to point out that economic phenomena can be seen as a natural process. It has "cooperation", "competition", "selection", "survival of the fittest" and other many features that are also commonly found to be descriptive characteristics and processes in the field of biology.

In this thesis, we concentrate less in the analogy between biological and economic systems. But, we often use the metaphor to emphasize, even though at times implicitly, that the process of innovation is closely related to the biological process. For example, we discuss how the pressures of market selection and competition - which is triggered by consumers' craze for the "new"-compel producers to permanently seek for newer market strategies and novel products. By its very nature, innovation is a process that involves permanent change as producers know that any product innovation that survive competition may do wonders for the first generation, but they do it less well for the second generation, 
and still less for the third.

While real life examples of innovation are easily associated with high technological devices produced somewhere by sophisticated means and highly trained scientists working in centers of excellence of the advanced world economies, the truth is that innovation, as an engine of economic activity, is found everywhere. Kinder eggs, the popular chocolate candy that is found practically all around the world would be much less popular would not children come to realize there is a good chance of a ceaseless offer of new collectible miniature toys packed inside them. And, likewise, the baker around the corner knows - even if they probably aren't conscious of possessing such a knowledge - that rather than producing the whole stock of bakery early in the morning, a successful business depends on the smell of baking bread instead, hence, on having a permanent offer of freshly baked products all through the day.

Extending this line of reasoning to the economy wide level and to the context of international economics we reach the conclusion that, however important, technology diffusion and its adoption by backward countries would be ineffective without domestic assimilation, a process by which the new technology is found to have practical and profitable commercial applications. Technology acquisition matters, but the wonder of technology progress lies less in technology consumption per se and more in being able to put technology to productive use.

The diffusion of major technologies certainly helps to resolve the productivity problem, e.g, they help to resolve the problem of 'how to produce'. But beyond the ability to produce more of the same products, or producing them at a lower unitary cost, the problem that remains is 'what to produce'. This involves thinking of new product varieties able to lure new and existing costumers and, more in general, thinking of novel strategies to take advantage of the commercial opportunities opened up by the newest technology breakthroughs, both in domestic and international markets. Thus, we claim in this thesis that a broad view of innovation inclusive of both low-tech and high-tech innovations is needed if we are going to gain better understanding of the process of economic growth and catching up of backward countries.

The innovation systems approach is also well established in the research into the impact of innovation on economic growth and catching up issues. In this thesis we have narrowed the numerous and some times overlapping features attributed in the specialized literature to this framework, to just three mechanisms that we consider essential and encompassing among the many desirable characteristics of a good innovation system. We call them leadership, sponsorship and coordination mechanisms.

We have shown that leadership, which relates to public innovation and collaboration with the private sector; coordination, which summarizes a wide range of strategies designed by the government to encourage the spread of innovation throughout the different sectors of economic activity and the different parts of the innovation system; and sponsorship, which copes with a broad range of public programs to financially support private innovation initiatives, are the three major defining attributes of the innovation system approach as it has been actually implemented in practical policy making in the most successful catching 
up economies worldwide.

The main theme in our discussion of this framework is that knowledge of the three components of the NIS approach can be useful in formulating innovation promoting strategies. Based on this rationale, policymakers can realize that the formulation of innovation policy goes far beyond friendly regulations to foreign technology and mere financing facilities that are currently stressed in some branches of the literature, and which have become commonplace in the policy practice and growth strategies of less successful economies.

However, we have stressed also that much progress can be done in analyzing the actual economic growth and development impact of innovation by linking the insights of the evolutionary theory and the NIS framework - which are conceptually richer and more policy oriented - with the mainstream methodological and analytical framework - which is firmly established an approach to study the technical and mathematical issues that are of importance when the focus is on the economy as a planning problem over the long-run.

It is hard to know whether the ideas developed here will influence actual decision making or not at some point of time, so that they can reach the stage of social impact. A most immediate step toward this 'major goal' is to boost controversy and, hopefully, to make it through the contest for the "survival of the fittest".

To this end, parts of the research that led to the present thesis have been submitted for publication in specialized outlets: the World Bank Economic Review, The Journal of Economic Growth, the Journal of Evolutionary Economics and the Journal of International Trade and Economic Development among others. We have obtained encouraging peer review feedback suggesting that by no means our research approach is off the mark. And also, we have managed to publish some of the submissions and others are close to being published: Perilla 2015, 2019a, 2019b. Also, we have taken part in conferences and seminars where the ideas developed in this thesis have being presented to academic communities.

\section{References}

Perilla, J. (2019a). Testing the Impact of technology diffusion and innovation on long-run growth using cointegration techniques. Journal of International Trade and Economic Development. (Under second revision)

Perilla, J. (2019b) Mainstream and evolutionary views of technology, economic growth and catching up. Journal of Evolutionary Economics 29 (3) 823-852.

Perilla, J. (2015) A non-parametric approach to innovation gaps and economic growth. Journal of Economic and Financial Studies 3(5). 


\section{CURRICULUM VITAE}

Juan Ricardo Perilla Jiménez was born 15 May 1971 in Bogotá, Colombia. in 1997 he obtained his B.A. In economics from the Universidad Nacional de Colombia. In 2005 he obtained a MA Degree from the Institute of Social Studies (The Hague, now part of Erasmus University Rotterdam), where he studied International Development Economics with a major in International Political Economy and Development (IPED). In 2013 he obtained a MSc (research) in Economics and Econometrics from the University of Groningen. Between 2013 and 2017 he was a PhD candidate at the School of Business and Economics in Maastricht University under the supervision of Bart Verspagen and Thomas Ziesemer. In 1990 Juan Ricardo was awarded a scholarship by the Universidad Nacional de Colombia tu pursue his BA. In 2004 he was awarded with the Colombian ICETEX-DNP Scholarship to pursue his MA in the ISS (The Hague, The Netherlands). And in 2011-2013 he was awarded with the University of Groningen Scholarship to pursue his MSc at this university. During his doctoral studies Juan Ricardo was hired by Maastricht University as a PhD candidate. Juan Ricardo has held numerous academic positions as lecturer at different universities in Colombia among which, Universidad Nacional de Colombia, Pontificia Universidad Javeriana, Universidad del Rosario, Universidad del Bosque and Universidad Santo Tomas. He has had research positions at the Colombian National Department of Statistics and the Colombian National Department of Planning, and he has been also consultant researcher for the Organization of Ibero American States and the Inter American Development Bank. Juan Ricardo main research topics of interest relate to the theory and policy practice of economic growth, international development economics, political economy and mathematical economics. He has published his work in numerous of the most prestigious outlets in Colombia: Planeación y Desarrollo, Revista de economía de la Universidad del Rosario, Revista de economía institucional, Desarrollo y Sociedad; he also has published his research outcomes in renowned international journals as Trimestre Económico and The Journal of Evolutionary Economics. Currently, Juan Ricardo holds a position as Assistant Professor of Macroeconomics at the Universidad del Norte, Barranquilla-Colombia, one of top universities in the country. 
This thesis is endeavored to address the question whether and how catching up by backward countries depends more on technology diffusion or on indigenous innovation. We claim that the apparently obvious answer to this question involves a range of frequently controversial issues regarding the very definition of innovation and the role of government within the innovation system.

One of the key lessons the avid reader may derive from the discussion of the theory and empirical evidence throughout the different chapters of the book, is the need to rectify the theoretical structure from which relevant policy recommendations may be obtained regarding the promotion of innovation as a fundamental engine of economic growth. We hold that such recommendations are better informed by the evolutionary and innovation systems approaches than by the more extended reliance on the advantage of backwardness approach.

Summing up, we argue that a broad view of innovation, inclusive of both low-tech and high-tech innovations, is needed if we are going to gain a better understanding of the determinants of growth and catching up in backward countries. And among the many desirable characteristics of a good innovation system, we hold that there are three encompassing mechanisms that feature prominently in successful catching up economies regarding the role of government: leadership, sponsorship and coordination. Thus we conclude that, despite their importance, to be effective, innovation policy needs to go beyond the conventional focus on financial facilities and friendly regulations to foreign technology. 